\title{
Genetic polymorphism of HLA class I
}

Citation for published version (APA):

Swelsen, W. T. N. (2005). Genetic polymorphism of HLA class I. [Doctoral Thesis, Maastricht University]. Datawyse / Universitaire Pers Maastricht. https://doi.org/10.26481/dis.20050930ws

Document status and date:

Published: 01/01/2005

DOI:

10.26481/dis.20050930ws

Document Version:

Publisher's PDF, also known as Version of record

\section{Please check the document version of this publication:}

- A submitted manuscript is the version of the article upon submission and before peer-review. There can be important differences between the submitted version and the official published version of record.

People interested in the research are advised to contact the author for the final version of the publication, or visit the DOI to the publisher's website.

- The final author version and the galley proof are versions of the publication after peer review.

- The final published version features the final layout of the paper including the volume, issue and page numbers.

Link to publication

\footnotetext{
General rights rights.

- You may freely distribute the URL identifying the publication in the public portal. please follow below link for the End User Agreement:

www.umlib.nl/taverne-license

Take down policy

If you believe that this document breaches copyright please contact us at:

repository@maastrichtuniversity.nl

providing details and we will investigate your claim.
}

Copyright and moral rights for the publications made accessible in the public portal are retained by the authors and/or other copyright owners and it is a condition of accessing publications that users recognise and abide by the legal requirements associated with these

- Users may download and print one copy of any publication from the public portal for the purpose of private study or research.

- You may not further distribute the material or use it for any profit-making activity or commercial gain

If the publication is distributed under the terms of Article $25 \mathrm{fa}$ of the Dutch Copyright Act, indicated by the "Taverne" license above, 
Genetic polymorphism of HLA class I 
Copyright (c) 2005 W.T.N. Swelsen, Maastricht ISBN 90-5278-466-3

Cover design: Frank Mulders

Layout: Tiny Wouters

Production: Datawyse | Universitaire Pers Maastricht

Financial support for the publication of this thesis by the Dutch Kidney Foundation and the Dutch Transplantation Society (NTV) is gratefully acknowledged. 


\title{
Genetic polymorphism of HLA class I
}

\author{
PROEFSCHRIFT
}

ter verkrijging van de graad van doctor

aan de Universiteit Maastricht.

op gezag van de Rector Magnificus,

Prof.mr. G.P.M.F. Mols,

volgens het besluit van het College van Decanen,

in het openbaar te verdedigen

op vrijdag 30 september 2005 om 12.00 uur

door

Wendy Tonnie Nicole Swelsen

geboren op 9 mei 1978 te Heerlen

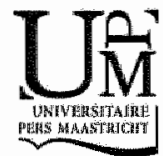


Promotor:

Prof.dr. P.M. van den Berg-Loonen

Copromotor:

Dr. C.E.M. Voorter

Beoordelingscommissie:

Prof.dr. M.H. Hofker (voorzitter)

Prof.dr. F.H.J. Claas (Leids Universitair Medisch Centrum)

Prof.dr. J.P.M. Geraedts

Prof.dr, J.P. van Hooff

Dr. S.G.E. Marsh (Anthony Nolan Research Institute, United Kingdom) 
Aan mijn ouders

Voor Erik 



\section{Contents}

Chapter 1 Introduction

Chapter 2 Sequence-based typing of the HLA-A10/A19 group and confirmation of a pseudogene coamplified with $A^{*} 3401$

Chapter 3 Sequence analysis of exons $1,2,3,4$ and 5 of the HLA-B5/35 cross-reacting group

Chapter 4 Ambiguities of human leukocyte antigen-B resolved by sequence-based typing of exons 1,4 , and 5

Chapter 5 Elucidation of exon 1, 4, and 5 sequences of 39 infrequent HLA-B alleles

Chapter $6 \quad B^{*} 27$ in molecular diagnostics: Impact of new alleles and polymorphism outside exons 2 and 3

Chapter 7 Intron sequences of HLA-B*73

Chapter 8 Polymorphism of intron 4 in HLA-A, $-B$ and $-C$ genes

Chapter 9 No HLA-A gene detectable on one of the haplotypes in a Caucasian family

Chapter 10 General discussion

Summary

Samenvatting

Dankwoord

Curriculum vitae 


\section{Chapter 1}

Introduction 
10 Chapter 1 


\section{Introduction}

\section{MHC region}

The human leukocyte antigen (HLA) genes, encoded within the human major histocompatibility complex (MHC), are the most polymorphic loci in the human genome. The essential role of the HLA molecules lies in the controll of selfrecognition and thus defence against foreign antigens. The presence of HLA antigens on human leukocytes was first described in the 1950s. Dausset abserved agglutinating antibodies against leukocytes in the sera of multiple blood transfused patients ${ }^{1}$ and van Rood and Payne recognized them in sera of multiparous females ${ }^{2,3}$. The $\mathrm{MHC}$ region, located on the short arm of chromosome $6^{4}$, encompasses some four million base pairs of DNA and can be divided into three regions; class $\|$, class $\|$ and class \|\|$^{5}$.

The class I region, at the telomeric end of the chromosome, contains genes coding for the heavy chain of the three major classical HLA molecules, A, B and $\mathrm{C}$. Some non-classical HLA class I molecules also exist, namely HLA-E, -F and $-G$. The non-classical HLA molecules have restricted tissue expression and show little polymorphism as compared with the classical class I antigens. In addition, the class I region contains a number of pseudogenes, such as $H L A-H,-J,-K$ and $-L$, which are non-functional genes closely related in nucleotide sequence to the functional class I genes.

The centromerically located cluster of known HLA genes, the class II region, contains the genes encoding the three major classical gene products HLA-DR, -DQ and -DP and the class II-like molecules HLA-DM and -DO. HLA class II molecules are heterodimers composed of $\alpha$ and $\beta$ chains encoded by an $A$ and $B$ gene. Essentially all polymorphism is located in the $B$ genes. The DRA gene is thought to be non-polymorphic, and DQA1 and DPA1 genes exhibit a low level of polymorphism. The DR region presents an additional complexity level, since a second DRB gene may be expressed, i.e. DRB3 in DR3/DR11/DR12/ DR13/DR14 haplotypes, DRB4 in DR4/DR7/DR9 haplotypes and DRB5 in DR15/DR16 haplotypes ${ }^{6}$. The class II molecules are restricted in their distribution and limited to a number of cell types, such as B-cells, monocytes, dendritic cells and activated T-cells.

The class III region, located between the other two clusters, is densely packed with genes coding for molecules with a variety of functions, including some components of the complement system ( $\mathrm{C} 2, \mathrm{C} 4$ and factor $\mathrm{B})$, cytokines (tumour necrosis factor and lymphotoxin $\alpha$ and $\beta$ ) and other molecules with a role in immune responses ${ }^{7}$. In figure 1.1, a simplified schematic representation 
of the genomic organization of the MHC region is depicted. The class II and III regions are beyond the scope of this thesis and will not be discussed further.

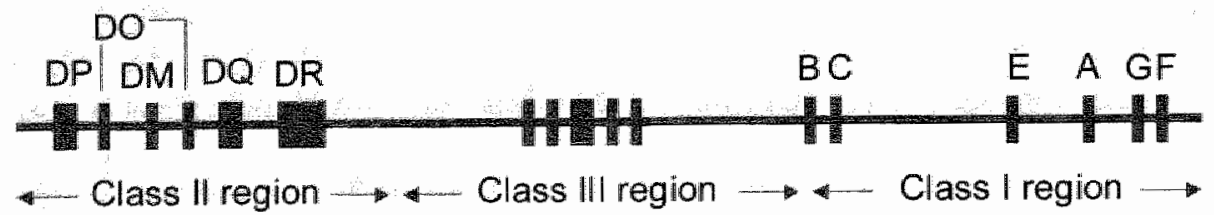

Figure 1.1 A simpliffed map representing the genomic organisation of the MHC region.

The HLA complex is characterised by several unique features. Pedigree analysis of the segregation of HLA specificities revealed that HLA molecules are inherited in a Mendelian manner and expressed codominantly. Both paternal and maternal inherited antigens are present on the cell surface. The close linkage of the HLA genes means that they tend to be inherited "en bloc". The term haplotype indicates the particular HLA alleles an individual carries on one of his or her chromosomes 6 . Since there are four possible combinations of the two paternal and the two maternal haplotypes, siblings have a chance of $25 \%$ to carry identical HLA alleles. Large differences exist between the frequencies in which the HLA antigens occur in different ethnic groups. For example, the HLA-B8 antigen is found predominantly in Caucasians with a frequency of approximately $15 \%$, whereas it is almost absent in Japanese ${ }^{9}$. Another important feature of the HLA region is the existence of linkage disequilibrium. This phenomenon refers to the presence of antigens at different loci occurring together more frequently than would be expected on the basis of the frequencies of the separate antigens. For example, in Caucasians the haplotype A1, B8 and DR3 is found more frequently than one would expect ${ }^{8}$.

\section{HLA class I molecules}

HLA class I molecules are glycoproteins expressed on the surface of all nucleated cells and platelets. They consist of two polypeptide chains, a polymorphic $\mathrm{MHC}$-encoded heavy chain of $45 \mathrm{kD}$ and a noncovalently associated light chain of $12 \mathrm{kD}$ called $\beta 2$-microglobulin $(\beta 2 \mathrm{~m})^{5,9} \cdot \beta 2 \mathrm{~m}$ is required for the formation of a stable class I complex. The molecule is encoded by a gene located on chromosome 15, which is considered non-polymorphic.

In 1987. Bjorkman et al. have determined the three-dimensional structure of HLA-A2 by $X$-ray crystallography ${ }^{10}$, the tertiary protein structure of HLA-B27 has been clarified in $1992^{11}$. The heavy chain of class 1 molecules is composed 
of three extracellular domains, $\alpha 1, \alpha 2$ and $\alpha 3$, a hydrophobic transmembrane region and a hydrophilic cytoplasmic tail. The highly polymorphic $\alpha 1$ and $\alpha 2$ domains together form the peptide binding groove. A schematic representation of the structure of the HLA class I molecule is shown in figure 1.2. The binding groove is composed of two $\alpha$ helices lying across a platform of an eightstranded $\beta$-pleated sheet. Because the class I groove is closed at both ends, class I molecules only bind peptides that are between 8 and 10 residues in length. In healthy cells the peptides bound by class I are derived from normal cellular components whose routine turnover and proteolytic degradation takes place in the cytosol. If a cell is infected with a pathogen, some of the peptides presented by class $I$ are derived from degradation of foreign proteins. The sidechains of the peptide need to fit within the class I groove and make a number of specific contacts with residues of the class I molecule. The refined crystallographic structure of HLA-A2 has shown that the binding groove consists of six specificity pockets designated $A$ through $F^{12}$. Polymorphic residues of the class I heavy chain are primarily located at positions within these pockets, where they can change the shape, size and charge of the pockets and in such a way determine which peptide side-chains are preferentially bound. HLA class I molecules bound to T-cell receptors have also been analysed by $X$-ray crystallography ${ }^{13-15}$. In contrast to the HLA class II molecules, which present antigenic peptides to CD4 positive T-cells, class I molecules present antigenic peptides to CD8 positive T-cells. The T-cell receptors interact simultaneously with the $\alpha 1$ and $\alpha 2$ domains of the class 1 molecule and the exposed residues of the bound peptide. The CD8 co-receptor was shown to interact with the $\alpha 3$ domain of the class I molecule $e^{16-18}$.

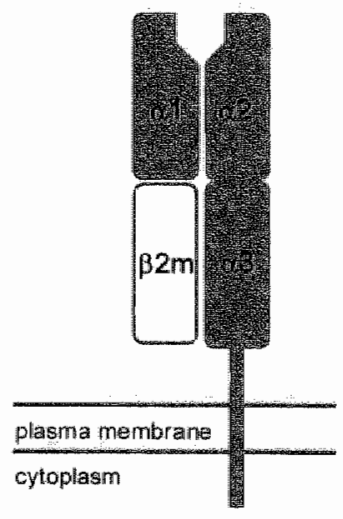

Figure 1.2 Schematic representation of the structure of the HLA class I molecule. 


\section{HLA class 1 genes}

The genes that give rise to HLA class I heavy chains have a characteristic structure in which different domains of the protein are encoded by separate exons. The leader peptide (LP), necessary for transport into the endoplasmic reticulum, is encoded by exon 1, whereas the genetic information of the three extracellular domains $\alpha, \alpha, 2$ and $\alpha 3$ is located in exons 2,3 and 4 . Exon 5 codes for the transmembrane (TM) region and exons 6,7 and/or 8 for the cytoplasmic tail (CYT) (figure 1.3). HLA-B has the stop codon located in exon 7 and HLA-A and $-C$ in exan $8^{5,19}$.

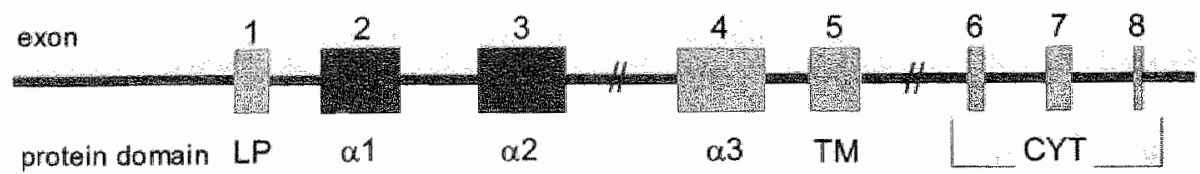

Figure 1.3 Schematic representation of the exon/intron organisation of HLA class I genes. The different domains of the HLA class I heavy chains are encoded by separate exons. Small differences in the length of the cytoplasmic tail of the different lacil exisis due lo different location of the termination cadon withim exan 7 or 8

The number of nucleotides varies between the different exons. Exon 1 consists of 73 base pairs, exon 2 of 270 , exon 3 has 276 nucleotides as has exon 4 . There is variation in exon 5 length among HLA-A, $-B$ and $-C$ genes. Exon 5 of HLA-C is usually three nucleotides longer than that of HLA-A and $-B$ resulting in 120 instead of 117 nucleotides. Furthermore, exon 5 of $B^{*} 7301$ is also three nucleotides longer than that of all other HLA-B alleles and is as long as exon 5 of HLA-C ${ }^{20}$. Exon 5 of $\mathrm{CW}^{*} 1701$ is 18 nucleotides longer than all other HLA-C alleles ${ }^{20}$. The complete sequences of $B^{*} 7301$ and $C W^{*} 1701$ have revealed highly divergent class 1 molecules defining lineages distinct from HLA-B and $-C^{21.22}$. Exon 6 consists of 33 nucleotides. For exon 7 there is a variation in the number of coding nucleotides for the different loci it is 44 nucleotides long in HLA-B and 48 in HLA-A and $-C$. Exon 8 of HLA-A and $-C$ consists of five coding nucleotides. In total the coding exons of class I genes consist of 10891119 nucleotides and code for $362-372$ amino acid residues of the total protein $^{19}$.

The exons are separated by non-coding regions, the introns, which are transcribed into an RNA molecule but are subsequently excised by RNA splicing when mRNA is produced. The regulation of transcription of HLA class I 
genes is controlled by a number of conserved stretches of DNA sequences, promoter and enhancers, located in the $5^{\prime}$ untranslated flanking region of HLA class I genes. Several well-established functional regulatory elements have been determined, like enhancer $A$, enhancer $B$, the interferon response sequence and CAAT- and TATA-boxes ${ }^{23}$.

\section{Antigen processing and presentation}

The HLA class I molecules present antigenic peptides to CD8 positive cytotoxic T lymphocytes and natural killer (NK) cells ${ }^{24-26}$. The HLA class I molecules are loaded with peptides derived from intracellular antigens ${ }^{27}$, whereas the peptides presented by HLA class II molecules are derived from extracellular proteins ${ }^{28}$. Extracellular antigens are taken up into endosomes and lysosomes, where they are degraded to peptides. The pathway by which intracellular antigens are processed and presented by HLA class I molecules is different from the extracellular one. In the cytoplasm, proteins are degraded by proteasomes into small peptides and are transported into the lumen of the endoplasmic reticulum (ER) by the TAP protein (transporter associated with antigen processing). Furthermore, assembly of the HLA class I heavy chain/ $\beta 2 \mathrm{~m}$ complex, which is chaperoned by the protein calnexin, takes place in the ER. Association of TAP with class I molecules enables peptide loading. The stable assembly of class I molecules with peptides is controlled by a variety of accessory proteins, including chaperones with general housekeeping functions and factors with dedicated roles. This multi-subunit complex has been called the peptide loading complex. The peptide-filled class I molecules leave the ER and are transported by the Golgi apparatus to the cell surface ${ }^{29-31}$. In general, presentation of endogenously derived self-peptides by HLA class 1 molecules will normally be ignored by the immune system due to self-tolerance. However, presentation of peptides derived from foreign proteins, like viral antigens, will lead to the triggering of CD8 positive cytotoxic $T$ lymphocytes and/or NK cells ${ }^{24-26}$.

\section{Polymorphism}

The HLA-A, $-B$ and $-C$ heavy chains were found to be highly polymorphic. The molecules not only serve as peptide presenters but also interact with $\beta 2 \mathrm{~m}$, T-cell receptor, CD8 co-receptor, class I receptors on NK cells and the peptideloading complex. Polymorphism can modulate all these interactions ${ }^{32}$. The extreme polymorphism of HLA genes is illustrated by the huge number of different alleles identified for each locus. In the past 15 years the number of HLA class I alleles has increased from 68 in 1989 to 1157 in $2005^{19,33}$. HLA-B is the most polymorphic locus with 626 different alleles. For HLA-A 349 and for 
HLA-C 182 alleles have been demonstrated. The DNA sequences of the HLA alleles are stored in the comprehensive IMGTIHLA Sequence Database ${ }^{19}$.

An important effect of the polymorphic class I HLA-A, $-B$ and $-C$ molecules is that it provides individuals with a diversity in antigen presentation necessary for population survival. The most polymorphic residues of the molecule are demonstrated in or around the peptide binding groove. Furthermore, most nucleotide substitutions result in a change of the amino acid sequence of the encoded protein, potentially altering the peptide binding specificity. These observations suggest that there is an evolutionary pressure for generation and maintenance of diversity in the peptide binding groove, driven by pathogenic pressure $^{34}$.

New alleles arise by changes in the nucleotide sequence of the gene. Several genetic mechanisms have been demonstrated" point mutations, deletions, duplications, recombinations and conversions. A conversion that involves the exchange of sequences between alleles of the same locus is called allele conversion, whereas it is named gene conversion if it occurs between alleles of different but homologous loci. Some polymorphic variations have functional implications for HLA expression. More than 40 HLA class I null alleles, which are not expressed at the cell surface, have been demonstrated ${ }^{19}$. The lack of expression can be different in origïn, either point mutations giving rise to premature stop codons ${ }^{35-43}$, deletions or insertions leading to frame shift and premature or delayed termination ${ }^{37,44-53}$, deletions causing a structural defect in the molecule ${ }^{54}$, mutations affecting transcription ${ }^{55,56}$ and RNA splicing ${ }^{37,47,57-59}$ or hypermethylation leading to gene inactivation ${ }^{60}$.

\section{Nomenclature}

The complexity of the HLA system demands a universally accepted nomenclature system. In 1965, an HLA Nomenclature Committee was formed under the auspices of the World Health Organization (WHO) ${ }^{61}$. Traditionally, the antigens were defined by serological methods and named by the gene letter and a serial number. Refinement of serology led to elucidation of splits, antigens that were previously considered to represent single allotypes were split into different components.

The development of DNA based HLA typing introduced a genetic nomenclature. In this nomenclature the name of the locus is followed by an asterisk and a number of digits. The first two digits define the allele group corresponding to the serological family in most instances. To define the subtypes the third and fourth digits are used and numbers being assigned in 
the order in which the DNA sequences have been elucidated. Alleles with a different four digit name differ in one or more nucleotide positions that change the amino acid sequence of the encoded protein (non-synonymous). To indicate nucleotide substitutions without an amino acid difference (synonymous) the fifth and sixth digit are used. Alleles that only differ by sequence polymorphisms in introns or in the $5^{\prime}$ and $3^{\prime \prime}$ untranslated regions of the genes are distinguished by the use of a seventh and eighth digit. In some instances, alleles are characterised by substitutions that prevent expression of a functional class I protein at the cell surface. These so-called null alleles are given the suffix ' $N$ ' to indicate null or non-expression. Other suffixes are an ' $\mathrm{L}$ ' to define low expression and an ' $S$ ' to indicate an allele specifying a soluble 'secreted' molecule, which is not expressed on the cell surface ${ }^{62}$. In 2002 the HLA nomenclature has been changed. Until then the fifth digit was used for the distinction of sequences differing only by synonymous nucleotide substitutions. However, as the number of alleles increased, a problem was encountered because the fifth digit could distinguish only nine variants of an allele. Therefore an extra digit was introduced between the fourth and fifth digit to allow identification of up to 99 synonymous variants of each allele. Two other nomenclature problems involve the first two digits defining the allele groups and the third and fourth digit defining subtypes. These digits can distinguish up to 99 variants. It was decided that if the total number of subtypes exceeds 99 , a second allele group number will be used to extend the first one. For DPB1 a different solution had to be chosen because the allele group numbers exceeded $99^{62}$.

A variety of techniques, including serological and molecular methods, have been used to detect HLA polymorphism. The typing results differ in the level of resolution. Typing at low resolution level identifies the first two digits, whereas with high resolution typing at least four digits are determined.

\section{HLA typing methods}

HLA antigens or specificities have been defined traditionally by serological typing using the complement-dependent cytotoxicity test $(C D C)^{63.64}$. It is based on the incubation of lymphocytes and antisera of known HLA specificity. In a second step, (rabbit) complement is added and activated by the binding of HLA specific antibodies to cell surface antigens. As a result, the cell is lysed and the cell membrane becomes permeable to vital dyes, enabling discrimination from living cells. Drawbacks in serological typing are the lack of available monospecific allosera and monoclonal antibodies and the requirement of viable cells. In general low resolution typing is obtained. 
The discovery of DNA amplification techniques has brought a revolution in HLA typing by enabling detection of polymorphism at the genetic level. In comparison with serology, molecular techniques improve reproducibility and offer greater accuracy and flexibility of resolution ${ }^{65-69}$. The difference between serological and molecular typing is that molecular typing can only identify the genes, which code for the different specificities, whereas serological typing demonstrates the expressed molecules on the cell surface. Discrepancies between serology and DNA typing demonstrated the presence of null alleles.

Several molecular methods were developed to type the HLA genes; the three major techniques in common use are PCR-SSP (sequence specific primers), PCR-SSOP (sequence specific oligonucleotide probes) and SBT (sequencebased typing $)^{70}$. PCR-SSP is based on multiple PCR reactions where each reaction is specific for an allele or a group of alleles ${ }^{71-75}$. The method relies on matching of the amplification primers at the 3 ' end of the primer sequence with the target DNA sequence. Taq polymerase can extend $3^{\prime}$ matched primers but not $3^{\prime}$ mismatched primers. For amplification to take place both primers have to match with target DNA. By performing many PCR reactions with specific primer combinations an HLA typing can be generated. The PCR-SSOP method employs PCR amplification of the HLA gene of interest, followed by hybridisation of probes to the PCR product. Many different probes are used which ultimately determine an allele-group specific pattern of sequence motifs, which results in the identification of the individual HLA alleles or allele groups. Two different hybridisation methods are in use. In the conventional method the PCR products are immobilised on a membrane and subsequently hybridised with labeled SSO probes $^{77}$. The reverse SSO technique is based on hybridisation of labeled PCR products to different probes which are immobilised on a solid phase ${ }^{78}$. A major drawback of SSP and SSOP is that these methods need constant updating to take account of each newly discovered allele because the number of HLA alleles is continually increasing. To define every HLA allele at a given locus requires a large number of primers or probes. As a result both methods are usually performed to type at a low or intermediate resolution level. At present several innovative high-throughput typing techniques have been developed, suct as a microsphere based SSO liquid array (Luminex)

\section{Sequence-based typing technique}

DNA sequencing as HLA typing strategy is the most detailed method to identify alleles and to discover new polymorphism directly ${ }^{79}$. Techniques to determine the sequence of DNA were developed in the late $1970 \mathrm{~s}^{80,81}$ and by the end of the 1980 s had become sufficiently rapid, simple and cheap to be considered as 
tissue typing techniques. Originally there were two different DNA sequencing methods, the enzymatic (or dideoxy chain termination) method of Sanger and the chemical degradation method of Maxam and Gilbert. The Sanger method is based on the synthesis of a DNA strand from a single-stranded template by a DNA polymerase ${ }^{80}$ and the Maxam and Gilbert method involves chemical degradation of the original $\mathrm{DNA}^{81}$. Nowadays, the enzymatic chain termination method, with more reliable results and faster and easier to perform, is by far the most popular and widely used technique for sequence determination. The Sanger method starts with the amplification of the DNA region to be sequenced. To produce single stranded DNA the PCR product is denaturated, followed by the annealing of a sequencing primer to the single stranded DNA. The chain termination method relies on the fact that dideoxynucleotides (ddNTPs) are incorporated into the new strand in the same way as the conventional deoxynucleotides (dNTPs). However, ddNTPs differ from dNTPs because they do not have the $3^{\prime} \mathrm{OH}$ group necessary for chain elongation. The chain elangation stops when a ddNTP is incorporated into the growing strand because the lack of the hydroxyl group prevents formation of a phosphodiester bond with the succeeding dNTP. By using the correct ratio of the conventional dNTPs and the ddNTPS in a reaction with DNA polymerase, a population of polynucleotide chains with different lengths is generated. Elongation is initiated at the position where the sequencing primer is annealed to the single stranded DNA and each chain is terminated at a specific base (either $A, C, G$ or $T$ depending on which ddNTP was incorporated). By using four different ddNTPs the complete sequence information can be obtained. After synthesis the chain terminated fragments, which are still bound to the single stranded DNA template, are released by heating these partially double stranded molecules and/or adding a denaturing agent such as formamide. The chain terminated fragments are separated using high resolution denaturating gel electrophoresis or capillary electrophoresis ${ }^{79,82,83}$. In capillary electrophoresis, the separation occurs in a very thin gel or a glass capillary with an inside diameter of approximately fifty microns. Within such a systern, very high electric fields can be applied enabling fast separations ${ }^{84}$.

At present different sequencing approaches are known, each with its own advantages and disadvantages ${ }^{85}$. Santamaria et al. were the first to develop a comprehensive approach to sequence-based typing (SBT) for both HLA class I and $11^{86,87}$. The use of RNA as starting material provided simple means of amplifying the relatively short exonic region of each HLA gene needed for SBT to be applied. The absence of pseudogenes prevents problems in designing gene-specific amplification primers due to their sequence homology with the classical HLA genes. Nowadays genomic DNA, easier to handle and less prone to degradation, is the most commonly used starting material. The 
sequencing reaction can be performed by a solid phase or a solution phase technology. In solid phase sequencing background signals are reduced due to isolation of single stranded DNA before sequencing. Different DNA polymerases can be used to synthesize the new strands in the sequencing reactions, such as Sequenase, T7 polymerase and Taq polymerase. Each enzyme has its own particular properties and qualities. Sequencing can be performed by a one-step sequencing reaction or by cycle sequencing. In both methods, a single sequencing primer is used to linearly amplify a region of target DNA using DNA polymerase in the presence of a mixture of dNTPS and ddNTPS. Both methods are based on the generation of a new DNA strand from single stranded DNA, synthesis starting at the site where the sequencing primer has annealed and terminating when a ddNTP is incorporated. The difference is that in cycle sequencing the reaction occurs not just once, but 2030 times under the control of a thermal cycler and requires a thermostable DNA polymerase. This method needs less template and is less laborious ${ }^{82}$. The sequencing reaction products are detected by their label. Different labelling methods are known, labeling of the sequencing primer, the deoxynucleotides or the dideoxynucleotides. The development of four different fluorescent dyes brought advantages to sequencing strategies as all four sets of sequencing products could be run on a single lane resulting in a four fold increase in the number of samples which could be loaded on a gel. The use of four dyes on the four dideoxynucleotides has the advantage that the dideoxynucleotide sequencing reactions can be performed in a single tube, further simplifying the sequencing procedure. However, spectral overlap and migration differences can interfere with the use of four different dyes.

The amplification primers can be located in the exons or the introns. If the primers are located in the introns, the complete exon information can be obtained by sequencing. However, limited information is available on the intron sequences. The sequencing reaction can be performed in both forward and reverse direction using different sequencing primers. If an internally located sequencing primer is chosen only specific PCR products will be sequenced, but no data will be available on the 5' end of the PCR product. When an M13 tailed amplification primer is used, only one M13 sequencing primer is required. However all PCR products, including aspecific ones, and the amplification primer will be sequenced. Another choice is a sequencing primer identical to the amplification primer, but again all PCR products will be sequenced.

Sequencing a particular HLA gene, one must be aware that individuals can bear two different alleles for the same locus. Both allele-specific and heterozygous amplification and sequencing can be performed. In the allelespecific approach the alleles are amplified separately by using different 
amplification primers for the different alleles. The cis/trans location of the nucleotides is determined, but this method requires previous low resolution typing. In the heterozygous approach the alleles are amplified simultaneously. resulting in the presence of a maximum of two alleles in one PCR product. After sequencing, the presence of two different nucleotides can be detected at some of the polymorphic positions. These heterozygous peaks are indicated according to IUB Nomenclature ( $K=G+T, M=A+C, R=A+G, S=C+G, W=A+T$ and $Y=C+T)^{88}$. The advantage of heterozygous sequencing is that no prior typing result is needed. However, ambiguous typings can be obtained when more than one allele pair has identical heterozygous sequences. These ambiguities can be resolved by allele-specific amplification and sequencing. $A$ second type of ambiguity arises when single alleles cannot be discriminated because the nucleotide differences between the alleles are located outside the region analysed. These ambiguities can be resolved by sequencing other regions or by serology to show the difference between expressed versus null alleles. Whether all encountered ambiguities should be resolved depends on the typing purpose. With the recognition of new alleles, ambiguity lists will increase further. To be able to reanalyse the typings with respect to new alleles the actual sequences must be stored ${ }^{89,90}$.

\section{Clinical implications of HLA typing}

In solid organ and bone marrow/stem cell transplantation HLA matching of donor and recipient has shown to be beneficial. Matching prevents contact of allogeneic cells and tissue which leads to both humoral and cellular immune responses and thereby give rise to complications such as graft rejection and in case of bone marrow or stem cell transplantation, graft-versus-host disease. However only a small part of the recipients can acquire a completely HLAmatched donor because of the extensive polymorphism of the HLA region. It is actually only realistic to count on a well-matched unrelated donor, within a reasonable waiting time, for recipients carrying frequently occurring HLA haplotypes ${ }^{91}$.

Another important reason for HLA typing is the association of HLA with susceptibility and resistance to disease. An increasing number of diseases has been shown to be associated with one or more determinants of the HLA system, such as insulin-dependent diabetes mellitis, systemic lupus erythematosus, myasthenia gravis and multiple sclerosis ${ }^{92}$. Whether the associated HLA antigen is actually involved in the cause of the disease or only a marker for an undiscovered polymorphism in a linked gene is not known until the mechanism causing the disease has been clarified ${ }^{5}$. The association between HLA-B27 and ankylosing spondylitis (AS), recognized in 1973, is one 
of the strongest known HLA associations ${ }^{93-95}$. The presence of B27 in $94 \%$ of all AS patients and in only $9.5 \%$ of controls has been described ${ }^{56}$. The strength of an HLA association can be indicated by the relative risk which is the ratio between the risk of developing the disease in individuals with the antigen and the risk of developing the disease in individuals without the antigen. A general mechanism that has been proposed for the B27 association is that of molecular mimicry, which assumes that immune responses to bacterial peptides crossreact with an antigen-peptide complex of B27 $7^{94,97}$. Historically, a lot of HLA associations were described with susceptibility to autoimmune diseases. However associations with other diseases are also known, like infectious diseases. Several associations between HLA antiglens and human immunodeficiency virus (HI' ) infection have been found ${ }^{98}$ and in western Africa HLA-B53 was found to be associated with resistance to severe malaria ${ }^{99}$.

\section{Aim and outline of this thesis}

The HLA genes, encoded within the human major histocompatibility complex (MHC), are the most polymorphic loci in the human genome. The polymorphism of HLA class 1 is mainly located in exons 2 and 3 , which code for the extracellular $\alpha 1$ and $\alpha 2$ domains and include the antigenic peptide binding site. However, more and more polymorphism is detected in coding regions outside exons 2 and 3 and in the non-coding intron regions. In this thesis the polymorphism of HLA class I genes is analysed in the coding regions including exons 1 through 5 as well as in the noncoding regions, the introns.

To assess the degree of polymorphism, sequence-based typing (SBT) methods for HLA-A and $-B$ have been developed, with special emphasis on the A10/A19 group for HLA-A and the B5/35 cross-reacting group for HLA-B (Chapters 2 and 3). The strategies are based on separate amplifications of exons 2 and 3 , followed by forward and/or reverse heterozygous sequencing of the alleles. The major advantage of heterozygous sequencing is that no prior typing result is needed. However, if two or more allele combinations have identical heterozygous sequences, this leads to ambiguous typing. These ambiguities can be resolved by allele-specific amplification and sequencing.

Another type of ambiguity is noticed when alleles have identical exon 2 and 3 sequences, but differ in other regions. The elucidation of exon 1,4 and 5 sequences of the HLA-A, $-B$ and $-C$ alleles has led to an increase of these ambiguities. To resolve the ambiguities and study the polymorphism in exons 1,4 and 5 we have designed an SBT protocol for HLA-B to sequence the exons heterozygously (Chapter 4 ). Furthermore, we have elucidated the exon 
1,4 and 5 sequences in 39 infrequent $B$-alleles of which these sequences were previously unknown to assess the degree of polymorphism (Chapter 5). Findings were compared with known sequences and evolutionary origin of the allele concerned. Chapter 6 deals with two molecular methods used for detection of $B^{*} 27$. The $B^{*} 27$ allele group is known to be associated with ankylosing spondylitis. The PCR-SSP method was performed to identify the presence or absence of $B^{*} 27$, whereas the SBT method was used to identify the $B^{\star} 27$ subtype. To enable correct assignment of all $B^{\star} 27$ alleles the exons 1 through 4 were sequenced.

The sequence database of HLA class I genes focuses on the coding sequences, the exons. Limited information on polymorphism was available for the non-coding sequences of the different class I alleles. The intron 1, 2 and 3 sequences of HLA-B ${ }^{*} 7301$ were unknown. The allele was known to have a 'very peculiar' coding sequence, which defined a second lineage of the HLA-B alleles. Whether the noncoding introns 1 to 3 of $B^{*} 7301$ also have unique sequences is described in Chapter 7 . To assess the degree of polymorphism of the non-coding intron 4 region, the intron 4 nucleotide sequence of at least one representative of each major allelic group of HLA-A, $-B$ and $-C$ was determined (Chapter 8 ). The ellucidated intron 4 sequences were a useful resource for the design of gene-specific amplification primers in order to obtain complete exon 4 and 5 sequences.

Chapter 9 deals with a special case of polymorphism detected in a family of a Caucasian renal transplant patient. HLA-A analysis of the family demonstrated the absence of HLA-A on one of the haplotypes present in two family members. Different methods were performed for HLA-A detection. Full-length amplification, microsatellite analysis and fluorescent in situ hybridisation (FISH) technology were used to confirm the deletion of the HLA-A gene.

In Chapter 10 the overall results are discussed. 


\section{References}

1. Dausset J. Leuco-agglutinins $\| \mathrm{V}$ : leuco-agglutinins and blood transfusion. Vox Sanguinis 1954:4:190-8.

2. Payne $R$, Rolfs MR. Fetomaternal leukocye incompatibility. J Clin Invest 1958;37:1756-63.

3. Rood van $J$. . Eemisse $J G$. Leeuwer van $A$. Leucocyte antibodies in sera from pregnant women. Nature 1958:181:1735-6.

4. Breuning $M H$, Berg van den-Loonen EM, Bernini LF et al. Localization of HLA on the short arm of chromosome 6. Hum Genet 1977;37:131-9.

5. Marsh SGE, Parham P. Barber LD. The HLA Factsbook. San Diego, San Francisco, New York, Boston, London, Sydney, Tokyo: Academic Press, 2000.

6. Mccluskey $\mathbb{d}$. Peh $\mathrm{CA}$. The thuman leucocyte antigens and clinical medicine: an overwiew. Rev Immunogenet 1999:1:3-20.

7. Aguado $B$, Milner $\mathrm{CM}_{1}$ Campbell RD. Genes of the MHC class III region and the functions of the proteins they encode. In: Browning $M_{1}$ McMichael $A_{n}$ ed. HLA and MHC: genes, molecules and function. Leicester \& Oxford: BIOS Scientific Publishers Ltd, 1996:39-75 (chapter 3 ).

8. Mayer S, Tonglo MM. Joint report: B8. In: Terasaki PI, ed. Histocompakibility Testing. Los Angeles: University of California, 1980:358-60.

9. Cresswell $P$, Turner $M J$, Strominger $\mathrm{JL}$. Papain-solubilized $\mathrm{HL}-\mathrm{A}$ antigens from cultured human lymphocytes contain two peptide fragments. Proc Natl Acad Sci 1973;70:1603-7.

10. Bjorkman PJ, Saper MA, Samraoui $B$, Bennett WS, Strominger JL, Wiley DC. Structure of the human chass I histocompatibility antigen, HLA-A2. Nature 1987;329:506-12.

11. Madden DR, Gorga JC, Strominger JL, Wiley DC. The three-dimensional structure of HLAB27 at 2.1 A resolution suggests a general mechanism for tight peptide binding to MHC. Cell $1992 ; 70: 1035-48$.

12. Saper MA, Bjorkman $P_{w}$, Wiley DC. Refined structure of the human histocompatibility antigen HLA-A2 at 2.6. A resolution. J Mol Biol 1991;219:277-319.

13. Ding $Y H$, Smith KJ, Garboczi DN, Utz U, Biddison WE, Wiley DC. Two human T cell receptors bind in a similar diagonal mode to the HLA-A2/Tax peptide complex using different TCR amino acids. Immunity 1998;8:403-11.

14. Garboczi DN, Biddison WE. Shapes of MHC restriction. Immunity 1999;10:1-7.

15. Bjorkman PJ, Saper MA, Samraoui $B$, Bennett WS, Strominger $U^{L}$, Wiley $D C$. The foreign antigen binding site and $T$ cell recognition regions of class I histocompatibility antigens. Nature 1987;329:512-8.

16. Gao GF, Tomo J Gerth UC et al. Crystal structure of the complex between human CD8alpha-allpha and HLA-A2. Nature 1997;387;630-4.

17. Salter RD, Norment AM, Chen BP et. al. Polymorphism in the alpha 3 domain of HLA-A molecules affects binding to CD8. Nature 1989;338:345-7.

18. Giblin PA, Leahy DJ. Mennone J, Kavathas PB. The role of charge and multiple faces of the CD8-alpha-alpha homodimer in binding to major histocompatibility complex class I molecules: support for a bivalent model. Proc Natl Acad Sci 1994:91:1716-20.

19. Robinson J, Waller MJ, Parham $P$ et al. IMGT/HLA and IMGT/MHC: sequence databases for the study of the major histocompatibility complex. Nucleic Acids Res 2003;31:311-4.

20. Crew MD. Compilation of distinct HLA-A, $\cdots$ and $-C$ transmembrane and cytoplasmic domainencoding sequences. Eur J Immunogenet 1997;24:443-9

21. Parham $P$, Arnett $K L$, Adams EJ et all. The HLA-B73 antigen has a most unusual structure that defines a second lineage of HLA*B alleles. Tissue Antigens 1994:43:302-13.

22. Herrero $M J$, Vilches $C$, Pablo de $R$, Puente $S$, Kreisler $M$. The complete primary structure of $C w^{*} 1701$ reveals a highly divergent HLA class I molecule. Tissue Antigens 1997;49:267-70.

23. Israel $A$, Kourilsky P. Regulation of MHC class I gene expression. In. Browning M, McMichael $A_{n}$ ed. HLA and MHC: genes, mollecules and function. Leicester \& Oxford: BIOS Scientific Publishers Ltd, 1996:139:57 (chapter T) 
24. Townsend $A$, Bodmer $H$. Antigen recognition by class thestricted $T$ lymphocytes: Annu Rev Immunol 1989;7:601-24.

25. Long EO, Rajagopalan S. HLA class I recognition by killer cell lg-like receptors. limmunology 2000;12:101-8.

26. Moretta A, Biassoni R, Bottino $C$ et al: Major histocompatibility complex class l-specific receptors on human natural killer and T lymphocytes. Immuinol Rev 1997;155:105-17.

27. Heemels M-T, Ploegh $H$. Generation, translocation, and presentation of MHHC class-1 restricted peptides. Annu Rev Immunol 1995;64:463-91.

28. Germain RN. MHC-dependent antigen processing and peptide presentation: providing ligands for T-lymphocyte activation. Cell 1994;76:287-99.

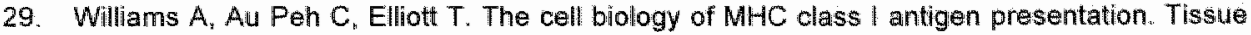
Antigens 2002;59:3-17.

30. Brodsky $F M$. Lem $L$, Bresnahan PA. Antigen processing and presentation. Tissue Antigens 1996;47:464-71.

31. Kaer van L. Major histocompatibility complex class I-restricted antigen processing and presentation. Tissue Antigens 2002;60:1-9.

32. Parham $P$. Adams EJ, Amett $K L$. The origins of HLA $A, B, C$ polymorphism. Immunol Rev $1995: 143: 141-80$.

33. Bodmer JG, Marsh SGE, Albert E. Nomenclature for factors of the HLA system, 1989. Immunol Today 1990;11:3-10.

34. Lawlor DA, Zemmour $J$, Ennis $P D$, Parham $P$. Evolution of class-1 MHC genes and proteins: from natural selection to thymic selection. Annu Rev Immunol 1990;8:23-63.

35. Bunce M, Procter J, Dunn PPJ, Day S, Rass J, Welsh Kl. Idientification of the null HLA-A2 allele, $A^{*} 0232 \mathrm{~N}$. Tissue Antigens 2000;55:31-6.

36. Wu G-G, Cheng L-H, Deng $Z-H$ et al. Cloning and complete sequence of a novel HLA-A null allele, $A^{*} 0253 \mathrm{~N}$, with a termination codon generated by a $C$ to $G$ mutation in exom 2 . Tissue Antigens 2002;59:328-30.

37. Magor KE, Taylor EJ, Shen $S Y$ et al. Natural inactivation of a common HLA allele (A'2402) thas occurred on at least three separate occasions. J Immunol 1997;158:5242-50.

38. Ishikawa $Y$, Tokunaga $K$, Tanaka $H$ et al. HLA-A null allele with a stop codon, HLA-A*0215N. identified in a homozygous state in a healthy adult. Immunogenetics 1995:43:1-5.

39. Mine $H$, Isthikawa $Y$, Hojo M t al An HLA-B null allele $\left(B^{*} 1526 N\right)$ with a stop codon in axon 3 generated by a point mutation. Tissue Antigens 1997;50:35:1-4.

40. Hollander den $N, L i J$, Oosterwijk van $A, N g C-M$, Singal DP. Identification of a new HLA-B null allele, $B^{\prime \prime} 1817 \mathrm{~N}$, in a family. Tissue Antigens $2002 ; 59: 341-3$.

41. Hammond $L$, Street J, Downing J, Thompson J, Darke $C$. Immunogenetics of a new HLA-B null allele, HLA-B*4423N. Eur J Immunogenet 2003:30:385-6.

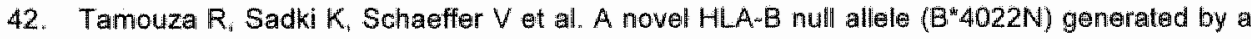
inonsense codon in the alpha-1 domain. Tissue Antigens 2000;55:378-80.

43. Hou JY, Luning Prak $E$, Kearns $J$ et al. A nonsense mutation in exon 3 results in the HLA-B null allele $B^{*} 5127 \mathrm{~N}$. Tissue Antigens $2002 ; 60: 262-5$.

44. Li J, Hollander den $N$, Oostenwijk van $A, N g C-M$, Singal DP. Identification of a new HLA.A null allele, $A^{*} 2436 \mathrm{~N}$. Tissue Antigens $2002 ; 60: 184-5$.

45. Laforet $M$, Froelich $N$, Parissiadis $A$ et al. A null HLA $A^{*} 68$ allele in a bone marrow donor. Tissue Antigens 1999;53:573-5.

46. Laforet $M_{3}$ Froelich $N_{8}$ Parissiadis $A$ et al. A nucleotide insertion in exon 4 is responsible for the absence of expression of an HLA-A*01 allele. Tissue Antigens 1997;50:347-50.

47. Zanone-Ramseier $R$, Gratwohl $A$, Gmür J Roosnek $E$, Tiercy JM. Sequencing of two HLA-A blank alleles: implications in unrelated bone marrow donor matching. Transplantation 1999: 67:1336-41.

48. Dormoy $A$, Froelich $N$, Parissiadis $A$, Cazenave J-P, Tongio MM. Second HLA A*B8 null allele, $A^{*} 6818 \mathrm{~N}$, identified. Tissue Antigens 2002;60:88-90.

49. Carter V, Dunn PPJ, Cavanagh $G$, Day $S$, Ross $J_{n}$ Chapman $C$. An HLA-B null allele ( $B^{*} 0808 N$ ) caused by a nucleotide deletion in exon 3 , found in the family of a bone marrow transplant recipient. Tissue Antigens 2000:55:61-4. 
50. Dumne C. Lithe AM, Cox ST at. Identification and nucleotide sequence of a new null allele,

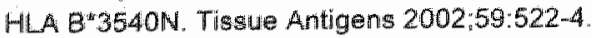

51. Bettens $F$. Tiercy $M$ M. Sequence of a new dass I null allele within the HLA-B44 specificty Tissue Aritigens $2000,56: 44$. $1-5$.

52. Batals $A$, Santos $S$, Aviles MS et al. Elongation of the cytoplasmic doman, due to a point deletion at exon 7, results in an HLA-C null allele, Cw*408N. Tissue Antigens: 2002:59:95. 100.

53. Elsner H-A. Drábek \& Rebmanin V: Ambruzova Z, Grosse-Wide H, Blasczyk R. Nanexpresision of HLA-B*5111N is caused by an insention into the cytosine istand at exor: 4 creathy a framestufft stop codon. Tissue Antigens 2001;57:369-72.

54. Lienert $K$. Russ $Q$, Lester $S$, Bennett G, Gao X, McCluskey J. Stable inheritance of an HLA"blarik" phenotype associated with a structural mutation in the HLA.A.0301 gene. Tissue Antigens $1996,48: 187-91$

55. Lardy NH, Otting N, Horst wan der AR, Bontrop RE. Waal de LP. 5 Regulatory nucleotide sequence of an HLA-A 0101 null allele. immunogenetics $1997: 46: 152-5$.

56. Balas A, Garciam Sanchez $F$, Gómez-Reino $F$, Vicario $J$. HLA class I allele (HLA-A2) expression defect associated with a mutation in its enhancer $B$ inwerted cat box in two families. Hum immunol $1994,41: 69-73$.

57. Elsner H-A. Bernard $G$, Eiz-Vesper B, Matteis de M, Bernard A, Blasczyk R. Non-expression of HLA-A $2901102 \mathrm{~N}$ is caused by a nucleotide exchange in the mRNA splicing site at the beginning of intron 4 . Tissue Antigens 2002;59:139-41.

58. Laforet $M_{1}$ Froelich $N$, Parissladis $A$. Bausinger $H$, Pfeffer $B$, Tongio $M M$. An intronic mutation responsible for a low level of expression of an HLA-A*24 allele. Tissue Antigens 1997;50:3406.

59. Curran MD. Williams F, Litte AM, Rima BK, Madrigal JA, Middleton D. Aberrant splicing of intron 1 creates a nowel nut: HLA-B*1501 allele. Tissue Antigens 1999:53:244-52.

60. Lee KW. Shin J-Y, Lee J-Y. Expression defect of an HLA-A.24 allele associated with DNA methylation in a norm individual. Tissthe Antigens 2003:61:325-9.

61. WHO Nomenclature Committee. Bull WHO 1968:39:483.

62. Marsh SGE, Abert ED, Bodmer WF et, Nomenclature for factors of the HLA system, 2002. Tilssue Antigens 2002:60:407-64.

63. Terasaki: Pl, McClelland UD. Microdroplet assay of human serum cytotoxins. Nature 1964; 204:998-1000.

64. Engelinet CP, Britten A. The cytotoxic test for leucacyte antibodies. A simple and reliable technique. Vox Sanguinis 1965, 10:660-74.

65. Bunce M. Bamardo MCNM, Procter J Marsh SGE, Vilchas C. Welsh KI. High resolution HLAC typing by PCR -SSP: identification of allelic frequencies and linkage disequilibria in 604 unrelated random UK Caucasolds and a comparison with serology. Tissue Antigens 1996; $48: 680.91$.

66. Lorentzen DF. Wwanaga KK, Mewer KJ, Moritz TL Watkins DI. A $25 \%$ error rate in serologic typing of HLA-B homozygotes. Tissue Antigens 1997;50:359-65.

37. Mytilineos $J$, Lempert M. Middeton D al. HLA class I DNA typing of 215 "HLA.A.,B,-DR zero mismatched" kidmey transplants. Tissue Antigens 1997 :50:355-8.

68. Yu $N$, Oneshi $M$, Aolsco $S$ et al. Accurate typing of HLA-A antigens and analysis of serological deficiencies. Tissue Antigens 1997;50:380-6.

69. Adono D, Canossi A, Fapola Fet al Comparison between HLA class II PCR-ARMS and serologlic typing in cadaveric kidney transplantation. Transpl Proc 1997;1:1423-5.

70. Bidwell JL. Navarrete $\mathrm{C}$. Histocompatibility Testing. London: Imperial College Press, 2000.

71. Otenup $O_{1}$ Zetterquist H. HLA-DR typing by PCR amplification with sequence-specific primers (PCR-SSP) in 2 hours: An alternative to serological DR typing in clinical practice including donor-reciplent matching in cadaveric transplantation. Tissue Antigens 1992;39:225-35.

72. Krausa P, Moses J, Bodmer W. Bodmer J, Browning M. HLA-A locus alleles identified by sequence specific PCR. Lancel $1993 ; 341: 121-2$ 
73. Sadler $A M$, Petronzelli $F$, Krausa $P$ al. Low-resolution DNA typing for HLA-B using sequence-specific primers in allele- or group-specific ARMSIPCR. Tissue Antigens 1994:44: 148-54.

74. Bunce W. Welsh KI. Rapid DNA typing for HLA-C using Sequence-Specific Primers (PCRSSP): Identification of serological and non-serologically defined HLA-C alleles including several new alleles. Tissue Antigens 1994;43:7-17.

75. Bunce $M$, ONell CM. Barnardo MCNM et al. Phototyping: comprehensive DNA typing for HLA $-A, B, C$ DRB1, DRB3, DRB4, DRB5 \& DQB1 by PCR with 144 primer mixes utilizing sequence-specific primers (PCR-SSP). Tissue Antigens 1995;46:355-67

76. Savelkoul PHM, Bruyn de-Geraets. DP, Berg wan den-Loonen PM. High resolution HLA-DRB1 SSP typing for cadaveric donor transplantation. Tissue Antigens 1995;45:4\%-8

77. Saiki RK, Bugawan TL, Horn GT, Mlullis KB, Erlich HA. Analysis of enzymatically amplified beta-globin and HLA-DQ-alpha DNA with allele-specific oligonucleotide probes. Nature 1986 $324: 163-6$.

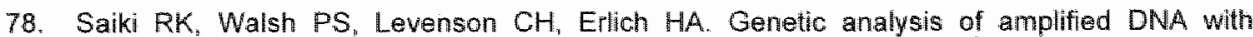
immobilized sequence-specific oligonucleotide probes. Proc Natl Acad Sici 1989;86:6230-4.

79. Voorter CEM, Berg van den-Loonen EM. HLA and HPA typing - advances in the application of molecular biology. In: Smith Sibinga CTh, Klein $H_{G}$, ed. Molecular Biology in Blood Transfusion. Dordrecht, Boston, London: Kluwer Academic Publishers, 2000:61-71.

80. Sanger $F$. Nicklen $S$, Coulson AR. DNA sequencing with chain-terminating inhibitors. Proc Natl Acad Sc: 1977;74:5463-7.

81. Maxam AM, Gilbert W. A new method for sequencing DNA. Proc Natl Acad Sci 1977;74: 560 4.

82. Griffin HG, Griffin AM. DNA sequencing. In: Griffin HG, Griffin AM, ed. Methods in molecular biology: DNA sequencing protocols. Totowa New Jersey: Humana Press Inc, 1993:1-8 (chapter 1).

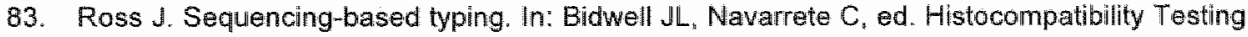
London: Imperial College Press, 2000:213-46 (chapter 7).

84. Wetzsteon PJ. Understanding sequence-based typing. Ashi quarterly 1997;21:4-22.

85. Blasczyk R. HLA diagnostic sequencing - conception, application and automation. J Lab Med $2003 ; 27: 359-68$.

86. Santamaria P, Boyce-Jacino MT, Lindstrom AL, Barbosa لJ. Faras AJ, Rich SS. HLA class II "typing": direct sequencing of DRB, DQB, and DQA genes. Hum Immunol 1992;33:69-81.

87. Santamaria P, Lindstrom AL. Boyce-Jacino MT et al. HLA class I sequence-based typing. Hum Immunol 1993;37:39-50.

88. Nomenclature Committee of the International Union of Biochemistry (NC.IUB). Nomienclature for incompletely specified bases in nucleic acid sequences. Recommendations 1984. Eur $J$ Biochem 1985:150:1-5.

89. Rozemuller EH. SBT resolution and ambiguilies. Chapter 6. In: Tilanus MG. Mansen JA, Hurley CK, ed. IHWG technical manual: genomic analysis of the human MHC DNA based fyping for HLA alleles \& linked polymorphisms. Seattle USA: Fred Hutchinson Cancer Research Center, 2001:TM6-2-TM6-33.

90. Swelsen WTN, Voorter CEM, Berg van den-Loonen EM. A specially designed database enables reanalysis of sequence-based HLA typings. Genes and Immunity 2004;5:\$57.

91. Claas FHU, Roelen DL, Oudshoorn M, Doxiadis IIN. Future HLA matching strategies in clinical transplantation. In: Sundmacher $R_{\text {, }}$ ed. Adequate HLA matching in keratoplasty. Dev Ophthallmol. Basel: Karger, 2003:62-73.

92. Lechler $R_{i}$ Warrens A. HLA in Health and Disease. London: Academic Press, 2000.

93. Brewertion DA. Caffrey M. Hart FD, James DCO Nicholls $A$. Sturrock RD. Ankylosing spondylitis and HL-A 27. Lancet 1973:1:904-7.

94. Ramos $M_{1}$ Lopez-Castro de JA. HLA-B27 and the pathogenesis of spondyloarthritis. Tissue Antigens 2002;60;191-205.

95. Berg yan den-Loonen EM, Dekker-Saeys Bd, Meuwissen SGM, Nijenhuis LE, Engelfitet CP Histocompatibility antigens and other genetic markers in ankylosing spondylitis and inflammatory bowel diseases. J Immunogenet 1977;4:167-75. 
96. Brown MA, Pile KD, Kennedy LG et al. HLA class I associations of ankylosing spondylitis in the white population in the United Kingdom. Ann Rheum Dis $1996 ; 55: 268-70$.

97. Benjamin R, Parham P. Guitt by association: HLA-B27 and ankylosing spondylitis. Immunol Today 1990;11:137-42.

98. Glynne PA, Price NM. HLA and infectious diseases. In: Lechler R, Warrens A, ed. HLA in health and disease. London: Academic Press, 2000:299-326 (chapter 20).

99. Hill AVS, Alsopp CEM, Kwatkowski D et al, Common West African HLA antigens are associated with protection from severe malaria. Nature 1991;352:595-600. 


\section{Chapter 2}

Sequence-based typing of the HLA-A10/A19 group and confirmation of a pseudogene coamplified with $A^{*} 3401$

Wendy TN Swelsen, Christina EM Voorter and Ella $M$ van den Berg-Loonen Human Immunology 2005;66:535-542 


\section{Abstract}

The strategy for sequencing human leukacyte antigen (HLA)-A was based on separate amplification of exons 2 and 3 , followed by forward and reverse heterozygous sequencing of the alleles. Validation of the method was obtained by sequencing 11 indiwiduals carrying alieles from all different HLA-A allele groups, except *43. All alleles could be coirectly identified except $A^{*} 3401$. Unaxpected polymarphic positions were ldentified in exon 3 , even in indiwiduals homozygous for $A * 3401$. The pseudogene HLA-COQ or HLA-DEL linked to A*3401 was coamplified and sequenced in addition. The problem was solved by using different amplification primers for exon 3 with mismatchies for the two pseudogenes

A total of 252 unrelated individuals with at least one allele belonging to the $A 10$ or $A 19$ group were typed for HLA-A by this strategy. Ten different alleles were identified in the A10 group and 14 in the A19 group. As second allele a further 30 different subtypes from all different groups were sequenced. In 21 individuals sequencing exon 1 was necessary to distinguish $A^{*} 7401$ from $A^{*} 7402$. The sequencing strategy, with separate amplification of the exons, has proven to be a robust method, resulting in reliable and efficient high-resolution HLA-A typing. 


\section{Introduction}

The human leukocyte antigens (HLA) are highly polymorphic cell-surface glycoproteins encoded by the major histocompatibility complex, which play an important role in the immune response. For HLA-A, more than 320 alleles are identified by sequence analysis ${ }^{1}$. The polymorphism is mainly located in exons 2 and 3 encoding the extracellular domains $\alpha 1$ and $\alpha 2$, which are responsible for peptide binding and recognition by both $T$ and natural killer cells $s^{2-4}$.

The antigens of the HLA-A10 group, A25, A26, A34 and A66 form a so-called cross-reacting group ${ }^{5}$. Most antisera with A10 specificity react with two or more of the subtypes and monospecific antibodies against A26 and A66 are rarely seen. This implicates that the definition of some of these antigens is largely dependent on the interpretation of serologic patterns obtained with different anti-A10 sera. The subdivision of HLA-A10 into the two subtypes A25 and A26 was described in 1971 by Richiardi et al. and by Legrand et al. ${ }^{6.7}$. A third specificity belonging to the A10 group was described later and named A34 in $1975^{8-10}$. In 1983, a Dutch group described another split of the A10 antigen, later named $A 66^{11.12}$. At present, thirty-eight different $A 10$ subtypes are known, giving rise to 36 different proteins. Five $A^{*} 25$ alleles, $23 A^{*} 26$ alleles, $6 A^{*} 34$ alleles and $4 A^{*} 66$ alleles are described'. Comparison of the sequences suggests that shared A10 epitopes, which define the family serologically, may be formed by residues of the $\alpha 2$ helix. In particular, the motif of threonine at position 149 together with glutamic acid at 152 is shared by almost all $A 10$ molecules. The only other HLA-A, $-B$ or $-C$ molecules in which this motif has been found are the $A^{*} 0203$ and $A^{*} 0238$ subtypes of $A 2^{1,13}$.

The HLA-A19 complex is another group of serologically cross-reactive antigens, which was first described in $1973^{14}$. The group now includes six subtypes, $A 29, A 30, A 31, A 32, A 33$ and $A 74$, with $A 74$ as the last one assigned in $1987^{15}$. Currently, sixty alleles for $A 19$ subtypes are known; 14 for $A^{\star} 29,12$ for $A^{*} 30,9$ for $A^{*} 31,8$ for $A^{*} 32,7$ for $A^{*} 33$ and 10 for $A^{*} 74$. The 60 alleles represent 55 different proteins ${ }^{*}$. The alleles of $A^{*} 29,{ }^{*} 31,{ }^{*} 32,{ }^{*} 33$ and ${ }^{*} 74$ are serologically and genetically closely related, sharing the unique sequence motifs of leucine at position -11 and phenylalanine and arginine at positions 298 and $307^{4,16}$. The $A^{*} 30$ alleles are genetically related to the $A^{*} 01 /{ }^{*} 03 / * 11$ group, implicating that they arose from the same ancestral allele ${ }^{16-18}$. The serologic relationship of $A^{\star} 30$ with the other members of the A19 group has been proposed to be the result of a conversion event ${ }^{16}$.

Several different sequencing protocols for HLA-A have already been established ${ }^{19-25}$. We report a unique sequencing strategy with separate 
amplification and sequencing of exons 2 and 3 , enabling robust heterozygous sequencing of HLA-A. The sequence-based typing (SBT) strategy was validated against a panel of 11 individuals carrying alleles from all different HLA-A allele groups. In addition, 252 unrelated individuals with at least one allele belonging to the $A 10$ or A19 group were typed for HLA-A by this strategy. Coamplification of a pseudogene linked to $A^{\star} 3401$ was observed, as previously noticed by other groups ${ }^{26.27}$.

\section{Materials and methods}

\section{Samples}

A panel of 11 individuals carrying HLA-A alleles from 20 different allele groups was selected to validate the SBT protocol. The different HLA-A groups included in the panel were: $A^{*} 01,{ }^{*} 02,{ }^{*} 03,{ }^{*} 11,{ }^{*} 23,{ }^{*} 24,{ }^{*} 25,{ }^{*} 26,{ }^{*} 29,{ }^{*} 30,{ }^{*} 31,{ }^{*} 32$, ${ }^{*} 33,{ }^{*} 34,{ }^{*} 36,{ }^{*} 66,{ }^{*} 68,{ }^{*} 69,{ }^{*} 74$ and ${ }^{*} 80$. No individuals carrying $A^{*} 43$ were available. Furthermore, the SBT protocol was used to type a total of 252 unrelated individuals for HLA-A. They were selected to possess at least one HLA A allele of the A10 (A*25, ${ }^{*} 26,{ }^{*} 34$ and $\left.{ }^{*} 66\right)$ or A19 (A *29, ${ }^{*} 30,{ }^{*} 31,{ }^{*} 32$, *33 and *74) group. The individuals typed were laboratory personnel, blood bank donors, patients, organ donors and quality control samples; in the latter, consanguinity was sometimes unknown. The ethnic origin of the individuals was not always known, but at least half of them were non-Caucasians. All samples were previously typed by serology and/or low-resolution polymerase chain reaction with sequence-specific primers (PCR-SSP). The latter was carried out using locally developed A-locus SSP primer mixes with the SSP amplification protocol ${ }^{28}$ or the commercially available PCR-SSP HLA-A kit (Dynal, Biotech, Oslo, Norway). Each individual shown to be HLA-A homozygous by SBT was subsequently retyped by low resolution PCR-SSP to exclude allele drop-out.

\section{DNA isolation}

DNA was isolated from fresh heparinized blood or from lymphocytes stored in liquid nitrogen, either by the "salting out" extraction procedure as described by Miller et al. ${ }^{29}$ or by using QIA-AMP kits following the suppliers protocol (Qiagen. Westburg, Leusden, the Netherlands). Concentration and purity of DNA samples were measured at optical densities of 260 and $280 \mathrm{~nm}$. 


\section{Primers and approach}

The strategy used for SBT of HLA-A included separate amplification and sequencing of exons 2 and 3 using primers located in adjacent exons and introns to obtain complete exon sequences. Locations and sequences of all primers tested are indicated in table 2.1. Table 2.2 shows the final combinations of primers used for the heterozygous sequencing strategy of exons 2 and 3 of HLA-A. All primers were designed locally. The Cy-5 labeled sequencing primers were located internally of the PCR products to ensure specific sequencing.

Table 2.1 Sequence and location of amplification and sequencing primers tested for the heterozygous sequencing of exons 2 and 3 of HLA-A.

\begin{tabular}{|c|c|c|c|}
\hline Name & Sequence & Location & Posittion". \\
\hline \multicolumn{4}{|l|}{ Exon 2} \\
\hline $5 \mathrm{~A} 97107$ & CCAGACGCCGAGGATGGCC & 5UTIEN & $-13-6$ \\
\hline $3: A 97104$ & GGCCTAAACTGAAAATGAAACC & 12 & $622-643$ \\
\hline $5 \mathrm{~A} 97080 \mathrm{C}$ & ${ }^{C y 5}$ TCTCAGCCACTSCTCG & 11 & $181-196$ \\
\hline 5 A01026C & ${ }^{\mathrm{Cy} 5}$ GGGGAGAAGCAASGGGC & 11 & $108-124$ \\
\hline 3A96093C & ${ }^{C Y S}$ ATCTCGGACCCGGAGACT & 12 & $542-559$ \\
\hline \multicolumn{4}{|c|}{ 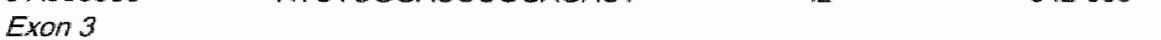 } \\
\hline 5'A98009 & GACAGCGACGCCGCGAGC & E2 & $311-328$ \\
\hline $5: A 00056$ & CCOGGGAAGCCGCGCCT & 11 & $146-162$ \\
\hline 3:A96090 & TGTTGGTCCCAATTGTCTCCCCTC & 13 & $1055-1078$ \\
\hline $5: A 96094 \mathrm{C}$ & ${ }^{C S^{T}}$ TCATITTCAGTTTAGGCCA & 12 & $626-644$ \\
\hline $5 \mathrm{~A} 98010 \mathrm{C}$ & ${ }^{D y 5}$ GGGACYGGGCTGACC & 12 & $684-698$ \\
\hline $5^{\prime} A 98027 \mathrm{C}$ & Cy5.GACGGCAAGGATTACA & E3 & $798-813$ \\
\hline 3'A99045c & ${ }^{C \times}$ AGGCCAGCCCGGGAG & 13 & $1032-1046$ \\
\hline
\end{tabular}

'The nucleotide positions are numbered according to the genomic alignments of HLA-A'

Table 2.2 Combination of primers used for sequence-based typing of exons 2 and 3 of HLA-A.

\begin{tabular}{lllll}
\hline & $\begin{array}{l}5^{*} \text { amplification } \\
\text { primer }\end{array}$ & $\begin{array}{l}3^{\prime} \text { amplification } \\
\text { primer }\end{array}$ & $\begin{array}{l}5^{\prime} \text { sequencing } \\
\text { primer }\end{array}$ & $\begin{array}{l}3^{\prime \prime} \text { sequencing } \\
\text { primer }\end{array}$ \\
\hline Exon 2 & A97107 & A97104 & A97080c & A96093c \\
Exon 3 & A98009 & A95090 & A96094C & A99045C \\
Exon 3 A*3401 & A00056 & A96090 & A96094C & A99045c \\
\hline
\end{tabular}

The amplification of exon 2 was performed using an A-locus specific $5^{\prime}$ primer (A97107) located in the transition from the $5^{\prime}$ untranslated region and exon 1 combined with a $3^{\prime}$ primer (A97104) located in intron 2. Two forward and one reverse sequencing primer were tested to achieve complete sequencing of exon 2. Exon 3 was amplified with a $5^{\prime}$ primer located in exon 2 (A98009) and an A-locus specific 3' primer located in intron 3 (A96090). For correct 
sequerting of exon 3 , three forward and one reverse sequencing primer were tested. To achieve correct amplification of individuals possessing an $A * 3401$

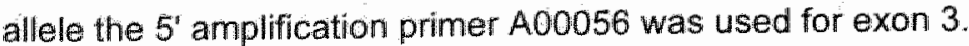

\section{Amplification and sequencing of exons 2 and 3}

The PCR conditions used were identical to the conditions for SBT of HLA-B exons 2 and 3 as previously described ${ }^{30}$. In brief, the PCR reaction was carried out in a final volume of $60 \mu$, containing $600 \mathrm{ng}$ DNA, 2.0 U Amplitaq DNA polymerase, 20 pmol of biotinylated primer, 40 pmol of unbiotinylated primer, PCR buffer according to Bunce ${ }^{34}(67 \mathrm{mM}$ Tris-HCl, $\mathrm{pH} 8.8,16.6 \mathrm{mM}$ $\left(\mathrm{NH}_{4}\right)_{2} \mathrm{SO}_{4,}, 0.01 \%(\mathrm{v} / \mathrm{v})$ Tween 20), $1.5 \mathrm{mM} \mathrm{MgCl}, 6 \mu \mathrm{g}$ cresol red, $200 \mu \mathrm{M}$ each dNTP and $5 \%$ glycerol. The cycling conditions consisted of an initial denaturation at $96^{\circ} \mathrm{C}$ for $2 \mathrm{~min}, 10$ cycles of $10 \mathrm{~s}$ at $94^{\circ} \mathrm{C}, 60 \mathrm{~s}$ at $65^{\circ} \mathrm{C}$ and 30 cycles of $10 \mathrm{~s}$ at $94^{\circ} \mathrm{C}, 50 \mathrm{~s}$ at $61^{\circ} \mathrm{C}$ and $30 \mathrm{~s}$ at $72^{\circ} \mathrm{C}$, followed by a final extension at $72^{\circ} \mathrm{C}$ for $10 \mathrm{~min}$. The presence of PCR products with the correct base llength was checked by agarose gel electrophoresis. A solid phase sequencing approach was used as previously described ${ }^{28,32-34}$. The nonbiotinylated DNA strand was removed by alkaline denaturation after attachment of $40 \mu \mathrm{l}$ of biotinylated product to streptavidin-coated beads (Dynal, ITK diagnostics, Uithoorn, the Netherlands). After annealing of the Cy-5 labeled sequencing primer, the sequencing reaction was performed at $37^{\circ} \mathrm{C}$ for $5 \mathrm{~min}$. The samples were heated at $90^{\circ} \mathrm{C}$ for $2 \mathrm{~min}$, prior to loading on a $0.5 \mathrm{~mm}$-thick $6 \%$ polyacrylamide-7M urea gel. Electrophoresis was performed on an ALFexpress automated sequencer (Pharmacia Biotech, Uppsala, Sweden). Sequence data were processed automatically and evaluated manually. The combined sequences of exon 2 and 3 were used for automatic alignment to the HLA-A sequence database of October 2003 and allele assignment was obtained using the HLA Sequityper software (Pharmacia Biotech).

\section{Results}

\section{Validation of SBT strategy}

The HLA-A SBT strategy was validated against a panel of 11 individuals. Exons 2 and 3 were amplified separately using heterozygous primers located in adjacent exons and introns. All alleles could be correctly identified except $A^{*} 3401$, described in detail below. The 5' amplification primer for exon 2 (A97107) showed a mismatch with the $A^{*} 11$ alleles at position 13 from the $3^{\prime}$ end of the primer sequence ${ }^{1.22}$. Nevertheless, no allelic drop-out or preferential amplification was detected in the heterozygous sequencing of 21 individuals 
carrying an $A^{*} 11$ allele next to another A-allele and equal peak heights were found for the polymorphic positions. All other primers showed no mismatches with any of the HLA-A alleles.

Sequencing of exon 2 using one forward sequencing primer (A97080c) resulted in high quality sequence data, but in approximately $40 \%$ of the individuals incomplete sequence reading at the end of exon 2 was shown. Furthermore, in several cases, the first bases of exon 2 were difficult to interpret, missing two polymorphic sites (positions 78 and 81 ) at the 5 end of exon 2. Therefore, two other sequencing primers were designed and tested, one forward primer located more to the $5^{\prime \prime}$ end of intron 1 (A01026c) and one reverse (A96093c). The forward sequencing primer resulted in unreliable typing data because of high background signals and sequencing artefacts, but the first nucleotides of the exon 2 sequence could reliably be assigned. The reverse sequencing primer showed correct results and the end of exon 2 was always reliably determined. Because of these results the forward sequencing primer $\mathrm{A97080 \textrm {C }}$ and reverse sequencing primer $\mathrm{A} 96093 \mathrm{c}$ were chosen for inclusion in the final protocol (table 2.2).

For exon 3, two forward sequencing primers were tested: $A 98010 \mathrm{c}$ located in intron 2 and A98027c located in the middle of exon 3 . The sequencing results obtained were reliable; however, in all cases, approximately 18 nucleotides at the start of exon 3 were not readable because of a strongstop. Therefore, two other sequencing primers were tested: one forward primer located more to the 5 ' end of intron 2 (A96094c) and one reverse primer (A99045c). These sequencing primers showed correct results and the complete exon 3 sequence was obtained. The primers were included in the final protocol (table 2.2).

\section{Sequencing results $\mathrm{A} 10$ and $\mathrm{A} 19$ group}

A total of 252 unrelated individuals were sequenced for HLA-A. Two hundred and ten of them were heterozygous, with one allele belonging to the A10/A19 group, in 34 individuals both HLA-A alleles belonged to the A10/A19 group, and 8 individuals were homozygous for an A10/A19 subtype. The homozygosity of the latter was checked by PCR-SSP.

Table 2.3 shows the different A10/A19 group alleles identified in the study with the number of individuals in which these alleles were found. In total, 286 A10/A19 alleles were detected, 103 alleles belonged to the A10 group and 183 to the A19 group. Ten different alleles were recognized in the A10 group $\left(A * 250101,{ }^{*} 2601,{ }^{*} 2603,{ }^{*} 2608,{ }^{*} 2615,{ }^{*} 3401,{ }^{*} 3402,{ }^{*} 3404,{ }^{*} 6601\right.$ and $\left.{ }^{*} 6602\right)$ and 14 in the A19 group (A*29010101, "290201, "3001, "3002, "3004, *3009, *3011, "310102, *3201, "3301, "330301, "7401, "7402 and *7403). Despite the fact that different $A^{*} 25$ alleles have been described, only $A^{*} 250101$ was identified. In the $A^{*} 26$ group, four different alleles were detected with 
36 Chapter 2

$A^{*} 2601$ as the most common subtype $(n=34)$. Two $A^{*} 29$ alleles have been found $A^{*} 290201$ being the most frequent one $(n=18)$. Our study confirmed that $A^{*} 30$ is a heterogeneous group; in our mixed sample population $A^{*} 3001$ and $A^{*} 3002$ were found most frequently. Only one allele was identified for the $A^{*} 31$ and $A^{*} 32$ group. Two different $A^{*} 33$ alleles were found, $A^{*} 3301$ and $A^{*} 330301$, which were present in approximately equal numbers. Furthermore, three different $A^{*} 34$, two different $A^{*} 66$ and three different $A^{*} 74$ alleles were identified. In the $A^{*} 74$ group, $A^{\star 7} 7402$ was detected only once.

In the heterozygous individuals the non-A10/A19 alleles included alleles belonging to $A^{*} 01,{ }^{*} 02,{ }^{*} 03,{ }^{*} 11,{ }^{*} 23,{ }^{*} 24,{ }^{*} 36,{ }^{*} 68,{ }^{*} 69$ and ${ }^{*} 80$. Although the study focussed on the A10/A19 group alleles, a total of 54 different HLA-A alleles were identified.

Table 2.3 The different A10/A19 group alleles identified by SBT with the number of individuals (n) in which these alleles were identified.

\begin{tabular}{|c|c|c|c|c|c|}
\hline & Allele & $n$ & & Allele & $n$ \\
\hline \multirow[t]{2}{*}{ HLA-A'25 } & & & HLA-A*32 & & \\
\hline & $" 250101$ & 9 & & 3201 & 33 \\
\hline \multirow[t]{5}{*}{ HLA-A 26} & & & HLA $-A^{*} 33$ & & \\
\hline & 2601 & 34 & & 3301 & 19 \\
\hline & 2603 & 3 & & *330301 & 21 \\
\hline & 2608 & 3 & HLA-A 34 & & \\
\hline & 2615 & 1 & & $* 3401$ & 18 \\
\hline \multirow[t]{3}{*}{ HLA-A. 29} & & & & $* 3402$ & 6 \\
\hline & *29010101 & 3 & & 3404 & 2 \\
\hline & *290201 & 18 & HLA-A*66 & & \\
\hline \multirow[t]{6}{*}{$H L A-A^{*} 30$} & & & & ${ }^{*} 6601$ & 19 \\
\hline & *3001 & 16 & & ${ }^{*} 6602$ & 8 \\
\hline & $* 3002$ & 11 & HLA A A*74 & & \\
\hline & ${ }^{*} 3004$ & $\pi$ & & $" 7401$ & 20 \\
\hline & 3009 & 1 & & 7402 & 1 \\
\hline & 3011 & 4 & & 7403 & 4 \\
\hline \multirow[t]{2}{*}{ HLA-A $=31$} & & & & & \\
\hline & 310102 & 31 & & & \\
\hline
\end{tabular}

\section{Ambiguities}

The major advantage of heterozygous sequencing is that no prior typing results are needed. However, if two or more allele combinations have identical heterozygous sequences an ambiguous typing is obtained. In the present study, 18 different ambiguous allele combinations were encountered. They are indicated in table 2.4 and were identified in 45 of 252 individuals. All ambiguities were resolved by allele-specific amplification and sequencing. For 
the alleles of the $\mathrm{A} 10$ and $\mathrm{A} 19$ group, allele-specific primers located in intron 1 (A99012,A00056) (table 2.5) or in intron 3 (A00005) (table 2.5) were used depending on the alleles present in the individual.

Table 2.4 Ambiguities identified in the study ( $n=18)$. The correct allele combination abtained after allele-specific sequencing is represented in bold.

\begin{tabular}{|c|c|c|c|c|}
\hline No. & Allele combination 1 & Allele combination 2 & Allele combination 3 & $n^{n}$ \\
\hline 1 & $010101 / 0104 N+290201$ & $2903+3604$ & & 1 \\
\hline 2 & $010101 / 0104 N+310102$ & $3105+3604$ & & 1 \\
\hline 3 & $02 G 1^{2}+250101$ & $0206+2503$ & & 1 \\
\hline \multirow[t]{2}{*}{4} & $02 G 1+2601$ & $0224+2610$ & $0225+2614$ & \\
\hline & $0226+26 \# 2$ & $0255+260702$ & & 1 \\
\hline 5 & $02 \mathrm{G} 1+310102$ & $022001+3102$ & & 7 \\
\hline 6 & $02 \mathrm{G} 1+3201$ & $0240+3206$ & & 7 \\
\hline 7 & $02 \mathrm{G} 1+6601$ & $0235+2603$ & & 3 \\
\hline 8 & $02 \mathrm{G} 1+6602$ & $0234+6603$ & & 1 \\
\hline 9 & $030101 G 1^{3}+2601$ & $0308+2613$ & & 5 \\
\hline 10 & $2301 / 2307 N+310102$ & $2304+3105$ & & 1 \\
\hline 11 & $24 \mathrm{G} 1^{4}+250101$ & $2406+2504$ & & 2 \\
\hline 12 & $24 G 1+2601$ & $2406+2608$ & $2421+2610$ & 5 \\
\hline 13 & $24 G 1+290201$ & $240301 / 2433+2903$ & $2405+2909$ & 1 \\
\hline 14 & $24 G 1+310102$ & $240301 / 2433+3105$ & & 3 \\
\hline 15 & $24 G 1+3201$ & $2432+3203$ & & 2 \\
\hline 16 & $250101+680102 / 6811 \mathbb{N}$ & $2502+680301$ & & 1 \\
\hline 17 & $2601+680102 / 6811 \mathrm{~N}$ & $2613+680301$ & & 1 \\
\hline 18 & $2502+7401 / 7402$ & $3201+6601$ & & 2 \\
\hline
\end{tabular}

${ }^{i} n=$ the number of individuals in which these ambiguities were identified

${ }^{2}$ 02G1 $=A^{*} 02010101 / * 02010102 \mathrm{~L} /{ }^{*} 020108 /{ }^{*} 0209 /{ }^{*} 0243 \mathrm{~N}^{*} 0266$

${ }^{3} 030101 \mathrm{G} 1=\mathrm{A}^{*} 03010101 /{ }^{*} 03010102 \mathrm{~N}$

${ }^{4} 24 G 1=A^{*} 24020101 / * 24020102 L^{*} 240203 / * 2409 N / * 2411 \mathrm{~N}$

Table 2.5 Location and sequence of primers used to resolve ambiguous typings.

\begin{tabular}{llll}
\hline Name & Sequence & Location & Position \\
\hline 5'A98021 & GTCCAGGCTGGTGTCTGG & 13 & $1432-1449$ \\
5'A99012 & AAGCAAGGGGCCCGCCC & 11 & $114-130$ \\
5'A00056 & CCCGGGAAGCCGCGCCT & 11 & $146-162$ \\
5'A02101 & CATTGGGTGTCGGGTTCC & 5 UT & $-104-86$ \\
3'A96057 & GCGACCACAGCTCCAGYGAT & E5 & $2016-2035$ \\
3'A97028 & GTGGCCCCTGGTACCCGT & E3/13 & $987-1004$ \\
3'A00005 & GGCCCAAGGCTGCTGCCG & 13 & $1259-1276$ \\
5'A02100G & Cy5CCGCACGCACCCACCG & 5 UT & $-44-29$ \\
5'A98022C & Cy5CATGACAGATGCAAAATG & 13 & $1525-1542$ \\
\hline
\end{tabular}

\footnotetext{
The nucleotide positions are numbered according to the genomic alignments of HLA-A'
} 
Another type of ambiguity was noticed when alleles had identical exon 2 and 3 sequences and differences were located outside these exons. At the fourth digit level this involved eight identical pairs of alleles, i.e., $A^{*} 0101={ }^{*} 0104 \mathrm{~N}$, $A^{*} 0201=* 0209=* 0243 N=* 0266, \quad A^{*} 0207=* 0215 N, \quad A^{*} 2301={ }^{*} 2307 N, \quad A^{*} 2402=$ ${ }^{*} 2409 \mathrm{~N}={ }^{*} 2411 \mathrm{~N}, A^{*} 2403=* 2433, A^{*} 680102=* 6811 \mathrm{~N}$ and $A^{*} 7401=* 7402$. The ambiguities involving null alleles were shown in 71 individuals and were all resolved by positive serologic reactions with specific antisera. All other ambiguities were resolved by sequencing the exon in which the difference was located, the primers used are indicated in table 2.5 . The ambiguity A*0201/0209/0243N/0266 was shown 39 times and resolved by sequencing exon 4. Ail individuals were identified as $A^{*} 0201$. The combination A*2403/2433 was found four times and sequencing of exon 4 revealed the presence of $A^{*} 2403$ in all cases. The ambiguity $A^{*} 74011^{*} 7402$ was seen in twenty-one cases and resolved by sequencing exon 1. All individuals were identified as $A * 7401$ except one, that was identified as $A^{*} 7402$.

\section{Pseudogene coamplified with $A * 3401$}

Amplification and sequencing of the $A * 3401$ allele using the heterozygous primers of our protocol showed problems in all eighteen individuals carrying the allele. For exon 3, unexpected heterozygous positions were found which did not fit any HLA-A allele combination. These heterozygous results were also detected in three individuals homozygous for $A^{*} 3401$. Individuals typed $A^{*} 3402$ or $A^{\star 3404}$ did not show the problem. Subtracting the sequence of $A * 3401$ from the unexpected polymorphic positions resulted in a sequence that was identical to the sequence of the pseudogenes HLA-COQ and HLA-DEL. Therefore, the heterozygous results in $A^{*} 3401$ positive individuals were due to coamplification of either of these pseudogenes. Because HLA-COQ and HLA-DEL have identical exon 3 sequences, it was not possible to discriminate which pseudogene was sequenced in addition to $A * 3401$ in our SBT protocol. Exon 2 sequencing showed no problems. The $5^{\prime}$ amplification primer (A97107) has a mismatch with the pseudogenes HLA-COQ and HLA-DEL at the $3^{\prime}$ end of the primer sequence (table 2.1$)^{2 \oplus}$, preventing coamplification. By contrast, the amplification primers used for exon 3 could coamplify HLA-COO and HLA-DEL, because both primers (A98009 and A96090) completely matched the pseudogene sequences (table 2.1) . $^{26}$. Although the sequencing primer $\mathrm{A} 96094 \mathrm{C}$ showed a mismatch at position 5 with the pseudogenes this was apparently not sufficient to prevent cosequencing of the pseudogenes. To achieve correct amplification of individuals with an $A^{*} 3401$ allele a different $5^{\prime}$ amplification primer (A00056) was used for exon 3 with mismatches for the two pseudogenes $^{26}$. 


\section{Discussion}

In this study, a reliable solid-phase SBT strategy for HLA-A is described, enabling identification of HLA-A alleles without the necessity of prior typing results. Exons 2 and 3 were amplified separately and sequenced heterozygously in both forward and reverse direction. The protocol was validated against a panel of 11 individuals carrying HLA-A alleles from 20 different allele groups and was used to type 252 unrelated individuals for HLAA. Alignments and assignments were correct for all alleles tested, except $\mathrm{A}^{*} 3401$.

Unexpected heterozygous positions in exon 3 were identified for all $18 \mathrm{~A}^{\star} 3401$ positive individuals. This phenomenon has previously been described by Coquillard et al. ${ }^{26}$. They identified two novel HLA-A associated class I pseudogenes, HLA-COQ and HLA-DEL, which were sequenced in addition to $A^{* 3401}$. The additional unexpected A-locus-like sequence found in our study has also been caused by these pseudogenes. Coquillard et al. detected the pseudogenes HLA-COQ and HLA-DEL only in Filipino individuals with the haplotype HLA-A*3401, $B^{*} 1521$ or ${ }^{*} 1525$ and $C w^{*} 0403$. Six of the $18 A^{*} 3401$ positive individuals in our study were exactly the same samples as used by Coquillard et al. (UCLA cells 1038, 1066, 1067, 1117, 1132 and 1139). In our study, eight individuals were positively identified to be of Filipino origin; the ethnicity of the others was not known. Compared with the study of Coquillard et al., different haplotypes were present in our sample population. In addition to the haplotype described ${ }^{26}$, which was identified in 11 individuals in our study, in 6 individuals another haplotype was present. For four individuals no family studies were performed and therefore no haplotype was available. However, no HLA-B $B^{*} 1521, B^{*} 1525$ or $C w^{*} 0403$ was present, the individuals were typed as $A^{*} 3401,0201, \quad B^{*} 4002,5602, \quad C w^{*} 0102,1502 ; \quad A^{*} 3401, \quad B^{*} 4002,5601$, $C w^{*} 0102,1502 ; A^{*} 3401, B^{*} 380201,380202, \quad C w^{*} 0702$ and $A^{*} 3401,2601$, $B^{*} 1535,4002, C w^{*} 0702,1502$. In two individuals, family studies were conducted resulting in definition of two $A^{*} 3401$ haplotypes: one was $A^{*} 3401, B 27$, the other $A^{*} 3401, B 38$. In one individual no typing information was available for HLA-B and $-C$. Thus, in our study, the pseudogene HLA-COQ and/or HLA-DEL was detected in individuals with at least three different haplotypes in addition to the one found by Coquillard et al. ${ }^{26}$.

To achieve correct amplification of individuals with an $A^{*} 3401$ allele a different $5^{\prime}$ amplification primer (A00056) was used for exon 3 . This amplification primer anneals to alleles from the allele groups $A^{*} 25, A 26, A^{*} 34, A^{*} 43, A^{*} 66, A^{*} 68$ and $A^{*} 69^{1.22}$, and shows many mismatches with the two pseudogenes ${ }^{26}$. It depends on the second allele present in an individual whether HLA-A is amplified heterozygously or allele-specific with primer A00056. 
The HLA-A strategy in this study is based on both forward and reverse sequencing. Another option to obtain a correct sequence at the end of an exon is the use of an additional forward sequencing primer located in the middle of the exon. The advantage of forward and reverse sequencing is the possibility to read the complete exon sequence twice, with overlap in sequence reading. Because of the solid phase sequencing method used, differently labeled amplification primers for forward and reverse sequencing are needed, because forward sequencing requires a $3^{\prime}$ biotinylated primer, whereas for reverse sequencing a $5^{1}$ biotinylated primer is needed.

The SBT protocol for HLA-A relies on heterozygous amplification and sequencing of exons 2 and 3. This could lead to ambiguous typing if two or more allele combinations have identical sequences. In this study, 45 of 252 individuals $(18 \%)$ showed this type of ambiguity. Although this number might be biased by the use of individuals that are either A10 or A19 positive, the low amount of ambiguities makes it worthwhile to start with heterozygous sequencing, for which no prior typing result is needed.

In several individuals, a different sequence pattern was seen by reverse sequencing of exon 2 compared with forward sequencing. The reverse sequencing pattern showed a compression at positions 313-315, the nucleotide sequence CKS was identified in stead of SYG detected with forward sequencing. The compression was only observed in individuals heterozygous for HLA-A with one of the A-alleles bearing the Bw4 motif. This motif is present in most alleles of the allele groups $A^{*} 23, A^{*} 24, A^{\star} 25$ and $A^{*} 32$. For HLA-B, the same compression was detected in reverse sequencing of exon 2 of individuals in whom both the Bw6 and Bw4 motif were present.

Most primers designed in this study were located in the $5^{\prime}$ untranslated region and introns 1 through 3 (table 2.1). The sequences of at least one allele of all A-allele groups are known for the non-coding regions ${ }^{1,22}$. In fact, the primers were designed based on sequence data of all HLA-A allele groups. At the moment, 325 different HLA-A alleles are known ${ }^{1}$. In the present study, a total of 54 different A-alleles were sequenced. Many alleles were not detected in this study, probably because of their low frequency in the population. Because the primers were located in the non-coding region and these sequences were unavailable for many alleles it is not certain whether the primers will amplify all alleles. However, the location of amplification and sequencing primers in rather conserved regions supports the idea that alleles not encountered in the present study will be correctly amplified and sequenced. Furthermore, each exon is sequenced separately in the HLA-A strategy and the sequence data of the different exons are combined in the assignment program. The chance to miss 
an allelle in all exons amplified and sequenced separately is very small, and therefore our SBT strategy was found to be very robust. The separate amplification, which guarantees a robust method, is a major difference with other HLA-A SBT strategies ${ }^{19-25}$. 


\section{References}

1. Robingon J, Waller MJ, Parham P. Groot de $N$, Bontrop $R$, Kennedy LJ, Stoehr P, Marsh SGE: IMGTHHLA and IMGTMHC: sequence databases for the study of the major histocompatibility complex. Nucleic Acids Res 2003:31(1):311.

2. Townsend A, Bodmer H: Artigen recognition by class 1-restricted T lymphocytes. Arinu Rev Immunal 1989;7:601.

3. Long EO, Rajagopalan S: HLA class I recognition by killer cell Ig-like receptors. Immunology $2000 \div 12: 101$.

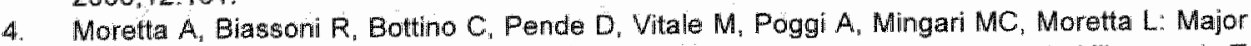
histocompatibility complex class l-specific receptors on human natural killer and $T$ Iymphocytes. Immunol Rev 1997;155:105.

5. Joysey $V$, Toit du ED, Martell RW. Taljaard DG, Crichton $B$, Doran $T$, Morishima $Y$. Wheeler $P$. Lazda $V$. Tait SM, Cambon-Thomsen A: Antigen societty \#2 report (A25, A26, AW34, AW43 and AW66). In Dupont B (ed): Immunobiology of HLA, vol 1. New York. SpringerVerlag. $1989: 119$.

6. Richiardi $P$. Curtoni $E S$, Plazza $A_{8}$ Mattiuz PL: Identification of two determinants included in "antigen" HLA-10 (TO 31 and TO 40) and of a new family of cross-reacting specificities (HLA1, 11, TO 30,31,40). Tissue Antigens 1971:1(4):162.

7. Legrand L. Dausset J Rapaport FT: Serological and genetic studies of the HL-A system. Results of host immunization within haplo-identical donor-recipient combinations. Transfusion $1971,11(5): 233$

8. Joysey VC, Roger $J H$, Abbas $A$, Bland $C$, Bolton $M$, Chan, Duraisamy $G$, Jones $A$, Joysey KA, Lopez CG, Megat BAR, Moorcroft M, Simons M, Simonsen M, Subramanian, Wilkinson M: Study of a Malay population. In Dausset $J$, Colombani $J$ (eds): Histocompatibility Testing. Copenhagen, Munksgaard, 1972:251.

9. Festenstein $H$, Aciams E, Brown J. Eurke J, Lincoln P, Oliver RTD, Rondiak G, Sachs JA, Welch $S G$. Wolf $E$ : The distribution of $H L-A$ antigens and other polymorphisms in Bantuspeaking. In Dausset $J$, Colombani $J$ (eds): Histocompatibility Testing. Copenhagen, Munksgaard, 1972:397.

10. Bodmer $\mathrm{J}$ : The $A B C$ of HLA. A serological report of the Gth Histocompatibility Testing Workshop. In Kissmeyer-Nielsen $F$ (ed): Histocompatibility Testing. Copenhagen, Munksgaard, 1975:24.

11. Mesman $B$, Lange de $G$, Engelfriet $C P$ : $A$ new HLA-A antigen, called $L N$, closely related to A25, A26 and AW34. Tisste Antigens 1983:21:192.

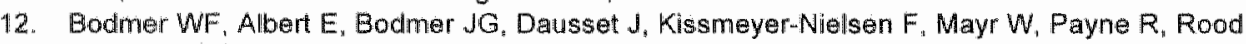
van $d J$. Trinka $Z$, Walford RL: Nomenclature for factors of the HLA system 1984. Immunogenetics 1984;20(6):593.

13. Madrigal $J_{A}$, Hildebrand WH, Belich MP, Benjamin RJ, Litte AM, Zemmour J, Ennis PD, Ward FE. Petzl-Erier ML, Toit du ED. Parham P: Structural diversity in the HLA-A10 family of allelles: correlations with serology. Tissue Antigens 1993,41(2):72.

14. Garpenteir CB, Dyer P, Festenstein H. Moraes J, Gagne J. McCloskey DJ, Manwick J, Tate D, Barbalho T. Beach M, Lima M, Mackintosh P. Moraes M, Ratner L: Artigen society \#3 report (AW19 and A32/Aw74). In Dupont B (ed): Immunobiology off HLA, vol 1. New York, SpringerVerlag, 1989:124.

15. Bodmer WF. Albert $E_{,}$Bodmer $\$ S_{\text {n }}$ Dupont $B$, Mach $B$, Mayr WR, Sasazuki $T$, Schreuder GMT, Svejgatiar A, Terasaki Pl: Nomenclature for factors of the HLA system, 1987. In Dupont $B$ (ed): lmmunobiology of HLA, vol 1. New York, Springer-Verlag, 1989:72.

16. Kato K. Trapani JA, Allopenna J, Dupont $B$, Yang SY. Molecular analysis of the serologically defined HLA-Aw 19 antigens. A genetically distinct family of HLA-A antigens comprising $A 29$, $A 31, A 32$, and $A w 33$, but probably not A30. J Immunol 1989;143(10):3371.

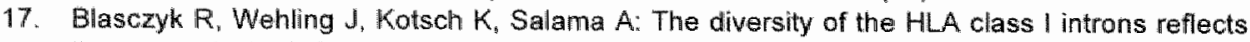
the serological relationship of the coding regions. Transfusionsmedizin 1996/1997;34:231. 
18. Elsner H-A, Rozas J, Blasczyk R: The nature of introns $4-7$ largely reflects the lineage specificity of HLA-A alleles. Immunagenetics $2002 ; 54(7): 447$.

19. Pera $C$, Delfino $L$, Morabito $A_{v}$ Longo $A_{s}$, Johnston-Dow $L$, White $C B$, Colonna M, Ferrara $G B$ : HLA-A typing: comparison between serology, the amplification refractory mutation system with polymerase chain reaction and sequencing. Tissue Antigens 1997;50(4);372

20. Norgaard L, Fugger $L$, Jakobsen BK, Svejgaard $A$ : Sequencing-based typing of HLA-A locus using mRNA and a single locus-specific PCR followed by cycle-sequencing with Amplitac DNA polymerase, FS. Tissue Antigens 1997;49(5):455.

21. Scheltinga SA, Johnston-Dow LA, White CB, Zwan van der AW, Bakema JE, Rozemuller EH, Tweel wan den JG, Kroninck MN, Tilanus MGJ: A generic sequencing based typing approach for the identification of HLA-A diversity. Hum Immunol 1997;57(2):120.

22. Kotsch $K$, Wehling $J$, Köhler $S$, Blasczyk R: Sequencing of HLA class I genes based on the conserved diversity of the noncoding regions: sequencing-based typing of the HLA-A gene. Tissue Antigens 1997;50(2):178.

23. Santamaria P. Lindstrom AL, Boyce-Jacino MT, Myster SH, Barbosa JJ, Faras AJ, Rich SS: HLA class I sequence-based typing. Hum Immunol 1993;37:39

24. Dormoy $A$, Froelich $\mathbb{N}$, Leisenbach $R$, Weschler $B$, Cazenave J.P. Tongio M-M: Mono-allelic amplification of exons $2-4$ using allele group-specific primers for sequence-based typing (SBT) of the HLA-A $-B$ and $-C$ genes: preparation and validation of ready-tomuse pre-SBT mini-kits. Tissue Antigens 2003;62(3):201.

25. Adams SD, Barracchini KC, Simonis TB, Stroncek D, Marincola FM: High throughput HLA sequence-based typing (SBT) utilizing the ABl Prism 3700 DNA Analyzer. Tumori 2001;87:\$40.

26. Coquillard G, Lau M, Kletzel M, Rodriguez-Marino SG: Identification of two pseudogenes with sequence homology to human and gorilla MHC class IA genes: ancestral haplotype in the Filipino population. Hum Immunol $2004 ; 65(6): 665$

27. Lau M, Park MS, Cecka $ل \mathrm{M}$, Reed EF. Report of the International Cell Exchange \#300. UCLA, Los Angeles, 2004:9-13.

28. Vlies van der SA, Voorter CEM, Berg van den-Loonen EM: A reliable and efficient high resolution typing method for HLA-C using sequence-based typing. Tissue Antigens 1998:52:558.

29. Miller SA, Dykes DD, Polesky HF: A simple salting out procedure for extracting DNA from human nucleated cells. Nucl Acids Res 1988;16(3):1215.

30. Voorter CEM, Vlies van der SA, Berg van den-Loonen EM: Sequence-based typing of HLA-B: the B7 cross-reacting group. Tissue Antigens 2000;56(4):356.

31. Bunce $M$, Barnardo MCNM, Welsh KI: Improvements in HLA-C typing using squencespecific primers (PCR.SSP) including definition of HLA-Cw9 and Cwh 10 and a new allele HLA. "Cw7/8v". Tissue Antigens 1994:44(3),200.

32. Voorter CEM, Rozemuller EH, Bruyn de-Geraets D, Zwan van der AW, Tilanus MGJ, Berg van den-Loonen EM: Comparison of DRB sequence-based typing using different strategies. Tissue Antigens 1997;49(5):471

33. Voorter CEM, Bruyn de-Geraets D. Berg van den-Loonen EM: High-resolution HLA lyping for the DRB3/4/5 genes by sequence-based typing. Tissue Antigens 1997:50(3):283

34. Voorter CEM, Kik MC, Berg van den-Loonen EM: High-resolution HLA typing for the DQB1 gene by sequence-based typing. Tisste Antigens 1998;51(1):80 


\section{Chapter 3}

Sequence analysis of exons 1, 2, 3, 4 and 5 of the HLA-B5/35 cross-reacting group

Wendy TN Swelsen, Christina EM Voorter and Ella M van den Berg-Loonen Tissue Antigens 2002;60:224-234 


\section{Abstract}

The HLA-B5/35 cross-reacting group (CREG) is a set of closely related antigens including $H L A-B 35, B 51, B 52, B 53$ and B78. The mucleotide sequences of exon 1 through 5 of the B5/35 CREG were determined to assess the level of polymorphism. For exons 2 and 3 , the previously described sequence-based typing (SBT) strategy was applied; the nucleotide sequences of exon 1 ; 4 and 5 were determined by allele-specific sequencing.

A total of 225 unrelated individuals were $H L A-B$ typed by heterozygous sequencing of exons 2 and 3. In the BS/36 CREG, 26 different alleles were identified. whereas 63 non-B5/35 CREG alleles were sequenced. The SBT strategy was proven to be reliable and efficient for high resolution typing of the B5/35 CREG. The nucleotide sequences of exon 1,4 and 5 were determined for the 26 different B5/35 CREG alleles to establish the level of polymorphism. For seven different alleles, of which the exon 1,4 and 5 sequences were hitherto unknown, the sequences were elucidated and in agreament with the known B5/35 sequences. Nineteen HLA-B5/35 CREG alleles with previously published exon 1, 4 and 5 sequences were sequenced in at least two individuals.

Three new alleles were identified. The first, $B^{*} 5204$, showed a difference at position 200 compared to $B^{*} 52011$, which was previously considered a conserved position. The other two alleles, $B^{*} 3542$ and $B^{*} 51015$, showed exan 2 and 3 sequences identical to $B^{*} 35011$ and $B^{*} 51011$, but differences in exons 1 and 4 , respectively. $B^{*} 3542$ had differences at position 25 and 72 and $B^{*} 51015$ showed a difference at position 636. More polymorphism might be present outside exons 2 and 3 than prewlously thought. 


\section{Introduction}

The most extensive allelic polymorphism of all human genes is presented by the major histocompatibility complex (MHC). The polymorphism of both class I and class II HLA genes is the result of evolutionary selection and correlates with the capacity to respond to different proteins. HLA-B is the most polymorphic. The polymorphism is mainly located in exons 2 and 3 , which code for the extracellular $\alpha 1$ and $\alpha 2$ domains and include the antigenic peptide binding site.

The antigens of the $B 5 / 35$ group belong to the historical specificity $4 c_{i}$ which was first described by Bodmer and Payne ${ }^{4}$. The cross-reacting group (CREG) $4 \mathrm{C}$ is known to include the antigens B5, B53, B35, B18 and B78. B5, first recognized in $1967^{2}$, was later shown to consist of two subspecificities $B 51$ and $\mathrm{B} 52^{3}$. In 1980, B51 was further subdivided by the recognition of B5102,5. B53 was described by Engelfriet et al. in $1972^{6}$, the closely related B35 by Bodmer in the same year ${ }^{7}$. Recently, B78 has been added to the $C R E G^{8}$. A number of antigens in the group are characterized by the fact that their recognition was difficult and for some antigens this is still the case, primarily due to lack of monospecific antisera. The antigen $\mathrm{B} 18$ has been clearly identified since $1970^{9}$.

Sequence analysis has shown that the alleles encoding the $B 5 / 35$ molecules are closely related. HLA-B51 and B52 differ by two amino acids at residues 63 and 67 , whereas eight substitutions in the $\alpha 2$ domain distinguish B35 and B51. A cluster of five residues associated with the Bw4/Bw6 epitopes in the $\alpha 1$ domain distinguishes $B 35$ and $B 78$ from B51, B52 and B53. As alleles encoding the HLA-B5/35 CREG antigens show limited polymorphism, they are suspected to share a common ancestor ${ }^{10-13}$. HLA-B35, B51 and B52 are found in many populations, supporting the hypothesis that these antigens may have evolved prior to divergence of the major ethnic groups ${ }^{14}$. In contrast, HLA-B53 is frequently detected in Negroids but is rare in Caucasians and Orientals ${ }^{13,15,16}$. Subtypes of $B^{*} 53$ were recently identified in Caucasians and Hispanics ${ }^{17.18}$. Frequencies of HLA-B53 in African populations could have increased due to association with protection from severe malaria ${ }^{15}$. The high frequency of $B^{*} 5301$ supports the idea that alleles can be positively selected under pathogenic pressure ${ }^{19}$. HLA-B78 was previously thought to be African restricted ${ }^{12,20}$, but recent studies have shown that subtypes of this antigen are found in native Americans, Caucasians, Hispanics and Orientals as well ${ }^{18,21-24}$.

We were particularly interested in the complex serological antigens of the $\mathrm{B} 5 / 35$ group and therefore studied the antigens $B 51, B 52, B 53, B 35$ and $B 78$ 
by sequence-based typing (SBT). The HLA-B-specific SBT strategy designed by Voorter et al. was applied ${ }^{25}$. It has proven to be reliable and efficient for high resolution typing of the HLA-B7 CREG and includes separate amplification of exons 2 and 3 using amplification primers located in intron 1,2 and 3 . In addition to exon 2 and 3 typing of the $B 5 / 35$ alleles ${ }_{4}$ the sequences of exon 1,4 and 5 were determined to assess the level of polymorphism.

\section{Materials and methods}

\section{Individuals}

SBT of HLA-B was performed for 225 individuals. They were selected to possess at least one HLA-B allele of the B5/35 CREG, i.e., B35, B51, B52, B53 or $B 78$. The ethnic origin of the individuals was not always known, but at least half of them were non-Caucasians. Most of the samples were previously typed by serology and/or low-resolution PCR-SSP. The latter was carried out using locally designed B-locus SSP primermixes with the SSP amplification protocol as previously described ${ }^{26}$. Each individual that was shown to be HLA-B homozygous by SBT, was subsequently retyped by low resolution PCR-SSP to exclude allelic dropout.

\section{DNA isolation}

DNA was isolated from fresh heparinized blood or from lymphocytes stored in liquid nitrogen either by the "salting out" extraction procedure as described by Miller et al. ${ }^{27}$ or by using QIA-AMP kits following the suppliers protocol (Qiagen, Westburg, Leusden, the Netherlands). Concentration and purity of DNA samples were measured at optical densities of 260 and $260 / 280 \mathrm{~nm}$.

\section{Amplification and sequencing of exons 2 and 3}

Exons 2 and 3 were amplified separately using amplification primers located in introns 1,2 and 3 . Separate amplification of exons 2 and 3 resulted in short polymerase chain reaction (PCR) products and enabled a solid-phase sequencing approach, which made correct assignment of heterozygous positions possible due to low background. One forward sequencing reaction was performed for exon 2, whereas for exon 3, two forward sequencing reactions were needed using two different sequencing primers located in intron 2 and exon 3. Location and sequence of amplification and sequencing primers for exons 2 and 3 , as well as the PCR conditions, have been described in detail by Voorter et al. ${ }^{25}$. The AutoreadTm sequencing kit (Amersham Pharmacia Biotech, Piscataway, USA) was used for the sequencing reaction as previously 
described $^{26,28-30}$. Electrophoresis was performed on an ALFexpress automated sequencer (Pharmacia Biotech, Uppsala, Sweden). Sequence data were processed automatically and evaluated manually. The combined sequences of exon 2 and 3 were used for automatic alignment to the HLA-B sequence database of April 2001 and allele assignment was obtained using the HLA Sequityper software (Pharmacia Biotech).

\section{Allele-specific sequencing of exons 1,4 and 5}

The exon 1,4 and 5 sequences of all different HLA-B5/35 CREG alleles encountered were determined. If no information of the exon 1,4 and 5 sequences was available, both forward and reverse sequencing were performed in duplicate for these exons. Heterozygous sequencing was performed as a control. The previously published nucleotide sequences of the other HLA-B5/35 alleles were checked in at least two positive individuals by forward sequencing. Allele-specific amplification of exons 1,4 and 5 was performed using the PCR conditions described previously ${ }^{25,26}$. The location and sequence of the amplification and sequencing primers for exons 1,4 and 5 are shown in table 3.1. The amplification of exon 1 was performed using one B-locus specific $5^{\prime \prime}$ primer (99022) combined with an allele-specific $3^{\prime}$ primer (98062, 98063, 00025 or 01008 ). For amplification of exon 4 , an allele-specific 5 ' primer (98044, 01022 or 01048) was combined with a generic $3^{\prime \prime}$ primer located in exon 5 (96069). For amplification of exon 5 , an allele-specific $5^{\prime \prime}$ primer $(98044,01022,01048)$ was combined with a generic $3^{\prime}$ primer located in exon $6(01030)$. The choice of the allele-specific primer used was mainly depending on the HLA-B allele that is present next to the B5/35 CREG allele. Forward sequencing required a $3^{\prime}$ biotinylated primer, whereas for reverse sequencing a $5^{\prime}$ biotinylated primer was needed. The Cy-5 labeled sequencing primers developed were located internally of the PCR product, to ensure specific sequencing. The sequencing reaction was performed as described above.

\section{Results}

\section{Sequencing results exons 2 and 3}

A total of 225 unrelated individuals were sequenced for HLA-B. Two hundred and four were heterozygous for one B5/35 CREG allele, both HLA-B alleles belonged to the B5/35 CREG group in 16, and 5 were homozygous for either B51 or B53. The homozygosity of these individuals was checked by PCR-SSP and serology. 
Table 3.1 Location and sequence of amplification and sequencing primers used for allele-specific sequencing of exons 1,4 and 5 of HLA-B.

\begin{tabular}{|c|c|c|c|}
\hline Name & Sequence & Location & Pasition \\
\hline 598044 & CCTGCGGAACCTGCGCG & Exon 2 & $303-319$ \\
\hline 599022 & GTCGGGTCCTTCTTCCAGS & SUT & $-153-135^{11}$ \\
\hline 501022 & TCTGTGCCCOTTCCCCACA & Intron 3 & $532-551^{2}$ \\
\hline 501048 & GGGCCAGGGTCTCACATCA & Exon 3 & $12-355$ \\
\hline 396069 & CCACGATGGGGAT/CGGTGGA & Exon 5 & $910-928$ \\
\hline 398062 & GCTCTGGTTGTAGTAGCGGA & Exan 2 & $317-336$ \\
\hline 398063 & TTGTAGTAGCCGCGCAGGT & Exon 2 & $311-329$ \\
\hline 300025 & TCCCGGCGCGGCTCCTCA & Intron 1 & $75-92$ \\
\hline 301008 & TGGCGCCCOGGGCTCCG & Exon 2 & $206-222$ \\
\hline 301030 & AGAGTAGCTCCCTCCTTTTC & Exon 6 & $1019-1038$ \\
\hline $5^{n} 98042$ & ACCCACCCGGACTC & $5^{\prime} \cup T$ & $-45--21$ \\
\hline 501039 & 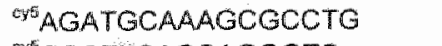 & Intron 3 & $614-629$ \\
\hline 501044 & CCCTTCAGCAGGGTC & Intron 4 & $60-74$ \\
\hline 399027 & CTGCGCCCCCGCCT & Intron 1 & $56-70$ \\
\hline 301041 & TCGTGCTITCCOTGAG & Intron 4 & $32-47$ \\
\hline 301045 & CCCCAGTGGGACAAG & Intron 5 & $36-50^{3}$ \\
\hline
\end{tabular}

The $5^{\circ}$ untranslated region positions are numbered according to Yao et al. ${ }^{50}$

${ }^{2}$ The intron $1-3$ nucleotide positions are numbered according to Cereb et al. ${ }^{33 .}$

${ }^{3}$ The intron 5 nucleotide positions are numbered according to Summers elt al ${ }^{54}$

Table 3.2 shows the different HLA-B5/35 cross-reacting alleles identified in the study with the number of individuals in which these alleles were found. Twentyfive out of 86 known alleles were recognized, one new allele was identified by SBT of exons 2 and 3 , two new alleles were found by sequencing exons 1,4 and 5. Our study confirmed that B35 is a heterogeneous group; in our mixed sample population $B^{*} 35011, B^{*} 3502, B^{\star} 3503$ and $B^{\star} 3505$ occurred most frequently. These four alleles represented approximately $75 \%$ of the B35 positive individuals typed. Two $B^{*} 78$ alleles were demonstrated, $B^{*} 7801$ was the more frequent one $(n=9), B^{*} 78021$ was identified only once. In the B51 group, eight different alleles were detected with $B^{*} 51011$ being the most common subtype $(n=69)$. Three different $B 52$ alleles were found. The alleles $B^{*} 52011$ and $B^{*} 52012$ were present in equal numbers ( $n=10$ for both), a new $B^{*} 52$ allele was found once. Despite the fact that different $B^{\star} 53$ alleles have been described, only $B^{*} 5301$ was identified. The rare $B 5 / 35$ CREG alleles were found predominantly in non-Caucasians.

In the heterozygous individuals, the non-B5/35 CREG alleles included alleles belonging to: $B^{*} 07,{ }^{*} 08 * 13,{ }^{*} 14,{ }^{*} 15,{ }^{*} 18,{ }^{*} 27,{ }^{*} 37,{ }^{*} 38,{ }^{*} 39, * 40,{ }^{*} 41,{ }^{*} 42,{ }^{*} 44$, ${ }^{*} 45, * 47, * 49,{ }^{*} 50, * 55,{ }^{*} 56, * 57, * 58,{ }^{*} 73, * 81$ and ${ }^{*} 82$. Although the study focussed on the B5/35 CREG alleles, a total of 91 different HLA-B alleles were identified. 
The SBT strategy described previously ${ }^{25}$ proved reliable and efficient for high resolution typing of the HLA-B5/35 CREG. Both alignments and assignments were correct and no allelic dropout or preferential amplification was noticed for the alleles tested. Equal peak heights were obtained by heterozygous sequencing. For reliable sequencing of exon 3 , two different sequencing primers were used; one located at the $3^{\prime}$ end of intron 2 and one located in the middle of exon 3 . One individual was HLA-B*73 positive. For correct amplification of $B^{\star} 73$ the protocol describes other primers to prevent allelic dropout due to mismatches between the amplification primers and $\mathrm{B} * 33$ intron sequences $^{25,31}$. The use of these primers resulted in correct amplification and assignment.

Table 32 The different HLA-B5/35 cross-reacting alleles identified by SBT with the number of individuals $(\mathrm{n})$ in which these alleles were identified.

\begin{tabular}{|c|c|c|c|c|c|}
\hline & Allele & $n$ & & Allele & $n$ \\
\hline \multirow[t]{15}{*}{ HLA-B 35} & & & HILA-B* 51 & & \\
\hline & $* 35011$ & 16 & & $\star 51011$ & 69 \\
\hline & ${ }^{*} 3502$ & 14 & & 51012 & 2 \\
\hline & $* 3503$ & 22 & & $" 51015^{\prime}$ & 1 \\
\hline & 3504 & 2 & & $* 51021$ & 7 \\
\hline & 3505 & 14 & & $* 51022$ & 4 \\
\hline & 3508 & $T$ & & 5106 & 2 \\
\hline & 3511 & 2 & & $* 5107$ & 3 \\
\hline & 3512 & 2 & & 5108 & 3 \\
\hline & 3516 & 1 & HLA-B ${ }^{*} 52$ & & \\
\hline & 3517 & 3 & & "52011 & 10 \\
\hline & $* 3523$ & 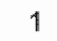 & & 52012 & 10 \\
\hline & 3530 & 1 & & ${ }^{\star} 5204$ & 1 \\
\hline & 3531 & 1 & HLAMB*53 & & \\
\hline & $35.42^{4}$ & 1 & & $* 5301$ & 32 \\
\hline \multicolumn{6}{|l|}{ HLA-B*78 } \\
\hline & 7801 & 9 & & & \\
\hline & 78021 & 1 & & & \\
\hline
\end{tabular}

"Newly identified alleles.

\section{Ambiguities}

The major advantage of heterozygous sequencing is that no prior typing results are needed. However, if two or more allele combinations have identical heterozygous sequences, this could lead to ambiguous typing. In the present study, 31 different ambiguous allele combinations were encountered. They are indicated in table 3.3 and were identified in 59 out of 225 individuals. 
5.2 $\mid$ Chapter 3

Table 3.3 Ambiguities and correct allele combination obtained after allele-specific sequencing (bold).

\begin{tabular}{|c|c|c|c|c|c|}
\hline No. & Combination 1 & Combination 2 & Combination 3 & Combination 4 & $n$ \\
\hline $1^{a}$ & $07021+35011$ & $0718+3505$ & $0709+3534$ & $0724+3515$ & 2 \\
\hline $2^{\mathrm{a}}$ & $07021+3503$ & $0724+3533$ & & & 4 \\
\hline $3^{b}$ & $07021+51011 / 11 N$ & $0724+5116$ & & & 3 \\
\hline $4^{b}$ & $07021+7801$ & $0708+5606$ & & & 1 \\
\hline $5^{8}$ & $0801+3503$ & $0807+3506$ & & & 1 \\
\hline $6^{\mathrm{i}}$ & $0801+51011 / 11 \mathrm{~N}$ & $0803+7801$ & & & 2 \\
\hline \multirow[t]{2}{*}{7} & $15011+35011$ & $1520+1522$ & $1515+3510$ & $1556+3520$ & \\
\hline & $1508+3528$ & $1505+3514$ & & & 1 \\
\hline \multirow[t]{2}{*}{8} & $15011+51011 / 11 \mathrm{~N}$ & $1538+51021$ & $1556+5107$ & $1508+52012$ & \\
\hline & $1504+5106$ & $15012+51014$ & $1522+5202$ & $1524+78022$ & 7 \\
\hline 9 & $15011+5107$ & $1515+52012$ & & & 1 \\
\hline 10 & $15011+52011$ & $1524+7805$ & & & 3 \\
\hline 11 & $15011+5301$ & $1524+35011$ & & & 1 \\
\hline 12 & $1502+3505$ & $1555+3511$ & & & 2 \\
\hline 13 & $1502+51012$ & $1513+78021$ & & & 1 \\
\hline 14 & $1503+3503$ & $4564+3513$ & & & 1 \\
\hline 15 & $1503+7801$ & $1561+78022$ & & & 1 \\
\hline 16 & $1510+51011 / 11 \mathrm{~N}$ & $1537+51021$ & & & 1 \\
\hline 17 & $1518+51011 / 11 \mathrm{~N}$ & $1529+5122$ & $1523+78022$ & & 1 \\
\hline 18 & $1801+51011 / 11 \mathrm{~N}$ & $1807+5107$ & & & 2 \\
\hline 19 & $1801+5301$ & $1811+5302$ & & & 1 \\
\hline 20 & $27052 / 054 / 13+35011$ & $2708+5303$ & & & 1 \\
\hline 21 & $27052 / 054 / 13+51011 / 11 \mathrm{~N}$ & $2710+5109$ & & & 3 \\
\hline 22 & $35011+4002$ & $3504+4003$ & $3528+4008$ & & 1 \\
\hline \multirow[t]{2}{*}{$23^{\mathrm{ai}}$} & $35011+51011 / N 11$ & $5301+78022$ & $5306+7804$ & $3524+51021$ & \\
\hline & $3537+5104$ & $3511+5109$ & & & 6 \\
\hline 24 & $3503+4002$ & $3506+4018$ & & & 1 \\
\hline 25 & $3503+44021 / 19 \mathrm{~N}$ & $3513+4412$ & & & 3 \\
\hline $26^{a}$ & $3503+51011 / 11 \mathrm{~N}$ & $3534+51132$ & $5304+78022$ & & 1 \\
\hline $27^{a}$ & $3503+52012$ & $3513+5107$ & & & 1 \\
\hline 28 & $3701+51011 / 11 \mathrm{~N}$ & $3704+51021$ & & & 1 \\
\hline 29 & $4001+51011 / 11 \mathrm{~N}$ & $4007+5107$ & & & 3 \\
\hline 30 & $4001+5107$ & $4025+52012$ & & & 1 \\
\hline 31 & $4002+51011 / 11 \mathrm{~N}$ & $4019+78022$ & $4008+52012$ & & 1 \\
\hline
\end{tabular}

$n=$ number of individuals in which the ambiguities were identified

* Ambiguities resolved by primerpairs 98062/98063 for exon 2 and 98043/98044 for exon 3 (see table 3.4 ), combined with the locus specific primers in intron 1 and intron 3 , respectively

b Ambiguities resolved by primerpairs $98004 / 98006$ (see table 3.4), combined with locus specific primers in intron 2 and intron 3

All other ambiguous typings were resolved by intron primers described by Cereb et al ${ }^{62}$

All ambiguities were resolved by allele-specific amplification and sequencing Table 3.4 shows the location and sequence of the allele-specific primers used. The primers were combined with HLA-B locus specific primers already used for heterozygous exon 2 and 3 sequencing. The primers 98062/98063 and $98043 / 98044$, which include Bw4/Bw6 motives, were used for sequencing exon 2 and 3 , respectively. 
Table 3.4 Location and sequence of allele-specific primers used to resolve ambiguous typings.

\begin{tabular}{llll}
\hline Name & Sequence & Location & Position \\
\hline $597100^{\circ}$ & CGGGGGCGCAGGACCTGA & Intron 1 & $60-77$ \\
$597101^{\circ}$ & GGGGGCGCAGGACCCGG & Intron 1 & $61-77$ \\
598004 & TGCTGCTCTGGGGGGCAG & Exon 1 & $32-49$ \\
598006 & TCCTCCTGCTGCTCTCGGC & Exon 1 & $26-44$ \\
598043 & GAGAGAACCTGCGGATCGC & Exon 2 & $296-314$ \\
598044 & CCTGCGGAACCTGCGCG & Exon 2 & $303-319$ \\
398062 & GCTCTGGTTGTAGTAGCGGA & Exon 2 & $317-336$ \\
398063 & TTGTAGTAGCCGCGCAGGT & Exon 2 & $311-329$ \\
\hline
\end{tabular}

"Intron primers described by Cereb et al. ${ }^{52}$

Another type of ambiguity was noticed when alleles had identical exon 2 and 3 sequences and differences were located outside these exons. At the four digit level, this involved five identical pairs of alleles, i.e., $B^{*} 0705={ }^{*} 0706$, $* 1512=* 1519, \quad{ }^{*} 2705={ }^{*} 2713, \quad * 44021=4419 \mathrm{~N}$ and ${ }^{*} 51011=* 5111 \mathrm{~N}$. The ambiguity $B^{*} 0705 / 0706$ was shown once, sequencing of exon 5 revealed the presence of $B^{*} 0705$. The combination $B^{*} 1512 / 1519$ was also found once and was identified as $B^{*} 1512$ by sequencing exon 4 . The ambiguity $B^{*} 2705 / 2713$ was seen seven times and resolved by sequencing exon 1 . All individuals were identified as $B^{\star} 2705$. The two ambiguities involving null alleles were shown in 84 individuals and were all resolved by positive serological reactions with specific antisera.

\section{Exon 1,4 and 5 sequences}

The nucleotide sequences of exon 1, 4 and 5 were determined for 26 HLAB5/35 CREG alleles (table 3.2) to establish the level of polymorphism. Nineteen HLA-B5/35 CREG alleles with previously published exon 1, 4 and 5 sequences, were sequenced allele-specific in at least two individuals. Three new polymorphisms were found in the B5/35 CREG. They resulted in the identification of two new alleles, $B^{*} 3542$ and $B^{*} 51015$, described below. For seven alleles, $B * 3516,{ }^{*} 3517,{ }^{*} 3523,{ }^{*} 3530,{ }^{*} 5106,{ }^{*} 5107$ and ${ }^{*} 5204$, the exon 1,4 and 5 sequences were hitherto unknown. The sequences were elucidated and in agreement with the other B5/35 sequences known from the literature.

The sequence data will appear in the EMBL Nucleotide Sequence Database with the accession numbers; AJ316290, AJ417678, AJ417667 (B 3516), AJ316291, AJ417679, AJ417668 (B*3517), AJ429190, AJ429191, AJ429192 (B*3523), AJ417674, AJ417681, AJ417670 (B*3530), AJ316285, AJ417682, AJ417671 (B*5106), AJ316292, AJ417683 and AJ417672 (B*5107). 


\section{New alleles}

Three new alleles were detected, one by SBT of exons 2 and 3 and two by sequencing exons 1,4 and 5 . The alignment of the sequences of exon 1 through 5 for HLA-B*3542, $B^{*} 51015$ and $B^{*} 5204$ with HLA-B*07021 and the most common subtypes, $B^{*} 35011, B^{\star} 51011$ and $B^{*} 52011$, is shown in figure 3.1 .

HLA-B*5204 was detected by heterozygous sequencing of exons 2 and 3 in an individual with the serological typing $A 11 ; B 52, B 61 ; B w 4, B w 6$. High resolution typing revealed the alleles $A^{*} 11011 ; B^{*} 40061, B^{*} 5204 ; C w^{*} 0602, C w^{*} 1502$. The new allele showed one mismatch with $B^{*} 52011$ in exon 2 at nucleotide position 200, changing codon 43 of the mature protein from CCG to CAG, which resulted in an amino acid change from proline to glutamine. As nucleotide position 200 was previously thought to be conserved, PCR-SSP was used for confirmation. A specific $5^{\prime}$ primer located in exon 2 at positions 183200 , was combined with two different HLA-B locus specific $3^{\prime}$ primers. One was located in intron 2 (96133) and one in intron 3 (96092) as previously described $^{25}$. The individual carrying the $B^{*} 5204$ allele, showed positive PCRreactions, whereas individuals typed as $B^{*} 52011$ were negative.

The other new alleles, $B^{*} 3542$ and $B^{*} 51015$, were detected by sequencing exons 1,4 and 5 . The individual carrying the $B^{*} 3542$ allele was serologically typed A3, A24; B35, B41; Bw6; Cw4; DR15, DR4; DQ6, DQ2. High resolution typing revealed the alleles $B^{*} 35011, B^{*} 4101 ;$ DRB1*1501, DRB1*04051; DRB4*0103, DRB5*0101; DQB1*0202, DQB1*0602. Sequencing exon 1 of $B * 35011$ revealed two mismatches at nucleotide positions 25 and 72 (figure 3.1). The difference at position 25 , codon 9 of the leader peptide (GTC $\rightarrow$ CTC), resulted in an amino acid change from valine to leucine. The difference at nucleotide position 72 changed codon 24 from GCC to GCT. As both codons code for alanine, the nucleotide difference did not result in an amino acid change. The $B^{*} 51015$ allele was detected in an individual with high resolution typing $A^{*} 3303, A^{*} 68012 ; B^{*} 1501, B^{*} 51011 ; \quad C w^{*} 03031, C w^{*} 14021$. By sequencing exon 4 , a new allele was identified showing one mismatch with $B^{\star} 5101^{1 /}$ at position 636 (figure 3.1 ). This nucleotide difference $(C \rightarrow T)$ resulted in a silent mutation at codon 188. Both codon sequences $\mathrm{CAC}$ and CAT represent the amino acid histidine. 
B*7021 AGCATGTACGECTCGACTEGGGCCGGACGGGCGCCHCCTCCGCGUGCATGACCAGTHC

B*35011

B*3542

13 51011

E*51015

B*52011

* 5204

B*07021

- 35011

B) 3542

B*51011

B. 51015

B* 52011

$B * 5204$

B*07021

B*35011

$B * 3542$

$\mathrm{B}^{*} 51011$

B* 51015

B* 52011

B*5204

*07021 B*35011

B*3542

B*51011

B*51015

$B * 52011$

$B * 5204$

1. 07021 1 35011

4. 35.42

B 5101.

D. 51015

B) 52011

B) 5204

$3 * 07021$.

B*35011

B*3542

B* 51011

B 51015

B*52011

B.15204

AGCATGTACGGCTGCGACGTGGGGCCGGACGGGCGCCHCCTCGGCGGGCATGACCAGTAC

$-\mathrm{C}-\mathrm{C}-\mathrm{\textrm {T }}-\mathrm{C}-\mathrm{C}-\mathrm{C}-\mathrm{C}-\mathrm{C}--\mathrm{C}-\mathrm{C}-\mathrm{C}$

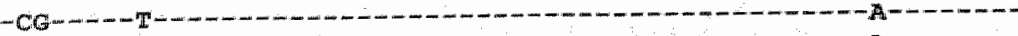

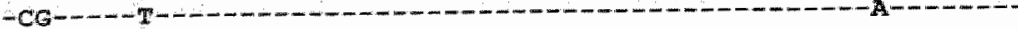

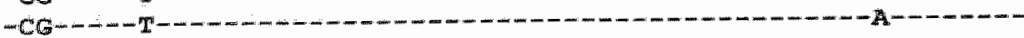

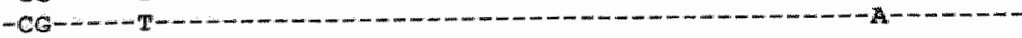

$\begin{array}{rrrrr}430 & 40 & 450 & 460 & 470\end{array}$

GCCTACGAGGCAAGGATHCATCGCCCTCAACGAGACCTGCGCTCCTGGACCGCCGCG

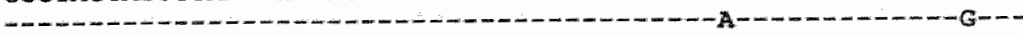

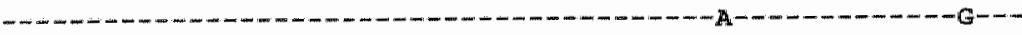

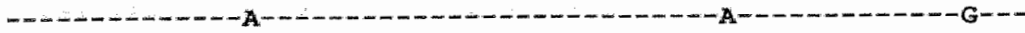

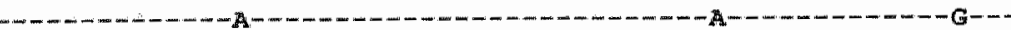

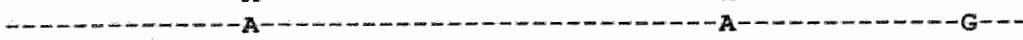

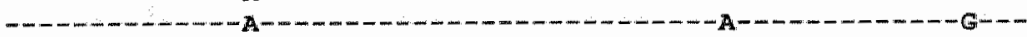

$490 \quad 500 \quad 510 \quad 520 \quad 530 \quad 540$

GACACGGCGGCTCAGATCACCCAGCGCAAGTGGGAGGCGGCCCGTGAGGCGGAGCAGCGG

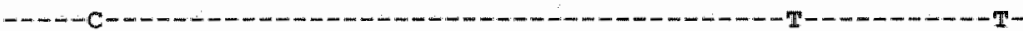

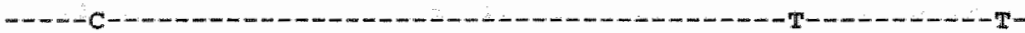

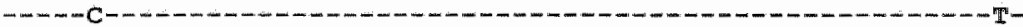

-

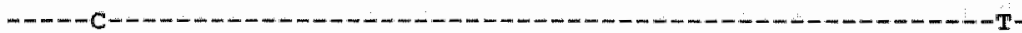

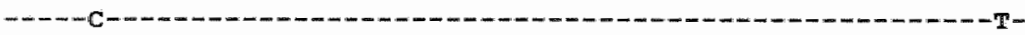

$\begin{array}{rrrrrr}550 & 560 & 570 & 580 & 590 & 600 \\ * & * & * & *\end{array}$

AGAGCCTACCTGGAGGGCGAGTGCGGGAGTGGCTCCGCAGATACCTGGAGAACGGGAAG

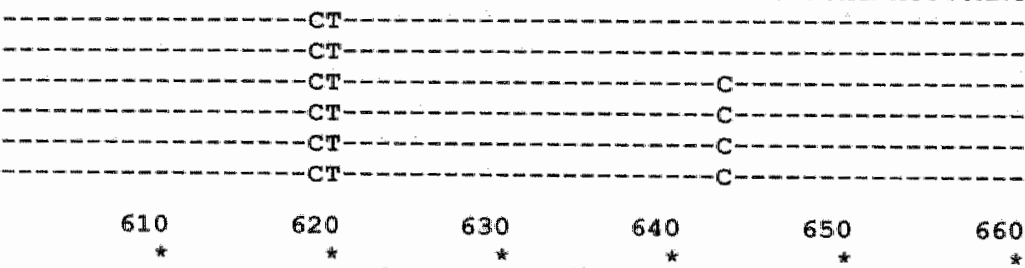

GACAAGCTGGAGCGCGCTCACCCCCCAAAGACACACGTGACCCACCACCCCATCTCTGAC

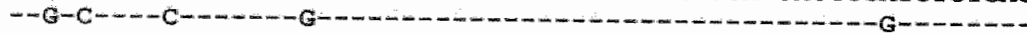

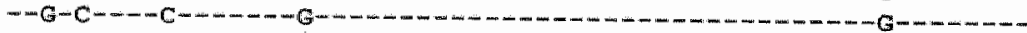

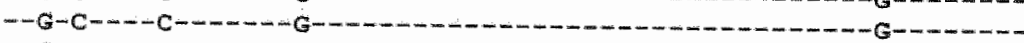

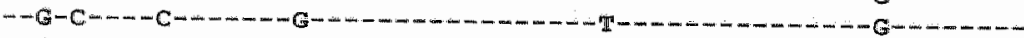

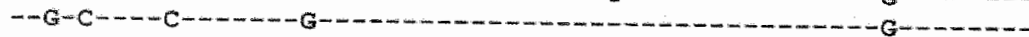

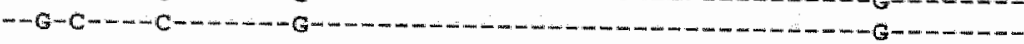

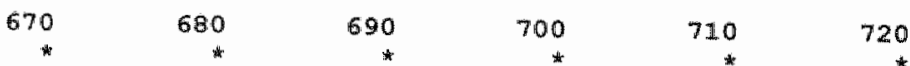

CAWGAGGCCACOCTGAGETGCTGGGCCTGGGTTTTACCCRGCGGAGATCACACTGACC

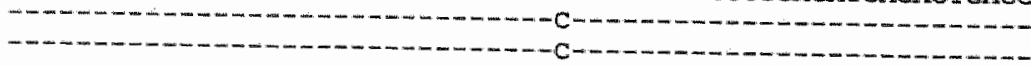

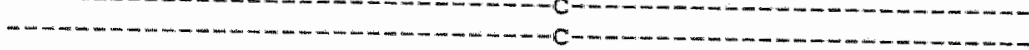
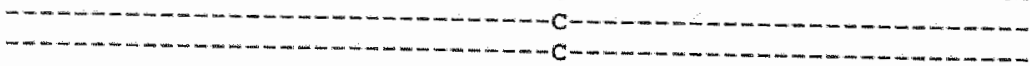

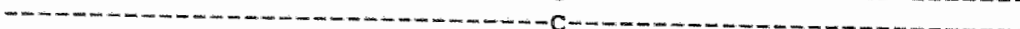

Figure 3.1 continued 
730

740

750

760

770

780

$B * 07021$

B* 35011

B* 3542

B*51011

B*51015

B* 52011

B*5204

$B * 07021$

$B * 35011$

$B * 3542$

B*51011

$B * 51015$

B* 52011

B*5204

$B * 07021$

B 35011

$B * 3542$

B*51011

$B * 51015$

$B * 52011$

$B * 5204$

$B * 07021$
$B * 35011$
$B * 3542$
$B * 51011$
$B * 51015$
$B * 52011$
$B * 5204$

B.07021 B 35011

B* 35.42

B*51011

B*51015

$B * 52011$

B* 5204

Figure 3.H

\section{TGGCAGCGGGATGGCGAGGACCAAACTCAGGACACTGAGCTTGTGGAGACCAGACCAGCA}
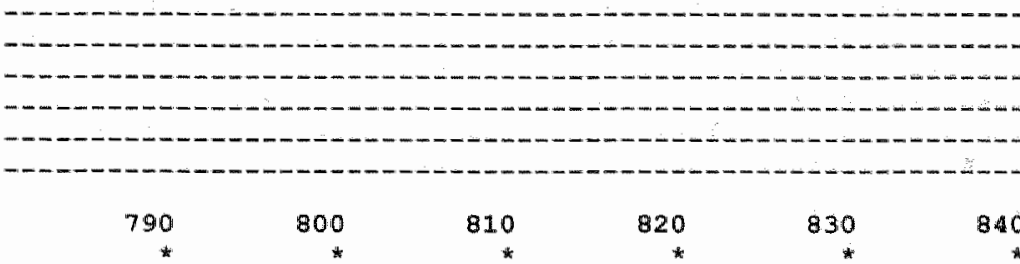

GGAGATAGAACCTTCCAGAAGTGGGCAGCTGTGGTGTGCCTTCTGGAGAAGAGCAGAGA

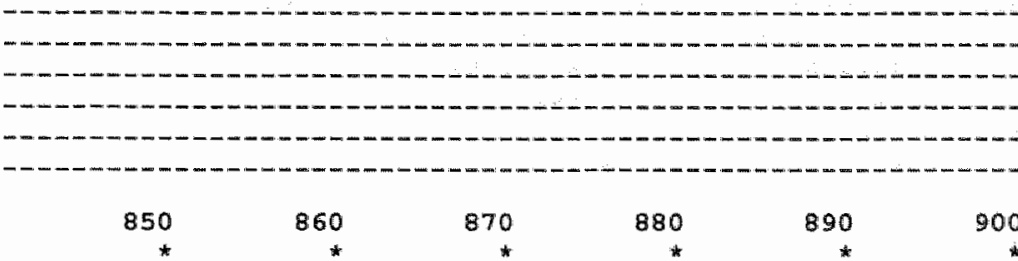

TACACATGCCATGMACAGCATGAGGGGCTGCCGAAGCCCCTCACCCTGAGATGGGAGCCG

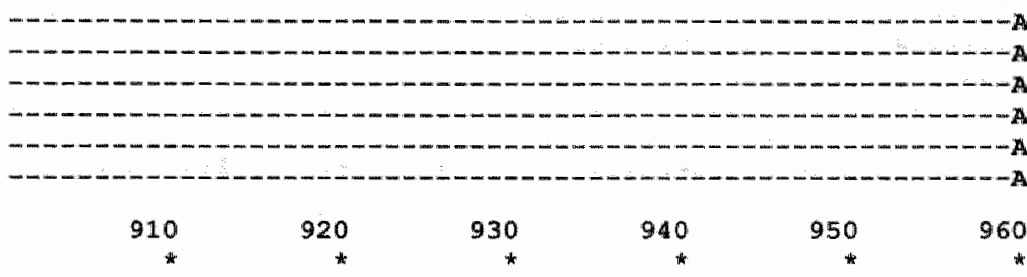

TCTTCCCAGTCCACCGTCCCCATCGTGGGCATTITGCTGGCCTGGCTGTCCTA . . . GCA

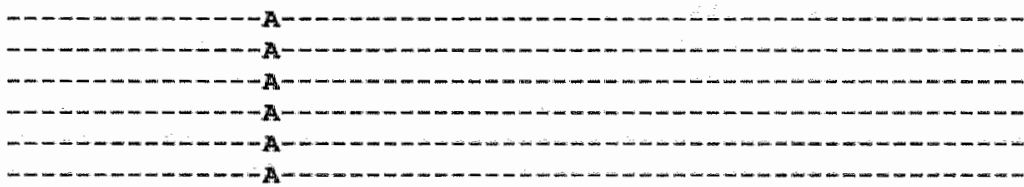

$\begin{array}{rrrrr}970 & 980 & 990 & 1000 & 1010\end{array}$

GTTGTGTCATCGGAGCTGTGTCGCTGCTGTATGTGTAGGAGGAAGATTCAG

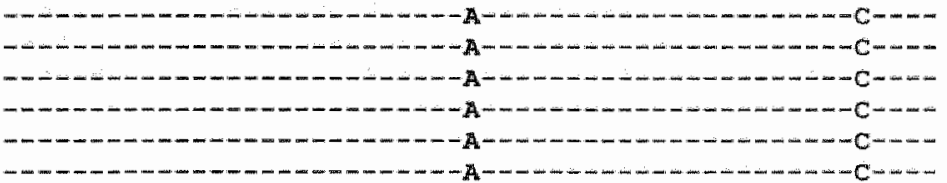

Alignment of exon $1-5$ nucleotide sequences of HLA. $B^{*} 3542, B^{*} \cdot 1015$ and $B^{*} 5204$ to the sequences of HLA-B*07021, $B^{*} 35011, B^{*} 51011$ and $B^{*} 52011$. Nudeotide identity with the sequence of HLAm $B^{*} 07021$ is indicated by dashes, dots reflect deletions and numbers above the sequences refer to the nucleotide positions of the coding sequence. 


\section{Discussion}

In this study, nucleotide sequences of exon 1 through 5 of the HLA-B5/35 CREG were determined to assess the level of polymorphism. A total of 225 unrelated individuals were typed. Four new polymorphisms were detected. resulting in three new alleles, $B * 3542, B^{*} 51015$ and $B * 5204$.

For sequencing of exons 2 and 3 , the HLA-B SBT strategy designed by Voorter et al. ${ }^{25}$ was applied. A total of 133 different HLA-B alleles have now been identified with this method. No allelic-dropout or preferential amplification was noticed for the alleles tested. The sequencing primer located in intron 2 , showed mismatches with $B^{\star} 5101$ and $B^{\star} 5201$, according to the intron sequences published ${ }^{32.33}$. In a previous study, equal peak heights were found at heterozygous positions in individuals carrying $B^{*} 5101$ or $B^{*} 5201^{25}$. In the present study, an extended number of individuals with $B^{\star 5} 5101 \quad(n=69)$ and $B^{*} 5201(n=10)$ alleles were sequenced and no problems were encountered. Although the intron sequences of other $B^{*} 51$ and $B^{*} 52$ alleles are unknown, we sequenced a further nine alleles, all of which showed equal peak heights at heterozygous positions.

Two different types of ambiguities were observed, as described in the results. The first type of ambiguity was noticed in $59(26 \%)$ individuals, whereas identical exon 2 and 3 sequences occurred in five allele pairs involving 93 $(41 \%)$ individuals. The high percentage is mainly due to the large number of individuals typed $B^{*} 51011 /{ }^{*} 5111 N(n=69)$. In the B7 CREG study, the first type of ambiguity was found in $13 \%$ and the second type in $19 \%$ of the individuals. Although the frequency of ambiguities is dependent on the alleles studied, the higher number of ambiguities in the present study might also be the result of the use of an extended database compared to the previous study. Recently, another pair of identical alleles was identified, namely $\mathrm{B}^{*} 35011 /{ }^{*} 3540 \mathrm{~N}$, the difference being located in exon 4 . All individuals in this study carrying $B^{*} 35011$ $(n=16)$ showed positive serological reactions with specific antisera.

Sequencirig exons 1,4 and 5 of 45 individuals, carrying alleles with known sequences, showed three new polymorphisms. They identified two new alleles with identical exon 2 and 3 sequences to $B * 35011$ and $B * 51011$, but different for exons 1 and 4 , respectively. This supports the idea that polymorphism outside exons 2 and 3 will contribute to the increase of new HLA-B alleles. In a previous study, the exon 1,4 and 5 sequences of different HLA-C alleles were determined in 28,17 and 59 individuals, respectively ${ }^{34}$. Two new alleles were detected with a polymorphic position outside exons 2 and 3 . The number of new polymorphisms detected in both studies is comparable. 
The HLA-B5/35 CREG currently consists of 99 different alleles i.e. $44 B^{*} 35,34$ $B^{*} 51$, six. $B^{\star} 52$, nine $B^{*} 53$ and six $B^{*} 78$ alleles (MGT/HLA databank ${ }^{35}$, version April 2002 and this paper). They encode 85 different HLA molecules. Most polymorphic nucleotide positions are detected in exons 2 and 3, namely 64 . This number is relatively low in comparison to other HLA-B groups. Eight polymorphic positions have been identified for exons 1,4 and 5 . The number of polymorphic positions is comparable to other HLA-B groups, with the exception of the B40 and B12 groups which show more polymorphic positions in exons 1. 4 and 5 in relation to the number of sequences known.

Three new alleles, $B^{*} 3542, B^{*} 51015$ and $B^{*} 5204$ were detected in the study.

The HLA-B*3542 allele showed two mismatches with $B^{\star} 35011$ in exon 1 at positions $25(\mathrm{G} \rightarrow \mathrm{C})$ and $72(\mathrm{C} \rightarrow \mathrm{T})$. The HLA-B alleles $\mathrm{B}^{*} 18,{ }^{*} 27,{ }^{*} 37,{ }^{*} 40$ and * 47 also bear a $C$ and a $T$ at position 25 and 72 , respectively, and are identical to the exon 1 sequence of $B^{*} 3542$. This suggests that $B^{*} 3542$ arose by an allele conversion event, with $\mathrm{B}^{*} 35011$ serving as backbone and one of the alleles bearing $\mathrm{a} C$ and $\mathrm{a} T$ acting as the donor gene.

The $B^{\star} 51015$ allele had one mismatch in exon 4 with $B^{\star} 51011$ at position 636 , changing a $C$ to $a T$. The $T$ at this position is also present in severall other HLA$B$ alleles. The $B^{*} 51015$ allele is the only one with both $T$ at 636 and $G$ at 652 .

The $B^{*} 5204$ allele showed a mismatch at nucleotide position $200(C \rightarrow A)$ compared to $B^{*} 52011$. None of the HLA-B alleles has an $A$ at position 200 , nor has any of the HLA-C alleles. In contrast, most HLA-A alleles have an $A$ at this position. The differences between HLA-A and $B^{*} 5204$ at positions 198 and 206 make gene conversion between $B^{*} 52011$ and HLA-A with such a small fragment very unlikely as the origin for the $B^{\star} 5204$ allele. The new allele most probably arose by point mutation.

It is questionable whether the polymorphism outside exons 2 and 3 has functional impact. Exon 1 encodes the leader peptide of the HLA molecule and therefore does not contribute to the protein structure at the cell surface. However, HLA-E can present peptides derived from leaders of other class I molecules $^{36}$. The HLA-E expression on the cell surface is dependent on the peptide sequence and therefore polymorphism of exon 1 may affect this process $^{37}$. Exons 4 and 5 encode the $\alpha 3$ domain and the transmembrane domain, respectively. These domains are not directly involved in antigen presentation and recognition. However, the HLA molecules not only serve as peptide presenters, but also interact with $\beta 2$-microglobulin, $\alpha \beta \mathrm{T}$-cell receptors, CD8 and $\mathrm{NK}$ cells ${ }^{38}$.

The $\alpha 3$ domain has an important function in maintaining the structure of the HLA molecule and associates with the T-cell co-receptor, CD8, during T-cell recognition ${ }^{39-41}$. Several clusters of residues in the $\alpha 3$ domain were found to 
contribute to the $\mathrm{CD} 8$ binding site and mutations were found to affect the lysis by CD8-dependent cytotoxic T-lymphocytes (CTLS) ${ }^{40,42,43}$. Another crucial role of the $\alpha 3$ domain is its interaction with $\beta 2$-microglobulin ${ }^{44} . \beta 2$-microglobulin is not only a structural subunit of the MHC-class I complex, but also plays a role in the folding of the MHC molecule ${ }^{45}$. The interaction of the $a 3$ domain with $\beta 2-$ microglobulin seems to be crucial for the chaperone function ${ }^{46}$. Mutations in the a3 domain have been shown to result in changes in the assembly with $\beta 2$ microglobulin ${ }^{47}$.

Concerning the transmembrane domain, Osborn et al. ${ }^{48}$ showed a reduction of the MHC class I antigen cell-surface stability by variation of the length of the transmembrane domain, but not by variation of the composition. This implies that polymorphism in the transmembrane domain does not affect cell surface stability, unless it changes the length of the transmembrane domain. In this respect it is worth mentioning that there is a variation in exon 5 length among HLA-A, $B$ and -C genes.

Variability in the $\alpha 1$ and $\alpha 2$ domain residues may be originated by a high selective pressure to cope more efficiently with different pathogens through the peptide binding region. The low polymorphism found at present outside these domains might be due to some selective force against variability, probably due to some functional impact ${ }^{38}$. Variability outside the polymorphic $\alpha 1$ and $\alpha 2$ domains still has to be assessed, since most studies have concentrated on the polymorphism of the peptide binding graove.

The nucleotide sequence data reported in thils paper will appear in the EMBL Nucleotide Sequence Database with the accession numbers AJ316289, AJ426469, AJ426468, AJ417680, Av417669 $\left(B^{*} 3542\right), \quad A J 426462, \quad A J 426465, \quad A J 426466, \quad A J 426463, \quad A J 426464 \quad\left(B^{*} 51015\right), \quad A J 316288$, A.J426470, A.J426467, AJ417684, A.J417673 (B'5204).

The names $\mathrm{B}^{* 3542,}, 51015$ and $* 204$ have been officially assigned by the WhO Nomenclature Committee. This follows the agreed policy that subject to the conditions stated in the most recent Nomenclature Report ${ }^{2}$, names will be assigned to new sequences as they are identified. Lists of such now names will be published in the following WHO Nomenclature Report. 


\section{References}

1. Bodmer WF, Payne R. Theoretical consideration of leukocyte grouping using multispecific antisera. In: Bainer $\mathrm{H}$, ed. Histocompatibility Testing. Copenhagen: Munksgaard. 1965:141.

2. Dausset J. The workshop data, tabie III. In: Curtoni ES, Mattiuz PL Tosi RM, ed. Histocompatibility Testing. Copenhagen: Munksgaard, 1967:448.

3. Badmer J. The A B C of HLA. A serological report of the 6th Histocompatibility Testing Workshop. In: Kissmeyer-Nielsen F, ed. Histocompatibility Testing. Copenhagen: Munksgaard, 1975:21-69.

4. Hammond MG. Further splits of HLA-B5. In: Terasaki PI ed. Histocompatibility Testing. Los Angeles: University of California $1980: 758$.

5. Naik S, Mittall KK. Segregation of BW51, BW52, BW53, and BW35 in families: splitting of BW51 into 'long' and "short' variants. In: Terasaki PI, ed. Histocompatibility Testing. Los. Angeles: University Of California, 1980:759.

6. Engelfriet CP, Veenhoven-Riesz von LE, Kort-Bakker M, Berg van den-Loonen PM. Some studies with anti-4C, anti-R, anti-HL-A5, anti-W5, W18 and the description of a new antigen of the four segregant series, called H.R. In: Daussel J. Colomboni J, ed. Hilistocompatibility Testing 1972:475-8.

7. Bodmer JG, Colombani J, Rocques P, Degos L, Bodmer WF, Dausset J. Population Studies لn: Dausset $J$ Colombani $J$, ed. Histocompatibility Testing. Copenhagen: Munksgaard "1972 $621-67$.

8. Zemmour $\rfloor$, Parham P. HLA class I nucleotide sequences, 1991. Hum Immunol 1991;31: 195-206.

9. Albert ED, Mickey MR, MCNicholas AC, Terasaki P. Serology and genetics of Te58 (W18) and other specificities included in the $4 c$ complex. In: Terasaki $P$, ed. Histocompatibility Testing. Copenhagen: Munksgaard, 1970:221,

10. Ooba $T$, Hayashi $H$, Karaki $S$, Tanabe $M$, Kano K, Takiguchi $M$. The structure of HLA-B35 suggests that it is derived from HLA-Bw58 by two genetic mechanisms. Immunogenetics $1989 ; 30: 76-80$.

11. Hayashi H, Ennis PD, Ariga H et al. HLA-B51 and HLA.Bw52 differ by only two amino acids which are in the helical region of the alpha-1 domain. J Immunol 1989;142:306-11.

12. Sekimata $M$, Hiraiwa $M$, Andrien $M$ et al. Allodeterminants and evolution of a novel HLA-B5 CREG antigen, HLA-B SNA. \Immunol 1990;144:3228-33.

13. Hayashi $H$, Oaba $T$, Nakayama $S$, Sekimata $M$, Kano $K$, Takiguchi $M$. Allospecificities between HLA-Bw53 and HLA-B35 are generated by substitution of the residues associated with HLA-Bw4/Bw6 public epitopes, Immunogenetics 1990;32:195-9.

14. Kato $N$, Ward $F$, Kano $K$, Takiguchi $M$. Conservation of genes encoding $H L A-B S$ and $B 35$ cross-reactive group antigens in warious races. Hum Immunol 1992:35:253-5.

15. Hill AVS Allsopp CEM, Kwiatkowski D et al. Common West African HILA antigens are associated with protection from severe malaria. Nature 1991;352:595-600.

16. Ellis JM, Hoyer RJ, Costello $C N$ et al. HLA-B allele frequencies in Cote d'woire defined by direct DNA sequencing: identification of HLA-B*1405, $B^{*} 4410$, and $B^{\star} 5302$. Tissue Antigens 2001:57:339-43.

17. Anholts JDH, Kemps-Mols $B$, Verduijn W, Oudshoor $M$, Schreuder GMTh. Three newly identified HLA-B alleles: $B^{*} 5124, B^{*} 5306, B^{*} 5307$ and confirmation of $B^{*} 0809$ and $B^{*} 5606$. Tissue Antigens 2001;58:38-41.

18. Steiner NK, Kosman $C_{\text {v }}$ Jones PF et al. Twenty-nine new HLA-B alleles associated with antigens in the $5 \mathrm{C}$ CREG. Tissue Antigens 2001;57:481-5.

19. Allsopp CEM, Harding RM, Taylor $C$ ef all Interethnic genetic differentiation in Africa: HLA, class I antigens in the Gambia. Am J Hum Genet 1992,50:411-21.

20. Madrigal JA, Belich MP. Hildebrand WH et al. Distinctive HLAxA,B antigens of black populations formed by interallelic conversion. J Immunol 1992;149:3411-5.

21. Priliman $K$, Steiner $N$, Ellexson $M$ et all. Novel alleles HLA.B*7802 and $B^{*} 51022$ : evidence for convergency in the HLA-B5 familly. Tissue Antigens 1996;47:49-57. 
22. Andrien M, Defleur $V$, Canck De I ef al. $B^{*} 78022$, a new Caucasian member within the $B 78$ family. Tissue Antigens 1997;49:79-83.

23. Gaidufis $L$, Krausa $P$, Schaub $B$, Senitzer $D$. Identification of a new HLA-B 78 allele in a Hispanic family. Tissue Antigens 2000,56:184-7.

24. Sekimoto $T$, Araseki $M$. Sato $S$, Sakaya $S$, Kato $T$, lkeda $H$. Identification of a novel allele HLA-B" 7805 in a Japanese female. Tissue Antigens 2001,58:345-8.

25. Voorter CEM, Vlies wan der SA, Berg van den-Loonen EM Sequence-based typing of HLA-B: the $B 7$ cross-reacting group. Tissue Antigens 2000;56:356-62.

26. Whes van der SA, Voorter CEM, Berg van den-Loonen EM. A reliable and efficilent high resolution typing method for HLA-C using sequence-based typing. Tissue Antigens $1998 ; 52: 558-68$.

27. Miller SA, Dykes DD. Polesky HF. A simple salting out procedure for extracting DNA from human nucleated cells. Nucleic Acids Res 1988;10:1215

28. Voorter CEM, Rozemuller EH, Bruyn de-Geraets D, Zwan van der AW, Tilanus MGJ, Berg van den-Loonen EM. Comparison of DRB sequence-based typing using differentit strategies. Tissue Antigens 1997:49:47116.6

29. Voorter CEM, Bruyn de-Geraets D, Berg van den-Loonen EM. High-resolution HLA typing for the DRB3/4/5 genes by sequence-based typing. Tissue Antigens 1997;50:283-90.

30. Voorter CEM, Kik MC, Berg van denmLoonen EM. Highi-resolution HLA typing for the DQB1 gene by sequence-based typing. Tissue Antigens 1998;51:80-7.

31. Voorter CEM, Swelsen WTN, Berg wan den-Loonen EM. Intron sequences of HLA-B*73. Tissue Antigens, 2001;57:463-8.

32. Gomez-Casado E Vargas-Alarcon $G_{s}$ Martinez Laso J et al. Generation of the HLA-B35, -B5, $-B 16$, and B15 groups of alleles studied by intron 1 and 2 sequence analysis. Immunogenetics 1997:46:469m76.

33. Cereb $N$. Kong $Y$, Lee $S$, Maye $P$, Yang SY. Nucleotide sequences of MHC class I introns 1,2 , and 3 in humans and intron 2 in nonhuman primates. Tissue Antigens 1996:47:498-511.

34. Vies van der $S A_{1}$ Voorter CEM, Berg van den-Loonen EM. There is more to HLA-C than exons 2 and 3 : sequencing of exons 1, 4 and 5 . Tissue Antigens 1999;54:169-77.

35. Robinson J, Malik A, Parham P, Bodmer JG, Marsh SGE. IMGT/HLA database - a sequence database for the human major histocompatibility complex. Tissue Antigens 2000;55:280-7.

36. Braud $V$, Jones EY, McMichael $A$. The human major histocompatibility complex class Ib molecule HLA-E binds signal sequence-derived peptides with primary anchor residues at positions 2 and 9 . Eur J Immunol 1997:27:1164-9.

37. Braud VM, Allan DSJ, OCallaghan C.A et al. HLA.E binds to natural killer cell receptors CD94/NKG2A, B and C. Nature 1998;391:795-9.

38. Parham $\mathrm{P}$. Adams EJ. Armett KL. The origins of HLA-A,B,C polymorphism. Immunal Rev $1995 ; 143: 14: 1-80$.

39. Salter RD. Noment AM, Chen BP of al. Polymorphism in the alpha 3 domain of HLA-A molecules affects binding to CD8. Nature 1989;338:345-7.

40. Wesley PK, Clayberger C, Lyu S, Krensky AM. The CD8 coreceptor interaction with the alpha 3 domain of HLA cllass I is critical to the differentiation of human cytotoxic T-lymphocytes specific for HLA-A2 and HLA-Cw4. Hum Immunol 1993;36:149.55.

41. Fayen J. Huang $\mathrm{dH}$, Meyerson $H$ et all. Class 1 MHC alpha 3 domain can function as an independent structural unit to bind CD8 alpha. Mol Immunol 1995;32:267-75.

42. Salter RD, Benjamin RJ, Wesley PK et al. A binding site for the T-cell co-receptor CD8 on the alpha 3 domain of HLA.A2. Nature 1990;345:41-6.

43. Connolly JM, Hansenin TH, Ingold AL. Potter TA. Recognition by CD8 on cytotoxic $T$ lymphocytes is ablated by several substitutions in the class I alpha 3 domain: CDB and the T. cell receptor recogrize the same class \& molecule. Proc Natl Acad Sci USA 1990;87:2137-41.

44. Bjorkman PJ. Saper MA, Samraoui B, Bennett WS, Strominger Jt, Wiley DC. Structure of the human elass I histocompatibility antigen, HLA-A2. Nature 1987;329:506-12. 45. Solheim JC. Class I MHC molecules: assembly and antigen presentation. Immunol Rev 1999;
$172,11-9$. 
46. Hebert AM. Strohmaier J, Whitman MC et al. Kinetics and thermodynamics of beta-2 microglobulin binding to the alpha 3 domain of major histocompatibility complex class I heavy chain. Biochemistry 2001;40:5233-42.

47. Salter RD. Mutant HLA-A201 heavy chains with lowered affinity for beta2m are transported after growth at reduced temperatures. Hum Immunol 1992;35:40-9.

48. Osborn CK, Grigoriev V, Crew MD. Modulation of class 1 major histocompatibility complex antigen cell-surface stability by transmembrane domain length variation. Mol Immunol 1997; 34:771-80.

49. Marsh SG, Bodmer JG, Albert ED et al. Nomenclature for factors of the HLA system, 2000. Tissue Antigens 2001:57:236-83.

50. Yao $Z$, Volgger $A_{\text {, }}$ Scholz $S$, Albert ED. Sequence polymorphism in the HLA-B promoter region. Immunogenetics $1995 ; 41: 343-53$.

51. Summers CW, Hampson VJ "Taylor GM. HLA class I non-coding nucleotide sequences. 1992. Eur J Immunogenet 1993;20:201-40.

52. Cereb $N$, Yang SY. Dimorphic primers derived from intron 1 for use in the molecular typing of HLA-B alleles. Tissue Antigens 1997;50:74-6. 


\section{Chapter 4}

Ambiguities of human leukocyte antigen-B resolved by sequence-based typing of exons 1 , 4 , and 5

Wendy TN Swelsen, Christina EM Voorter and Ella M van den Berg-Loonen Tissue Antigens 2004:63:248-254 


\section{Abstract}

The elucidation of the sequences of human leukocyte antigen-B (HLA-B) exons 1 through 5 has led 10 an increase of ambiguities with alleles having identical exon 2 and 3 sequences, but differences in other exons. At the moment, $26 \mathrm{HLA}-\mathrm{B}$ alleles show such ambiguities which can be resolved by sequencing the exons in which the differences are located. Here we report a sequence-based typing (SBT) strategy for heterozygous sequencing of exons 1,4 and 5 , in addition to the previously described exons 2 and 3 .

The strategy was validated against a panel of 25 individuals, carrying HLA-B alleles from 33 different allele groups. Correct assignment of all HLA-B alleles was obtained for exons 1 through 5 . In addition the SBT protacol was used to resolve ambiguities in 50 individuals. The ambiguous: combinations studied were $B^{*} 0705 / 06, B^{* 0801 / 19 N,} B^{* 1512 / 19}, B^{* 180101 / 17 N,}$ $B^{*} 270502 / 13 / 0504, B^{*} 350101 / 42 / 40 N, B^{*} 390101 / 0103, B^{*} 400102 / 0101, B^{*} 440201 / 19 N / 27$ and $B * 510101 / 11$ N/0105/30/32. In all cases sequencing revealed the first allele to be present, except for three individuals with $B^{*} 07$. One of them typed $B^{*} 0705$; the other two were $B^{*} 0706$. The described SBT protocol for sequencing exons 1,4 and 5 is a valuable tool for resolving ambiguities of HLA.B alleles with differences in these exons, as well as for studying the polymorphism of HLA-B outside exons 2 and 3. 


\section{Introduction}

The human leukocyte antigen (HLA) class I and class II genes, encoded within the human major histocompatibility complex (MHC), are the most polymorphic loci in the human genome. The diversity of the HLA loci is the result of positive evolutionary selection and correlates with the capacity to respond to different proteins. Of the class I genes, HLA-B is the most polymorphic with currently more than 500 alleles identified by DNA sequence analysis (HLA databank, April 2003).

HLA-B antigens are highly polymorphic cell surface glycoproteins involved in the recognition of cytotoxic $T$ and natural killer $(\mathrm{NK})$ cells during the immune response $e^{1-3}$. The polymorphism is mainly located in exons 2 and 3 , which code for the $\alpha 1$ and $\alpha 2$ domains and include the antigenic peptide binding site. The function of polymorphism outside these regions is not well understood. Exon 1 encodes the leader peptide that is cleaved off after transport of the HLA molecule through the endoplasmatic reticulum. The role of polymorphism in this exon is unclear. Part of the leader peptide of class I is presented by HLA-E on the cell surface and this combination can function as ligand for NK or T cell receptors $^{4-6}$. Exon 4 encodes the $\alpha 3$ domain, which plays an important role in the interaction with $\beta 2$ microglobulin, the association with the peptide loading complex and the CD8 binding ${ }^{7-9}$. CD8 binding affects cytotoxic $T$ cell recognition, whereas interaction with $\beta 2$ microglobulin is required for correct folding of the MHC protein ${ }^{40,11}$. Mutations in the $\alpha 3$ domain have shown to result in CD8 binding affinity variation, reduced cell surface expression and variation in peptide binding loading efficiency ${ }^{9,12-16}$. The transmembrane domain encoded by exon 5 was shown to be important for cell surface stability. which was affected by length variation of this domain ${ }^{17}$.

Sequence-based typing (SBT) methods for HLA-B are based on elucidation of exon 2 and 3 sequences. Extension of the method with sequences of other exons occurs more and more frequently ${ }^{18-20}$. This has led to an increase of ambiguities with alleles having identical exon 2 and 3 sequences but differences in other exons. Up to the sixth digit level, this involves 10 identical allele combinations, i.e., $B^{*} 0705={ }^{*} 0706, B^{*} 0801={ }^{*} 0819 N, B^{*} 1512={ }^{*} 1519$, $B^{*} 180101=* 1817 N, \quad B^{*} 270502={ }^{*} 2713=* 270504, \quad B^{*} 350101={ }^{*} 3542={ }^{*} 3540 N$, $B^{*} 390101=* 390103, \quad B^{*} 400101={ }^{*} 400102, \quad B^{*} 440201={ }^{*} 4419 N={ }^{*} 4427$ and $B * 510101=* 5111 \mathrm{~N}={ }^{*} 510105=* 5130=* 5132$. The ambiguities can be resolved by sequencing the exon in which the difference is located. In this study, we describe an SBT strategy for heterozygous sequencing of exons 1, 4 and 5 , which is an extended protocol of our previously reported HLA-B study ${ }^{21}$. The strategy was validated against a panel of 25 individuals. Furthermore, the SBT 
protocol was used to resolve HLA-B ambiguities with differences in exons 1.4 or 5 in 50 individuals.

\section{Materials and methods}

\section{Samples}

A panel of 25 individuals, carrying HLA-B alleles from 33 different allele groups. was selected to validate the SBT protocol. The individuals were typed by sequencing exons 2 and 3 , as previously described ${ }^{21}$. The different $H L A-B$ groups included in the panel were: $B^{*} 07,{ }^{*} 08,{ }^{*} 13,{ }^{*} 14,{ }^{*} 15,{ }^{*} 18,{ }^{*} 27,{ }^{*} 35,{ }^{*} 37$, ${ }^{*} 38,{ }^{*} 39,{ }^{*} 40, * 41,{ }^{*} 42,{ }^{*} 44, * 45, * 46, * 47,{ }^{*} 48,{ }^{*} 49,{ }^{*} 50,{ }^{*} 51,{ }^{*} 52,{ }^{*} 53,{ }^{*} 54,{ }^{*} 55$, ${ }^{*} 56,{ }^{*} 57,{ }^{*} 58,{ }^{*} 67, * 73,{ }^{*} 78$ and ${ }^{*} 81$. No individuals representing $B * 59$ and $B * 83$ were available. $B^{*} 82$ was not tested, because $B^{*} 8201$ was the only $B^{*} 82$ allele available, and the exon 1,4 and 5 sequences of this allele are not yet known.

Furthermore, the SBT protocol was used to resolve 10 different HLA-B ambiguities in 50 individuals. In four individuals, two ambiguities were detected. Table 4.1 shows the ambiguities and the exon in which the difference is located, as well as the number of individuals in which the ambiguity was resolved by sequencing the appropriate exon.

Table 4.1 Ambiguities, locatiom of differences and the number of individuals tested $(n)$.

\begin{tabular}{llll}
\hline B-alleles with identical exon 2 and 3 sequences & Difference located in At position & $n$ \\
\hline$B^{*} 0705=B^{*} 0706$ & exon 5 & 916 & 3 \\
$B^{*} 0801=B^{*} 08 * 19 N$ & exon 4 & 724 & 3 \\
$B^{*} 1512=B^{*} 1519$ & exon 4 & 821 & 3 \\
$B^{*} 180101=B^{*} 1817 N$ & exon 1 & 41 & 5 \\
$B^{*} 270502=B^{*} 2713=B^{*} 270504$ & exon 1 & 14,72 & 9 \\
$B^{*} 350101=B^{3} 542=B^{*} 3540 N$ & exon $1+4$ & $25,72,807$ & 8 \\
$B^{*} 390101=B^{* *} 390103$ & exon 5 & 1008 & 3 \\
$B^{*} 400101=B^{*} 400102$ & exon 1 & 72 & 7 \\
$B^{*} 440201=B^{*} 4419 N=B^{*} 4427$ & exon $1+4$ & 5,668 & 4 \\
$B^{*} 510101=B^{*} 5111 N=B^{*} 510105=B^{*} 5130=B^{*} 5132$ & exon 4 & $628,636,787,872$ & 9 \\
\hline
\end{tabular}

\section{DNA isolation}

DNA was isolated from fresh heparinized blood or from lymphocytes stored in liquid nitrogen either by the "salting out" extraction procedure as described by Miller et al ${ }^{22}$ or by using QIA-AMP kits following the suppliers protocol (Qiagen, Westburg, Leusden, the Netherlands). Concentration and purity of DNA samples were measured at optical densities of 260 and $260 / 280 \mathrm{~nm}$. 


\section{Primers and approach}

To obtain complete exon sequences, amplification and sequencing primers were located in adjacent exons or introns. Locations and sequences of all primers tested are indicated in table 4.2. Table 4.3 shows the final combinations of primers used for the heterozygous sequencing protocol of exons 1,4 and 5 of HLA-B. All primers were designed locally. The Cy-5 labeled sequencing primers developed were located internally of the polymerase chain reaction (PCR) product to ensure sequencing of specific PCR products.

Table 4.2 Sequence and location of amplification and sequencing primers tested for the heterozygous sequencing of exons 1,4 and 5 of HLAmB.

\begin{tabular}{|c|c|c|c|}
\hline Name & Sequence & Lociation & Position \\
\hline \multicolumn{4}{|l|}{ Exon 1} \\
\hline $5 \mathrm{Bg} 9022$ & GTCGGGTCCTTCTTCCAGG & 5" UT & $-153-135^{1}$ \\
\hline 3"B96133 & ACTGAAAATGAAACCGGGTAAAC & Intron 2 & $617-639$ \\
\hline $3 \mathrm{~B} 98015$ & ACTGAAAATGAAACCGGGTAAAG & Intron 2 & $617-639$ \\
\hline $3 \mathrm{~B} 03019$ & CCCCCGCCTGCGGT & Intron 1 & $123-136$ \\
\hline $5 \mathrm{C} 98042 \mathrm{c}$ & ${ }^{5} \mathrm{ACCCACCCGGACTC}$ & $5 \cup T$ & $-35-22$ \\
\hline \multicolumn{4}{|l|}{ Exon 4} \\
\hline 5801015 & TGTTCCCCGCTCAGAGACTC & Intron 3 & $1369-1388$ \\
\hline 3"B01051 & AGCCCTGGGCACTGTCG & Exan 7 & $1050-1066$ \\
\hline 5"B01005c & ${ }^{C{ }^{5}}$ ATTTTCTGACTCTTCCC & Intron 3 & $1543-1559$ \\
\hline $5 " \mathrm{~B} 01039 \mathrm{c}$ & ${ }^{\circ 5}$ AGATGCAAAGCGCCTG & Intron 3 & $1526-1541$ \\
\hline $5 " B 01040 \mathrm{c}$ & ${ }^{55}$ GCGCCTGWAWTTTCTGA & Intron 3 & $1535-1551$ \\
\hline $5 " B 02160 \mathrm{c}$ & ${ }^{45}$ CATGGGTGGTCCTAGG & Intron 3 & $1498-1513$ \\
\hline $5 \mathrm{~B} 02161 \mathrm{C}$ & CACACTGACCTGGCA & Exon 4 & $711-725$ \\
\hline \multicolumn{4}{|l|}{ Exon 5} \\
\hline 5801015 & TGTTCCCCGCTCAGAGACTC & Intron 3 & $1369-1388$ \\
\hline $3^{\prime} \mathrm{B} 01051$ & AGCCCTGGGCACTGTICG & Exon 7 & $1050-1066$ \\
\hline $5802096 c$ & AGCAGGGTCAGGGCC & Intron 4 & $1896-1910$ \\
\hline $3^{\prime} \mathrm{B} 01046 \mathrm{c}$ & ${ }^{25}$ CTTGAAACCCCCAGTG & Intron 5 & $2092 \cdot 2107$ \\
\hline
\end{tabular}

${ }^{1}$ The $5^{\prime}$ untranslated region and intron positions are numbered according to Cox et al ${ }^{20}$

Table 4.3 Combination of primers used for SBT of exons 1,4 and 5 of HLA-B.

\begin{tabular}{llll}
\hline & $5^{\prime}$ amplification primer & $3^{\prime}$ amplification primer & $5^{x}$ sequencing primer \\
\hline Exon 1 & $\mathrm{B} 99022$ & $\mathrm{~B} 96133$ & $\mathrm{C} 98042 \mathrm{C}$ \\
Exon 1 $\mathrm{B}^{*} 73$ & $\mathrm{~B} 99022$ & $\mathrm{~B} 98015$ & $\mathrm{C} 98042 \mathrm{C}$ \\
Exon 4 & $\mathrm{B} 011015$ & $\mathrm{~B} 01051$ & $\mathrm{~B} 01039 \mathrm{C}$ \\
Exon 5 & $\mathrm{B} 01015$ & $\mathrm{~B} 01051$ & $\mathrm{~B} 20206 \mathrm{C}$ \\
\hline
\end{tabular}

The amplification of exon 1 was performed using a $5^{\prime}$ primer (B99022) located in the $5^{\prime}$ untranslated region combined with a B-locus specific $3^{\prime}$ primer 
(B96133). The mismatch of $B^{*} 73$ with the $3^{\prime}$ primer at the $3^{\prime}$ end prevented correct amplification of exon 1 of $B^{*} 73$. Two other primers were tested, one $B$-locus specific (B03019) and one $B^{*} 73$ specific (B98015). Exons 4 and 5 were amplified together, using B-locus specific primers located in intron 3 (B01015) and exon 7 (B01051).

One forward sequencing reaction was sufficient to obtain rellable results for exons 1 and 5 of all B-alleles. Reverse sequencing of exon 5 of B*73 was performed with sequencing primer B01046C. For exon 4, in some instances, two different forward sequencing primers were needed to obtain complete heterozygous sequences, one located in intron 3 (B01039c) and one in the middle of exon 4 (B02161c). Three other sequencing primers (B01005c $\mathrm{B} 01040 \mathrm{C}$ and $\mathrm{B} 02160 \mathrm{c}$ ) located in intron 3 were tested to achieve complete sequencing of exon 4 with one sequencing primer.

\section{Amplification and sequencing of exons 1, 4 and 5}

The PCR conditions used were identical to the conditions for SBT of HLA-B exons 2 and 3 , as previously described ${ }^{21}$. In brief, the PCR reaction was carried out in a final volume of $60 \mu \mathrm{l}$, containing $600 \mathrm{ng}$ DNA, $1.5 \mathrm{U}$ Amplitaq DNA polymerase, 20 pmol of biotinylated primer, 40 pmol of unbiotinylated primer, PCR buffer according to Bunce ${ }^{23}$ (67 mM Tris-HCl, pH 8.8, $16.6 \mathrm{mM}$ $\left(\mathrm{NH}_{4}\right)_{2} \mathrm{SO}_{4}, 0.01 \%(\mathrm{~V} / \mathrm{V})$ Tween 20$), 1.5 \mathrm{mM} \mathrm{MgCl}{ }_{2,}, \mu \mathrm{g}$ cresol red, $200 \mu \mathrm{M}$ each dNTP and $5 \%$ glycerol. The cycling conditions consisted of an initial denaturation at $96^{\circ} \mathrm{C}$ for $2 \mathrm{~min}, 10$ cycles of $10 \mathrm{~s}$ at $94^{\circ} \mathrm{C}, 60 \mathrm{~s}$ at $65^{\circ} \mathrm{C}$ and 30 cycles of $10 \mathrm{~s}$ at $94^{\circ} \mathrm{C}, 50 \mathrm{~s}$ at $61^{\circ} \mathrm{C}$ and $30 \mathrm{~s}$ at $72^{\circ} \mathrm{C}$, followed by a final extension at $72^{\circ} \mathrm{C}$ for $10 \mathrm{~min}$. The presence of PCR products with the correct base length was checked by agarose gel electrophoresis. A solid phase sequencing approach was used as previously described ${ }^{24-27}$. The nonbiotinylated DNA strand was removed by alkaline denaturation after attachment of $40 \mathrm{Nl}$ of biotinylated product to streptavidin-coated beads (Dynal, ITK diagnostics, Uithoorn, the Netherlands). After annealing of the Cy-5 labeled sequencing primer, the sequencing reaction was performed at $37^{\circ} \mathrm{C}$ for $5 \mathrm{~min}$. The samples were heated at $90^{\circ} \mathrm{C}$ for $2 \mathrm{~min}$, prior to loading on a $0.5 \mathrm{~mm}$-thick $6 \%$ polyácrylamidle-7M urea gel. Electrophoresis was performed on an ALFexpress automated sequencer (Pharmacia Biotech, Uppsala, Sweden). Sequence data were processed automatically and evaluated manually. Typing was performed using the HLA Sequityper software (Pharmacia Biotech). 


\section{Results}

\section{SBT of exons 1,4 and 5}

\section{Exon 1}

The strategy for exon 1 was validated against a panel of 25 individuals. No allelic drop-out or preferential amplification was noticed, except for the $B^{\star} 73$ allele. Exon 1 of this allele could not be amplified using the primers of the heterozygous protocol. $B^{\star} 73$ has a mismatch with the $3^{\prime}$ amplification primer (B96133) at the $3^{\prime}$ end of the primer sequence, preventing correct amplification $^{21}$. Another $3^{\prime}$ primer (B03019) located in intron 1 was designed to match all B-alleles. This primer was tested in seven panel individuals, but the sequence results were not reliable. In all individuals tested, preferential amplification was noticed, which could result in misassignment of polymorphic positions in the heterozygous protocol. Therefore, $B * 73$ was amplified separately using a $3^{\prime}$ primer (B98015) with a $B^{*} 73$ matched nucleotide at the $3^{\prime}$ end $^{28}$.

\section{Exon 4}

Correct amplification of all B-alleles was obtained using the amplification primers B01015 and B01051. Comparison of the HLA-B sequences (IMGT/HLA database, $\left.{ }^{20,29}\right)$ with the primer sequences used for amplification revealed one mismatch with $B^{\star} 4901$. The mismatch concerns the $5^{\prime}$ amplification primer located in the middle of the primer sequence ${ }^{20}$. Nevertheless, no allelic dropout or preferential amplification was detected in the heterozygous protocol for two individuals carrying a B*4901 allele next to another B-allele. The sequencing primer B01039c showed a mismatch with B*5401, according to published intron sequences ${ }^{29}$, but no problems were encountered during heterozygous sequencing of exon 4 of two $B^{*} 54$ positive individuals. Equal peak heights were obtained in the heterozygous sequence.

In five of the 25 panel individuals (typed as $B^{*} 1302 / 270502, B^{*} 1402 / 3503$, $B^{*} 4201 / 7801, B^{*} 0801 / 4901$ and $\left.B^{*} 1302 / 440301\right)$, an incomplete sequence reading was shown for exon 4 using the sequencing primer $B 01039 \mathrm{c}$. Three other sequencing primers (B01005c, B01040c and B02160c) located in intron 3 were tested, in order to obtain one sequencing primer with reliable sequence results for all HLA-B alleles. The primer $\mathrm{B} 02160 \mathrm{c}$, which was located $5^{\prime}$ of primer B01039c, also showed no reliable sequence results for the five individuals described above. The two other primers tested (B01005c and $\mathrm{B} 01040 \mathrm{c}$ ) were located more to the $3^{\prime}$ end of intron 3 . Sequencing with these primers resulted in a so-called "strong stop" at the start of exon 4 , which prevented correct identification of the nucleotides present. The problem was 
solved by the use of an additional primer (B02161c) located in the middle of exon 4, if necessary.

\section{Exan 5}

Exon 5 was coamplified with exon 4 and sequenced with a primer located in intron 4 (B02096c). Correct amplification and sequencing were obtained for all B-alleles. In exon 5 , the $B^{* 73}$ allele has an insertion of three nucleotides at position 955, in comparison with all other HLA-B alleles. Heterozygous sequencing of the $B^{*} 73$ allele resulted in an out-of-phase alignment, once the point of insertion is reached. Because the Sequityper program can deal with these heterozygous positions, it was possible to directly align and assign $B * 73$ next to another B-aliele. In case of difficulties reading the out-of-phase sequence, reverse sequencing can be performed in addition, to complete the exon 5 sequence at the other side of the insertion. As for exon 4, heterozygous sequencing of exon 5 of two individuals carrying a $B^{*} 4901$ showed no allelic drop-out or preferential amplification, despite the mismatch with the $5^{\prime \prime}$ amplification primer (B01015). The sequencing primer of exon 5 (B02096c) showed a mismatch with $B^{*} 3701$ and $B^{*} 7301$, in the middle of the primer sequence 20,30 . No problems were encountered by sequencing exon 5 of individuals carrying these alleles.

\section{Resolving HLA-B ambiguities}

The protocol was used for resolving HLA-B ambiguities in 50 individuals. Table 4.1 shows the different ambiguities, the exon in which the difference was located and the number of individuals tested. The ambiguity $B^{*} 0705 / 06$ was detected in three individuals. Heterozygous sequencing of exon 5 revealed the presence of $B^{*} 0706$ in two cases and $B^{*} 0705$ in one. In seven individuals the $B^{*} 40$ ambigulty was identified. Remarkably, the second allele, $B^{*} 400102$, was detected in all individuals by heterozygous sequencing of exon 1. Resolving the other ambiguities by sequencing the appropriate exon, resulted in the identification of the first allele in all individuals. In four of the eight individuals with the ambiguity $B^{*} 350101 / 42 / 40 N$, exon 1 was sequenced for identification of $B^{*} 350101 / 42$. The absence of the null allele was identified by serological reactions with $B 35$ specific antisera. Serological results were also taken into account in one of the four individuals with the ambiguity $B^{*} 440201 / 19 \mathrm{~N} / 27$.

\section{Discussion}

In this study, a reliable solid-phase SBT strategy for heterozygous sequencing of exons 1,4 and 5 is presented, in addition to the previously described exons. 
2 and $3^{21}$. The protocol was validated against a panel of 25 individuals carrying HLA-B alleles from 33 different allele groups. No allelic drop-out or preferential amplification was noticed by using the newly designed primers. $B^{*} 73$ was an exception; no amplification product could be obtained for exon 1 due to a mismatch with the $3^{\prime}$ amplification primer (B96133). Amplification primers, which can amplify all B-alleles, would be most suitable for a uniform protocol. Removing the mismatched nucleotide at the $3^{\prime}$ end of primer $B 96133$ was no option, because the HLA-B specificity would be lost. Another 3 " primer designed to match all $B$-alleles resulted in preferential amplification and was therefore not applicable. Separate amplification of $B^{\star} 73$ with a $B^{*} 73$ specific $3^{\prime}$ primer was chosen as solution. The heterozygous sequence protocol enabled the use of generic primer combinations for all other B-alleles without the necessity of prior typing results. Because exons 2 and 3 were also sequenced heterozygously, the allele assignment was directly available by comparing the sequences of all exons with the database.

One forward sequencing reaction was sufficient to obtain reliable results for exons 1 and 5. For exon 4, in some instances two different sequencing primers were needed to obtain the complete heterozygous sequence. The solid-phase sequencing approach, the use of an internally located sequencing primer, a one-step sequencing reaction using $T 7$ polymerase and the typing results of the panel individuals, resulted in high-quality sequence data necessary for reliable identification of heterozygous positions. Therefore we considered sequencing in only one direction justified.

The primers described in this study can also be used with other sequencing methods. Possibly these methods need additional reverse sequencing to obtain reliable results. For exons 4 and 5 reverse sequencing using the same amplification primers is feasible. Reverse sequencing of exon 1 is a problem, because an insertion is present in some but not all B-alleles at the start of intron 1. The use of a sequencing primer located $3^{\prime \prime}$ of this insertion will result in an out-of-phase alignment in several allele combinations. Locating the sequencing primer $5^{\prime}$ of the insertion gives an overlap of exon 1 and primer sequence, making complete exon 1 sequencing impossible. This will prevent correct identification of the $B^{*} 27, B^{*} 35$ and $B^{*} 40$ ambiguities, because of sequence differences at nucleotide position 72 at the $3^{\prime}$ end of exon 1 .

The previously described SBT protocol for HLA-B ${ }^{21}$ relies on heterozygous amplification and sequencing of exons 2 and 3 . The major advantage of heterozygous sequencing is that no prior typing result is needed. However, if two or more allele combinations have identical sequences, this could lead to ambiguous typing. In this study, three out of 25 panel individuals and 19 out of 
50 individuals tested showed this type of ambiguity. The ambiguities were resolved by allele-specific amplification and sequencing of exons 2 and 3 .

The primers designed in this study were located in the $5^{\prime}$ untranslated region, introns 1 through 5 and exon 7 (table 4.2). The sequences of at least one allele of almost all HLA-B groups are known for the different regions (IMGT/HLA database, ${ }^{20,29.34}$ ). In fact, the primers are designed on sequence data of almost all HLA-B allele groups. Moreover, the primers were tested with a panel of 25 individuals representing 33 different HLA-B allele groups. Three allele groups; $B^{*} 59, B^{*} 82$ and $B^{*} 83$, were not present in the panel. The intron sequences of these three allele groups are incomplete. The location of amplification and sequencing primers in rather conserved regions supports the idea that alleles not encountered in the present study will be correctly amplified and sequenced. Furthermore, each exon is sequenced separately in the HLA-B strategy and the sequence data of the different exons are combined in an assignment program. The chance to miss an allele in all exons amplified and sequenced separately is very small, and therefore our SBT strategy seems to be rather robust.

In order to check the newly designed primers for allelic drop-out or preferential amplification, the HLA-B allele combinations of the 25 panell individuals had to be polymorphic. For exon 1,21 out of 25 individuals had a polymorphic allele combination with a range from one to eight polymorphic positions. For exon 4 and 5 , the rumber of individuals with a polymorphic HLA-B combination was 20 (range 1-14) and 18 (range 1-37), respectively.

In exon 1, 11 different polymorphic positions are present, in exon 4 and 5,22 and 39 polymorphic positions are known, respectively. A large part of the polymorphic positions of exons 4 and 5 is due to one allele, namely $B^{*} 7301$. Ten of the 11 polymorphic positions of exon 1 were checked with the panel. The $B^{*} 2713$ allele shows a unique substitution at position 14 . Because this allele was not available position 14 could not be evaluated. In exon 4 , all 22 polymorphic positions were identified in the panel, except position 821 . This position shows a unique substitution for $B^{\star} 1519$ not present in the panel. For exon 5, all 39 polymorphic positions were verified with the panel.

In conclusion, the heterozygous SBT strategy for exons 1,4 and 5 is a valuable tool for identification of the presently known HLA-B alleles with polymorphic positions in these exons, as well as for studying the HLA-B locus polymorphism outside exons 2 and 3 . No discrepancies were detected between the obtained sequences and the reported sequence data for exons 1,4 and 5 , and no new polymorphic positions were identified. 


\section{References}

1. Townsend $\mathrm{A}_{n}$ Bodmer $H$. Antigen recognition by class 1-restricted T lymphocytes. Ann Rev Immunol 1989;7:601:24.

2. Long EO. Rajagopalan S. HLA class I recognition by killer cell lg-like receptors. Immunology 2000;12:101-8.

3. Moretta $A$, Biassoni $R$, Bottino $C$ et al. Major histocompatibility complex cless 1-specific receptors on human natural killer and T Iymphocytes. Immunol Rev 1997; 155:105-17.

4. Garcia $P$. Llano M, Heredia de AB et al. Human T cell receptor-mediated recognition of HLA. E. Eur J Immunol 2002;32:936-44.

5. O'Callaghan CA. Molecular basis of human natural killer cell recognition of HLA.E (human leucocyte antigen-E) and its relevance to clearance of pathogen-infected and tumour cells. Clin Science 2000;99:9-17.

6. Braud VM, Allan DSJ, McMichael AJ. Functions of nonclassical MHIC and non-MHC-encoded class I molecules. Curr Opin Immunol 1999;11:100-8.

7. Fayen $\mathfrak{J}$, Huang $\mathrm{J}-\mathrm{H}$, Meyerson $\mathrm{H}$ et al. Class I MHC alpha 3 domain can function as an independent structural unit to bind CD8 alpha. Mol Immunol 1995;32:267-75.

8. Bjorkman PJ, Saper MA, Samraoui B, Bennett WS, Strominger JL, Wiley DC. Structure of the human class I histocompatibility antigen, HLA-A2. Nature 1987:329:506-12.

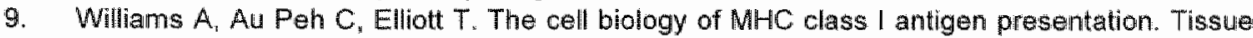
Antigens 2002,59:3-17.

10. Salter RD, Benjamin RJ, Wesley PK et al. A binding site for the T-cell ca-receptor CD8 on the alpha 3 domain of HLA-A2. Nature 1990;345:41-6.

11. Hill DM, Kasliwal $T$, Schwarz $E$ et al. A dominant negative mutant 3.2 -microglobulin blocks the extracellular folding of a major histocompatibility complex class I heavy chain. $J$ Biol Chem $2003 ; 278: 5630-8$.

12. Gao GF, Willcox BE, Wyer JR et al. Classical and nonclassical class II major histocompatibility complex molecules exhibit subtle conformational differences that affect binding to $\mathrm{CD}$ alpha alpha. J Biol Chem 2000;275:15232-8.

13. Salter RD, Morment AM, Chen BP et al. Polymorphism in the alpha 3 domain of HLA-A molecules affects binding to CD8. Nature 1989;338:345-7.

14. Connolly $J M$, Hansen $T H$, Ingold $A L$, Potter TA. Recognition by $C D 8$ on cytotoxic $T$ lymphocytes is abllated by several substitutions in the class I alpha 3 domain. CDB and the T. cell receptor recognize the same class I molecule. Froc Natl Acad Sici USA 1990;87:2137-41.

15. Wesley PK, Clayberger C, Lyu S, Krensky AM. The CD8 coreceptor interaction with the alpha 3. donnain of HLA class I is critical to the differentiation of human cylotoxic T-lymphocytes specific for HLA-A2 and HLA-Cw4. Hum Immunol 1993;36:149-55.

16. Salter RD. Mutant HLA-A201 heavy chains with lowered affinity for beta2m are transported after growth at reduced temperatures. Hum Immunol 1992;35:40-9.

17. Ostborn $\mathrm{CK}$, Grigoriev V: Crew MD. Modulation of class I major histocompatibility complex antigen cell-surface stability by transmembrane domain length variation. Mol Immutiol 1997; 34:771-80.

18. Voorter CEM, Swelsen WT, Berg van den-Loonen EM. B*27 in molecular diagnostics: impact of new alleles and polymorphism outside exons 2 and 3 . Tissue Antigens 2002;60:25-35.

19. Swelsen WTN, Voorter CEM, Berg van den-Loonen EM. Sequence analysis of exonis $1,2,3$, 4 and 5 of the HLA-B5/35 cross-reacting group. Tissue Antigens $2002 ; 60: 224-34$.

20. Cox ST, McWhinnie AJ, Robinson $J$ et al. Cloning and sequencing full-length HLA-B and $-\mathrm{C}$ genes. Tissue Antigens 2003;61:20-48.

21. Voorter CEM, Vlies van der SA, Berg wan den-Loonen EM. Sequence-based typing of HLA-B: the B7 cross-reacting group. Tissue Antigens 2000;56:356-62.

22. Miller $S A$, Dykes DD, Polesky HF. A simple salting out procedure for extracting DNA from human nucleated cells. Nucl Acids Res 198: $16: 1215$. 
$76 \mid$ chapter 4

23. Bunce $\mathrm{M}$. Barnardo MCNM, Welsh $\mathrm{K}$. Improvements in HLA-C typing using sequencespecific primers $(\mathrm{PCR}-\mathrm{SSP}$ ) including definition of $\mathrm{HLA}-\mathrm{CW} 9$ and $C W 10$ and a new allele $H L A-$ "Cw7/dv". Tissue Antigens 1994;44:200-3.

24. Vies van der $S A$, Voorter CEM. Berg van den-Loonen EM. $A$ reliable and efficient high resolution typing method for HLA-C using sequence-based typing. Tissue Antigens 1998;52: 558-68.

25. Voorter CEM, Rozemuller EH, Bruyn de-Geraets D. Zwan van der AW, Tilanus MGJ, Berg van den-Loonen EM. Comparison of DRB sequence-based typing using different strategies. Tissue Antigens 1997:49:471-6.

26. Woorter CEM, Bruyn de-Geraets D, Berg wan den-Loonen EM. High-resolution HLA typing for the DRB3/4/5 genes by sequence-based typing. Tissue Antigens 1997:50:283-90.

27. Voorter CEM, KIK MC, Berg van den-Loonen EM. High-resolution HLA typing for the DQB1 gene by sequence-based kyping. Tissue Antigens 1998;51:80-7.

28. Voorter CEM, Sweisen WTN, Berg van den-Loonen EM. Intron sequences of HLA-B"73. Tissue Antigens 2001:57:463-8.

29. Cereb $N$, Kong $Y_{1}$ Lee $S$, Maye $P$, Yang $S Y$, Nucleotide sequences of MHC class I intrans 1 . 2 , and 3 in humans and intron 2 in nonhuman primates. Tissue Antigens 1996;47:498-511.

30. Swelsen WTN, Voorter CEM, Berg wan den-Loonen EM. Polymorphism of intron 4 in HLA-A, $B$, and $-C$ genes. Tissue Antigens 2003;61:475-B3.

31. Yao $Z$, Volgger $A$, Scholz $S$, Albert ED. Sequence polymorphism in the HLA-B promoter region. Immunogenetics 1995:41:343-53.

32. Summers CW. Hampson VJ, Taylor GM. HLA class I non-coding nucleotide sequences, 1992. Eur J Immunogenet 1993;20:201-40.

33. Gomez-Casado $E$, Vargas-Alarcon $G$, Martinez Laso $J$ et al Evolutionary relationships between HLA-B alleles as indicated by an analysis of intron sequences. Tissue Antigens $1999: 53: 453-60$.

34. Gomez-Casado E, Vargas-Alarcon G, Martinez Laso J et al. Generation of the HLA-B35, -B5, $-B 16$, and B15 groups of alleles studied by intron 1 and 2 sequence anallysis. Immunogenetics 1997:46:469-76. 


\section{Chapter 5}

Elucidation of exon 1, 4, and 5 sequences of 39 infrequent HLA-B alleles

Wendy TN Swelsen, Christina EM Voorter, Kang Yuen Chak and Ella M van den Berg-Loonen

Human immunology 2005;66:543-553 


\section{Abstract}

Mor than 590 human letukocyte aintigen (HLA)-B alleles have been identified by sequence analysis. Although the polymorphic exon 2 and 3 sequences of all HLA-B alleles are described, the sequences of the other exons of a number of infrequent $B$-alleles are unknown.

In this study, the exon 1,4 andfor 5 sequences of 39 different HLA-B alleles were elucidated by allele-specific sequencing. Overall, these exon sequences showed identity with the majority of the known sequences from the corresponding allele groups, except for four alleles $B^{*} 4010, B^{*} 4415$ $B^{*} 4416$ and $B^{*} 5606$. The exon 1 sequence of $B^{*} 4010$ had nucleotide differences with all $B^{*} 40$ alleles, but was identical to the $\mathrm{B}^{\star} 54,{ }^{*} 55,{ }^{*} 56$ and ${ }^{*} 59$ allele groups. $\mathrm{B}^{*} 4416$ differed from $B^{*} 440201$ at position 988 , which was previously considered a conserved position. $B^{*} 4415$ showed exon 1,4 and 5 sequences deviating from the other $B^{*} 44$ alleles, but identical to $B^{*} 4501$. The exon 1 and 4 sequences of $B^{*} 5606$ differed from other $B^{*} 56$ alleles, but were in complete agreement with $B^{*} 7801$. The deviating exon sequences of $B^{*} 4415$ and $B^{*} 5606$ confirmed the evolutionary arigin of these alleles suggested by the sequences of exons 2 and 3 . The polymorphism observed in exons 1,4 and 5 merely reflects the lineage-specificity of HLA-B. 


\section{Introduction}

The major histocompatibility complex (MHC) presents the most extensive allelic polymorphism of all human genes. The diversity of both class I and II human leukocyte antigen (HLA) genes is thought to originate through a high selective pressure that enables the population to cope more efficiently with different pathogens through the antigen peptide binding region.

HLA-B is the most polymorphic of the HLA loci. More than 590 HLA-B alleles have been identified by sequence analysis'. The polymorphic exon 2 and 3 sequences of all HLA-B alleles are known. These regions are the current minimum sequence requirements for the assignment of an official allele name by the WHO Nomenclature Committee for factors of the HLA system ${ }^{2}$. Exons 2 and 3 encode the polymorphic protein domains $\alpha 1$ and $\alpha 2$, that are responsible for peptide binding and recognition by both $T$ and natural killer cells ${ }^{3-5}$.

The degree of polymorphism outside these regions is not well investigated, neither is the role of such polymorphisms. Exon 1 encodes the leader peptide, which is cleaved from the mature HLA protein after transport across the endoplasmatic reticulum. Part of the leader peptide of class I binds to HLA-E, which then migrates to the cell surface where it interacts with receptors on natural killer or $T$ cells $^{6-8}$. Exon 4 encodes the $\alpha 3$ domain, which plays an important role in the CD8 binding, the peptide loading complex and the interaction with $\beta 2$ microglobulin $^{9-11}$. CD8 binding affects cytotoxic $T$ cell recognition, whereas interaction with $\beta 2$ microglobulin is required for correct folding of the HLA protein ${ }^{12,13}$. Mutations in the $\alpha 3$ domain have shown to result in CD8 binding affinity variation, reduced cell surface expression and variation in peptide binding loading efficiency ${ }^{11,4-18}$. The transmembrane domain encoded by exon 5 was shown to be important for cell surface stability, which was modulated by transmembrane domain length variation ${ }^{19}$.

The exon 1,4 and 5 sequences of a number of infrequent HLA-B alleles are unknown. In the present study, the exon 1,4 and/or 5 sequences of 39 of such $\mathrm{B}$-alleles were elucidated. The exon 1 sequence was determined for $31 \mathrm{~B}$ alleles and the exon 4 and 5 sequence for 29 and 35 B-alleles, respectively. The sequences were elucidated by allele-specific sequencing in both forward and reverse direction. Findings were compared with known sequences and evolutionary origin of the concerning allele. 


\section{Materials and methods}

\section{Samples}

A total of 39 individuals were investigated for their HLA-B alleles. Sequencebased typing (SBT) was performed by heterozygous sequencing of exons 2 and 3, extended with allele-specific sequencing and/or sequencing of other exons if necessary ${ }^{20-22}$. The individuals typed were quality control samples, blood bank donors and patients waiting for a transplant and their familly members. The unknown exon 1,4 and 5 sequences were elucidated, except exons 4 and 5 of $B^{\star} 140601$ and exon 5 of $B^{*} 4035$ because of lack of material. DNA was isolated from fresh heparinized blood or from lymphocytes stored in liquid nitrogen, either by the "salting out" extraction procedure as described by Miller et all, ${ }^{23}$ or by using QIA-AMP kits following the suppliers protocol (Qiagen, Westburg, Leusden, the Netherlands). Concentration and purity of DNA samples were measured at optical densities of 260 and $280 \mathrm{~nm}$.

\section{Primers and approach}

The exon 1, 4 and 5 sequences of the different HLA-B alleles were elucidated by both forward and reverse allele-specific sequencing. The location and sequence of the amplification and sequencing primers used for exons 1,4 and 5 are shown in table 5.1. All primers were designed locally. Because of the solid-phase approach forward sequencing required a 3 ' biotinylated amplification primer, whereas for reverse sequencing a 5 biotinylated primer was needed. The Cy-5 labeled sequencing primers were located internally of the polymerase chain reaction (PCR) products to ensure specific sequencing. If an unexpected nucleotide sequence was detected, the exon 1.4 or 5 sequence of the specific allele was confirmed in another individual positively typed for that allele or, if such an individual was not available, additional forward sequencing of the same individual was performed. In four cases $\left(B^{*} 1506, B^{*} 1527, B^{*} 1537\right.$ and $B^{*} 4012$ ) the exon 1,4 and/or 5 sequence had to be elucidated by heterozygous sequencing because the second B-allele of the individual belonged to the same allele group.

The amplification of exon 1 was performed using one B-locus specific $5^{\prime}$ primer located in the $5^{\prime}$ untranslated region combined with an allele-specific $3^{\prime}$ primer located in exon 2 or introns 1 or 2 . Exons 4 and 5 were amplified together using an allele-specific $5^{\prime}$ primer located in exons 2,3 or 4 or intron 3 and a B-locus specific $3^{\prime}$ primer located in exon 7 . The allele-specific primers used were dependent on the combination of HLA-B alleles present in the individual. One forward sequencing reaction was sufficient to obtain reliable results for exons 1 and 5 of all B-alleles. For exon 4 , two different forward sequencing primers were needed in a number of instances to obtain complete sequences, one 
located in intron 3 (B01039c) and one in the middle of exon 4 (B02161c). Reverse sequencing was performed with one sequencing primer for exons 1 and 5 and if needed two sequencing primers for exon 4 .

Table 5.1 Location and sequence of primers used for amplification and sequencing of exons 1.4 and 5 of HLA-B.

\begin{tabular}{|c|c|c|c|}
\hline Name & Sequence & Location & Position $^{1}$ \\
\hline $5^{*} B 98044$ & CCTGCGGAACCTGCGCG & $\mathrm{E2}$ & $431-447$ \\
\hline $5^{8} \mathrm{~B} 99022$ & GTCGGGTCCTTCTTCCAGG & 5'UT & $-153-135$ \\
\hline $5^{\prime} \mathrm{BD} 1015$ & TGTTCCCCGCTCAGAGACTC & 13 & $1369-1388$ \\
\hline $5^{*} \mathrm{BO} 1020$ & GTCCTAGGGTGTCCCATGAG & 13 & $1508-1527$ \\
\hline $5^{\prime} \mathrm{BO} 1021$ & GTCCTAGGGTGTCCCATGAA & 13 & $1508-1527$ \\
\hline $5^{\prime} \mathrm{BO} 1022$ & TCTGTGCCCCTTCCCCACA & 13 & $1450-1468$ \\
\hline $5^{\prime} \mathrm{B0} 1023$ & TCTGTGCCCCTTCCCCACC & 13 & $1450-1468$ \\
\hline $5^{*} \mathrm{B01024}$ & TGGGTGGTCCTAGGGTGTG & 13 & $1502-1520$ \\
\hline $5^{8} \mathrm{~B} 01047$ & GCCAGGGTCTCACACTTGG & 12/E3 & $712-730$ \\
\hline $5^{\circ} \mathrm{B01048}$ & GGGCCAGGGTCTCACATCA & $12 / E 3$ & $710-728$ \\
\hline $5^{\prime \prime} 801050$ & AYGTGACCCACCACCCCA & E4 & $1582-1599$ \\
\hline $5^{\prime \prime} \mathrm{B02023}$ & AGCCTACCTGGAGGGCGA & E3 & $916-933$ \\
\hline $5^{\prime \prime} \mathrm{B02024}$ & AGCCTACCTGGAGGGCCT & E3 & $916-933$ \\
\hline $5^{1} \mathrm{~B} 02025$ & GAACCTACCTGGAGGGCAC & E3 & $915-933$ \\
\hline $5^{n} \mathrm{~B} 04031$ & TGGGAGGCGGCCCGTGA & E3 & $884-900$ \\
\hline $3^{n} \mathrm{~B} 96133$ & ACTGAAAATGAAACCGGGTAAAC & 12 & $617-639$ \\
\hline $3^{n} 1898062$ & GCTCTGGTTGTAGTAGCGGA & E2 & $445-464$ \\
\hline $3^{n} \mathrm{~B} 98063$ & TTGTAGTAGCGGCGCAGGT & $E 2$ & $439-457$ \\
\hline $3^{\prime \prime} \mathrm{B00025}$ & TCCCGGCGCGGCTCCTCA & 11 & $146-163$ \\
\hline $3^{\prime \prime} 1800027$ & CGGCGCGGCTCCCCGG & 11 & $145-160$ \\
\hline $3^{\prime \prime} B 01006$ & CGGCGCCCGCGGCTCCT & $E 2$ & $334-350$ \\
\hline $3^{\prime \prime} \mathrm{B0} 1008$ & TGGCGCCCGGGGCTCCG & E2 & $334-350$ \\
\hline $3^{\prime} B 01009$ & CGTCCACGTAGCCCACGGT & E2 & $270-288$ \\
\hline $3^{\prime} B 01010$ & CGTCCACGTAGCCCACTGC & E2 & $270-288$ \\
\hline $3^{\prime} \mathrm{B0} 1051$ & AGCCCTGGGCACTGTCO & E7 & $2638-2654$ \\
\hline $3^{\mathrm{B}} \mathrm{B02020}$ & GTCGAACCTCACGAACTGG & E2 & $293-31$ y \\
\hline $3^{\prime} \mathrm{B02021}$ & GTCGAACCTCACGAACTGC & E2 & $293-311$ \\
\hline $3^{\mathrm{B}} \mathrm{B02022}$ & CGTCCACGTAGCCCACTGA & $\mathrm{E} 2$ & $270-288$ \\
\hline $5^{\prime \prime} \mathrm{Cg8042c}$ & ${ }^{25}$ ACCCACCCGGACTC & $5 \mathrm{UT}$ & $-35-22$ \\
\hline $5^{\circ} \mathrm{B01039c}$ & AGATGCAAAGCGCCTG & 13 & $1528-1543$ \\
\hline $5^{\prime} \mathrm{B02096 \textrm {C }}$ & ${ }^{5} \mathrm{AGCAGGGTCAGGGCC}$ & 14 & $1897-1911$ \\
\hline $5^{\prime \prime} \mathrm{BO2161 \textrm {C }}$ & ${ }^{45}$ CACACTGACCTGGCA & E4 & $1658-1672$ \\
\hline $3^{\mathrm{B}} \mathrm{B} 99027 \mathrm{c}$ & ${ }^{5} \mathrm{CTGCGCCCCCGCCT}$ & 11 & $128-44$ \\
\hline $3^{n} B 01041 c$ & TCOTGCTTTCCCTGAG & 14 & $1874-1889$ \\
\hline $3^{n} B 01045 c$ & ${ }^{c y 5}$ CCCCAGTGGGACAAG & 15 & $2087-2101$ \\
\hline $3^{\prime \prime} \mathrm{BO} 4030 \mathrm{C}$ & ${ }^{15} \mathrm{CCACTTCTGGAAGGTTC}$ & E4 & $1735-7151$ \\
\hline
\end{tabular}

"The exon and intron nucleotide positions are numbered according to the genomic alignments of $H L A-B^{3}$ 


\section{Allele-specific sequencing of exons 1,4 and 5}

The PCR conditions used were identical to the conditions for SBT of HLA-B exons 2 and 3 , as previously described ${ }^{20.21}$. In brief, the PCR reaction was carried out in a final volume of $60 \mu \mathrm{l}$, containing $600 \mathrm{ng}$ DNA, $2.0 \mathrm{U}$ Amplitaq DNA polymerase, 20 pmol of biotinylated primer, 40 pmol of unlabeled primer, PCR buffer according to Bunce ${ }^{24}(67 \mathrm{mM}$ Tris- $-\mathrm{HCl}, \mathrm{pH} 8.8,16.6 \mathrm{mM}$ $\left(\mathrm{NH}_{4}\right)_{2} \mathrm{SO}_{4,} 0.01 \%$ ( $\mathrm{v} / \mathrm{V}$ ) Tween 20 ), $1.5 \mathrm{mM} \mathrm{MgCl}, 6 \mu \mathrm{g}$ cresol red, $200 \mu \mathrm{M}$ each dNTP and $5 \%$ glycerol. The cycling conditions consisted of an initial denaturation at $96^{\circ} \mathrm{C}$ for $2 \mathrm{~min}, 10$ cycles of $10 \mathrm{~s}$ at $94^{\circ} \mathrm{C}, 60 \mathrm{~s}$ at $65^{\circ} \mathrm{C}$ and 30 cycles of $10 \mathrm{~s}$ at $94^{\circ} \mathrm{C}, 50 \mathrm{~s}$ at $61^{\circ} \mathrm{C}$ and $30 \mathrm{~s}$ at $72^{\circ} \mathrm{C}$, followed by a final extension at $72^{\circ} \mathrm{C}$ for $10 \mathrm{~min}$. The presence of PCR products with the correct base length was checked by agarose gel electrophoresis. A solid-phase sequencing approach was used as previously described ${ }^{25-28}$. The non-biotinylated DNA strand was removed by alkaline denaturation after attachment of $40 \mu \mathrm{l}$ of biotinylated product to streptavidin-coated beads (Dynal, ITK diagnostics, Uithoorn, the Netherlands). After annealing of the Cy-5 labeled sequencing primer, the sequencing reaction was performed at $37^{\circ} \mathrm{C}$ for $5 \mathrm{~min}$ with T7 DNA polymerase. The samples were heated at $90^{\circ} \mathrm{C}$ for $2 \mathrm{~min}$, prior to loading on a $0.5 \mathrm{~mm}$-thick $6 \%$ polyacrylamide-7M urea gel. Electrophoresis was performed on an ALFexpress automated sequencer (Pharmacia Biotech, Uppsala, Sweden). Sequence data were processed automatically and evaluated manually.

\section{Results}

Thirty-nine individuals were sequenced for exons 1,4 and/or 5 . The different HLA-B alleles for which the exon sequences were elucidated are shown in table 5.2, together with the Genbank accession numbers obtained. The exon 1 sequence was determined for $31 \mathrm{~B}$-alleles, the exon 4 and 5 sequences for 29 and $35 \mathrm{~B}$-alleles, respectively. Alignments of the elucidated exon 1, 4 and 5 sequences of the different HLA-B alleles to the consensus sequence of $B^{*} 070201$ are shown in figures $5.1-5.3$, respectively. For comparison the sequences of the first alleles of each allele group to which the B-alleles belong are given in italic.

\section{Exon 1}

The exon 1 sequence was elucidated by allele-specific sequencing in 28 individuals. In three individuals positive for $B^{*} 1506, B^{*} 1527$ and $B^{*} 1537$, both HLA-B alleles were sequenced simultaneously because the second B-allele of 
the individual belonged to the same $B^{*} 15$ group. In these cases forward sequencing showed a homozygous sequence, but with reverse sequencing an out-of-phase alignment was detected. A deletion in intron 1 at genomic position 85 has been reported to be present in several $B^{*} 15$ alleles ${ }^{1}$. The out-of-phase alignment might therefore be due to the presence of this deletion in one of the $B^{*} 15$ alleles and not in the other. Resolving the out-of-phase sequence resulted in a sequence identical to the one obtained by forward sequencing. In figure 5.1 the obtained exon 1 sequences are compared to the exon 1 sequences of the first alleles of the allele groups to which the HLA-B alleles belonged. These sequences correspond to the sequence of most alleles within that allele group, except for $B^{*} 40$. The $B^{*} 40$ group thas two distinctive sequence motifs, and therefore the sequence of $B^{*} 4002$ is also shown. In 3 of 31 cases the exon 1 sequence was not identical to the group sequence; $B^{*} 4010, B^{*} 4415$ and $B^{*} 5606$. The $B^{*} 4010$ allele had four nucleotide differences with $B^{*} 400101$ (positions 25, 41, 44 and 72 ), resulting in three amino acid substitutions (-16 $V \rightarrow L,-11 \quad S \rightarrow W$ and $-10 \quad A \rightarrow G)$, and also four differences with $B^{*} 4002$ (positions 15, 48, 49 and 72) with one amino acid change $(-8 \mathrm{~V} \rightarrow L)$. The $B^{*} 4415$ allele differed from $B^{*} 440201$ at positions $15,25,41,44,48$ and 49 , giving rise to four amino acid differences $(-16 \mathrm{~L} \rightarrow \mathrm{V},-11 \mathrm{~W} \rightarrow \mathrm{S},-10 \mathrm{G} \rightarrow \mathrm{A}$ and -8 $V \rightarrow L)$. The $B^{*} 5606$ allele showed differences with other $B^{*} 56$ alleles at positions $15,25,48$ and 49 resulting in two amino acid substitutions $(-16 \mathrm{~L} \rightarrow \mathrm{V}$ and $-8 \mathrm{~L} \rightarrow \mathrm{V})$. $\mathrm{B}^{*} 4035$ showed seven nucleotide differences with $\mathrm{B}^{*} 400101$ (positions $15,25,41,44,48,49$ and 72 ), leading to four amino acid substitutions $(-16 \mathrm{~V} \rightarrow \mathrm{L},-11 \mathrm{~S} \rightarrow \mathrm{W},-10 \mathrm{~A} \rightarrow \mathrm{G}$ and $-8 \mathrm{~L} \rightarrow \mathrm{V})$, but no differences with $B^{*} 4002$ were observed.

\section{Exon 4}

In figure 5.2 the exon 4 sequences of the 29 different HLA-B alleles were aligned and compared with the sequences of the corresponding allele group. The exon 4 sequences were identical to the sequences of the allele group, with the exception of $B^{*} 4415$ and $B^{*} 5606$. The $B^{*} 4415$ allele showed one nucleotide difference at position 668 , a $C$, where most other $B^{*} 44$ alleles had a $T$. This resulted in an amino acid change at residue 199 of the mature protein from valine (GTC) to alanine (GCC). The exon 4 sequence of $B * 5606$ revealed a difference with all other known $B^{\star} 56$ alleles at position 652 , changing an $A$ into a $G$, and thereby substituting isoleucine to valine. The $B^{*} 4035$ allele was found to be identical to $B^{*} 4002$, with one mismatch with $B^{*} 400101$ at position 693 . The alleles $B^{*} 4002$ and $B^{*} 4035$ had a $C$, whereas $B^{*} 400101$ had a $T$. This nucleotide difference resulted in a silent mutation at codon 207. Both codon sequences GGT and GGC represent the amino acid glycine. 
Table 5.2 The different HLA-B alletes of which the exon 1,4 and/or 5 sequences were elucidated and the corresponding EMBL accession numbers.

\begin{tabular}{|c|c|c|c|c|c|c|}
\hline \multirow{2}{*}{$\frac{\text { No }}{1}$} & \multirow{2}{*}{$\frac{\text { HLA-B: }}{0709}$} & \multirow[t]{2}{*}{ Exon 1} & \multirow{2}{*}{$\frac{\text { Exan } 4}{x}$} & \multirow{2}{*}{$\frac{\text { Exan } 5}{x}$} & \multicolumn{2}{|c|}{ EMBL accession number ${ }^{\prime}$} \\
\hline & & & & & A 1850166 & \\
\hline 2 & 0715 & $x$ & $x$ & $x$ & A. 8550138 & A.J850167 \\
\hline 3 & 0726 & $x$ & $x$ & $x$ & A.s850139 & A.J850168 \\
\hline 4 & 0804 & $x$ & $x$ & $x$ & AJ850140 & A 1850169 \\
\hline 5 & 0809 & $x$ & & $x$ & A.j850141 & A.J850192 \\
\hline 6 & 1403 & $x$ & & $x$ & A 8850142 & A. 850193 \\
\hline 7 & 140601 & $x$ & & & AJ850143 & \\
\hline 8 & $1506^{2}$ & $x$ & & & & \\
\hline 9 & 1507 & $x$ & & & A 1850144 & \\
\hline 10 & $1527^{2}$ & $x$ & * & $x$ & & \\
\hline 11 & 1529 & & & $x$ & A. 850194 & \\
\hline 12 & 1530 & $x$ & $x$ & $x$ & Av850145 & AJ 850170 \\
\hline 13 & 4535 & $x$ & $x$ & $x$ & A. 850146 & A.J85017" \\
\hline 14 & $1537^{2}$ & $x$ & $x$ & $x$ & & \\
\hline 15 & 1539 & $x$ & $x$ & $x$ & A.J850147 & AJ850172 \\
\hline 16 & 1557 & & $x$ & $x$ & AJ 850173 & \\
\hline 17 & 1809 & $x$ & $x$ & $x$ & AJ 850148 & AJ850174 \\
\hline 18 & 3528 & & $x$ & $x$ & AJ 850175 & \\
\hline 19 & 3530 & $x$ & $x$ & x & AJ850149 & AJ 850176 \\
\hline 20 & 380202 & $x$ & $x$ & $x$ & AJ 850150 & A. 1850177 \\
\hline 21 & 4010 & $x$ & & $x$ & AJ850151 & A.J850195 \\
\hline 22 & $4012^{2}$ & & $x$ & $x$ & & \\
\hline 23 & 4016 & & $x$ & $x$ & AJ850178 & \\
\hline 24 & 4035 & $x$ & $x$ & & A.J850152 & A 4850179 \\
\hline 25 & 4202 & $x$ & $x$ & $x$ & AJ850153 & A.J850180 \\
\hline 26 & 4406 & & $x$ & $x$ & A.J85018\# & \\
\hline 27 & 4415 & $x$ & $x$ & $x$ & A.J850154 & A.J850182 \\
\hline 28 & 4416 & $x$ & & $x$ & AJ850155 & AJ850196 \\
\hline 29 & 4702 & & & $x$ & A. 850197 & \\
\hline 30 & 4703 & $x$ & $x$ & $x$ & A. 850156 & A.J850183 \\
\hline 31 & 4803 & $x$ & $x$ & $x$ & A.4850157 & AJI850184 \\
\hline 32 & 4903 & $x$ & * & $x$ & A.l850158 & A J850\#85 \\
\hline 33 & $5111 \mathrm{~N}$ & $x$ & & $x$ & AJ850159 & AJJ850 98 \\
\hline 34 & 5509 & $x$ & $x$ & $x$ & A.J850160 & AJ850186 \\
\hline 35 & 5604 & x & $x$ & $x$ & A.J850161 & AJ850187 \\
\hline 36 & 5606 & $x$ & $x$ & $x$ & A. 1850162 & AJ850188 \\
\hline 37 & 5607 & $x$ & $x$ & $x$ & A. 1850163 & A.J850189 \\
\hline 38 & 670102 & $x$ & $x$ & $x$ & AJl850164 & A.J850190 \\
\hline 39 & 8201 & $x$ & $x$ & $x$ & AJ 850165 & AJ 850191 \\
\hline
\end{tabular}

The sequences of exon 4 and 5 were joined in one EMBL accession number

${ }^{2}$ No accession numbers available because of heterozygous sequencing

\section{Exon 5}

Exon 5 was coamplified with exon 4 and sequenced for the B-alleles. Figure 5.3 shows the elucidated exon 5 sequences of 35 different HLA-B alleles aligned to the exon 5 sequences of the allele groups. All exon 5 sequences were identical to the known exon 5 sequences with the exception of $B^{*} 4415$ 
and $B^{*} 4416$. The $B^{*} 4415$ allele showed three nucleotide differences with $B^{*} 440201$ at positions 900,916 and 985 , leading to two amino acid changes (282 $\mathrm{V} \rightarrow 1$ and $305 \mathrm{~A} \rightarrow \mathrm{T}$ ). $\mathrm{B}^{*} 4416$ showed one nucleotide difference with $B^{*} 440201$ at position 988 , a previously considered conserved position. The difference changed codon 306 of the mature protein from GTG to CTG, which resulted in an amino acid substitution from valine to leucine.

10

20

30

40

50

60

70

B*070201

B*0715

$8 * 0726$

$B * 0801$

B. 0804

$B * 0809$

B*1401

$B * 1403$

อ* 10601

B*150101

$B * 1506$

B*11507

$B * 1527$

B* 1530

B*1535

$B * 1537$

$B * 1539$

B*180101

B*1809

B* 350101

$B * 3530$

B* 3801

B*380202

B*400101

E. 4002

B* 4010

$B * 4035$

D) 4201

B*4202

B. 40201

$B * 415$

B. 416

B* 470101

403

B $4 B Q 1$

B 4003

B*4901

18.4903

B*510101

B* $511 \mathrm{~N}$

$B * 5501$

B* 509

$B * 5601$

D. 604

B. 5506

5607

B*670101

B*670102

$B * 8.202$

急: 801

ATGCTGGTCATGGCGCCCCGAACCGTCCTCCTGCTGCTCTCGGCGGCCCTGGCOCTGALCGAGACCTGGGCCO

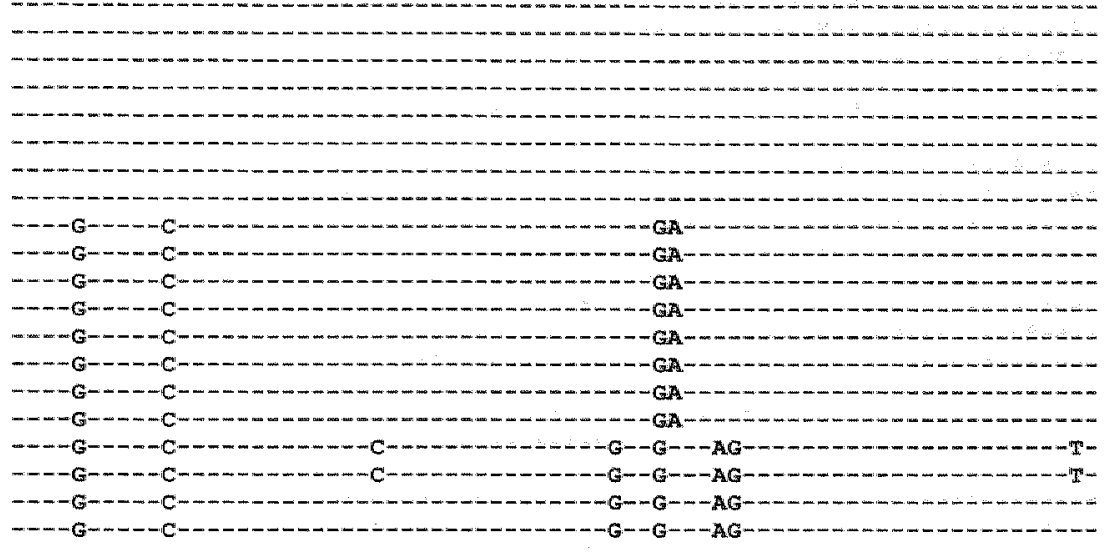

-

$-\mathrm{G}-\mathrm{C}-\mathrm{A}-\mathrm{A}-\mathrm{C}$

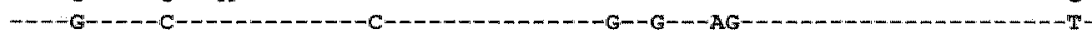

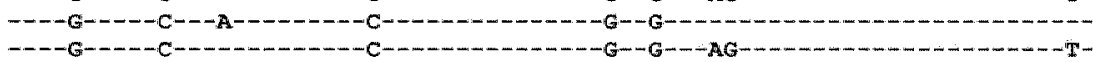

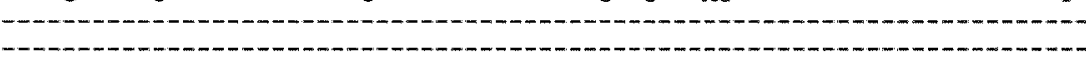

$-\mathrm{G}-\mathrm{G}-\mathrm{C}-\mathrm{G}-\mathrm{G}-\mathrm{C}-\mathrm{C}-\mathrm{A}-\mathrm{C}-\mathrm{C}-\mathrm{C}-\mathrm{C}-\mathrm{G}-\mathrm{AG}-\mathrm{G}$

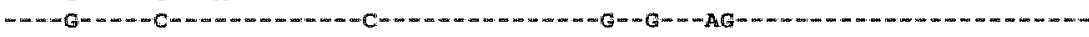

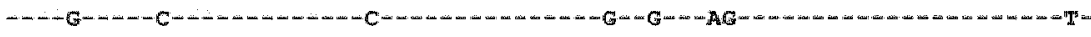

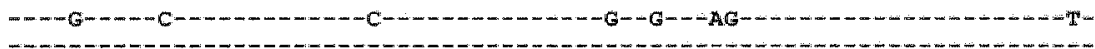

-

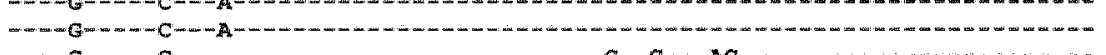

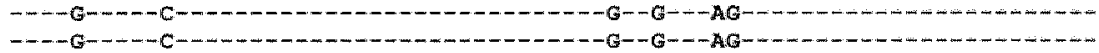

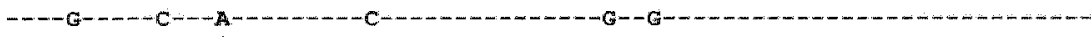

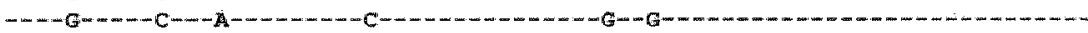

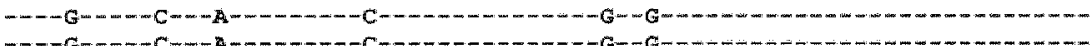

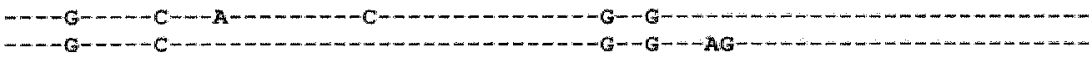

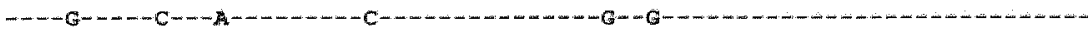

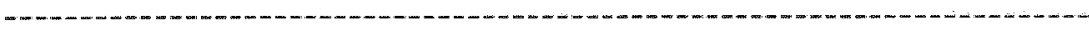

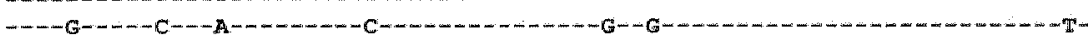

Figure 5.1 Alignment of the eluciclated exon 1 sequences of 31 HLA-B alleles with the consensus sequence $B^{*} 070201$. For comparison the sequences of the first alleles of each allele group to which the B-alleles belong are given in italic. Nucleotide identity with the consensus sequence is indicated by dashes and numbers above the sequences refer to the nucleotide positions of the coding sequence. 


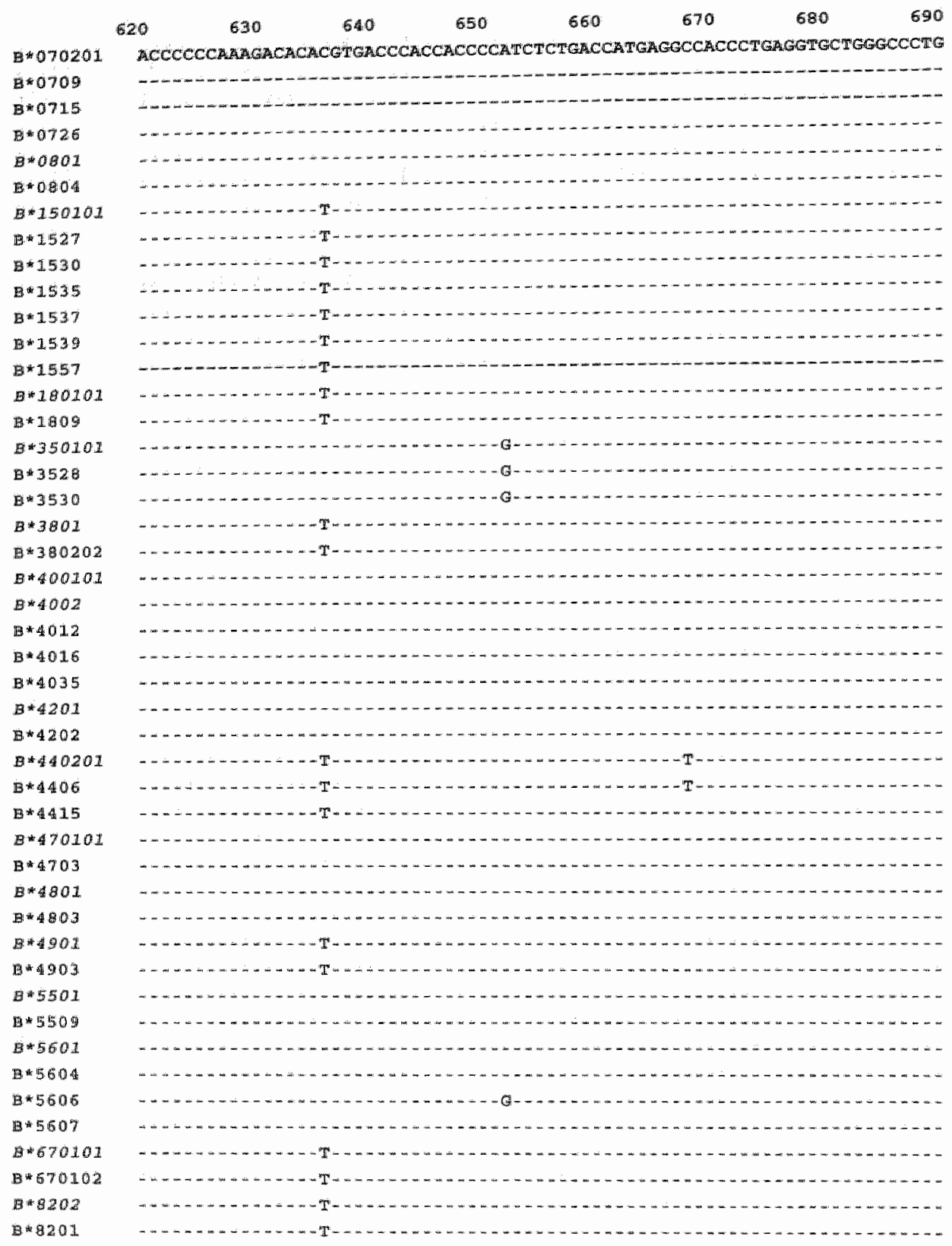

Figure 5.2 continued 
$\begin{array}{lllllll}700 & 710 & 720 & 730 & 740 & 750 & 760\end{array}$

B*070201 GGTTCTACCCHCOCAGATCACACTGACCTGCAGCGGGATGGOGAGACCAAMCTCAGGACACTOMGC

B. $* 0709$

B*0715

B-0726

B*10801

$B \times 0804$

B. 150101

$B * 1527$

B* 1530

B 1535

B*1537

B*1539

요 1557

B. 180101

B*1809

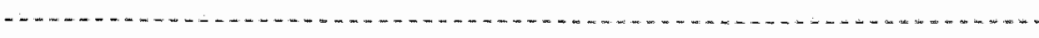

B: 350101

E*3528

$B * 3530$

B. 3801

B*380202

B.400101

B) 1002

B*4012

$B * 4016$

$B * 4035$

B) 4201

$B * 4202$

B*440201

B*4.06

$B+4415$

B. 40201

B*4703

B) 401

B. 803

E*4901

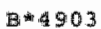

B. 5501

-5509

$B * 5601$

B*5604

B. 5606

D4507

$-\infty$

$-\infty \mathrm{C}$

$--$

$-C$

$-\mathrm{C}-\cdots$

$-C$

$C=\ldots$

$--c$

C. $+\cdots$

$-\mathrm{C}$

c....

$\therefore \mathrm{C}$

$-c-\ldots$

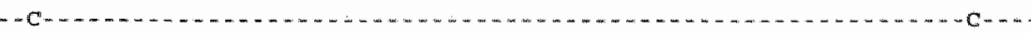

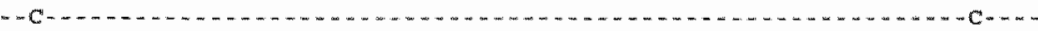

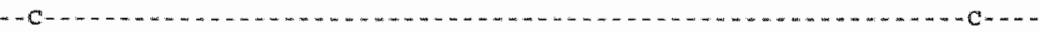

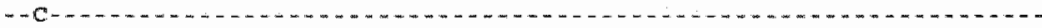

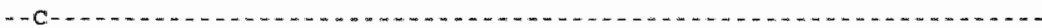

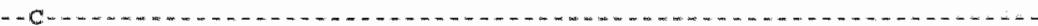

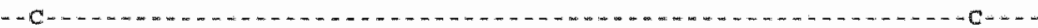

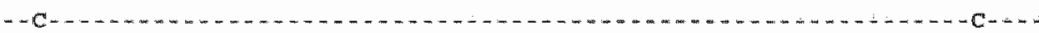

-

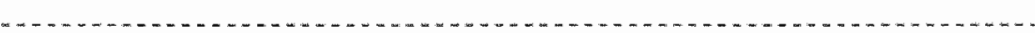

C

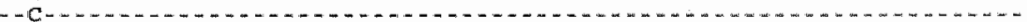

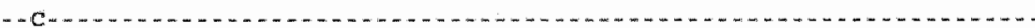

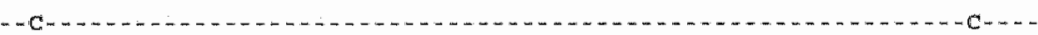

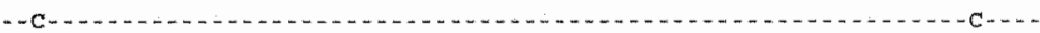

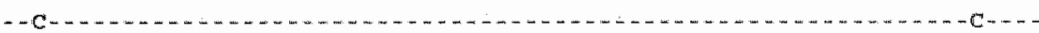

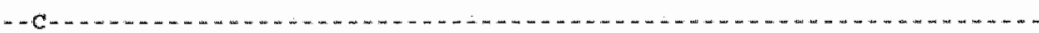

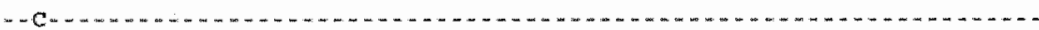

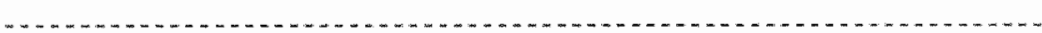

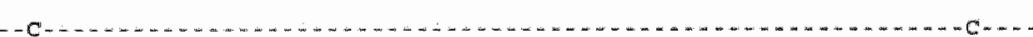

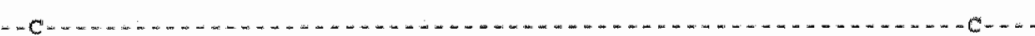

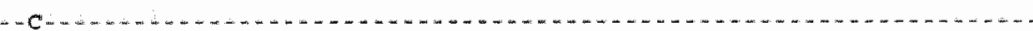

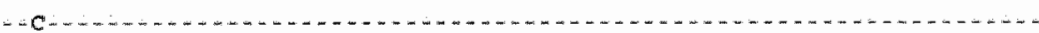

- - C C

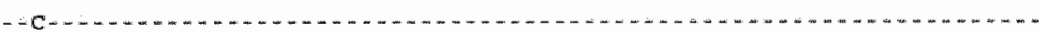

- - C $-\mathrm{C}-\ldots$.

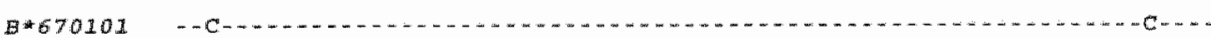

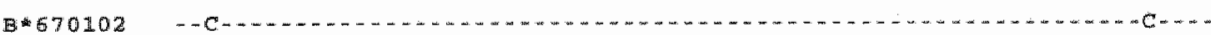

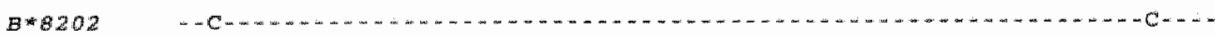

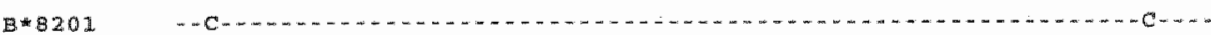

Figure 5.2 continued 


\section{0}

P*070201

B) 0709

为40715

B. 0726

a*081

20004

E*150101

B*1527

E 1530

- 1535

स* 153 \%

(2) 153 5

B* 1557

Q 10101

B*2.09

B*30101

B. 352

- 3530

B* 380.2

D:30202

100101

E*4002

2*4012

$B=4016$

D*4035

$B * 4201$

B. 4202

E.40201

B*4406

E* 4425

B*470101

B).4703

BN4801

A* 4803

Ex山. 4001

1*4. 901

a. 5501

(2) 5509

- 560.1

14*3604

15 5606

D*5607

4 470101

2.60102

E* 202

[- 8201

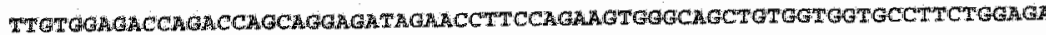
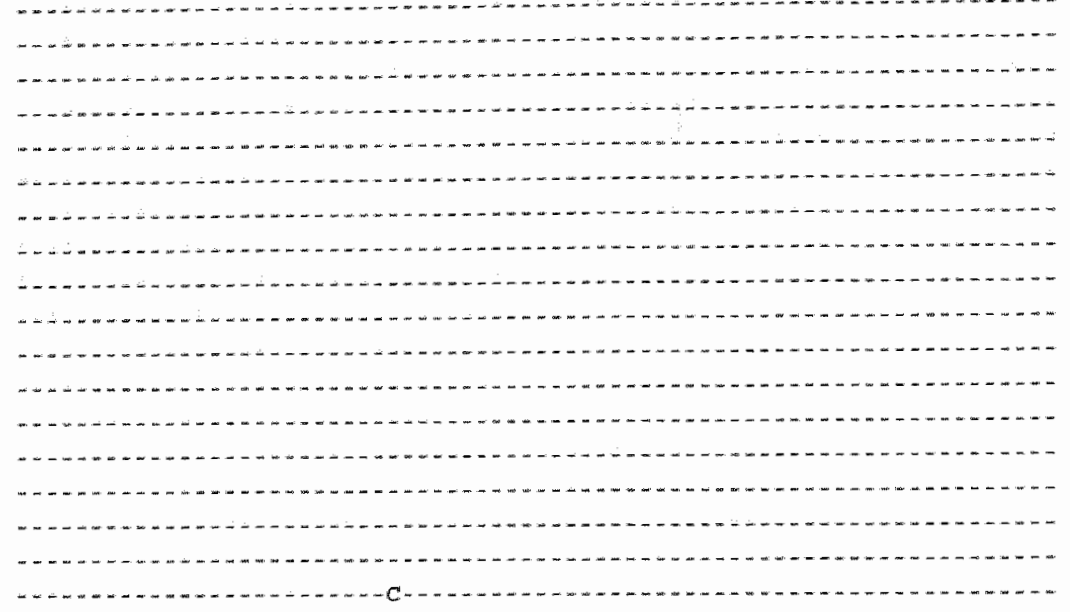

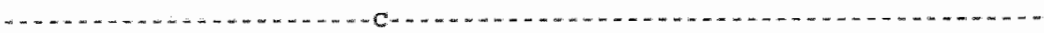

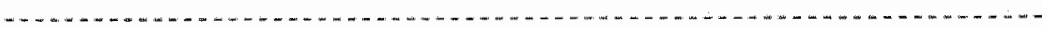

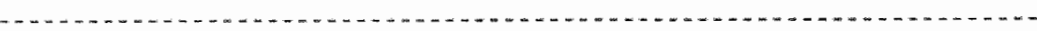

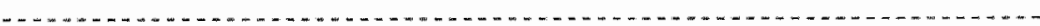

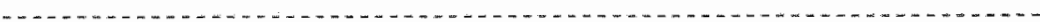
б

$-A$

$-1$

Figure 5.2 continued 


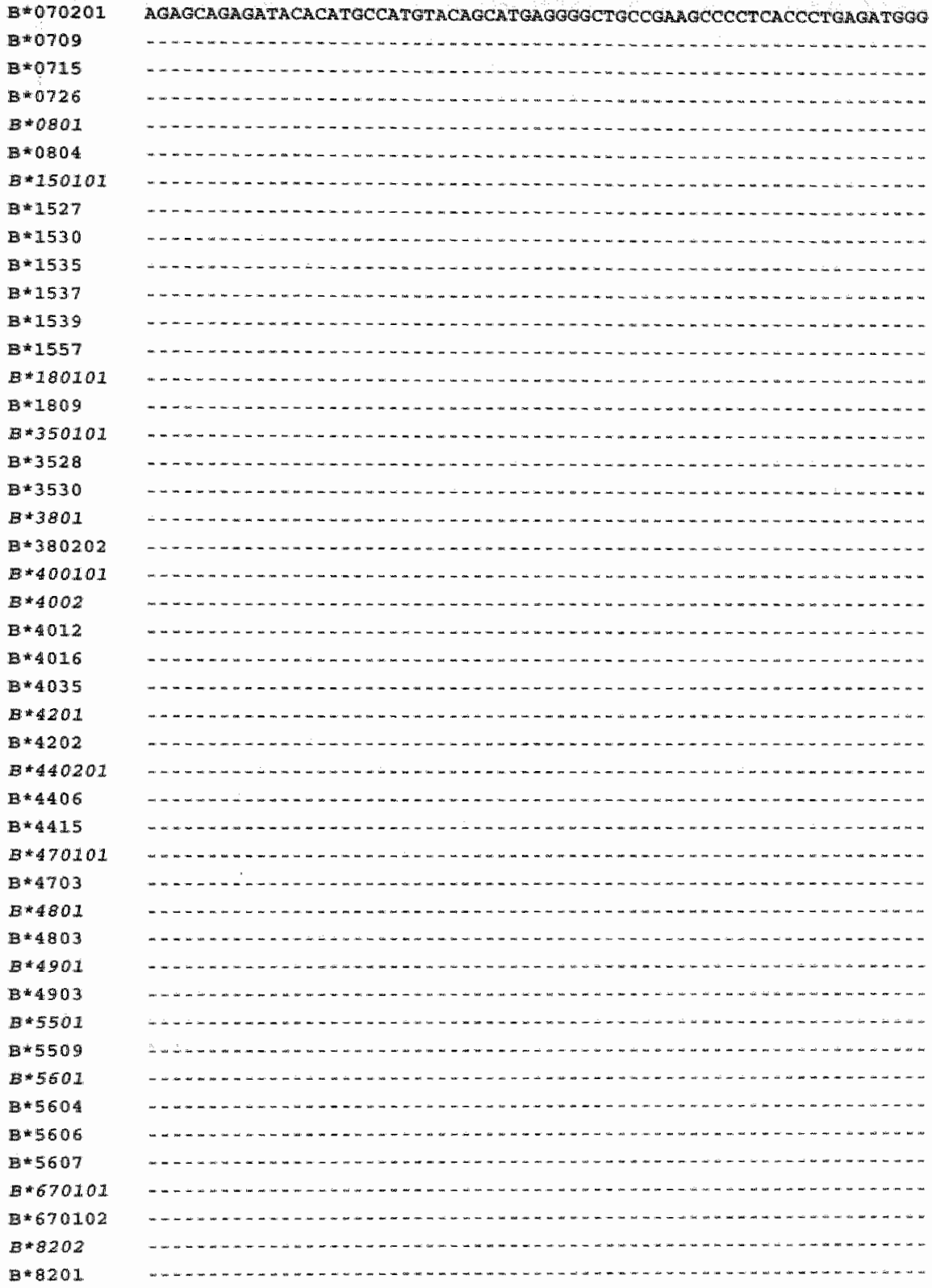

Figure 5.2 Alignment of the elucidated exon 4 sequences of $29 \mathrm{HLA}$-B alleles with the consensus sequence $B^{*} 070201$. For comparison the sequences of the first alleles of each allete group to which the B-alleles belong are given in italic. Nucleotide identity with the consensus sequence is indicated by dashes and numbers above the sequences refer to the nucleotide positions of the coding sequence. 
$900 \quad 910 \quad 20 \quad 930 \quad 940 \quad 950 \quad 960$

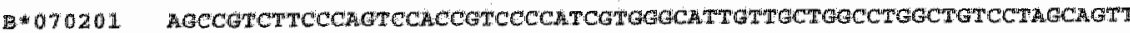
B*0709 $40 \% 15$ D. 0726 a 001 : 0089 D: 1201 E*1403 B. 150101 E* 1527 E* 1529 $\$ 1530$ \& 1535 E*1.53\% Bu. 1539 B. 1557 201010.1 . $* 1809$ 20 350101 स*13 328 B: 353 5*3801 B * 390202 100101 स3 4010 - 4012 $3 * 4016$ B*4201 E. 4202 B 40201 B. HA 406 B-415

B*416 D*470101 B*4702 E* 703 B*4501

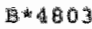
곤.1901. 争 4903 10. 10201 D $5111 \mathrm{~N}$ B. 5501 4. 550 . a 3601 D 5500 B) 5606 g.t567 8.670101 6.670102 49202 18.201

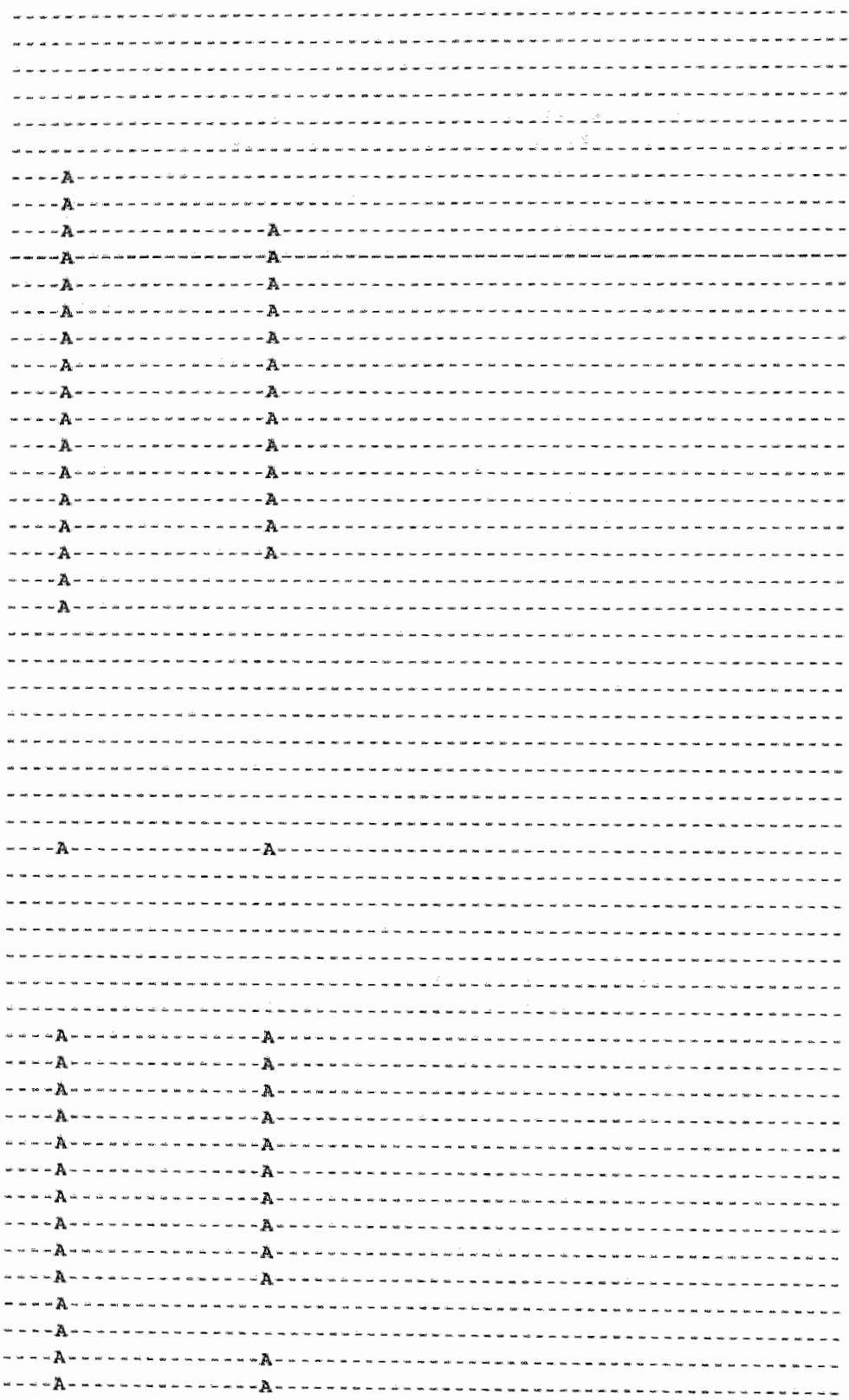

Figure 5.3 continued 


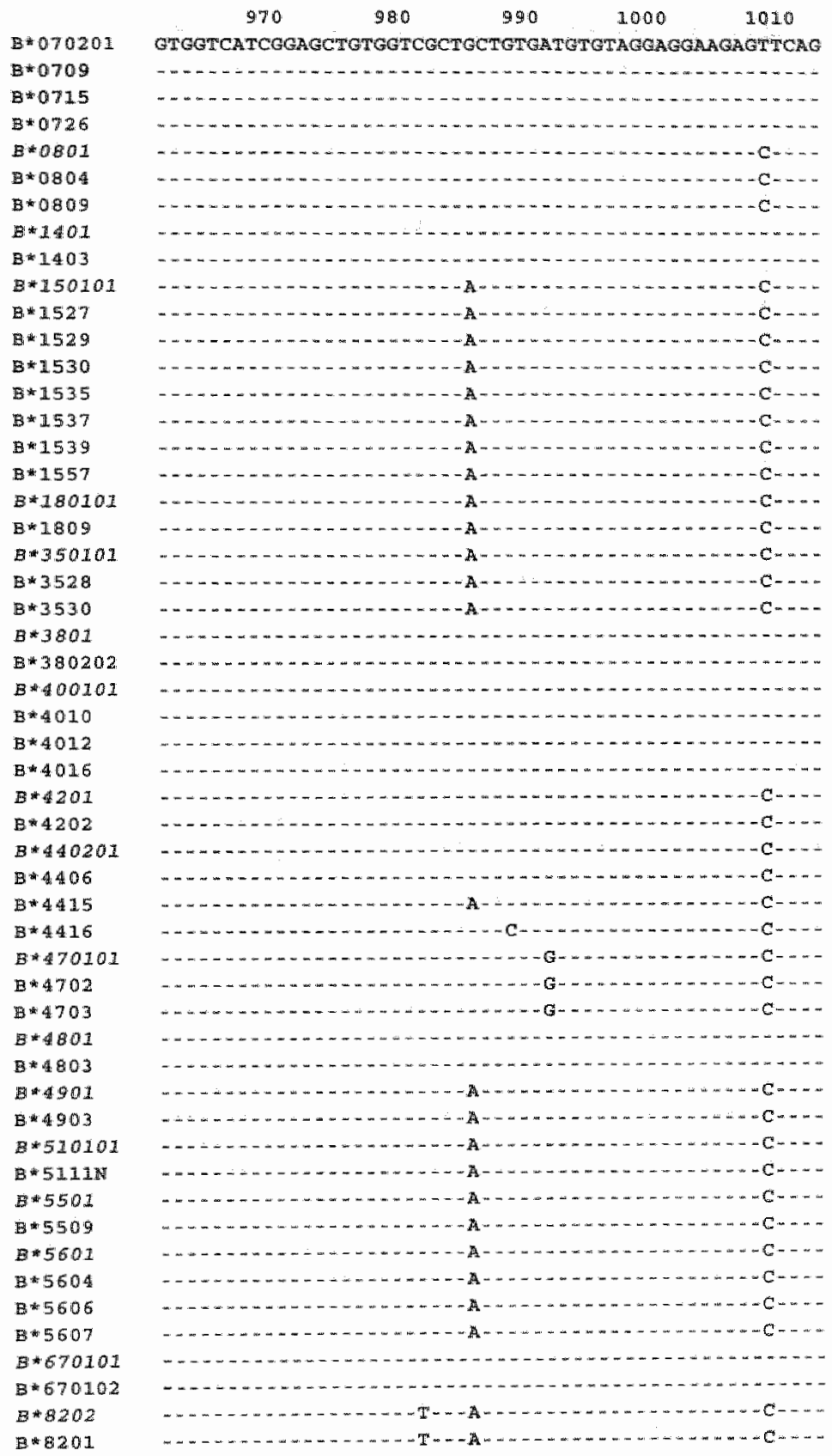

Figure 5.3 Alignment of the elucidated exon 5 sequences of 35 HLA.B alleles with the consensus sequence $B^{-070201}$. For comparison the sequences of the first alleles of ach allele group to which the B-alleles belong are given in italic. Nucleotide identity with the consensus sequence is indicated by dashes and numbers above the sequences refer to the nucleotide positions of the coding sequence 


\section{Discussion}

In this study, the exon 1 sequences of 31 infrequent HLA-B alleles and the exon 4 and 5 sequences of 29 and 35 different HLA-B alleles, respectively, were elucidated by allele-specific sequencing in both forward and reverse direction. In total, 39 HLA-B alleles were sequenced for exon 1, 4 and/or 5 . Overall, the elucidated exon 1,4 and 5 sequences of the rare HLA-B alleles showed identity with the sequences of the allele groups, except for four alleles namely: $B^{*} 4010, B^{*} 4415, B^{*} 4416$ and $B^{*} 5606$. The differences of these alleles were confirmed in a second individual or by an additional forward sequencing reaction.

At present, 592 different HLA-B alleles have been identified by sequence analysis ${ }^{1}$. The polymorphic exon 2 and 3 sequences of all B-alleles are known. However, the exon 1,4 and 5 sequences of approximately $65 \%$ of these alleles are still unknown most probably the result of their low frequency in the population. In this study, the exon 1, 4 and/or 5 sequence of 39 different Balleles were elucidated, representing all alleles with unknown sequences present in our databank.

In four individuals positive for the alleles $B^{*} 1506, B^{\star} 1527, B^{*} 1537$ and $B^{*} 4012$, the exon 1, 4 and/or 5 sequence was elucidated by simultaneous sequencing of both HLA-B alleles because they belonged to the same allele group. No individuals positive for these alleles and with a second allele belonging to another group were available. Up to now, no allelic drop-out or preferential amplification was ever shown with the allele-specific primers used in this study. In case of the $B^{*} 15$ alleles the reverse sequencing of exon 1 showed an out-ofphase alignment, clearly demonstrating that both $B^{*} 15$ alleles were amplified and sequenced. Because identical primers were used for forward and reverse amplification, the obtained forward sequence is most likely also derived from both alleles, although no differences were noticed between them.

The $B^{*} 15$ positive individuals in which reverse sequencing showed out-of-

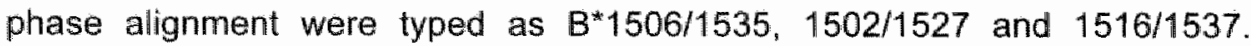
Whether the deletion in intron 1 at the genomic position 85 is present in the $B^{*} 15$ alleles of which the sequences were elucidated or the other $B^{*} 15$ alleles is not known. At present, only the intron 1 sequences of $B * 1501,{ }^{*} 1504$ and "1517 are described". The $B^{*} 1517$ allele possesses the deletion, whereas in $B^{*} 1501$ and $B^{* 1504}$ the deletion is not present. The deletion is also found in alleles from the allele groups $B^{*} 07,{ }^{*} 08,{ }^{*} 14,{ }^{*} 38,{ }^{*} 39,{ }^{*} 40,{ }^{*} 41,{ }^{*} 42,{ }^{*} 45,{ }^{*} 48$, ${ }^{*} 49, * 50,{ }^{*} 54,{ }^{*} 55,{ }^{*} 57$ and ${ }^{*} 73^{1,29}$. Also within the $B^{*} 40$ group, alleles with and 
without the deletion were identified as was the case for the $B^{*} 15$ group. The $B^{*} 4001$ allele has the deletion, whereas it is lacking in $B^{*} 4002$ and $B^{*} 4006^{1.29}$.

Within the $B^{*} 40$ allele group two groups can be distinguished based on both coding and non-coding sequences ${ }^{1,29,30}$. Also by serology two distinct antigens are identified, $\mathrm{B} 60$ and $\mathrm{B} 61^{31}$. The $\mathrm{B} 60$ corresponds to the alleles with sequences identical or similar to $B^{*} 4001$, whereas $B 61$ is encoded by the $B^{*} 4002$ allele group. Exon sequences were elucidated of four infrequent $B^{*} 40$ alleles, namely $B^{*} 4010, B^{*} 4012, B^{*} 4016$ and $B^{*} 4035$.

The exon 4 and 5 sequences of $B^{*} 4012$ and * 4016 were determined and found to be identical to the $B^{*} 4001$ group, as were their exons $1-3$ sequences (figures 5.2 and 5.3$)^{1,32-34}$.

The $B^{*} 4035$ allele belonged to the $B^{*} 4002$ group based on exons 2 and $3^{1,35}$. The exon 1 and 4 sequences were also found to be identical to the sequences of $B^{*} 4002$, as illustrated in the figures 5.1 and 5.2. The deletion in intron 1 at position 85 lacking in $B^{\star} 4002$ was also absent in $B^{\star} 4035$.

The $B^{*} 4010$ allele could be classified as an allele from the $B^{*} 4001$ group for exons 2,3 and $4^{1,36}$. The exon 5 sequence of this allele determined in this study was identical to the exon 5 sequence of the $B^{*} 4001$ group (figure 5.3 ). However, the exon 1 sequence was found to differ from both the $B^{*} 4001$ group and the $B^{*} 4002$ group (figure 5.1). The sequence was identical to the exon 1 sequences of the $B^{*} 54, B^{*} 55, B^{*} 56, B^{*} 59$ allele groups ${ }^{\uparrow}$. Furthermore, elucidation of the intron 1 sequence of $B^{*} 4010$ revealed also differences with both $B^{*} 4001$ and $B^{*} 4002$, but is identical to the sequences of $B^{*} 5401$, ${ }^{*} 5501$, *5509, 5512 and ${ }^{*} 5601^{1,29,37}$. Therefore, the $B^{*} 4010$ allele most probably arose by allele conversion of $B^{*} 400101$ with the exon 1 , intron 1 and part of exon 2 derived from an allele of the $B^{\star} 54, B^{*} 55, B^{*} 56$ or $B^{*} 59$ group (table 5.3).

Table 5.3 HLA-B alleles with deviating sequences and most likely origin.

\begin{tabular}{|c|c|c|c|c|}
\hline Allele & Mechanism" & Region & Putative acceptor & Putative donor \\
\hline$B^{*} 4010$ & conversion & exon 1 part of exon 2 & $B^{*} 400101$ & $\mathrm{~B} * 54 / 55 * 56 / 59$ \\
\hline$B^{*} 4415$ & conversion & $309-319$ & $\mathrm{~B}^{*} 4501$ & Bw4 positive allele \\
\hline$B^{*} 4416$ & point mutation & 988 & & \\
\hline$B^{\star 5} 5606$ & conversion & $272-283$ & $B^{ \pm} 7801$ & $\begin{array}{l}B^{*} 07 / * 42 /^{*} 54 / * 55 ! \\
56 / * 67^{*} 81 / 1^{*} 82\end{array}$ \\
\hline
\end{tabular}

The most likely mechanism is indicated

The sequences of exons 1,4 and 5 of the $B^{*} 4415$ allele showed nucleotide differences with $B^{*} 440201$ (figures $5.1-5.3$ ). Exons 2 and 3 were previously found to be highly different from $B^{*} 440201$ with 14 nucleotide differences 
between them ${ }^{38}$. These exons of $B^{*} 4415$ were more closely related to $B^{*} 4501$, showing only six nucleotide differences. The differences were all located in the Bw4/Bw6 sequence region ${ }^{3 B}$. Therefore, Williams et al. proposed that the HLA$B^{*} 4415$ allele was derived from $B^{*} 4501$ through a conversion event with a sequence bearing a Bw4 epitope ${ }^{38}$. Our exon 1,4 and 5 sequences of $B^{*} 4415$ support the finding of Williams et al., the sequences were in complete agreement with the sequence of $B^{*} 4501^{1}$ (table 5.3).

In exon 5 the $B^{*} 4416$ allele had one mismatch with $B^{*} 440201$ at nucleotide position 988 (figure 5.3). Codon 306 of the mature protein changed from GTG to $C T G$, which resulted in an amino acid change from valine to leucine. None of the HLA-B alleles has a $C$ at position 988 , nor has any of the HLA-A and $-C$ alleles. ${ }^{4}$. The new polymorphic position most probably arose by point mutation (table 5.3).

In a previous study, we have described the $B^{*} 5606$ allele and identified the sequences of exons 2 and 3 as well as the sequence of intron 1. Already then, we had hypothesized that the allele was derived from $B^{*} 7801$, rather than $B^{*} 5601$, based on the similarity of the exon and intron sequences with that specific allele ${ }^{37,39}$. Elucidation of the exon 1,4 and 5 sequences of $B^{*} 5606$ in this study further supports this hypothesis. For exons 1 and 4 nucleotide differences were detected between $B^{\star} 5606$ and $B^{*} 5601$ (figures 5.1 and 5.2 ) ${ }^{37}$. Both exon sequences of $B^{\star} 5606$ were identical to the exon sequences of $B^{*} 7801^{1}$. No differences in the exon 5 sequence identified for $B^{*} 5606$ and the sequence of $B^{*} 5601$ were noticed (figure 5.3). This might be due to the fact that the exon 5 sequences of $B^{*} 5601$ and $B^{*} 7801$ are identical ${ }^{1}$. The exon 1,4 and 5 sequences of $B^{*} 5606$ elucidated in this study are in complete agreement with the suggestion that $B^{*} 5606$ arose from $B^{*} 7801$ by allele conversion with an exchanged segment, encompassing at least residues $272-283$, derived from $B^{*} 07,{ }^{*} 42,{ }^{*} 54,{ }^{*} 55,{ }^{*} 56,{ }^{*} 67,{ }^{*} 81$ or ${ }^{*} 82^{1,37,39}$ (table 5.3).

The polymorphism of HLA-B is mainly located in exons 2 and 3 , which code for the extracellular $\alpha 1$ and $\propto 2$ domains and include the antigenic peptide binding site. The variability in the $\alpha 1$ and $\alpha 2$ domain residues is thought to originate from a high selective pressure to cope more efficiently with different pathogens through the peptide binding region. Although suggested in several studies, the question remains whether polymorphism outside exons 2 and 3 has any functional impact ${ }^{11,14-19}$. The exon 1,4 and 5 sequences of approximately $65 \%$ of the HLA-B alleles are unknown at present. Elucidating these sequences can reveal that there is more polymorphism present outside exons 2 and 3 than previously thought. Nucleotide differences in these regions are mainly found between different allele groups, but not between different alleles within the 
same group. The polymorphism in these exons merely reflects the lineagespecificity, with sequence heterogeneity between but not within a lineage, in contrast to exons 2 and 3 in which there is a high degree of polymorphism within a lineage. In this study, several alleles showed exon 1, 4 and/or 5 sequences not fitting with the sequences of the corresponding allele groups. In one case the nucleotide differences found, suggested an allele conversion with an allele from another lineage. In another case a point mutation most probably occurred. In two cases the nucleotide differences with the allele group corresponded with the proposed evolutionary origin of the allele. Elucidation of the sequences of other exons thus plays an important role in the identification or confirmation of the evolutionary origin of alleles.

\section{Acknowledgements}

The authors would like to thank Marie Lau (UCLA, International Cell Exchange, Los Angeles, USA), Thibaut Gervais (Brussels, Belgium) and Bouke Hepkema (Groningen, the Netherlands) for kindly providing material. Furthermore, the authors wish to thank Lisette Groeneveld, Christel Meertens, Eva Mulkers, Fausto Palusci, Melanie Schnijderberg and Dennis Visser (Maastricht, the Netherlands) for technical help and Diana van Bakel and Mieke Haemers (Maastricht, the Netherlands) for secretarial assistance. 


\section{References}

4. Robinson J. Waller MJ, Parham $P$, Groof de $\mathbb{N}$, Bontrop $R$, Kennedy LJ, Stoehr P, Marsh SGE: MGTIHLA and IMGT/MHC: sequence databases for the study of the major histocompatibility complex. Nucleic Acids Res 2003;31(1);311.

2. Marsh $S G E$, Abert ED, Bodmer WF, Bontrop RE, Dupont $B$, Erlich HA, Geraghty DE, Hansen $J_{1}$, Mach $B_{0}$, Mayr WR, Parham P, Petersdorf EW, Sasazuki T, Schreuder GMTh, Strominger $J$ L. Svejgard A. Terasaki Pl: Nomenclature for factors of the HLA system, 2002. Tissue Antigens 2002;60(5):407.

3. Townsend A, Bodmer $H$ : Antigen recognition by class l-restricted T lymphocytes. Annu Rev Immunol 1989:7:601.

4. Long EO, Rajagopalan S. HLA class I recognition by killer cell lg-like receptors. Immunology 2000;12:101.

5. Moretta A, Biassoni R, Bottino C, Pende D, Vitale M. Poggi A. Mingari MC, Moretta L: Major histocompatibility complex class 1 -specific receptors on human natural killer and $T$ lymphocyles. Immunol Rev 1997;155:105.

6. Garcia P, Llano M. Heredia de AB, Willberg CB, Caparrós E, Aparicio P, Braud VM, LópezBotet M: Human T cell receptor-mediated recognition of HLA-E. Eur $J$ Immunol 2002;32:936.

7. O'Cailaghan CA: Molecular basis of human natural killer cell recognition of HLA-E (human leucocyte antigen-E) and its relevance to clearance of pathogen-infected and tumour cells*. Clin Science 2000:99:9.

8. Braud VM, Allan DSJ, McMichael AJ: Functions of nonclassical MHC and non-MHC-encoded class I molecules. Curr Opin Immunol 1999:11:100.

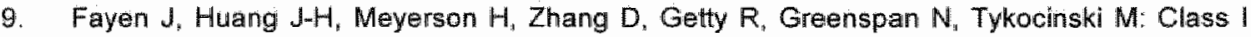
MHC alpha 3 domain can function as an independent structural unit to bind CD8 alpha. Mol linmunol 1995;32(4):267.

10. Bjorkman PJ, Saper MA, Samraoui B, Bennett WS, Strominger JL, Wiley DC: Structure of the human class I histocompatibility antigen, HLA-A2. Nature 1987;329:506.

11. Williams $A$, Au Peh $C$, Elliott $T$ : The cell biology of MHC class I antigen presentation. Tissue Antigens 2002;59(1):3.

12. Salter RD, Benjamin RJ, Wesley PK, Buxton SE, Garrett TP, Clayberger C, Krensiky AM, Norment AM, Littman DR, Parham P: A binding site for the T-cell co-receptor CD8 on the alpha 3 domain of HLA-A2. Nature 1990;345(6270):41.

13. Hill DM, Kasliwal T, Schwarz E, Hebert AM, Chen T, Gubina E, Zhang L, Kozlowski $S$ : A dominant negative Mutant B2-microglobulin blocks the extracellular folding of a major histocompatibility complex class I heavy chain. J Biol Chem 2003:278(8):5630.

14. Gao GF. Willoox BE, Wyer JR, Boulter JM, O'Callaghan C, Maenaka K, Stuart DI, Jones EY,

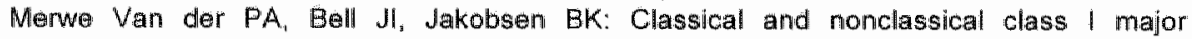
histocompatibility complex molecules exhibit subtle conformational differences that affect binding to $C D$ alpha alpha. $\mathrm{I}$ Biol Chem 2000;275:15232.

15. Salter $R D$, Norment $A M_{x}$ Chen $B P$, Clayberger $C_{0}$ Krensky $A M_{n}$ Littman $D R$, Parham $P$ : Polymorphism in the alpha 3 domain of HLA.A molecules affects binding to CD8. Nature 1989;338(6213):345.

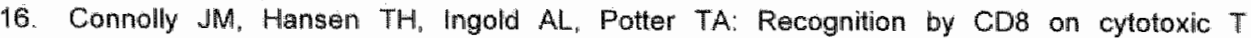
lymphocytes is ablated by several substitutions in the class 1 alpha 3 domain: CD8 and the Tcell receptor recognize the same class I molecule. Proc Natl Acad Sci USA 1990;87:2137.

17. Wesley PK, Clayberger C, Lyu S, Krensky AM: The CD8 coreceptor interaction with the alpha 3 domain of HLA class I is critical to the differentiation of human cytotoxic T-lymphocytes specific for HLA-A2 and HLA-CW4. Hum Immunol 1993;36:149.

18. Salter RD: Mutant HLA-A201 heavy chains with lowered affinity for beta2m are transported after growth at reduced temperatures. Hum timmunol 1992;35:40.

19. Osborn CK, Grigoriev V. Crew MD: Modulation of class I major histocompatibility complex antigen cell-surface stability by transmembrane domain length variation. Mol Immunol $1997 ; 34(11): 771$. 
20. Voarter CEM, Vlies van der SA, Berg van den-Loonen EM: Sequence-based typing of HLA-B: the $\mathrm{B} 7$ cross-reacting group. Tissue Antigens $2000 ; 56(4) ; 356$.

21. Swelsen WTN, Voorter CEM, Berg van den-Loonen EM: Sequence analysis of exons $1,2,3$, 4 and 5 of the HLA-B5/35 cross-reacting group. Tissue Antigens 2002;60(3):224.

22. Swelsen WTN, Voorter CEM, Berg-Loonen van den EM: Ambiguities of human leukocyte antigen-B resolved by sequence-based typing of exons 1,4 and 5 . Tissue Antigens $2004 ; 63(3): 248$.

23. Miller SA, Dykes DD, Polesky HF: A simple salting out procedure for extracting DNA from human nucleated cells. Nucl Acids Res 1988;16(3):1215.

24. Bunce $M$, Barnardo MCNM, Welsh Kl: Improvements in HLA-C typing using sequencespecific primers (PCR-SSP) including definition of HLA-Cw9 and Cw10 and a new allele HLA"Cw7/8v". Tissue Antigens 1994:44(3):200

25. Vlies van der SA, Voorter CEM. Berg van den-Loonen EM: A reliable and efficient high resolution typing method for HLA-C using sequence-based typing. Tissue Antigens $1998 ; 52: 558$

26. Voorter CEM, Rozemuller EH, Bruyn de-Geraets D, Zwan van der AW, Tillanus MGJ, Berg vam denmLoonen EM: Comparison of DRB sequence-based typing using different strategies. Tissue Antigens 1997:49(5):471

27. Voorter $C E M$, Bruyn de-Geraets $D$, Berg van den-Loonen EM: High-resolution HLA typing for the DRB3/4/5 genes by sequence-based typing. Tissue Antigens 1997;50(3):283.

28. Voorter CEM, Kik MC, Berg wan den-Loonen EM: High-resolution HLA typing for the DQB1 gene by sequence-based typing. Tissue Antigens 1998:51(1):80.

29. Cereb N, Kong Y, Lee S, Maye P, Yang SY: Nucleotide sequences of MHC class I introns 1 , 2, and 3 in humans and intron 2 in nonhuman primates. Tissue Antigens 1996;47(6):498.

30. Swelsen WTN, Voorter CEM, Berg van den-Loonen EM: Polymorphism of intron 4 in HLA-A, $B$, and $-C$ genes. Tissue Antigens 2003;61(6):475.

31. Schreuder GMTh, Hurley CK, Marsh SGE, Lau M, Maiers M, Kollman C, Norreen H: The HLA dictionary 1999: a summary of HLA-A, $-B,-C,-D R B 1 / 3 / 4 / 5,-D Q B 1$ alleles and their association with serologically defined HLA-A, $-B,-C,-D R$ and $-D Q$ antigens. Tissue Antigens $1999 ; 54: 409$.

32. Gourley IS, Wu J, Bassinger S, Montoya GD, Yee J, Griffith BB, Kearns J, Mckeen M, Birkos S, Williams TM, Kamoun M: A novel HLA-B* 40 allele and novel exon 1 sequences of two $\mathrm{B}^{*} 40$ alleles identified in potential marrow donors. Tissue Antigens 2000;55:374.

33. Ellis JM, Mack SJ, Leke RFG, Quakyi I, Johnson AH, Hurfey CK: Diversity is demonstrated in class I HLA-A and HLA.m alleles in Cameroon, Africa: description of HLA-A*03012, "2612, "3006 and HLA-B*1403,"4016,"4703. Tissue Antigens 2000;56:291.

34. Elsner H-A, O'Brien BJ, Bryan CF, Meyer JA. Diederich DA, Pierce GE, Lau M, Terasaki PI, Blasczyk R: HLA-B*4012: a now allele with unique serological features. Tissue Antigens 2000;56(2):180.

35. Voorter CEM, Hepkema BG, Lems SPM, Berg wan den-Loonen EM: Identification of a new HLA-B*40 variant, $B^{*} 4035$. Tissue Antigens 2003;61(1);89.

36. Steiner $N_{1} N g$ J, Bush J, Hartzman RJ, Johnston-Dow $L_{8}$ Katovich Hurley $C$ : HLA-B alleles associated with the B15 serologically defined antigens. Hum Immunol 1997;56(2):84.

37. Voorter CEM, Hepkema BG, Mulkers EMT, Lems SPM, Berg-Loonen van EM: Identification of two new HLA-B22 variants, HLA-B*5509 and $B^{*} 5606$. Tissue Antigens 2001;58(1):42.

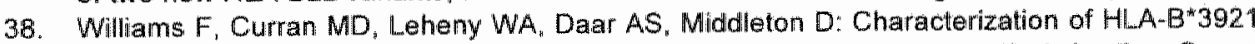
and confirmation of HLA-B* 4415 , two variant HLA-B alleles identified in the Omani population. Tissue Antigens 2000;56:376.

39. Anholts JDH. Kemps-Mols $B$, Verduijn $W$, Oudshoorn $M$, Schreuder GMTh: Three newly identified HLA-B alleles: $B^{*} 5124, B^{*} 5306, B^{*} 5307$ and confirmation of $B^{*} 0809$ and $B^{*} 5606$. Tissue Antigens $2001 ; 58(1): 38$. 
69 


\section{Chapter 6}

$B^{*} 27$ in molecular diagnostics: Impact of new alleles and polymorphism outside exons 2 and 3

Christina EM Voorter, Wendy TN Swelsen and Ella M van den Berg-Loonen Tissue Antigens 2002;60:25-35 


\section{Abstract}

HLA $B^{2} 27$ is known to be associated with ankylosing spondylitis and several methods have been applied to determine its presence or absence. In this report two molecular methods were used for detection of B*27. The polymerase chain reaction sequence-specific primer (PCR-SSP) method was performed to detect the presence or absence of $B^{*} 27$, whereas the sequence-based typing method (SBT) was used to identify the B' 27 subtype.

The PCR-SSP method used to detect $B^{*} 27$ was updated to enable the detection of all $B^{*} 27$ alleles. The typing results obtained by this method were compared with the serological typings of 262 individuals. Fifty of them were found to be $B^{*} 27$ positive by PCR-SSP, 46 also showed positive serological reactions with B27 specific sera. The four discrepancies were the result of the presence of $B^{*} 2712$ in three individuals and $B * 2715$ in one individual both alleles showed no serological reactions with $B 27$ specific antisera

With SBT the sequences of exons 1 through 4 were determined to unequivocally assign the $B^{*} 27$ alleles. Eleven different subtypes were detected in 78 individuals, including three new $B^{\text {ta }} 27$ alleles: $B^{*} 27054, B^{*} 2715$ and $B^{*} 2797$. The allele $B^{*} 27054$ showed an allelic drop out when exon 3 was amplified. Three differences with $\mathrm{B}^{*} 27052$ were demonstrated; one in exon 1 , one in intron 1 and one in intron 2, the latter one being responsible for the allelic drop out. The $B^{*} 2715$ allele was serologically not detectable with several B27 specific sera, but showed Bw4 positive reactions. The sequence of $B^{*} 2715$ showed two mismatches with $B^{*} 2704$. The sequence of $B^{*} 2717$ showed one mismatch with $B^{*} 27052$ at position $248(A \rightarrow T)$, which was considered to be a conserved position in all $\mathrm{B}$ alleles. 


\section{Introduction}

The major histocompatibility complex (MHC) class I antigen HLA-B27 shows a strong association with ankylosing spondylitis and related spondyloarthropathies. The association was first noticed by Brewerton and others ${ }^{1,2}$ in 1973 and has since been confirmed in many studies. The relative risk for subjects carrying HLA-B27 is high in all populations studied ${ }^{3}$ and typing for HLA-B27 is a meaningful tool for the differential diagnosis of ankylosing spondylitis.

Different methods have been developed to type for HLA-B27. Although B27 was usually assigned by the microcytotoxicity technique (CDC) or by flow cytometry, molecular typing methods to establish the presence or absence of HLA-B ${ }^{*} 27$ are more and more preferred. DNA typing is potentially more accurate and there is no requirement for viable cells. The different molecular typing techniques that have been used for HLA-B ${ }^{\star} 27$ determination are ligation of probes ${ }^{4}$, PCR-restriction fragment length polymorphism (PCR-RFLP) ${ }^{5-7}$, PCR-sequence-specific primer analysis (PCR-SSP) $)^{8-14}$, hybridisation with sequence-specific oligonucleotides (PCR-SSO) $)^{13,15-17}$ and sequence-based typing (SBT) ${ }^{18,49}$. All these methods have to cope with the rapidly increasing allelic diversity that is observed for the HLA genes. The number of HLA-B*27 alleles increased from seven in 1994 to 27 in 2001 . The 27 alleles give rise to 25 different proteins, in two alleles silent mutations are present. The more common subtypes $B^{*} 2705,2704,2702$ and 2707 are known by epidemiological studies to be disease associated ${ }^{20}$. The other subtypes of HLA-B*27 are rare and only limited information on disease association is so far available.

In this study two molecular methods were used for the detection of $B^{*} 27$. The PCR-SSP method was performed to detect the presence or absence of $B^{*} 27$, whereas SBT was used to identify the $B^{*} 27$ subtype. The previously described SBT method for exons 2 and 3 of HLA-B ${ }^{21}$ was extended to exons 1 and 4 to enable correct assignment of all $B^{*} 27$ alleles. Three new alleles were identified: $B^{*} 27054, B^{*} 2715$ and $B^{*} 2717$. The increasing polymorphism within the $B^{*} 27$ allele group necessitates the regular update of the PCR-SSP method in order to be able to detect the presence or absence of all hitherto known $B^{*} 27$ alleles. 


\section{Materials and methods}

\section{Individuals}

PCR-SSP of $B^{\star} 27$ was performed for 262 individuals, which were also typed by serology. All were clinical requests to determine disease association.

SBT was performed for a different population of 78 individuals, including laboratory personnel, kidney patients and quality control samples. The majority of the samples was of Caucasian origin.

\section{Serological typing}

Antisera routinely used for the serological detection of B27 were local sera MS183, MS145, MS050 and MS052. Additional sera on an extended tray included Delforge (Bouillenne, Liege, Belgium), B-de H (Otten, Utrecht, the Netherlands) T863a (Gazit, Israël) en D567 (Den Dievel, Leuven, Belgium). Antisera used for Bw4 were MS058 (local), 43064.5 (Schreuder, Leiden, the Netherlands), and ABER168 (Dupont. Brussels, Belgium). Serological typing was performed by complement dependent cytotoxicity (CDC). $1 \mu \mathrm{l}$ antiserum and $1 \mu$ lymphocyte-suspension at a concentration of $4 \times 10^{6}$ cells $/ \mathrm{ml}$ were incubated for $30 \mathrm{~min}$ at $20^{\circ} \mathrm{C} .5 \mu \mathrm{rabbit}$ complement (Bio-scope Foundation, Leiden, the Netherlands) was added and incubated for $60 \mathrm{~min}$ at room temperature. Cell lysis was assessed by automated fluorescence ratio measurements using CFDA and propidiumiodine as labeling for intact and lysed cells, respectively.

\section{DNA isolation}

Genomic DNA was isolated from fresh heparinized blood or from liquid nitrogen stored lymphocytes either by the "salting out" extraction procedure as described by Miller et al. ${ }^{22}$ or by using QIA-AMP kits following the suppliers protocol (Qiagen, Westburg, Leusden, the Netherlands). Concentration and purity of DNA samples were measured at $260 \mathrm{~nm}$ and $260 / 280 \mathrm{~nm}$.

\section{Sequence-based typing of exons $1-4$}

Sequence-based typing of exons 2 and 3 of HLA-B was performed as described previously $y^{21}$. Both exons were amplified and sequenced separately using amplification primers located in the adjacent introns (96091,96133, $96125,96092)$. To unequivocally assign the alleles the sequences of exons 1 and 4 were determined in addition. For amplification of exon 1 a locus-specific $5^{\prime}$ primer, located in the untranslated region (99022), was combined with an allele-specific primer located in the Bw4 region (98062). This resulted in a PCR 
product of $618 \mathrm{bp}$. For exon 4 , the locus-specific 5 primer used for exon 3 amplification (96125) was combined with a locus-specific 3 ' primer located in exon 5 (96069) resulting in a 1350 bp PCR product. All primers are indicated in table 6.1.

Table 6.1 Nucleotide sequences and location of primers used for SBT and allele specific sequencing of exons 1-5.

\begin{tabular}{llllll}
\hline Name & $5^{\prime} / 3^{\prime \prime}$ & Nucleotide sequence & Location & Positions $^{\text {t }}$ \\
\hline 96069 & $3^{\prime}$ & CCACGATGGGGAYGGTGGA & E5 & $910-928$ \\
96091 & $5^{\prime}$ & GGGAGGAGCGAGGGGACCSCAG & 11 & $36-57$ \\
96092 & $3^{\prime}$ & GGAGGCCATCCCCGGCGACCTAT & 13 & $37-70$ \\
96125 & $5^{\prime}$ & TACCCGGTTTCATTTCAGTTG & 12 & $163-184$ \\
96133 & $3^{\prime}$ & ACTGAAAATGAAACGGGTAAAC & 12 & $160-177$ \\
97101 & $5^{\prime}$ & GGGGGCGCAGGACCCGG & 11 & $61-77$ \\
98004 & $5^{\prime}$ & TGCTGCTCTGGGGGGCAG & E1 & $32-49$ \\
98062 & $3^{\prime}$ & GCTCTGGTTGTAGTAGCGGA & E2 & $317-336$ \\
99022 & $5^{\prime}$ & GTCGGGTCCTTCTTCCAGG & $5 U T$ & $-153-135$ \\
01020 & $5^{\prime}$ & GTCCTAGGGTGTCCCATGAG & 13 & $594-613$ \\
01030 & $3^{\prime}$ & AGAGTAGCTCCCTCCTTITC & E6 & $1019-1038$ \\
\hline
\end{tabular}

'Nucleotide positions in the introns are numbered according to Cereb et all ${ }^{31}$

The amplification reaction was set up in a volume of $60 \mu$, containing $P C R$ buffer according to Bunce ${ }^{23}\left(67 \mathrm{mM}\right.$ Tris- $\mathrm{HCl}, \mathrm{pH} 8.8 ; 16.6 \mathrm{mM}\left(\mathrm{NH}_{4}\right)_{2} \mathrm{SO}_{4}$; $0.01 \%(\mathrm{v} / \mathrm{v})$ Tween 20; $1.5 \mathrm{mM} \mathrm{MgCl}$ ), $6 \mu \mathrm{g}$ cresol red, $200 \mu \mathrm{M}$ each dNTP. $5 \%$ glycerol, $20 \mathrm{pmol}$ of biotinylated primer, 40 pmol of unlabeled primer, 600 ng DNA and 2.0 U AmpliTaq polymerase. The cycle conditions using a 9600 Perkin Elmer Cycler consisted of an initial denaturation at $96^{\circ} \mathrm{C}$ for $2 \mathrm{~min}, 10$ cycles of $10 \mathrm{~s}$ at $94^{\circ} \mathrm{C}, 60 \mathrm{~s}$ at $65^{\circ} \mathrm{C}$, and 30 cycles of $10 \mathrm{~s}$ at $94^{\circ} \mathrm{C}, 50 \mathrm{~s}$ at $61^{\circ} \mathrm{C}$ and $30 \mathrm{~s}$ at $72^{\circ} \mathrm{C}$, followed by a final extension at $72^{\circ} \mathrm{C}$ for $10 \mathrm{~min}$. The $P C R$ reaction mixture was checked by agarose gel electrophoresis for the presence of PCR product with the correct length.

For the sequencing reaction a solid phase approach was used with one biotinylated primer in the amplification reaction and streptavidin coated beads in the sequencing reaction. Sequencing was accomplished by the Autoread sequencing kit (Amersham Pharmacia Biotech, Uppsala, Sweden) as previously described ${ }^{24-27}$. Sequence data were processed automatically and evaluated manually.

\section{Allele-specific sequencing of exons 1.5}

To determine the sequences of the three new alleles, allele-specific amplification was needed. Identical allele-specific primers were used for amplification of exons 1-5. To obtain complete exon 2 and 3 sequences 
amplification primers located in the introns or in exon 1 were used. Separate amplification of exons 2 and 3 was performed using two different allele-specific $5^{\prime}$ primers (97101 or 98004) combined with the B-locus specific $3^{\prime}$ primers as described previously $(96133,96092)^{21}$. Exon 1 was amplified as described earlier. For amplification of exons 4 and 5 an allele-specific primer in intron 3 (01020) was combined with a locus-specific primer in exon 5 (96069) or a generic primer in exon 6 (01030). All primers are indicated in table 6.1.

All exons were sequenced in both directions using at least two different PCR products. For forward sequencing 3 ' biotinylated primers were used, whereas for reverse sequencing the $5^{\prime}$ primers were biotinylated.

\section{PCR-SSP}

To determine the presence or absence of $B^{*} 27$, a PCR-SSP was set up using four different primer mixes to enable detection of all hitherto known $B * 27$ alleles. Two additional primer mixes were used to detect the Bw4 and Bw6 motifs. A primer pair amplifying the third intron of DRB1 (796b) was used as internal control ${ }^{28,29}$.The primer mixes and the lengths of the resulting $P C R$ products are indicated in table 6.2.

PCR-amplification for SSP was carried out in a total volume of $10 \mu$ l containing $100 \mathrm{ng} \mathrm{DNA}_{\mathrm{v}}$ 0.33 U AmpliTaq DNA polymerase (Perkin Elmer Corporation, Roche Molecular Systems, Branchburg, USA), PCR buffer ${ }^{23}$ (67 mM Tris- $\mathrm{HCl}$, $\mathrm{pH} 8.8,16.6 \mathrm{mM}\left(\mathrm{NH}_{4}\right)_{2} \mathrm{SO}_{4}, 0.01 \%\left(\%_{v}\right)$ Tween $\left.20,1.5 \mathrm{mM} \mathrm{MgCl}_{2}\right), 1 \mu \mathrm{g}$ cresol red, $200 \mu \mathrm{M}$ each dNTP, $5 \%$ glycerol, 2 pmol of each internal control primer and $10 \mathrm{pmol}$ of each SSP primer. PCR amplifications were carried out in a GeneAmp PCR System 9600 (Perkin Elmer Cetus instruments, USA). The cycling conditions consisted of an initial denaturation at $96^{\circ} \mathrm{C}$ for $2 \mathrm{~min}$, followed by 10 cycles of $10 \mathrm{~s}$ at $94^{\circ} \mathrm{C}, 60 \mathrm{~s}$ at $65^{\circ} \mathrm{C}$, and finally 20 cycles of $10 \mathrm{~s}$ at $94^{\circ} \mathrm{C}, 50 \mathrm{~s}$ at $61^{\circ} \mathrm{C}$ and $30 \mathrm{~s}$ at $72^{\circ} \mathrm{C}$. The reaction mixture was analyzed by agarose gel electrophoresis followed by staining with ethidium bromide to detect the presence of PCR products with the correct base length.

\section{Results}

Different molecular methods are available to identify HLA B*27 and in our laboratory two DNA methods have been used for the determination of $B^{*} 27$ for several years. PCR-SSP detected the presence or absence of $B^{\star} 27$, whereas the sequence-based typing method was performed to determine the $B^{\star} 27$ subtype. 
Table 6.2 Specificity and nucleotide sequences and location of primers used for B*27 PCR SSP.

\begin{tabular}{|c|c|c|c|c|c|}
\hline Specificity & Mix & Primer & Exon & Lociation & Length \\
\hline $\mathrm{B}^{*} 27^{1}$ & 289 & $\begin{array}{l}\text { 5GCTACGTGGACGACACGCT } \\
\text { 3GTCTGTGCCTTGGCCTTGC }\end{array}$ & $\begin{array}{l}E 2 \\
E 2\end{array}$ & $\begin{array}{l}149-167 \\
272-290\end{array}$ & 142 \\
\hline $\mathrm{B}^{*} 27$ & 290 & $\begin{array}{l}\text { 5'GGTCTCACACCCTCCAGAAT } \\
\text { 3'GGAGCCACTCCACGCACTC }\end{array}$ & $\begin{array}{l}E 3 \\
E 3\end{array}$ & $\begin{array}{l}344-363 \\
559-577\end{array}$ & 234 \\
\hline$B^{*} 27$ & 291 & $\begin{array}{l}\text { 5'CCTGACCGAGACCTGGGCT } \\
\text { 3'GTCTGTGCCTTGGCCTTGC }\end{array}$ & $\begin{array}{l}E 1 \\
E 2\end{array}$ & $\begin{array}{c}54-72 \\
272-290\end{array}$ & 366 \\
\hline$B^{*} 27$ & 457 & $\begin{array}{l}\text { 5'GCTACGTGGACGACACGCT } \\
3^{\prime} \text { GCGCCCGCGGCTCCTCT }\end{array}$ & $\begin{array}{l}E 2 \\
E 2\end{array}$ & $\begin{array}{l}149-167 \\
204-220\end{array}$ & 72 \\
\hline Bw4 & 292 & $\begin{array}{l}\text { 5'GGGAGGAGCGAGGGACCSCAG } \\
\text { 3'GCTCTGGTTGTAGTAGCGGA }\end{array}$ & $\begin{array}{l}\mathbb{1 4} \\
\mathbb{E} 2\end{array}$ & $\begin{array}{c}36-57 \\
317-336\end{array}$ & 358 \\
\hline \multirow[t]{2}{*}{ Bw6 } & 293 & $\begin{array}{l}\text { 5'GGGAGGAGCGAGGGGACCSCAG } \\
\text { 3'GTTGTAGTAGCCGCGCAGGT }\end{array}$ & $\begin{array}{l}11 \\
E 2\end{array}$ & $\begin{array}{c}36-57 \\
311-330\end{array}$ & 352 \\
\hline & 10 & $\begin{array}{l}\text { 5'TGCCAAGTGGAGCACCCAA } \\
\text { 3"GCATCTTGCTCTGTGCAGAT }\end{array}$ & & & \\
\hline
\end{tabular}

"Previously described by Olerup"

\section{Sequence-based typing of exons $1-4$}

Of 78 individuals exons 2 and 3 of HLA-B were sequenced to determine the $B^{\star} 27$ subtype. In 23 cases an unequivocal typing was obtained, in 5 the presence of a new allele was demonstrated. The alleles have meanwhile been named $B^{\star} 2715$ and $B^{\star} 2717$. In 50 cases the typing turned out to be ambiguous. Two different kinds of ambiguities were observed; one as a result of two different allelic combinations showing the same heterozygous sequence in exons 2 and 3 , and the other due to two different alleles having identical exon 2 and 3 sequences. The first type of ambiguity was noticed in 13 individuals, 11 of which showed a combination with the second ambiguous type. Five different type 1 ambiguous allele combinations were observed, all of which have been described previously ${ }^{2 \pi}$. They were resolved by allele-specific amplification and sequencing using allele-specific primers as published previous $1 \mathrm{y}^{21,30}$. Identical exon 2 and 3 sequences occur in four $B^{*} 27$ alleles. $B^{*} 27052$ is identical to $B^{* 2713}$ with the difference located in exon 1 at position 14 and $B^{\star} 2706$ is identical to $B^{*} 2722$ with the difference in exon 4 at position 704 .

The ambiguous $B^{\star} 27052 / 2713$ combination was shown in 42 cases, $B^{*} 2706 / B^{*} 2722$ in six. To enable correct allele assignment, the sequence of the relevant exon was determined. For exon 1, group-specific amplification was performed by amplification of the Bw4 group. The use of a sequencing primer located in the $5^{\prime}$ untranslated region allowed the complete sequence of exon 1 to be determined. The sequence of exon 1 showed the presence of $B^{\star} 27052$ in 41 cases, $B^{\star} 2713$ was not present and one new allele, $B^{\star} 27054$, was detected. 
To determine the exon 4 sequence, amplification primers were located in intron 2 and exan 5 . Heterozygous forward sequencing was performed using a sequencing primer in intron 3 , enabling determination of the complete exon 4 sequence. From five out of six individuals who were typed ambiguously $B^{\star} 2706 / * 2722$, DNA was available for sequencing. All proved to be $B^{*} 2722$. The $B^{*} 2706$ allele was not present.

$A$ total of 11 different $B^{*} 27$ alleles were observed: $B^{*} 2702(n=8)$, 2703 (one), *2704 (three), *27052 (41), "27054 (one), *2707 (two), *2708 (four), *2712 (seven), " 2715 (two), *2717 (three) and "2722 (five).

\section{New alleles}

Three new $B^{*} 27$ alleles were found: $B^{*} 27054, B^{*} 2715$ and $B^{*} 2717$. Their exon 1.5 nucleotide sequences aligned with $B^{*} 2704$ and $B^{*} 27052$, are shown in figure 6.1.

\section{B*27054}

This allele was discovered in a Caucasian individual serologically typed as $A 3$, A31; B7, B27; Bw4, Bw6; Cw2, Cw7; DR15, DR13; DQ1. The B27 antigen showed positive reactions with all four anti-B27 sera used, as well as with three anti-Bw4 sera. SBT of HLA-B using the previously published protocol ${ }^{21}$ revealed allelic drop-out of $B^{*} 27$ in exon 3 . As already indicated at that time, drop-out was caused by improper annealing of the $5^{\prime}$ primer located in intron 2 . The sequence of intron 2 showed a $T$ at position 184 in stead of a $G$, which was present in all other known intron 2 sequences of $H L A-B^{31-34}$. This resulted in a mismatch at the $3^{\prime \prime}$ end of the primer, which prevented correct amplification. The sequence of exons 2 and 3 was identical to $B^{\star} 27052$ and thus also $B^{*} 2713$, as no sequence differences are present in exons 2 and 3 between $B^{*} 27052$ and $B^{*} 2713$. To determine whether differences elsewhere in the coding region were present, exons 1,4 and 5 were sequenced. In exon 1 a difference was found with the $B^{*} 27052$ sequence at position 72 , changing codon 24 from GCT to GCC. As both codons code for alanine, the nucleotide difference did not result in an amino acid difference. The difference between $B^{*} 27052$ and $B^{* 2713}$ is located in exon 1 at position $14(C \rightarrow A)^{35}$. The new allele showed a $\mathrm{C}$ at position 14, identifying the resulting HLA protein as identical to $B * 27052$ and not to $B * 2713$. The new allele was therefore named $\mathrm{B}^{*} 27054$.

By generating the exon 1 sequence the sequence of intron 1 was also obtained. A difference was observed between $B^{*} 27054$ and $B^{*} 27052$. At position 17 of intron 1 a $C$ for $B^{*} 27052$ was reported and confirmed by sequencing intron 1 of a $B^{*} 27052$ positive individual. However, for $B^{\star} 27054$ a $G$ was found at this position, using both forward and reverse sequencing. 
$\begin{array}{rrrrrr}10 & 20 & 30 & 40 & 50 & 60 \\ * & * & * & *\end{array}$

B 07021 ATGCTGGTCATGGCGCCCGAACCGTCCTCCTGCTGCTCTCGGCGGCCCTGGCCCTEACC

$3 * 2704$

B*27052

B* 27054

B*2715

B. 2717

3*07021

B*270

$B * 27052$

B*27054

B.2715

$B * 2717$

B*07021 $8 * 2704$

B 27052

$B \times 27054$

B*2715

B*2717

$B * 07021$

B*2704

B* 27052

E 27054

$B * 2715$

B*2717

B*07021.

B*2704

$B * 27052$

B. 27054

B*2715

D. 2717

B*07021

B 2704

B. 27052

B 27054

B. 2715

B*2717

ATGCTGGTCATGGCGCCCCGAACCGTCCTCCIGCIGCTCICGGCGGCCTGGCCCTGACC

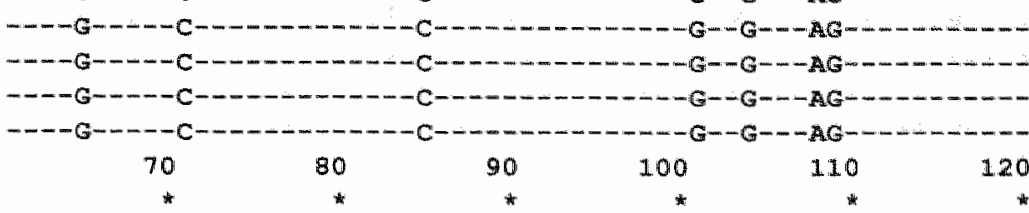

GAGACCTGGGCCGGCTCCCACTCCATGAGGTATTICTACACCTCCGTGTCCCGGCCCGGC

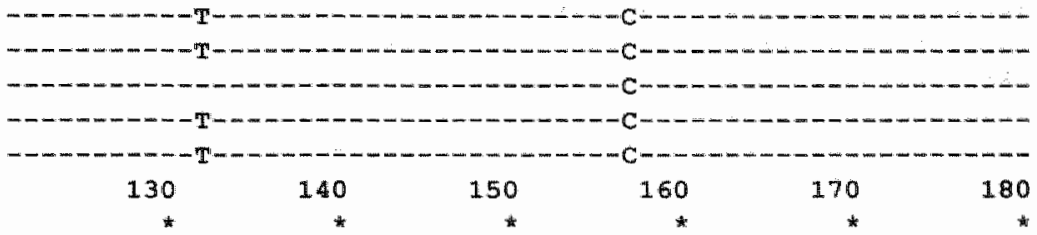

CGCGGGGAGCCCCGCTTCATCTCAGTGGGCTACGTGGCGACACCCAGTHCGTGAGGTTC

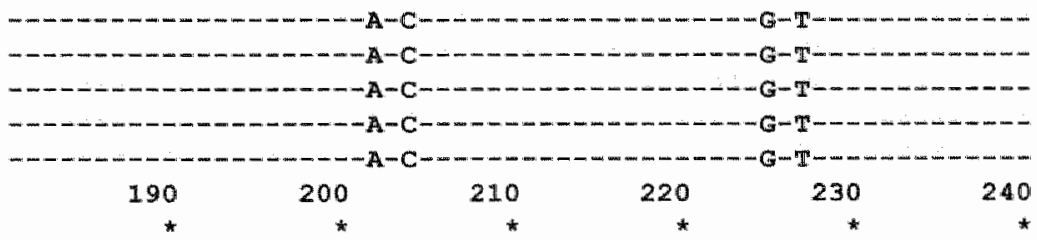

GACAGCGACGCCGCGAGTCCGAGAGAGGAGCCGCGGGCGCCGTGGATAGAGCAGGAGGGG

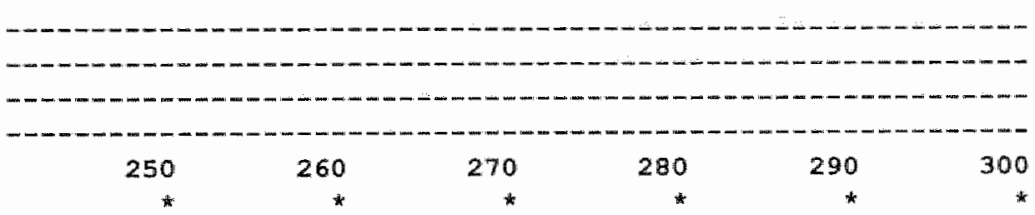

CCGGAGTATTGGGACGGGAACACACAGATCTACAAGGCCCAGGCACAGACTGACCGAGAG

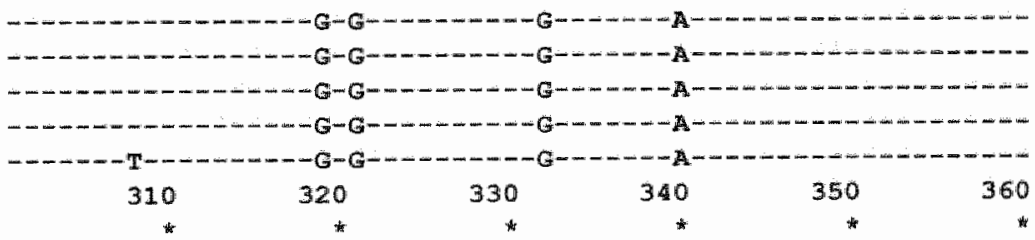

AGCCTGCGGAACCIGCGCGGCTACTACAACCAGAGCGAGGCCGGGTCHCACACCCTCCAG

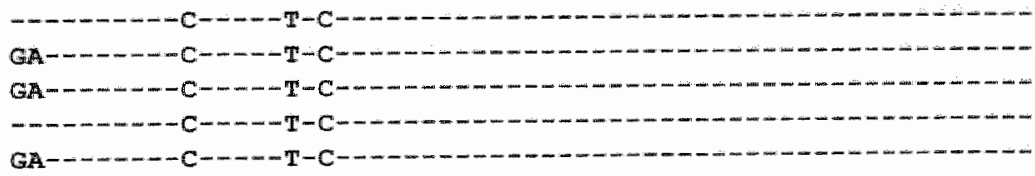

Figute 6.1 continued 


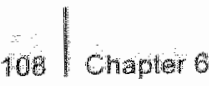

$\begin{array}{rrrrrr}370 & 380 & 390 & 400 & 410 & 420\end{array}$

B* 07021 AGCATGTACGGCTGCGACGTGGGCCGGACGGGCGCCTCCTCCGCGGGCATGACCAGTAC

B 2704

*27052

B*27054

*2715

B*2717

B*07021

B*:2704

B* 27052

B*27054

B* 2715

B*2717

B*07021

B*2704

B*27052

B*27054

B $* 2715$

\$ 2717

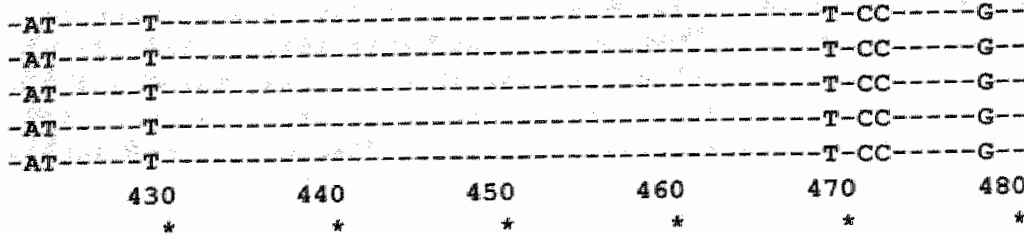

GCC TACGACGGCAAGGATIACATCGCCCTGAACGAGGACCTGCGCTCCTGGACCGCCGCG

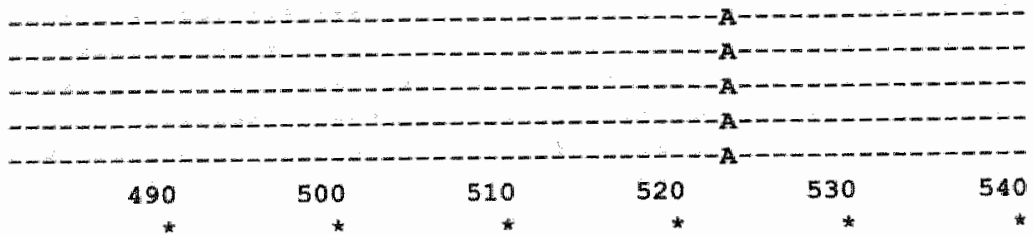

GACACGGCGGCTCAGATCACCCAGCGCAAGTGGGAGGCGGCCCGTGAGGCGGAGCAGCGG

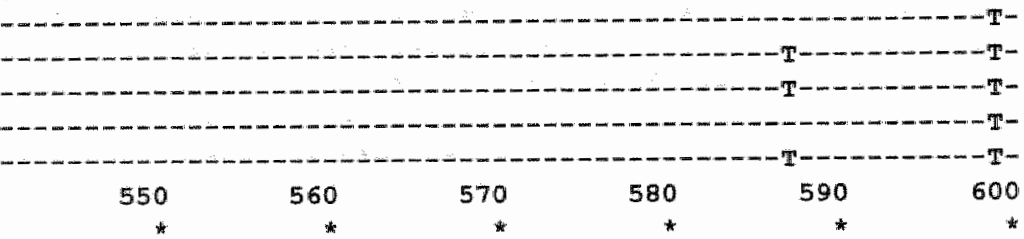

B*07021 AGAGCCTACCTGGAGGGCGAGTGCGTGGAGTGGCTCCGCAGATACCTGGAGAACGGGAAG $\mathrm{B} * 2704$

B*27052

$B * 27054$

$B * 2715$

$B \times 2717$

$B * 07021$

$\mathrm{B} \times 2704$

B*27052

B*27054

2715

$B * 2717$

B*07021

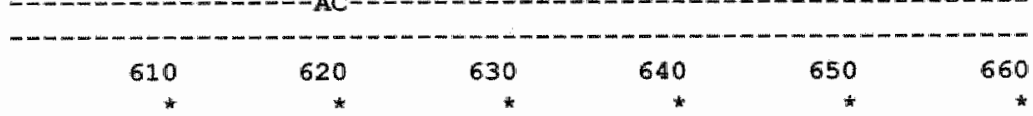

GACAAGCTGGAGCGCGCTGACCCCCCAAAGACACACGTGACCCACCACCCCATCTCTGAC

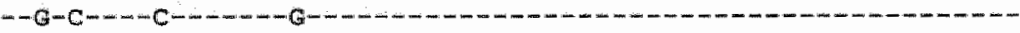

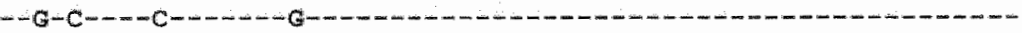

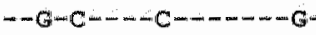

$-\mathrm{G}-\mathrm{C}-\mathrm{C}-\mathrm{C}-\mathrm{C}-\cdots-\mathrm{G}$

$--\mathrm{G}-\mathrm{C}-\cdots-\mathrm{C}-\cdots-\cdots-\mathrm{G}-\mathrm{G}$

$670 \quad 680$

690

700

710

720

B*0702

CATGAGECCACCCTGAGGTGCTGGGCCCTGGGTTTCWACCCTGCGGAGATCACACTGACC

1.27052

*27054

D*2715

B. 2717

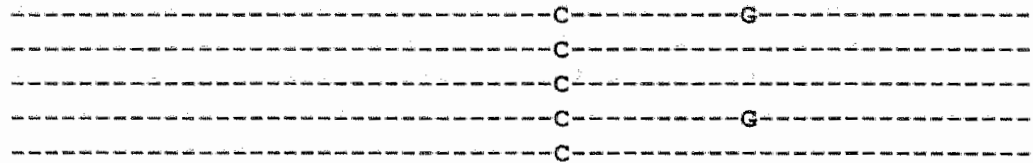

Figure 6.1 continued 


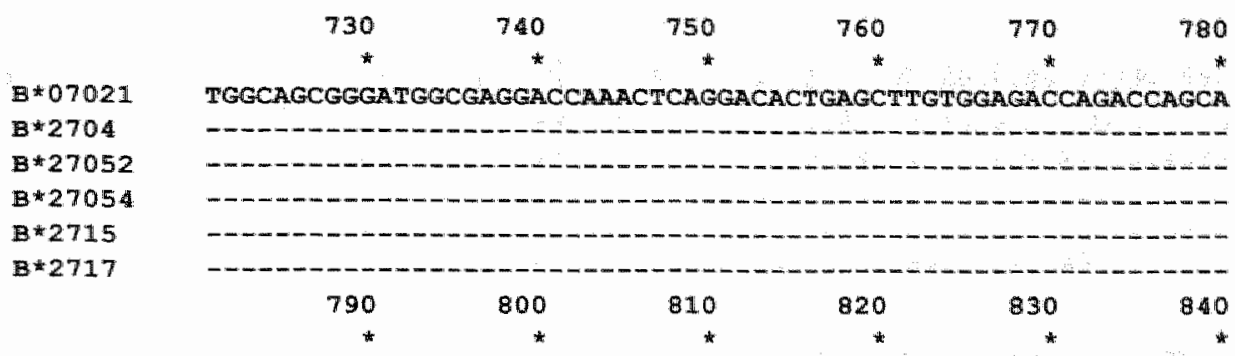

$B * 07021$

B*2704

B. 27052

B. 27054

$B * 2715$

B*2717

$B * 07021$

$B * 2704$

$\mathrm{B} * 27052$

$B * 27054$

$\mathbb{B}^{* 2715}$

B*2717

$B * 07021$

$B * 2704$

E*27052

$B * 27054$

$B * 2715$

B*2717

B*07021

B.2704

E. 27052

B. 2705 새

E. 2715

B.2717

Figure 6.1 Alignment of the nucleotide sequences of exons $1-5$ of $B^{* 27054,} B^{*} 2715$ and $B^{*} 2717$

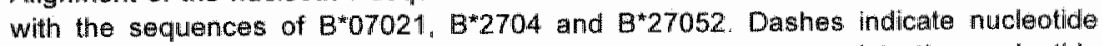
identity with the $B^{*} 07021$ sequence. Numbers above correspond to the nucleotide position.

A total of three differences were observed between $B^{*} 27054$ and $B^{*} 27052$. $B^{*} 27054$ has a $C$ at position 72 in exon 1, a $G$ at position 17 in intron 1 and a $T$ at position 184 in intron 2. $B^{*} 27052$ has a $T$ at position 72 (E1), a $C$ at position 17 (11) and a $G$ at position 184 (12). The intron nucleotide positions are numbered according to Cere $^{31}$. The three differences can not be explained by 
one event, because the intervening exon 2 sequence is completely identical to other $B^{*} 27$ alleles but not to any of the other $B$ alleles. Therefore $B^{*} 27054$ could have been arisen from $B^{\star} 27052$ by two different events, an allele or a gene conversion changing position 72 of exon 1 and 17 of intron 1, and a gene conversion or a point mutation changing position 184 of intron 2.

\section{$B 2715$}

The individual carrying the $B^{\star} 2715$ allele was of Asian origin and was serologically typed A11; B54; Bw4, Bw6; Cw1; DR12, DR14; DQ5, DQ7. No reactivity was seen with any of the four anti-B27 sera, however two out of three anti-Bw4 sera were positive. As a result of the positivity of both Bw4 and Bw6 the presence of a second allele was suspected and confirmed by typing of the family members. From the pedigree the presence of the Bw4 motif in the second allele was deduced (figure 6.2). Allele-specific sequencing of exons 2 and 3 of individual $1-2$ revealed a new $B^{*} 27$ allele, showing two mismatches with $B^{*} 2704$. The sequence was confirmed in the other two family members. The mismatches with $B^{*} 2704$ at positions 559 and 560 changed codon 187 from $G A G$ to $A C G$, resulting in an amino acid change from glutamic acid to threonine at position 163 of the mature protein. Approximately one out of each four HLA-B groups carry $A C$ at positions 559-560. This suggests that the $B * 2715$ allele might have arisen by an allele conversion event, with $B^{\star} 2704$ serving as a backbone and one of the alleles carrying $\mathrm{AC}$ acting as the donor gene.

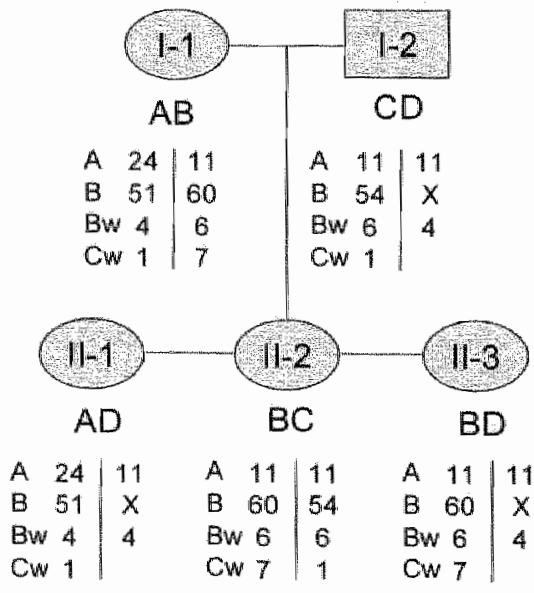

Figure 6.2 Segregation of Bw4 with the serologically undetectable $B^{*} 2715$ allele $(X)$ in the family. 
The change from Glu to Thr at position 163 seems to have a major impact on the serological detection. Four well known polyclonal sera failed to react with $B^{*} 2715$, but did show positive reactions with $B^{*} 2704$. The use of four additional anti-B27 sera showed weak reactions in two sera (T863a and D567).

Sequencing exons 1,4 and 5 of $B^{\star 2} 2715$ revealed a remarkable difference. The allele showed a $G$ at position 704, whereas other $B^{*} 27$ alleles have a $C$. $B^{\star} 2704$ also shows a $G$ at this position ${ }^{36}$, strengthening the assumption that $B^{*} 2715$ has been derived from $B^{*} 2704$. The allele $B^{*} 2722$ is the only other $B^{*} 27$ allele showing a $G$ at position 704 and therefore probably is also derived from $B^{*} 2704$.

\section{$B * 2717$}

This allele was encountered in a Caucasian individual serologically typed $A 1$, A2; B7, B27; Bw4, Bw6; Cw4, Cw7; DR15, DR4; DQ1, DQ3. All four anti-B27 sera showed positive reactions as did the anti-Bw4 sera. Sequence-based typing of exons 2 and 3 showed the best assignment for this individual to be either $B^{*} 07021$ with $B^{*} 27052$ or $B^{*} 07021$ with $B^{*} 2713$. However one mismatch was shown at position 248. The mismatch was interpreted as a $W$, whereas both $B^{*} 07021$ and $B * 27052 / 2713$ have an $A$ at this position. Allele-specific sequencing showed the presence of a new $B * 27$ allele, with a $T$ at position 248 . As this position was previously thought to be conserved, PCR-SSP was used for confirmation. A specific 5" primer located un exon 2 at positions 231-248 was combined with a B7CREG specific $3^{\prime}$ primer located at positions $559-577$ in exon 3 . The individual carrying $B^{*} 2717$ showed a positive $P C R$, whereas othen individuals, carrying $B^{*} 27052$ with or without $B^{*} 07021$, were found to be negative. The father and sister also showed the presence of $B^{*} 2717$ by $P C R$ SSP as well as by SBT of exons 2 and 3 . The nucleotide change at position $248(\mathrm{~A} \rightarrow \mathrm{T}$ ) changed codon 83 (TAT $\rightarrow$ TTT), resulting in an amino acid change from tyrosine to phenylalanine at position 59 of the mature protein.

The $B^{*} 2717$ allele is probably the result of a point mutation, as no other $B$ alleles have a $\mathrm{T}$ at position 248. The HLA-A and $-\mathrm{C}$ gene also have an $\mathrm{A}$ at this position, which makes gene conversion with these genes as the origin for the $B^{*} 2717$ allele unilkely.

Both $B^{*} 2715$ and 2717 showed exon 1 sequences identical to 12 other $B^{*} 27$ alleles with known exon 1 sequences. The exon 1 sequence of $B * 2707$ was not known hitherto and was here identified as identicall to the other $B^{*} 27$ alleles. The sequence was submitted to the EMBL databank with accession number A.J316294. Therefore the number of $B^{*} 27$ alleles for which exon 1 is known, has now increased to 17 . The exon 4 and 5 sequences of $B^{*} 27054$ and $B^{*} 2717$ proved identical with $B * 27052$. 


\section{PCR-SSP}

For HLA-B*27 detection, initially a PCR-SSP was set up with three different primer combinations (the first three in table 6.2), whereas the Bw4 and Bw6 primer mixes were used in addition. With these primer mixes the presence or absence of $B^{*} 27$ in 262 individuals was determined. These individuals were also serologically typed for HLA-A and $-B$ using local typing trays. With the three primer mixes all $B * 27$ alleles could be detected, with different positivity patterns. Of the 262 individuals 50 were found to be HLA-B*27 positive by PCR-SSP. Forty-five showed the SSP pattern +++, three were -+-, one was ++and one was +-+ . The patterns +++ and ++- showed positive reactions with specific anti-B27 sera. The ++- pattern indicated the presence of the allele $B * 27054$. The negative reaction with the third mix was explained by the mismatch with the $5^{\prime}$ primer at position 72 in exon 1 . Four $B^{\star} 27$ positive individuals by PCR-SSP showed no reactions with anti-B27 sera. Three of them showed the pattern - + - and were typed $B^{*} 2712$ by SBT. One individual with the SSP pattern +-+ was identified as $B^{*} 2715$.

Concerning the primer mixes for BW4 and Bw6, the reactions corresponded with the serological findings in all cases. In a number of Bw6 negative cases the mix for Bw6 showed an aspecific band, which did not interfere with correct assignment.

With the identification of new HLA-B*27 alleles the three SSP primer mixes were no longer sufficient to unequivocally determine the presence of $B^{\star} 27$. Theoretically the SSP patterns for $B^{*} 2716$ and $B^{*} 2723$ are identical to $B^{*} 3702$. Therefore a mix was added, which reacted with all $B^{*} 27$ but not with $B^{*} 3702$. The PCR-SSP with the four mixes was tested with the alleles $B^{\star} 2702,2703$, $2704,27052,27054,2707,2708,2712,2715,2717$ and 2722 . Their reactions are shown in table 6.3 . For the other $\mathrm{B}^{*} 27$ alleles the reactions were derived from their sequences. The sequence of exon 1 is not known for a number of alleles, and as the mix 291 uses one primer located in exon 1, the expected reactions are indicated by a question mark. 
Table 6.3 Reaction pattern of the different $B * 27$ alleles with PCR-SSP.

\begin{tabular}{|c|c|c|c|c|c|c|}
\hline Mix & 289 & 290 & 291 & 457 & 292 & 293 \\
\hline$B^{2} 2701$ & + & + & $?$ & + & $*$ & - \\
\hline $\mathrm{B}^{* 2702}$ & + & + & + & + & + & - \\
\hline$B^{*} 2703$ & + & + & + & * & + & - \\
\hline$B * 2704$ & + & + & + & + & + & - \\
\hline $18 * 27052$ & + & + & + & + & * & - \\
\hline$B^{*} 27053$ & 4 & + & $?$ & + & + & - \\
\hline$B^{* 27054}$ & + & + & - & + & + & - \\
\hline$B * 2706$ & + & + & + & + & + & - \\
\hline $\mathrm{B}^{*} 2707$ & + & - & + & + & + & - \\
\hline$B^{* 2708}$ & + & + & + & * & - & + \\
\hline$B^{m} 2709$ & + & + & + & * & + & - \\
\hline$B^{2} 2710$ & + & + & $?$ & + & + & - \\
\hline$B^{* 2711}$ & * & - & + & + & + & - \\
\hline$B^{*} 2712$ & - & + & - & + & - & + \\
\hline$B^{2} 2713$ & + & + & + & * & * & - \\
\hline$B^{* 2714}$ & + & - & + & + & + & - \\
\hline $\mathrm{B}^{2} 2715$ & + & - & + & + & + & - \\
\hline $\mathbb{B}^{* 2716}$ & - & + & - & + & + & - \\
\hline $18 \times 2717$ & + & + & + & + & + & - \\
\hline $\mathrm{B}^{\star} 2718$ & - & + & - & + & - & + \\
\hline$B^{* 2719}$ & * & - & $?$ & + & + & - \\
\hline$B^{*} 2720$ & + & + & $?$ & + & + & - \\
\hline$B^{+2721}$ & + & - & $?$ & $*$ & + & - \\
\hline$B^{*} 2722$ & + & + & + & * & + & - \\
\hline$B+2723$ & - & + & - & + & + & - \\
\hline $\mathrm{B}^{2} 2724$ & * & - & $?$ & + & + & - \\
\hline$B \times 2725$ & + & - & $?$ & + & + & - \\
\hline$B^{*} 3702$ & - & + & - & - & + & - \\
\hline
\end{tabular}

\section{Discussion}

The number of HLA-B alleles is increasing continuously and therefore molecular methods have to be updated regularly. We here report on an extended SBT method for subtyping of $B^{\star} 27$ and an updated PCR-SSP method to detect the presence or absence of $B^{*} 27$. The presence of HLA-B27 is used as a diagnostic marker for ankylosing spondylitis and related spondyloarthropathies and has been the subject of many studies, including molecular typing reports ${ }^{8-19,37,38}$. Several advantages of molecular typing of HLA-B*27 compared with serological methods have been mentioned: (1) potentially more accurate typing resulted from the reduced risk of false positive results caused by possible cross-reactivity of antibodies and of false negative results as a result of low B27 expression or bacterial infection; (2) no requirement of viable cells and thus no restrictions to shipment and storage of cells, enabling batchwise testing; (3) and cost effectiveness ${ }^{9,17 \cdot 95,17.39}$. 
One of the earliest reports on PCR-SSP for HLA-B*27 $7^{10}$ described a primer pair, which was extensively used in further studies ${ }^{1,37.38}$, including this one (mix 289, table 6.2). In the original report the $5^{\prime}$ primer used contained a deliberately introduced mismatch to achieve complete typing specificity ${ }^{10}$. In our hands this mismatch was not necessary for specificity, probably because of differences in PCR conditions. Specificity without the mismatch was also reported by Sayer et al. ${ }^{11}$, although several other authors still use the primer with the mismatch ${ }^{37.38}$. As the PCR mix showed no mismatches with any of the seven HLA-B $B^{\star} 27$ alleles known at that time, it was thought to be able to identify all HLA-B*27 alleles ${ }^{10}$. Unfortunately, with the growing list of alleles several $B^{*} 27$ alleles could no longer be identified. Both $B^{*} 2718$ and 2723 show a mismatch at the $3^{\prime}$ end of the primer, implicating that no amplification will occur. In this study the allele $B^{*} 2712$ showed no amplification with the PCR-mix, probably because of the number of mismatches present between the $3^{\prime}$ primer and $B^{*} 2712$. This implicates that also $B^{*} 2716$, with an identical sequence at these positions, will not be amplified.

The second mix used in our PCR-SSP contains the $B^{*} 27$ specific $5^{\prime}$ primer described previously ${ }^{12-14,16}$. As already identified at that time $B^{*} 2707$ was not amplified with this primer. With the identification of new alleles an additional five alleles $\left({ }^{*} 2711, * 2714, * 2719, * 2721, * 2724\right)$ were shown to contain mismatches with this primer, resulting in lack of amplification. The 3" primer chosen for the mix turned out to have a mismatch with $B^{*} 2715$ and $B^{*} 2725$ at the $3^{x}$ end, and thus no amplification of these alleles will be obtained.

The PCR-SSP initially used, with the three mixes for HLA-B*27 and the additional two mixes for Bw4 and Bw6, positively identified the presence of the alleles $B^{*} 270 *-2725$. Unfortunately, the reaction patterns for $B^{*} 2716$ and $B^{*} 2723$ were identical with the pattern for $B^{*} 3702$ (see table 6.3 ). The alleles $B^{* 2712}$ and 2718 might also be difficult to distinguish from $B * 3702$, as the only difference is the presence of Bw6. If both Bw4 and Bw6 are present in an individual no difference is visible. Therefore a fourth mix was included in the PCR-SSP (mix 457, table 6.2) with primers located in exon 2. This results in amplification of all $B * 27$ alleles known $(B * 2701-2725)$ without coamplification of other HLA-B alleles these primer locations are also used in the SSP HLA-B low resolution kit of Genovision). Although the use of mix 457 only would be sufficient to identify the presence or absence of HLA-B*27, the use of additional mixes, which amplify other exons, makes the method more robust.

Not only must PCR-SSP and SSO methods be updated to be able to recognize all recently identified alleles, also for SBT the method should be carefully evaluated. In the case of subtyping for $B^{\star 2} 27$ it is not always sufficient to analyze exons 2 and 3 to obtain an unequivocal result. With the extended molecular typing of HLA-B alleles polymorphism outside exons 2 and 3 was 
identified, and novel alleles that differed only outside exons 2 and 3 were detected. For $B^{*} 27$ this is the case for two alleles, $B^{*} 2713$ is identical to $B^{*} 27052$ for exons 2 and 3 and $B^{*} 2722$ shows identical exon 2 and 3 sequences to $B^{*} 2706$. In case a $B^{*} 27052 / 2713$ or $B^{*} 2706 / 2722$ ambiguity is identified by SBT of exons 2 and 3 , additional exon sequences are needed to assign the alleles. For subtyping at the four-digit level the same holds true for $\mathrm{B}^{*} 0705 / 0706 ; 1512 / 1519 ; 1801 / 1817 \mathrm{~N} ; 3501 / 3540 \mathrm{~N} ; 44021 / 4419 \mathrm{~N} / 4427$ and $51011 / 5111 \mathrm{~N}$. The combinations including a null allele could be assigned on the basis of serological reactions. For the others the sequence of exon 4 $(1512 / 1519 ; 44021 / 4427)$ or exon $5(0705 / 0706)$ is needed.

While analyzing exon 1 to resolve the $B^{*} 27052 / 2713$ ambiguities, a novell difference was found at position 72. All individuals were identified as $B^{*} 27052$, which seems to implicate that $B^{*} 2713$ is not a very common $B^{*} 27$ subtype among Caucasians. Surprisingly, the $B^{*} 2722$ allele was identified in all $B^{*} 2706 / 2722$ ambiguous cases.

Another problem encountered with SBT is the update of primers used for amplification and sequencing. This is an important issue in the prevention of allelic drop out and thereby incorrect homozygous results, especially with generic primers. The identification of three new alleles, described in this study, resulted in an increase of four pollymorphic positions within the HLA-B*27 group. Position 72 is $T$ in all; except $B * 27054$; positions 559 and 560 are $G A$ in all, except $B^{*} 2715$ and position 248 is $A$ in all $B$ alleles, except $B^{*} 2717$. Furthermore, $B^{\star} 27054$ showed two additional differences in intron 1 and 2 at positions 17 and 184, respectively. Especially the latter one is of importance, as this position was considered a B-locus specific position, which could be used for B-locus specific amplification.

SBT methods have been described for HLA-B in general and for $B^{*} 27$ in particular $^{19,21,40-44}$. Although in most approaches primers are used that amplify all HLA-B alleles, in some of them the sequence differences found in the three new HLA-B*27 alleles could interfere with correct amplification. Use of the amplification primer $A 1 M 1 D$, described by Eberle et al. ${ }^{43}$ for RT-PCR of HLA-B. will result in allellic drop out of $B^{\star} 2717$, as the primer is located at positions 235 255. carrying the mismatch of $B^{\star} 2717$ at position 248 . In the approach of Petersdorf ${ }^{44}$, primer $171 \mathrm{~N}_{2} .193 \mathrm{G}$ is located in intron 2 at positions 168-184 (numbering according to Cereb et al. ${ }^{31}$ ). As B*27054 shows a mismatch at position 184, the use of this primer will result in allelic drop out. In their study the primer was used to amplify several novel alleles for confirmation of exon 3 sequences. In our SBT approach ${ }^{21}$, primer 96125 (located at positions 163-184 in intron 2) was used for B-locus specific amplification of exon 3 and allelic drop out of $B^{*} 27054$ was shown. This demonstrates the advantage of separate amplification of exons 2 and 3 for SBT using different amplification primers. Especially when intron primers are used, allelic drop out could occur as a result 
of unknown sequence differences between primers and alleles. Separate amplification reduces the chance of complete allelic drop out in both amplifications. In the $\mathrm{B}^{\star} 27$ sequencing approach, used to discriminate the different $B^{*} 27$ alleles $^{19}$, primer MWO9 is used as $3^{\prime}$ primer for group specific amplification. This primer is located at positions 559-576 in exon 3. As $B^{*} 2715$ shows sequence differences at positions 559 and 560 with all other $B^{*} 27$ alleles, the use of primer MW09 will result in allelic drop out. it is clear that also for SBT updating of amplification primers is necessary to obtain unequivocal typing results. Furthermore, separate amplification of exons using different amplification primers at distinct positions reduces the chance of missing an allele completely and results in a more robust method.

The major drawback of molecular typing is that the actual presence of the antigen on the cell surface is not determined, implicating that so-called null alleles cannot be excluded. Null alleles are present at the DNA levell, but show no expression at the protein level. In most cases the underlying mechanism for non-expression has been elucidated at the molecular level, enabling correct identification of the alleles by molecular typing. Absence of serological reactions with specific antisera (serological blanks) does not immediately implicate presence of a null allele, because serological reactions are dependent on the epitopes that can be recognized. $B^{\star} 2712$ was first detected as a Bw6-associated blank antige ${ }^{45}$. Serological analysis showed that $B^{*} 2712$ was not recognized by $B 27$ monospecific antibodies. Also in our laboratory the sera used for detection of $B 27$ were all negative with $B^{*} 2712$. However, the allele showed positive serological reactions with different Bw6-specific sera, implicating that the antigen was indeed expressed at the cell surface, but that the epitopes recognized by $\mathrm{B} 27$ specific sera are not present Comparison of the amino acid sequence of $B^{*} 2712$ with other $B^{*} 27$ alleles revealed a difference at amino acids $69-71$ and $80-83$ with most $B^{*} 27$ alleles. The amino acids $80-83$ encompass the Bw6 motif, which is also present in $B^{*} 2708$, an allele that is positive with most B27 specific antisera. Therefore the changes at amino acids $69-71$ are rather critical for proper epitope recognition of $B^{\star} 2712$, as was noticed previously ${ }^{45}$. Comparable changes have been observed in $B^{*} 2716, B^{*} 2718$ and $B^{*} 2723$. However, the serological recognition of these alleles has not yet been described ${ }^{46}$.

One of the three new alleles, $B^{*} 2715$, described in this study also showed no serological reactions with $B 27$ specific sera. The presence of the antigen at the cell surface was demonstrated by positive serological reactions with Bw4specific sera. In two of the three individuals carrying $B^{\star} 2715$, the second $B$ allele was Bw6-associated, enabling the detection of Bw4 reactions as a result of the B27 antigen. The $B^{*} 2715$ allele differs from other $B^{*} 27$ alleles at amino acid 163 , which is a glutamic acid in $B^{*} 27$, whereas $B^{\star} 2715$ carries a threonine. 
As this is the only amino acid difference with $B^{*} 2704$, an allele positive with B27 specific antisera, it implicates that the absence of serological reactions with $B 27$ antisera can result from a single amino acid difference, namely $E 163 \rightarrow T 163$. This is rather remarkable because $E 163$ is not a $B 27$ specific amino acid, but is also present in other B7 CREG alleles.

Concerning the susceptibility for ankylosing spondylitis and related diseases the different $B^{*} 27$ subtypes show different relative risks for the disease. Furthermore, the different $B^{\star} 27$ alleles show a varied racial prevalence in the world, and the susceptibility is also related to the ethnic origin of the individual. The peptide-HLA interactions play a crucial role in conferring either susceptibility or resistance to immunological diseases associated with particular HLA alleles. Peptide selection is dependent on the structure of the peptide binding groove. The crystallographic study of HLA-A2 showed that the antigen binding groove consists of six specificity pockets, designated $\mathrm{A}$ through $F^{47}$. Two of the three novel $B^{\star} 27$ alleles described here showed an amino acid difference with known HLA-B*27 alleles. In $B^{\star} 2715$ amino acid 163 changed from glutamic acid to threonine, whereas in $B^{*} 2717$ a mutation of amino acid 59 from tyrosine to phenylalanine was observed. Both amino acids are located in the A pocket of the peptide binding groove. Amino acid differences in this $A$ pocket affect the binding of the amino terminus of the peptide and can thus have an impact on the subset of peptides that can be bound. Whether the differences of $B^{\star} 2715$ and $B^{*} 2717$ in the $A$ pocket affect peptide binding and/or disease susceptibility is as yet unknown. Previous comparison of antigen binding to $B^{\star} 2705$ and $B^{\star} 2703$, which differ only at amino acid 59 ( $\mathrm{Tyr} \rightarrow \mathrm{His}$ ), showed a clear difference in peptide binding specificity between the two alleles $^{48}$. The HLA molecule expressed by the $B^{*} 27054$ allele is identical to that expressed by the $B^{*} 27052$ allele. Therefore "comparable disease susceptibility for both alleles is expected.

The nucleotide sequence data reported in this paper will appear in the EMBL Nucleotide Sequence Database with the accession numbers A.l250630, A.J250631, A.J250632, A.J417675. A.1417664 $\left(B^{*} 27054\right), A J 316293, Y 16637, Y 16638, A J 417676, A J 419598\left(B^{*} 2715\right)$ and AJ316295, A.J243373, A.J243375, AJ417677, A.J419597 (B*2717).

The names $B^{*} 27054,{ }^{*} 2715$ and $* 2717$ have been officially assigned by the WHO Nomenclature Committee. This follows the agreed policy that, subject to the conditions stated in the most recent Nomenclature Report ${ }^{49}$, names will be assigned to new sequences as they are ideritified. Lists of such new names will be published in the following WHO Nomenclature Report. 


\section{References}

1. Brewerton DA, Caffrey $M$, Hart FD, James DCO, Nicholls A, Sturrock RD. Ankylosing spondylitis and HLA 27. Lancet 1973;1:904-7.

2. Schlosstein $L$, Terasaki $P$, Bluestone $R$, Pearsion CM. High association of an HL-A antigen, W27, with ankylosing spondylitis. N Engl Med 1973,288:704-6.

3. Chapter 6: Rheumatology and لlont Diseases. In: Tiwan Jl Terasaki PI, ed. HLA and Disease Associations. New York, Berlin, Heidelberg, Tokyo: Springer-Verlag, 1985:49-111.

4. Fischer GF. Fae I. Moser S et al. Ligation based HLA-B*27 typing. Tissue Antigens 1996:48: $148-52$.

5. Ness DB, Grumet FC. New polymorphisms of HLA-B27 and other B locus antigens detected by RFLP using a locus-specific probe. Hum Immunol 1987;18:65-73.

6. Nieto $A$, Fraile $A$, Vinasco d, Martim J. HLA-B*27 typing by PCR-restriction fragment length polymorphism. Tissue Antigens 1997:49:283-6.

7. Fraile A. Martin $\downarrow$, Lopez-Newot MA, Mataran L, Nieto A. HLA-B*27 subtyping by PCR-RFLP in Spanish patients with ankylosing spondylitis. Tissue Antigens 1998;52:492-6.

8. Bon MAM, Oeveren van-Dybicz A, Bergh vam den AJTM. Genotyping of HLA-B27 by realltime PCR without hybridization. Clin Chem 2000;47:1000-2.

9. Kilpatrick DC. HLA-B27 determination by polymerase chain reaction. Dísease Markers 1996: 12:247-51.

10. Olerup O. HLA-B27 typing by a group-specific PCR amplification. Tissue Antigens 1994,43: $253-6$.

11. Sayer DC, Cassell HS, Christiansen FT. HLA $-B^{*} 27$ typing by sequence specific amplification without DNA extraction. J Clin Path and Mol Path 1999:52:300-1.

12. Steffens-Nakken $H M_{1}$, Zwart $G$, Bergh van den FAJTM. Validation of allele-specific Polymerase Chain Reaction for DNA typing of HLA-B27. Clin Chem 1995;41:687-92.

13. Frankenberger $B$, Breitkopf $S$. Albert $E$ et al. Routine molecular genotyping of HLA-B27 in spondyloarthropathies overcomes the obstacles of serological typing and reveals an increased $B^{\star 2} 2702$ frequency in ankylosing spondylitis. J Rheumatol 1997;24(5):899-903.

14. Lucotte G, Burckel A. DNA typing of HLA-B27 by polymerase chain reaction. Molecullar and Cellular Probes 1997:11:313-5.

15. Hill AVS, Kwiatkowski D, Greenwood BM, Allsopp CE, Anstey NM. McMichael AJ. HLA class I typing by PCR: HLA-B27 and an African B27 subtype. Lancet 1991;337:640-2.

16. Dominguez $O$, Coto $E$, Martinez-Naves $E$, Choo SY, Lopéz-Larrea $C$. Molecular typing of HLA-B27 alleles. Immunogenetics 1992;36:277-82.

17. Wagner T. Oberkanins C. Weinmayr B, Heimberg W, Kury F. Lanzer G. HLA-B*27 typing by group specific hybridazation in microtiter plates. Tissue Antigens 1998;52:175-8.

18. Lopez-Larrea $C$. Gonzalez-Roces $S$. Pena $M$ et al. Characterization of $B 27$ Haplotypes by Oligotyping and Genomic Sequencing in the Mexican Mestizo Population with Ankylosing Spondylitis. Hum Immunal 1995;43:174-80

19. Blasczyk R, Weber M, Lessen van A, Schwella N, Huhn D, Salama A. Discrimination of HLAB27 alleles by group-specific amplification followed by solid-phase sequencing. Hum Immunot $1996 ; 45: 117-23$.

20. Khan MA. HLA-B27 polymorphism and association with disease. J Rheumatol 2000;27. $1140-4$.

24. Voorter CEM, Vlies van der SA, Berg van den-Loonen EM. Sequence-based typing of HLA-B: the $\mathrm{B} 7$ cross reacting group. Tissue Antigens 2000:56:356-62.

22. Miller SA, Dykes DD. Polesky HF. A simple salting out procedure for extracting DNA from human nucleated cells. Nucleic Acids Res 1988;16:1215.

23. Bunce M. Barnardo MCNM, Welsh KI. Improvements in HLA-C typing using sequencespecific primers (PCR-SSP) including definition of HLA-CW9 and $C W 10$ and a new allele $H L A-$ "Cw7/8v". Tissue Antigens 1994;44:200-3. 
24. Voorter CEM, Rozemuller EH, Bruyn de-Geraets D, Zwan van der AW, Tilanus MGJ, Berg van den-Loonen EM. Comparison of DRB sequence-based typing using different strategies. Tissue Antigens 1997;49:471-6.

25. Voorter CEM, Bruyn de-Geraets $D$, Berg van den-Loonen EM. High-resolution HLA typing for the DRB3/4/5 genes by sequence-based typing. Tissue Antigens 1997:50:283-90.

26. Voorter CEM, Kik MC, Berg van den-Loonen EM. High-resolution HLA typing for the DQB1 gene by sequence-based typing. Tissue Antigens 1998;51:80-7.

27. Viles van der SA, Voorter CEM Berg vam den-Loonen EM. A reliable and efficient high resolution typing method for HLA-C using sequence-biased typing. Tissue Antigens 1998;52: $558-68$

28. Olerup $O$, Zetterquist $H$. HLA-DR typing by PCR amplification with sequence-specific primers (PCR-SSP) in 2 hours: An altemative to serological DR typing in clinical practice including donor-recipient matching in cadaweric transplantation. Tissue Antigens 1992;39:225-35.

29. Bunce $M_{k}$ Taylor $C J$, Welsh KI. Rapid HLA-DQB typing by eight Polymerase Chain Reaction amplifications with Sequence-Specific Primers (PCR-SSP). Hum Immunol 1993;37:201-6.

30. Cereb $\mathbb{N}_{\text {, }}$ 'ang $S Y$. Dimorphic primers derived from intron 1 for use in the molecular typing of HLA-B alleles. Tissue Antigens 1997:50:74-6.

31. Cereb $N$, Kong $Y$, Lee $S$, Maye $P$, Yang $S Y$. Nucleotide sequences of MHC class $\|$ introns 1,2, and 3 in humans and intron 2 in nonhuman primates. Tissue Antigens 1996:47:498 511

32. Gomez-Casado E. Vargas-Alarcon G, Martinez Laso J et al. Evolutionary relationships between HLA-B alleles as indicated by an analysis of intron sequences. Tissue Antigens $1999 ; 53: 153-60$.

33. Gomez-Casado E, Vargas-Alarcon G, Martinez Laso J et al. Generation of the HLA-B35, -B5 $-B 16$, and B15 groups of alleles studied by intron 1 and 2 sequence analysis. Immunogenetics 1997;46:469m 76 .

34. Summers CW, Hampson WJ, Taylor GM. HLA class I non-coding nucleotide sequences, 1992 Eur J Immunogenet 1993;20:201-40.

35. Seurynck K, Baxter-Lowe LA. Novel polymorphism detected in exon 1 of HLA-B*2713. Tissue Antigens $1998 ; 52: 187-9$.

36. Rudwaleit $M$, Bowness $P$, Wordsworth $P$. The nucleotide sequence of HLA-B2704 revealls a new amino acid substitution in exon 4 which is also present in HLA-B2706. Immunogenetics $1996 ; 43: 160-2$

37. Sjöroos $M$, Ilonen J, Lävgren $T$. Salid-phase PCR with hybridization and time-resolved fluorametry for detection of HLA-B27. Clin Chem 2001;47:498-504.

38. Välimala $L_{n}$ Sjöroos $M$, Luhtala $M$, Toivanen $P$, Lovgren $T$. Honen J. Detection of HLA*B27 alleles by group-specific amplification and time-resolwed fuorometry. I Immunol Method $1998,219: 131-7$

39. Kirveskari $ل$, Kellner $H_{1}$ Wuorela $M$ et al. False-negative serological HLA-B27 typing results may be due to altered antigenic epitopes and can be detected by polymerase chain reaction. Brit J Rheumatol 1997;36:185-9.

40. Bettinotti MP, Mitsuishi $Y$, Bibee $K$, Lau M, Terasaki $P$. Comprehensive method for the typing of HLA-A, $B$ and $C$ alleles by direct sequencing of PCR products obtained from genomic DNA. J Immunotherapy 1997:20:425-30.

41. Pozzi S, Longo A Ferrara GB. HLA-B locus sequence-based typing. Tissue Antigens 1999 53:275-81.

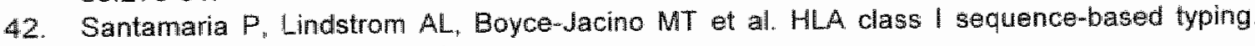
Hum Immunal 1993;37:39-50.

43. Eberle M, Knapp LA, lwanaga KK, Domanico MJ, Alyer K, Watkins Dil. HLA-B typing by allele seperation followed by direct sequencing. Tissue Antigens 1997;49:365-75.

44. Petersdorf EW, Hansen JA. A comprehensive approach for typing the alleles of the HLA.B locus by automated sequencing. Tissue Antigens 1995;46:73-85.

45. Balas $A$, Santos $S$, Garcia-Sanchez F, Lillo R, Merino Ji, Vicario Ji. Complete coding sequence of HLA-B*2712: a serologic B27-negative antigen associated to Bw6. Tissue Antigens 1998;51:394 7 
46. Steiner NK, Jones P, Kosman $C$ et al. Novel HLA-B alteles associated with antigens in the $7 C$ CREG. Tissue Antigens 2001;57:486-8.

47. Saper MA, Bjorkman PJ, Wiley DC. Refined structure of the human histocompatibility antigen HLA-A2 at 2.6 A resolution. J Mol Biol 1991:219:277-319.

48. Fognan D, Krebs $S$, Kuonen $O$, Lamas $J R$, Lopez de Castro JA. Folkers $G$. Fine specificity of antigen binding to two class | major histocompatibility proteins $\left(B^{*} 2705\right.$ and $\left.B^{*} 2703\right)$ differing in a single amino acid residue. J Comput Aid Moll Des 1997;11:463-78.

49. Bodmer JG, Marsh SGE, Albert ED et al. Nomenclature for factors of the HLA system, 1998. Tissue Antiglens 1999;53:407-46. 


\section{Chapter 7}

Intron sequences of HLA-B* 73

Christina EM Voorter, Wendy TN Swelsen and Ella M van den Berg Loonen Tissue Antigens 2001,57:463-468 


\section{Abstract}

Molecular typing methods of HLA-B, like sequence specific oligonucleotide hybridization and sequence-based typing, are based on gene-specific amplifications of exons 2 and 3 followed by probe hybridization or sequence-determination. The necessary gene-specific amplification primers are often located in rather conserved regions of the introns. In several of these procedures HLA. $B^{*} 73$ was not amplified; resulting in drop-out of the allele. To investigate the reason for the allelic urop-out; the sequences of introns 1, 2 and 3 of HLA.B $B^{\text {*7 } 7301}$ were determined.

Comparison of the intron sequence of $B^{\star} 7301$ with other $H L A-B$ and $H L A-C$ alleles revealed several remarkable features. The averall sequence resembles the sequence of other HLA-B alleles, although 35 differences were found with a consensus intron sequence. The insertions and deletions shiown in intron 2 of $\mathrm{B}^{\text {"7 }} 73$ were strikingly similar to the sequences of the HLA-C alleles, as was the $5^{n}$ end of intron 3. Furthermore, a unique deletion was observed in the middle of intron 3 . not noticed in other HLA-B or C alleles. The HLA-B specific primers, widely used for sequence specific digonucleotide hybridization and secquence-based typing purposes, showed mismatches with the $B^{* 73}$ intron sequences, causing the allelic drop-out. Correct amplification of complete exons 2 and 3 of $B^{*} 7301$ was enabled by the design of new primers in intron 2 and 3 . 


\section{Introduction}

The most extensive allelic polymorphism of all human genes is presented by the major histocompatibility complex (MHC). The polymorphism of both class I and class II HLA loci is the result of evolutionary selection and correlates with the capacity to respond to different proteins. Of the HLA loci the HLA-B locus is shown to be the most polymorphic and variable one, with currently 43 serological groups identified and more than 400 alleles assigned by molecular typing methods (HLA Databank January 2001). Most allelic sequence differences resulting in amino acid changes were found in exons 2 and 3 , encoding the $\alpha 1$ and $\alpha 2$ domains of the HLA molecule. Exons 4-8, encoding the $a 3$ domain, the transmembrane region and the cytoplasmic tail were found to be more homogeneous in sequence". The major exception to this rule is the B73 antigen, which showed a "very peculiar" sequence, different from the pattern defined by previously studied HLA-B alleles"

The HLA-B73 antigen was first described by Mayr \& Kirnbauer ${ }^{3}$ and was given an official status at the Ninth International Histocompatibility Workshop in 1984 (4). Since cross-reactivity was observed with B7, B22 and B27 the B73 antigen is serologically related to the $B 7$ cross-reacting group (CREG) ${ }^{4,5}$. The nucleotide sequence of CDNA encoding the B73 antigen was determined by 3 different groups $s^{2,5,6}$ and was found to be highly divergent from other HLA-B alleles. Although it shares polymorphic residues with B27 and B7 in the $\alpha 1$ and $\alpha 2$ domain, it contains multiple substitutions in the $\alpha 3$ domain and the transmembrane domain is one amino acid longer than the HLA-B consensus sequence.

For sequence-based typing (SBT) of HLA-B, at least the sequences of exons 2 and 3 are determined. To enable amplification of the complete exons, the amplification primers designed are often located in the introns. Major differences in intron sequences were found between the class I HLA loci, enabling design of gene-specific intron primers. Furthermore, the intron 1,2 and 3 sequences of HLA-B are relatively conserved compared with the polymorphic exons 2 and $3^{7.9}$. This has smoothened the choice for use of intron primers in molecular approaches without knowing the intron sequences of all HLA-B alleles. In several of these approaches, however, the HLA-B*73 allele was not amplified, resulting in allelic drop out ${ }^{10-12}$. This implicates that, although primers were designed located at conserved positions, the intron sequence of $B^{*} 73$ differs from other HLA-B alleles.

In this report the sequences of introns 1,2 and 3 of HLA-B ${ }^{*} 7301$ are presented and compared with intron sequences of other HLA-B alleles. Conform these 
sequences, intron primers were developed for correct amplification of HLA$B^{\star 7301}$ to enable SBT of this allele. In 10 serologically HLA-B73-positive individuals $S B T$ using these primers resulted in correct assignment of $B^{*} 7301$.

\section{Materials and methods}

\section{Individuals and DNA isolation}

The intron sequences of $B^{*} 7301$ were determined from 2 unrelated individuals, typed by serology as HLA-B73 and by SBT as HLA-B*7301. An additional eight unrelated individuals, all serologically B73 positive, were used for SBT. DNA of these individuals was isolated from fresh heparinized blood or from liquid nitrogen stored Iymphocytes either by the "salting out" extraction procedure as described by Miller et al. ${ }^{13}$ or by using QIA-AMP kits following the suppliers protocol (Qlagen, Westburg. Leusden, the Netherlands). Concentration and purity of DNA samples were measured at optical densities of 260 and $260 / 280$ nกา.

\section{Primers and approach}

To obtain complete intron sequences amplification primers were located in adjacent exons or introns. The introns 1 and 2 are rather short, enabling correct nucleotide assignment with one sequencing reaction only. Due to the length of intron 3 , two sequencing reactions were performed, one with a sequencing primer located at the $3^{\prime}$ end of exon 3 and one in the middle of intron 3 . The primers used for amplification and sequencing of introns 1,2 and 3 of $B^{\star} 73$ are indicated in table 7.1. All primers were designed locally. The primers located in introns 2 and 3 were designed, based upon preliminary results obtained by heterozygous sequencing using exon primers. The $\mathrm{Cy}-5$ labeled sequencing primers developed were located internally of the PCR product to ensure sequencing of specific PCR products.

\section{Amplification and sequencing}

The PCR conditions used were exactly as described for sequence-based typing of HLA-B and HLA-C ${ }^{11.14}$ "In brief, the PCR reaction was carried out in a final volume of $60 \mu \mathrm{l}$, containing $600 \mathrm{ng}$ DNA. 1.5 U Amplitaq DNA polymerase (Perkin Elmer Corporation, Roche Molecular Systems, Branchburg, USA), 20 pmol of biotinylated primer, 40 pmol of unbiotinylated primer, PCR buffer (67 $\mathrm{mM}$ Tris-HCl, $\mathrm{pH} 8.8,16.6 \mathrm{mM}\left(\mathrm{NH}_{4}\right)_{2} \mathrm{SO}_{4}, 0.01 \%(\%)$ Tween $20,1.5 \mathrm{mM}$ $\mathrm{MgCl}_{2}$ ), $6 \mu \mathrm{g}$ cresol red, $200 \mu \mathrm{M}$ each dNTP and $5 \%$ glycerol. The cycling conditions consisted of an initial denaturation at $94^{\circ} \mathrm{C}$ for $2 \mathrm{~min}, 10$ cycles of 
$10 \mathrm{~s}$ at $94^{\circ} \mathrm{C}, 60 \mathrm{~s}$ at $65^{\circ} \mathrm{C}$ and 30 cycles of $10 \mathrm{~s}$ at $94^{\circ} \mathrm{C}, 50 \mathrm{~s}$ at $61^{\circ} \mathrm{C}$ and $30 \mathrm{~s}$ at $72^{\circ} \mathrm{C}$, followed by a final extension at $72^{\circ} \mathrm{C}$ for $10 \mathrm{~min}$. The presence of PCR products with the correct base length was checked by agarose gelelectrophoresis. The AutoreadTm 200 sequencing kit (Pharmacia Biotech, Uppsala, Sweden) was used for solid-phase sequencing as previously described $^{14-17}$. The non-biotinylated DNA strand was removed by alkaline denaturation after attachment of $40 \mu \mathrm{l}$ of biotinylated product to streptavidincoated beads (Dynal, ITK diagnostics, Uithoorn, the Netherlands). The Cy-5 labeled sequencing primer was annealed at $65^{\circ} \mathrm{C}$ for $10 \mathrm{~min}$ and the sequencing reaction was performed at $37^{\circ} \mathrm{C}$ for $5 \mathrm{~min}$. The samples were heated at $90^{\circ} \mathrm{C}$ for $2 \mathrm{~min}$, prior to loading on a $0.5 \mathrm{~mm}$-thick $6 \%$ polyacrylamide-7M urea gel. Electrophoresis was performed on an ALFexpress automated sequencer (Pharmacia Biotech). Sequence data were processed automatically and evaluated manually.

Table 7.1 Sequence and location of amplification and sequencing primers used for SBT of introns 1,2 and 3 of H HLA-B*73.

\begin{tabular}{|c|c|c|c|}
\hline Name & Sequence & Exon/lntron & Location \\
\hline \multicolumn{4}{|l|}{ Intron 1} \\
\hline $5^{\prime} 99022$ & GTCGGGTCCTTCTTCCAGG & 5" UT & $-153-135$ \\
\hline 398015 & ACTGAAAATGAAACCGGGTAAAG & 12 & $152-174^{11}$ \\
\hline $5^{\prime} 98042 c F^{2}$ & ACCCACCCGGACTC & $5^{\prime}$ UT & $-35-22$ \\
\hline 3. $97094 \mathrm{cR}$ & TGTCGTCCACGTAGC & $\mathrm{E}_{2}$ & $149-163$ \\
\hline \multicolumn{4}{|l|}{ Intron 2} \\
\hline $5^{\prime} 98006$ & TCCTCCTGCTGCTCTCGGC & E1 & $26-44$ \\
\hline $3^{\prime \prime} 98016$ & GGAGGCCATCCCGGGCGATCTAT & 13 & $36-58$ \\
\hline $5^{*} 97090 \mathrm{CF}$ & GCTACTACAACCAGAG & E2 & $319-335$ \\
\hline $3^{\prime \prime} 97053 \mathrm{cR}$ & TTCAGGGCGATGTAATCCTT & $E 3$ & $581-576$ \\
\hline \multicolumn{4}{|l|}{ Mtran 3} \\
\hline $5: 00032$ & GACGATGTATGGCTGCGACA & $E_{3}$ & $361-379$ \\
\hline $3^{\prime} 00035$ & GCACGTGTATCTCTGTTCTTG & EA & $829-849$ \\
\hline $5 " 00036 \mathrm{cF}$ & ACCTGGAGAACGGGA & $\mathrm{E3}$ & $584-598$ \\
\hline $500055 \mathrm{cF}$ & TACTGATCAGGTGTCC & 13 & $222-237$ \\
\hline $3: 99046 \mathrm{cR}$ & CAGGGTGGCCTCATG & E4 & $661-675$ \\
\hline $300054 \mathrm{cR}$ & TCACGGTGCCCAAG & 43 & $266-283$ \\
\hline
\end{tabular}

The intron nucleotide positions are numbered according to figure 7.1

2 The indication $c$ in the primer name refers to $C y-5$ labeling of the primer, the indications $F$ and $R$ refer to use of the primer for forward or reverse sequencing, respectively 


\section{Sequence-based typing}

The previously used primers for SBT of $H L A-B^{14}$ resulted in allelic drop out of $B^{*} 73$, due to mismatches with the $3^{\prime}$ primers in intron 2 and intron 3 . Therefore new 3 primers were developed to enable amplification of $B^{*} 73$. For correct amplification of exon 2 of $B^{*} 73$, a specific $3^{4}$ primer (98015) was combined with the $5^{\prime}$ primer described previously $(96091)^{11}$. The second $B$ allele present, was amplified with primers 96133 and $96091^{11}$. For heterozygous sequencing of exon 2 both PCR products were mixed prior to the sequencing reaction. For correct amplification of exon 3 the newly developed $3^{\prime}$ primer (98016) was combined with the $5^{\prime}$ primer $96125^{11}$. This primer combination also amplified the second HLA-B allele, resulting in heterozygous sequencing of exon 3 . The primers used for SBT of exons 2 and 3 are shown in table 7.2. The PCR and sequencing conditions are described above.

Table 7.2 Sequence and location of amplification and sequencing primers used for SBT of axons 2 and 3 of HLA B

\begin{tabular}{|c|c|c|c|}
\hline Name & Sequence & Exon/mitron & Location \\
\hline \multicolumn{4}{|l|}{ Exon 2} \\
\hline $5^{\prime} 96091$ & GGGAGGAGCGAGGGGACCGHCCAG & 11 & $36-57^{1}$ \\
\hline $3^{\prime} 96133 b^{2}$ & ACTGAAAATGAAACCGGGTAAAC & 12 & $152-174$ \\
\hline $398015 b$ & ACTGAAAATGAAACCGGGTAAAG & 12 & $152-174$ \\
\hline $5^{4} 96022 c$ & GCTCCCACTCCATGA & E2 & $74 \sim 88$ \\
\hline \multicolumn{4}{|l|}{ Exon 3} \\
\hline $5^{\prime} 96125$ & TACCCGGTTTCATTTTCAGTTG & 12 & $155-176$ \\
\hline $3^{1} 98016 b$ & WOGGGGCCATCCCGGGCGATCTAT & 13 & $36-58$ \\
\hline $5^{\prime} 970720$ & ${ }^{\circ 5}$ GGGCTGACCGCGGGG & 12 & $234-248$ \\
\hline $5^{\prime} 98026 c$ & ${ }^{5}$ CTGAACGAGGACCTG & E3 & $448-462$ \\
\hline
\end{tabular}

The intron nucleotide positions are numbered according to figure 7.1

2 The indications b and $c$ in the primer name refer to biotinylation and Cy-5 labeling of the primers, respectively

\section{Results and discussion}

The sequences of introns 1,2 and 3 of $B^{\star} 7301$ are shown in figure 7.1 . The sequences were determined by allele-specific amplification followed by direct sequencing of the PCR product. Both forward and reverse sequencing were performed of two unrelated individuals, and the complete introns were sequenced at least 4 times using different PCR products. Furthermore, to confirm that the introns of $B^{*} 73$ were amplified allele-specific, the sequence of the exon which was included in the PCR product, was determined at least partial and sometimes completely. 
IWPTENON 1

COMn:s $\mathrm{B}$

73

Cows c

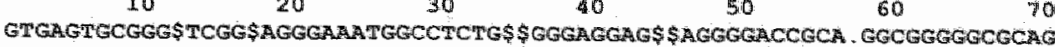
-

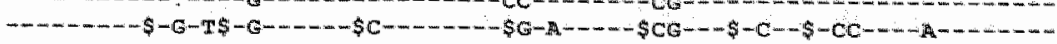
80
90
100
210
120
$\pm 30$

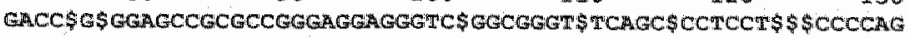

ins

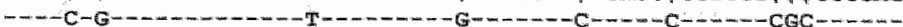

COWS $c$

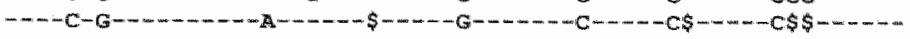

TMTIRON 2

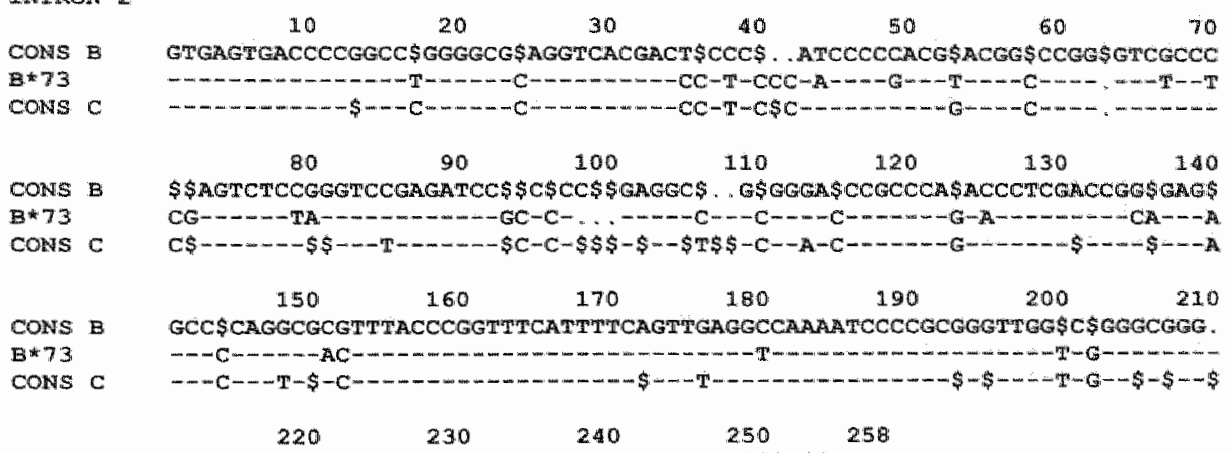

COHS

B* 73 GCGGGG\$\$\$\$CTGGGGGG\$C\$G\$GCTC\$CCGCGGGG\$\$ \$ \$ \$CCAG

CONS $C$ - - - . . . . - - - - - . - T-G-

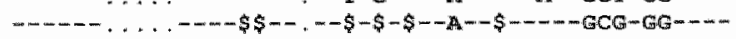

TWTROY 3

Cons B

$B+73$

CONS $\mathrm{C}$

10:

20

30

40

50

60

70

GTACCAGGGGCAGTGGGGAGCCT \$CCCCATCTCCTAMAGTCG \$CGGGGATGGS CUCC \$ACGAGAMASG 作 $80 \quad 90 \quad 100 \quad 110 \quad 120 \quad 130 \quad 240$ CONS H AGGAAAATGGATCAGCGCTAGAATGTCGCCCTCCCHTGAATGGAGAATGGCATGAGTTTTCCTGAGTT $B * 73$ CONS C

CONS $\mathrm{E}+73$ cons $\mathrm{C}$ AGGAAAATGGGATCAGCGTAGAATGTCGCCCTCCC ITGAATGGAGAAIGGCATGAGR ILCTGAGI -

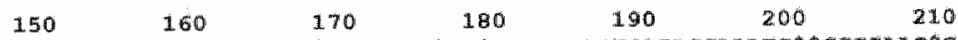

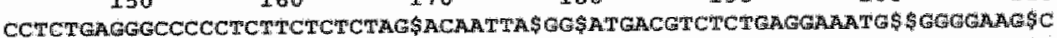
CC

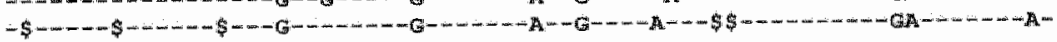
220
230
240
250
260
270
200

CONS B

B. 73

cons $\mathrm{C}$

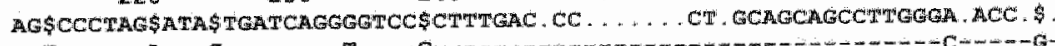

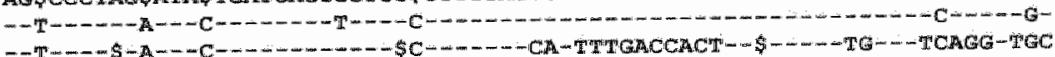

290

300

310

$320 \quad 330$

340

350

Cons $B$

B 73 CONS

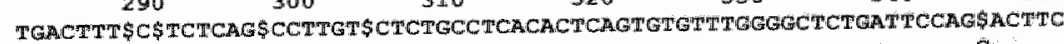

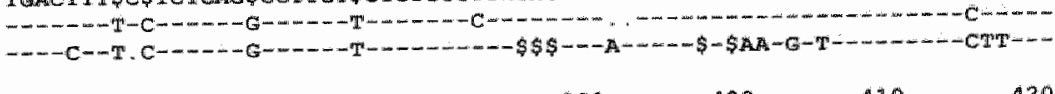
$\begin{array}{llllll}360 & 370 & 360 & 390 & 400 & 40\end{array}$

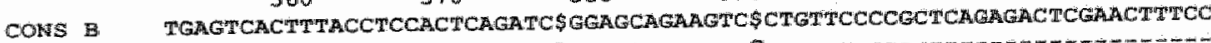
B+73 CONS $\mathrm{C}$

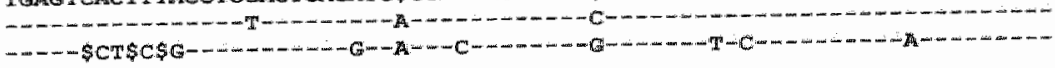

Figure 7.1 continued 


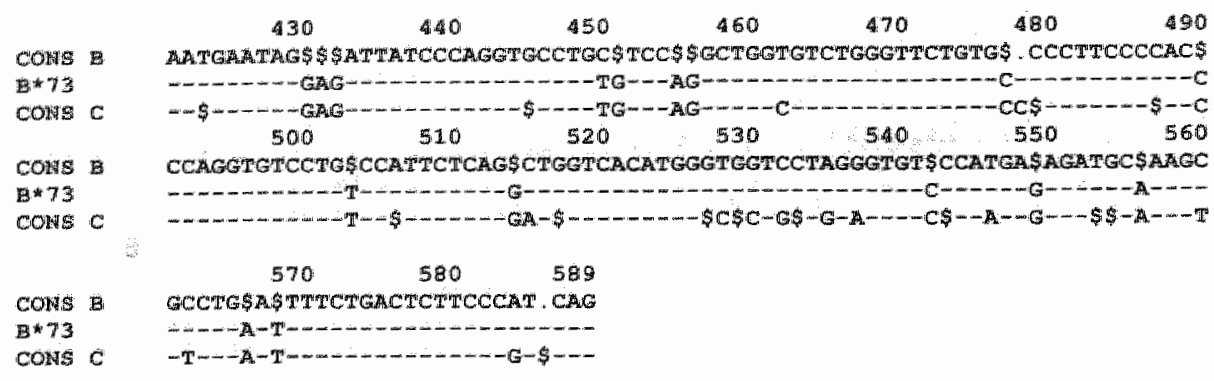

Figure 7.1 Alignment of the intron sequences of HLA-B*7301 to the consensus sequences of HLA-B and $-C$. The dollarsigns in the consensus sequences indicate polymorphic positions, dots reflect deletions in the sequences and nucleotide agreement with the consensus sequence of HLA-B is indicated by dashes. Numbers above the sequences refer to the nucleotide positions within each rion-coding region.

The nucleotide sequence data will appear in the EMBL Nucleotide Sequence Database with the accession numbers AJ297501 (intron 1), A.J297502 (intron 2) and AJ297539 (intron 3).

The $B * 7301$ intron sequences were compared with known intron sequences of HLA-B and $-C$ alleles. For this purpose an intron consensus sequence of HLA$B$ and $-C$ was generated using published sequence data ${ }^{7-9}$. For introns 1 and 2 of HLA-B, the sequences of 44 different alleles were used, whereas for intron 3,23 alleles were available. For the consensus sequence of HLA-C the intron sequences of 13 different alleles were used for all introns ${ }^{8}$. The dollarsigns in the consensus sequence indicate polymorphic positions as determined from published data. The consensus of HLA-B shows 14 polymorphic positions in intron 1,37 in intron 2 and 38 in intron 3. For HLA-C there are 11 polymorphic positions in intron 1,28 in intron 2 and 38 in intron 3.

Comparison of the $B^{*} 73$ intron sequences with the consensus sequences revealed several remarkable features. The intron 1 sequence of $B^{\star} 73$ resembles the consensus sequence of HLA-B with only one additional substitution at position 91. Comparison to the consensus sequence of HLA-C, yielded 11 differences in intron 1 . When the intron 2 sequences were compared, HLA-B*7301 showed a similar number of nucleotide differences with the HLA-B and HLA-C consensus sequence, namely 17 and 18 , respectively. The presence and absence of nucleotide deletions in the HLA-B*7301 sequence was strikingly similar to the HLA-C consensus and different from HLA-B, as noticed at positions $40-42$ and $98-100$. Also for intron 3 , the number of differences with HLA-C (62) outranks the number of differences with HLA-B (17), although several of the HLA-B mismatched nucleotides at the $5^{\prime}$ end were conserved in HLA-C. Furthermore, a unique deletion was observed in the 
middle of intron 3 not noticed in other HLA-B or $-C$ alleles. Overall the intron siequence of HLA-B*7301 is more similar to HLA-B than to HLA-C, although there are several HLA-C specific features present in intron 2 and at the $5^{\prime}$ end of intron 3 . This resembles the situation for the coding sequence of $H L A-B^{*} 73$, since discrete sets of epitopes are shared with $H L A-C^{5}$.

For sequence-based typing of HLA-B the sequences of exons 2 and 3 are determined. We use amplification primers located in the introns, in order to obtain the complete exon sequences. Comparison of the $B^{*} 73$ intron sequences with the primer sequences used for HLA-B SBT revealed one mismatch in the $3^{\prime}$ primer located in intron 2 and two mismatches in the $3^{\prime \prime}$ primer located in intron 3. Therefore new $3^{\prime \prime}$ primers were developed conform the intron sequences of HLA $B^{*} 73$ to accomplish correct amplification of $B^{*} 73$. The new primers were used to perform sequence-based typing of 10 unrelated individuals positive for $\mathrm{B} 73$.

The mismatch of $B^{*} 73$ with the $3^{\prime}$ primer in intron 2 was located at the $3^{\prime}$ end of the primer, preventing correct amplification of exon 2 of $B * 73$. The development of a new primer (98015) with a $B^{\star} 73$ matched nucleotide at the $3^{\prime}$ end, resulted in correct amplification of $B^{*} 73$. This new primer (98015) was not able to amplify exon 2 of any other B allele present, confirming that the $3^{\prime \prime}$ end of the primer is a major determinant for amplification to occur.

The $3^{\prime}$ primer located in intron 3 previously used for SBT of HLA-B, showed two mismatches with the intron sequence of $B^{\star} 73$. The exon 3 of $B^{\star} 73$ was not amplified with this primer, reflecting the need for development of a primer conform the intron sequence of $B^{*} 73$. Surprisingly, the combination of this new primer (98016) with the $5^{\prime \prime}$ primer 96125 resulted not only in correct amplification of $B^{*} 73$, but amplified also all other $B$ alleles present in the 10 individuals investigated. These alleles were $B^{*} 0808, B^{*} 1302, B^{*} 1501, B^{*} 1515$, $B^{*} 3503, B^{*} 3801, B^{*} 4001, B^{*} 4403, B^{*} 5101$ and $B^{*} 5801$. It is not clear why $B^{*} 73$ was not amplified with primer 96125 , showing two mismatches with the $B * 73$ intron sequence, whereas the other $B$ alleles were amplified with primer 98016 , showing two mismatches at identical positions. Although only 10 different HLA$B$ alleles were tested with this primer, it seems plausible to assume that also other HLA-B alleles will be amplified using this primer, since the primer is located in a rather conserved region of the intron.

Since the exon 3 sequences of both alleles were obtained and the sequences of exons 2 and 3 are combined for HLA-typing, it is convenient to sequence exon 2 of both alleles together. Therefore the two PCR products of one individual obtained with the $B^{*} 73$ specific primer (98015) and with the primer 
amplifying all other B alleles (96133) were mixed prior to the sequencing reaction. Another possibility would be to include both $3^{\prime}$ primers in one PCR reaction, but this has not been tested.

The sequence data obtained for exons 2 and 3 from the 10 individuals investigated were reliable with low background signals. Heterozygous positions showed equal peak heights for both exon 2 and 3 sequences, despite the mismatches in the intron 3 amplification primer.

The $3^{\prime}$ primer in intron 3, previously used for SBT of HLA-B, thas been described by Cereb et al. (3B/N3-37) ${ }^{18}$. This primer has been used in several SBT procedures as well as in sequence-specific oligonucleotide probe (SSOP) protocols for HLA-B specific amplification of the alleles ${ }^{10-12,18-21}$. The failure to amplify $B^{*} 73$ has already been noticed previously ${ }^{10-12}$. In this report the reason that $B^{\star} 73$ was not amplified was unraveled by analysis of the intron sequences of $B^{*} 73$. When the $3^{\prime}$ primer in intron 3 described by Cereb et al. ${ }^{18}$, is used for amplification of the HLA-B alleles and a homozygous result is obtained, the presence or absence of B73 must be established either by serology or by the use of the primers described in this report.

\section{Acknowledgement}

We thank Diana van Bakel for excellent secretarial assistance. 


\section{References}

1. Parham P, Adams EJ, Arnett $\mathrm{KL}$. The origins of HLA, $\mathrm{A}_{1} \mathrm{~B}_{3} \mathrm{C}$ polymorphism. Immunol Rev $1995 ; 143: 141 \%-80$.

2. Parham $P$. Arnett $K L$, Adams EJ et al. The HLA-B73 antigen has a most unusual structure that defines a second lineage of HLA-B alleles. Tissue Antigens 1994:43:302-13.

3. Mayr WR, Kumbauer M. Rare HLA-A, B, C antigens in Caucasoids. In: ad. The Immune System. 1981:217-23.

4. Kissmeyer-Nielsen F, Graugaard B, Kuhnl P, Mayr WR. Antigen Report: HLA-Bw73. In: Abert ED, Baur MP Mayr WR, ed. Histocompatibility Testing 1984.Springer-Verlag. 1984:175-6.

5. Hoffmann HJ, Kristensen TJ, Jensen TG. Graugaard B, Lamm LU. Antigenic characteristics and CDNA sequences of HLA-B73. Eur J Immunogenet 1995:2:2:231-40.

6. Vilches $C$. Pablo de R, Herrero Md, Moreno ME, Kreisler M. HLA-B73: an atypical HLA-B molecule carrying a Bw6-epitope motif variant and a B pocket identical to HLA-B27. Immunogenetics 1994:40:166.

7. Gomez-Casado E, Vargas-Alarcon G, Martinez Laso J et al. Generation of the HLA-B35, -BS, $-B 16$, and B15 groups of allels studied by intron 1 and 2 sequence analysis. Immumogeneitics 1997:46:469-76.

8. Cereb N, Kong $Y$, Lee $S$, Maye $P$, Yang SY. Nucleotide sequences of MHC dass I introns 1,2 , and 3 in humans and intron 2 in nonhuman primates. Tissue Antigens 1996:47:498-511.

9. Gomez-Casado $E$, Vargas Alarcon $G$, Martinez Laso $J$ et al. Evolutionary relationships between HLA-B alleles as indicated by an analysis of intron sequences. Tissue Antigens $1999: 53: 153-60$

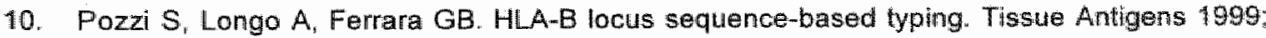
53:275-81.

11. Voorter CEM, Vlies van der SA, Berg van dien-Loonen EM. Sequence-based typing of HLA-B: the B7 cross-reacting group. Tissue Antigens 2000;56:356-62.

12. Fleischhauer $K$, Agostino $A$, Zino $E$ et all. Molecular characterization of HLA class I in Columbians carrying HLA-A2: high allelic diversity and frequency of helerozygotes at the HLA-B locus. Tissue Antigens 1999:53:519-26.

13. Miller $S A$, Dykes DD, Polesky HF. A simple salting out procedure for extracting DNA from human nucleated cells. Nucleic Acids Research 1988;16:1215.

14. Vies van der SA, Voorter CEM, Berg van den-Loonen EM. A reliable and efficient high resolution typing method for HLA-C using sequence-based typing. Tissue Antigens 1990;52 $558-68$.

15. Voorter CEM, Rozemuller EH. Bruyn de-Geraets D, Zwan van der AW, Tilanus MGJ, Berg van den-Loonen EM. Comparison of DRB sequence-based typing using differrant strategles. Tissue Antigens 1997:49:471-6.

16. Voorter CEM, KiK MC, Berg van den-Loonen EM. High-resolution HLA typing for the DQB1 gene by sequence-based typing. Tissue Antigens 1998;51:80-7.

17. Voorter CEM, Bruyn de-Geraets D, Berg van den-Loonen EM. High-resolution HLA typing for the DRB3/4/5 genes by sequence-based typing. Tissue Antigens 1997:50:283-90.

18. Cereb N, Maye P. Lee S, Kong Y, Yang SY. Locus-specific amplification of HLA class I gemes from genomic DNA: locus-specific sequences in the first and third introns of HLA-A, $-B_{\text {, and }}$ C alleles. Tissue Antigens 1995:45:1-11.

19. Levine JE, Yang SY. Allelic frequencies of the HLA-B17 antigen group: comparative anialysis by serology. IEF and PCR-SSOP typing. Tissue Antigens 1995;46:368-73.

20. Hurley CK, Steiner N, Kosman $C$ et al. Novel HLA-A and HLA-B alleles. Tissue Aritigens 1998:52:84-7.

21. Arguello JR, Little AM, Bohan E, Goldman JM, Marsh SGE, Madrigal IAA. High resolution HLA class I typing by reference strand mediated conformation analysis (RSCA). Tissue Antigens 1998;52:57-66. 
132 


\section{Chapter 8}

Polymorphism of intron 4 in HLA-A, -B and $-C$ genes

Wendy TN Swelsen. Christina EM Voorter and Ella M van den Berg-Loonen Tissue Antigens 2003;61:475-483 


\section{Abstract}

The sequence database of HLA clasis I genes focuses on the coding sequences, the exons. Limited information is available on the non-coding sequences of the different class I alleles. In this study we have determined the intron 4 nucleotide sequence of at least one representative of each major altelic group of $H H L A-A,-B$ and $-C$. The intron 4 sequences were determined for 27 HLA-A, 81 HLA-B and $30 \mathrm{HLA}-\mathrm{C}$ alleles by allele-specific sequencing, using primers located in adjacent exons and introns.

The sequences revealed that the length of intron 4 waries with a minimum of 93 and a maximum of 124 nucleotides as a result of insertions and deletions. There were remarkable similarities and differences within HLA-A, $-B$ and $-C$, as well as between them. Within HLA-A, a deletion of three nucleotides was detected in several HLA-A alleles. The HLA-B alleles could be divided into two groups with one group having a deletion of 11 nucleotides compared with the second group. Within $H L A-C$, all $\mathrm{CW}^{*} 07$ alleles showed remarkable differences with the other $\mathrm{CW}$-alleles. $\mathrm{CW}^{*} 07$ had an insertion of three nucleotides, shared only by the CW"17 group. Moreover $C W^{*} 07$ was found to have an aberrant nucleotide sequence. Differences between $H L A-A,-B$ and $-C$ alleles were also observed. Remarkable was the deletion of 20 nucleotides in all HLA-A and $-B$ alleles compared with HLA-C, whereas the HLA-A alleles showed an insertion of one nucleotide and a deletion of three nuclecitides compared with HLA-B and $-C$. Furthermore, 32 different polymorphic positions were detected between HLA-A, $-B$ and $-C$. 


\section{Introduction}

HLA class I molecules are glycoproteins encoded by the human major histocompatibility complex (MHC) genes on the short arm of chromosome 6 . They are expressed on the surface of almost all nucleated cells and play an important role in antigen presentation to cytotoxic. $T$ lymphocytes. The heavy chain of class I molecules is highly polymorphic and is composed of three extracellular domains ( $\alpha 1, \alpha 2$ and $\alpha 3$ ), a hydrophobic transmembrane region and a hydrophilic cytoplasmic tail. The polymorphism is mainly located in exons 2 and 3 encoding the extracellular domains $\alpha 1$ and $\alpha 2$, which are responsible for peptide binding and MHC restricted lymphocyte recognition by $\mathrm{T}$-cell receptors'.

Sequence-based typing methods of HLA class I are based on elucidation of exon 2 and 3 sequences. Extension of the methad with sequences of other exons occurs more frequently nowadays $\mathrm{s}^{2-6}$. This has led to an increase of ambiguities with alleles having identical exon 2 and 3 sequences but differences in other exons. The ambiguities can be resolved by sequencing the exon where the difference is located. HLA intron sequences are a useful resource for the design of gene-specific amplification primers in order to obtain complete exon sequences. However, the sequence database of HLA class I genes focuses on the coding sequences, the exons. Limited information is available on the non-coding sequences of the different class I alleles. Until now, only nucleotide sequences of the $5^{\prime}$ untranslated region and introns 1 through 3 of the common subtypes of HLA class $I$ alleles have been published $^{7-13}$.

In a previous study, we have determined the exon 4 and 5 sequences of different HLA-B5/35 cross-reacting group alleles ${ }^{4}$. For reverse sequencing of exon 4 and forward sequencing of exon 5 we designed sequencing primers located in intron 4. The unknown intron 4 sequence of different HLA-B alleles was elucidated by heterozygous sequencing, which resulted in an out-of-phase alignment in several allelic combinations, apparently because of a deletion in some but not all HLA-B alieles. In another study" intron 4 sequences of different HLA-C alleles were elucidated to design a sequencing primer for forward sequencing of exon 5 . Heterozygous sequencing revealed a length of intron 4 of 124 nucleotides and $\mathrm{CW}^{*} 07$ and $\mathrm{Cw}^{*} 17$ alleles were found to have an insertion of three nucleotides compared with other $C w$-alleles. As a result of these interesting findings, the intron 4 sequences of HLA-B and $-C$ were studied more extensively and intron 4 sequences of HLA-A were included in the study. To assess the degree of palymorphism of the non-coding intron 4 
region, the intron 4 nucleotide sequence of at least one representative of each major allelic group of HLA-A, $-B$ and $-C$ was determined.

\section{Materials and methods}

\section{Individuals}

The intron 4 nucleotide sequence of at least one representative of each major allelic group of $H L A-A,-B$ and $-C$ was determined. Identification of the alleles was obtained by heterozygous sequencing of exons 2 and 3 , extended with allele-specific sequencing and/or sequencing of other exons if necessary ${ }^{14-16}$ For HLA-A, the intron 4 sequences were determined for 20 different allelic groups: $A{ }^{\star} 01,{ }^{*} 02,{ }^{*} 03,{ }^{*} 11,{ }^{*} 23,{ }^{*} 24,{ }^{*} 25,{ }^{*} 26,{ }^{*} 29,{ }^{*} 30,{ }^{*} 31,{ }^{*} 32,{ }^{*} 33,{ }^{*} 34,{ }^{*} 36$, ${ }^{*} 66,{ }^{*} 68,{ }^{*} 69, * 74$ and ${ }^{*} 80 ; A * 43$ was not available in our laboratory. Thirty-four different HLA-B groups were studied: $B^{*} 07,{ }^{*} 08,{ }^{*} 13,{ }^{*} 14,{ }^{*} 15,{ }^{*} 18,{ }^{*} 27,{ }^{*} 35$, *37, "38, *39, *40, *41, *42, "44, *45, *46, *47, *48, *49, " $50,{ }^{*} 51,{ }^{*} 52,{ }^{*} 53,{ }^{*} 54$, ${ }^{*} 55,{ }^{*} 56,{ }^{*} 57,{ }^{*} 58,{ }^{*} 67,{ }^{*} 73,{ }^{*} 78,{ }^{*} 81$ and ${ }^{*} 82$. No individuals representing $B * 59$ and $\mathrm{B}^{*} 83$ were available. For HLA-C, 14 different allelic groups were sequenced: $C w^{*} 01,{ }^{*} 02,{ }^{*} 03,{ }^{*} 04,{ }^{*} 05,{ }^{*} 06,{ }^{*} 07,{ }^{*} 08,{ }^{*} 12,{ }^{*} 14,{ }^{*} 15,{ }^{*} 16,{ }^{*} 17$ and *18. Most allelic groups were represented by more than one allele. In total, the intron 4 nucleotide sequences were determined for 27 different HLA-A, 81 HLA-B and 30 HLA-C alleles.

\section{DNA isolation}

DNA was isolated from fresh heparinized blood or from lymphocytes stored in liquid nitrogen either by the "salting out" extraction procedure as described by Miller et al. ${ }^{17}$ or by using QIA-AMP kits following the suppliers protocol (Qiagen, Westburg, Leusden, the Netherlands). Concentration and purity of DNA samples were measured at optical densities of 260 and $260 / 280 \mathrm{~nm}$.

\section{Primers and approach}

To obtain complete intron 4 sequences, amplification and sequencing primers were located in adjacent exons or introns. The location and sequence of the primers used for allele-specific amplification and sequencing of intron 4 of HLA$A,-B$ and $-C$ are shown in table 8.1. All primers were designed locally. The $C y-$ 5 labeled sequencing primers developed were located internally of the PCR product to ensure sequencing of specific PCR products. For HLA-A and -B forward sequencing was performed, whereas for HLA-C either forward or reverse sequencing was necessary. If an aberrant nucleotide sequence was detected, the intron 4 sequence of the allele was confirmed in another 
individual positively typed for that allele or possessing another allele within the same group.

Table 8.1 Lacation and sequence of primers used for allele-specific amplification and sequencing of intron 4 of HLA $A,-B$ and $-C$.

\begin{tabular}{|c|c|c|c|}
\hline Name & Sequence & Location & Position \\
\hline 5:A02001 & GGGCCACGGGGCGCCTT & Intron 3 & $8-24^{1}$ \\
\hline SA02002 & AGGGATAAAATCTCTGAAGGAG & Intron 3 & $198-220$ \\
\hline $5: 402003$ & TGGTTCCCTITGACACACACA & Intron 3 & $254-274$ \\
\hline $5: 402004$ & CCGGCAGCAGCCTTGGGA & Intron 3 & $269-290$ \\
\hline $5 \mathrm{AO} 2005$ & GGTTCCCTTIGACACACACC & Intron 3 & $255-274$ \\
\hline 3:A02009 & CAGCGACCACAGCTCCAG & Exon 5 & $971-988$ \\
\hline 5:A02006 & ${ }^{15}$ ACCTTCCAGAAGTGGG & Exon 4 & $790-805$ \\
\hline $5 \mathrm{~A} 02019$ & GACCAGACCCAGGAC & Exon 4 & $739-753$ \\
\hline $5 \mathrm{~B} 98042$ & ACAGATCTACAAGGCCCAG & Exon 2 & $264-282$ \\
\hline 5896044 & CCTGCGGAACCTGCGCG & Exon 2 & $303-319$ \\
\hline $5 " \mathrm{~B} 98071$ & CCGCGGGCATAACCAGTTA & Exan 3 & $402-420$ \\
\hline 5 Bo1020 & GTCCTAGGGTGTCCCATGAG & Intron 3 & $594-613^{2}$ \\
\hline $5^{\prime} \mathrm{B} 01021$ & GTCCTAGGGTGTCCCATGAA & Intron 3 & $594-613$ \\
\hline $5^{\prime} \mathrm{B} 01022$ & TCTGTGCCCCTTCCCCACA & Intron 3 & $532-551$ \\
\hline $5^{\circ} \mathrm{BO} 1023$ & TCTGTGCCCCTTCCCCACC & Intran 3 & $532 \cdot 551$ \\
\hline $5^{\prime} B 01024$ & TGGGTGGTCCTAGGGTGTG & Intron 3 & $586-1606$ \\
\hline $5 \cdot 801025$ & TGGGTGGTCCTAGGGTGTC & Intron 3 & $586-606$ \\
\hline $5 B 01047$ & GCCAGGGTCTCACACTTGG & Exon 3 & $12-357$ \\
\hline $5 " B 01048$ & GGGCCAGGGTCTCACATCA & Exom 3 & $12-355$ \\
\hline $5^{\prime} \mathrm{B} 01050$ & AYGTGACCCACCACCCCA & Exon 4 & $635-652$ \\
\hline $5 \mathrm{~B} 02023$ & AGCCTACCTGGAGGGCGA & Exon 3 & $543-560$ \\
\hline $5^{\prime} \mathrm{B} 02024$ & AGCCTACCTGGAGGGCCT & Exon 3 & $543-560$ \\
\hline 3'B96069 & CCACGATGGGGAYGGTGGA & Exon 5 & 910.928 \\
\hline $5^{8} \mathrm{~B} 01011$ & ${ }^{Y 5}$ GACCTTCCAGAAGTGG & Exon 4 & $788-804$ \\
\hline $5^{\circ} \mathrm{C} 97071$ & ACCGAGTGAGGCTGCGGAAC & Exon 2 & $293-312$ \\
\hline $5^{\circ} \mathrm{C} 98006$ & GGGTCTCACACCCTCCAGT & Exon 3 & $\mid 2-361$ \\
\hline $5^{*} \mathrm{C} 98024$ & GCCTGTGTCCAGGCTGGC & Intron 3 & $506-523$ \\
\hline $5^{\prime} \mathrm{C} 98030$ & AGCACGAGGGGCTGCCA & Exton 4 & $857-873$ \\
\hline $5^{\circ} \mathrm{C} 98031$ & AGCACGAGGGGCTOCCG & Exon 4 & $857-873$ \\
\hline 5098049 & TTCTGTGCCOCCTTCCCT & Intron 3 & $531-548$ \\
\hline $3^{\prime} \mathrm{C} 96081$ & CCTCCTACACATCATAGCGGT & Exon 5 & $985-1005$ \\
\hline $3^{\prime} \mathrm{C} 97096$ & CTGSACGCAGCCTGAGAGC & Exon 6 & $1034-1052$ \\
\hline $3^{\mathrm{C}} \mathrm{C} 98018$ & AGAGCAGCTCCCTCCTTTTC & Exon 6 & $1019-1038$ \\
\hline $3 \mathrm{C} 98036$ & ${ }^{85}$ GAAAACGCAGACCCC & Intron 5 & $21-36^{3}$ \\
\hline
\end{tabular}

${ }^{1}$ The intron 3 positions of HLA-A are numbered according to Kotsch et al.

${ }^{2}$ The intron 3 positions of HLA-B and $-C$ are numbered according to Cereb et al.

"The intron 5 positions of HLA-C are numbered according to Summers et al. "3

For HLA-A the allele-specific $5^{\prime}$ primers were located in intron 3 and the locus specific $3^{\prime}$ primer (A02009) was located in exon 5. Different allele-specific $5 "$ primers were used dependent on the two HLA-A alleles present in the individual. Two different sequencing primers (A02006, A02019) located in exon 4 were used. The allele-specific $5^{\prime}$ primers for HLA-B were located in exon 2, 3 
or 4 or intron 3 and the locus-specific $3^{\prime \prime}$ primer (B96069) was located in exon 5. The sequencing primer (B01011) was located in exon 4. For HLA-C, allelespecific $5^{4}$ primers were designed located in exon 2, 3 or 4 or intron 3 . Two of them, C98030 and C98031, were located at the $3^{\prime}$ end of exon 4. Because of their location, forward sequencing with an internal sequencing primer was not possible, and therefore reverse sequencing was performed. In several homozygous individuals a locus-specific $5^{+}$primer (C98024) was used. The $3^{i}$ primers used for HLA-C were located in exon 5 or 6 . For forward sequencing the same sequencing primer (B01011) was used as for HLA-B. This primer was located at a conserved part of exon 4 with identical sequences for HLA-B and $C$ alleles. For reverse sequencing a primer (C98036) located in intron 5 was used.

\section{Amplification and sequencing of intron 4}

The PCR conditions used were identical to the conditions for SBT of HLA-B and $-\mathrm{C}$ as previously described ${ }^{15.16}$. In brief, the PCR reaction was carried out in a final volume of $60 \mu \mathrm{l}$, containing $600 \mathrm{ng}$ DNA, $1.5 \mathrm{U}$ Amplitaq DNA polymerase (Perkin Elmer Corporation, Roche Molecular Systems, Branchburg, USA), $20 \mathrm{pmol}$ of biotinylated primer, 40 prnol of unbiotinylated primer, PCR buffer according to Bunce ${ }^{18}(67 \mathrm{mM}$ Tris- $\mathrm{HCl}, \mathrm{pH} 8.8,16.6 \mathrm{mM}$ $\left(\mathrm{NH}_{4}\right)_{2} \mathrm{SO}_{4}, 0.01 \%$ (v/v) Tween 20 ), $1.5 \mathrm{mM} \mathrm{MgCl}_{2}, 6 \mu \mathrm{g}$ cresol red, $200 \mu \mathrm{M}$ each dNTP and $5 \%$ glycerol. The cycling conditions consisted of an initial denaturation at $96^{\circ} \mathrm{C}$ for $2 \mathrm{~min}, 10$ cycles of $10 \mathrm{~s}$ at $94^{\circ} \mathrm{C}, 60 \mathrm{~s}$ at $65^{\circ} \mathrm{C}$ and 30 cycles of $10 \mathrm{~s}$ at $94^{\circ} \mathrm{C}, 50 \mathrm{~s}$ at $61^{\circ} \mathrm{C}$ and $30 \mathrm{~s}$ at $72^{\circ} \mathrm{C}$, followed by a final extension at $72^{\circ} \mathrm{C}$ for 10 min. The presence of PCR products with the correct base length was checked by agarose gel electrophoresis. A solid-phase sequencing approach was used as previously described ${ }^{16,19-24}$. The nonbiotinylated DNA strand was removed by alkaline denaturation after attachment of $40 \mu \mathrm{l}$ of biotinylated product to streptavidin-coated beads (Dynal, ITK diagnostics, Uithoorn, the Netherlands). After annealing of the Cy-5 labeled sequencing primer, the sequencing reaction was performed at $37^{\circ} \mathrm{C}$ for $5 \mathrm{~min}$. The samples were heated at $90^{\circ} \mathrm{C}$ for $2 \mathrm{~min}$, prior to loading on a $0.5 \mathrm{~mm}$-thick $6 \%$ polyacrylamide-7M urea gel. Electrophoresis was performed on an ALFexpress automated sequencer (Pharmacia Biotech. Uppsala, Sweden). Sequence data were processed automatically and evaluated manually.

\section{Consensus sequence}

The intron 4 sequences of the different class I alleles were compared with each other. For this purpose an intron 4 consensus sequence was generated. At polymorphic positions the most frequently occurring nucleotide is represented 
in the consensus. Dots reflect deletions and nucleotide agreement with the consensus is indicated by dashes.

\section{Results}

The intron 4 nucleotide sequences of the different HLA-A, $-B$ and $-C$ alleles, aligned to the consensus sequence, are shown in figure 8.1 . The sequences revealed that the length of intron 4 varies with a minimum of 93 and a maximum of 124 nucleotides, as a result of insertions and deletions. There were remarkable similarities and differences within HLA-A, HLA-B and HLA-C. as well as between them.

\section{Comparison of intron 4 nucleotide sequences within HLA-A}

Between the HLA-A alleles only few differences were detected. Several HLA-A alleles, $A^{*} 02,{ }^{*} 25,{ }^{*} 26,{ }^{*} 29,{ }^{*} 31,{ }^{*} 32,{ }^{*} 33,{ }^{*} 34,{ }^{*} 66,{ }^{*} 68,{ }^{*} 69$ and ${ }^{*} 74$, showed a deletion of three nucleotides at positions 58-60 in comparison with other HLA-A alleles. Four polymorphic positions were identified, namely 14,30, 37 and 78 . According to these polymorphic positions five different groups could be recognized. The allelic groups $A^{*} 02,{ }^{*} 25,{ }^{*} 26,{ }^{*} 34,{ }^{*} 66,{ }^{*} 68$ and ${ }^{*} 69$ showed both a $C$ at position 14 and $a T$ at position 30 , whereas the consensus was $T$ and $C$, respectively. $A T$ at position 30 and a $C$ at position 37 was found in $A * 32$ and ${ }^{*} 74$. The allelic groups $A^{*} 29,{ }^{*} 31$ and ${ }^{*} 33$ all showed $a T$ at position 30 , with the other polymorphic positions in accordance with the consensus. The presence of a $T$ at position 30 seemed to be correlated with the presence of the three nucleotide deletions at positions 58-60, as both always occurred simultaneously. At nucleotide position 78 , the $A^{*} 8001$ allele had a unique mismatch with all other HLA-A alleles. The allelic groups $A^{*} 01,{ }^{*} 03, " 11, " 23$, ${ }^{*} 24,{ }^{*} 30$ and ${ }^{*} 36$ showed a sequence identical to the consensus sequence at the polymorphic positions.

\section{Comparison of intron 4 nucleotide sequences within HLA-B}

Within HLA-B a deletion of 11 nucleotides at positions 56-66 was observed in several allelic groups: $B^{*} 07,{ }^{*} 08,{ }^{*} 14,{ }^{*} 27,{ }^{*} 38,{ }^{*} 39,{ }^{*} 40, * 41,{ }^{*} 42,{ }^{*} 44,{ }^{*} 47,{ }^{*} 67$ and ${ }^{*} 81$. The $B^{*} 48$ group showed two different patterns, in $B^{*} 4801$ and 4803 the deletion was present, in $B^{*} 4802$ it was absent. Five polymorphic positions were identified, namely $30,76,79,106$ and 114. At nucleotide position 30, all $B^{*} 15$ alleles tested, $B^{*} 4501, B^{*} 4601, B^{*} 4901$ and $B^{*} 5001$ had $a$, whereas the other $B$-alleles had a $C$. The intron 4 nucleotide sequence of $B^{*} 7301$ was similar to ather B-alleles with only one unique nucleotide substitution from $A$ to 
$G$ at position 76 . The polymorphic position 79 resulted from a unique substitution in $B^{*} 3701$ from $G$ to A. Beside the deletion at position 56-66, another difference was observed within the $B^{*} 48$ group at nucleotide position 106. The alleles $B^{*} 4801$ and ${ }^{*} 4803$ had an $A$, whereas $B^{*} 4802$ had a $G$ at this position. The $G$ was further noticed in the allelic groups $B * 35,{ }^{*} 51,{ }^{*} 52,{ }^{*} 53$, ${ }^{*} 54,{ }^{*} 55,{ }^{*} 56,{ }^{*} 58$ and ${ }^{*} 78$. Also within the $B^{*} 40$ group differences were detected. The alleles $B^{*} 4002$, , 4003 , "4005, "40061, "4008 and *4035 had a T at nucleotide position 114 , whereas the other $B^{*} 40$ alleles in this study had a $C$. Similarly the groups $B^{*} 27,{ }^{*} 44$ and ${ }^{*} 47$ showed a $T$ at position 114 . In total seven different $B$ groups could be recognized on basis of the polymorphic positions as well as the presence or absence of the 11 nucleotide deletion. The group with the deletion could be subdivided into two sections, one with a $C$ at position 114 , the other with a $T$ at this position. The allelic groups $B^{*} 13, " 18$, * 57 and $* 82$ showed the consensus intron sequence.

\section{Comparison of intron 4 nucleotide sequences within HLA-C}

Within HLA-C, the $\mathrm{CW}^{*} 07$ alleles showed remarkable differences with all other Cw-alleles. This allelic group had an insertion of three nucleotides at positions 54-56, shared by the $\mathrm{Cw}^{*} 17$ alleles only. Furthermore, the $\mathrm{Cw}^{*} 07$ alleles showed nucleotide differences with all other $\mathrm{C}_{W}$-alleles at eight nucleotide positions, namely $12,16,25,26,28,33,38$ and 112 . Within the $\mathrm{Cw}^{*} 07$ allelic group, $\mathrm{Cw}^{*} 0706$ showed a difference with other $\mathrm{Cw}^{*} 07$ alleles at nucleotide position 117. $\mathrm{Cw}^{*} 0706$ had a $\mathrm{T}$ at this position, whereas all other $\mathrm{Cw}^{*} 07$ alleles had a $\mathrm{C}$. Next to the polymorphic positions present in the $\mathrm{CW}^{*} 07$ group, another six polymorphic positions were detected. At nucleotide position 23 , the allelic groups $\mathrm{Cw}^{*} 01,{ }^{*} 03,{ }^{*} 04,{ }^{*} 14$ and ${ }^{*} 18$ had a G, whereas all other groups had a C. Two allelic groups, $C w^{*} 02$ and ${ }^{*} 15$, showed a $T$ at position 70 , whereas the consensus for HLA-C was a $C$. At position 71, a unique substitution $(G \rightarrow A)$ was detected in the $\mathrm{Cw}^{*} 03$ group. Four groups, $\mathrm{Cw}^{*} 01,{ }^{*} 04,{ }^{*} 14$ and ${ }^{*} 18$, showed an AG sequence at positions 91 and 92 . A GT sequence was noticed in $\mathrm{CW}^{*} 17$, whereas all other HLA-C alleles showed a GG sequence at these positions. The polymorphic position 95 was the result of a unique substitution in $\mathrm{CW}^{*} 17$ from $\mathrm{C}$ to $\mathrm{A}$. In total, six different groups could be detected based on the polymorphic positions. The groups $C W^{*} 05,{ }^{*} 06,{ }^{*} 08,{ }^{*} 12$ and ${ }^{*} 16$ showed the consensus sequence for HLA-C at all polymorphic positions. 
A*01011

A*02011

A*0206

$A * 03011$

A.0305

A 11011

A*2301.

A. 24031

$A * 24.07$

A* 2419

A* 2501

A*2601

A*29011

$A * 3001 *$

A*3011

A*31012

A* $3201 *$

A*3301

$A * 3303$

$A * 3402$

$A * 3.404$

A. $* 361$

$A * 6601$

A 6802

A* 6901

A* 7.403*

A*8001*

B*07021

B*0715

$B * 0801$

B*1.302

B*1.402*

B*15011

B* 1502

1503

B. 1512

$B * 1516$

B. 15171

E. 1522

B*18011

B*1809

B*27052

B.270.54

B* 2715

B*2717

B*35011

* 3502

B. 3503 *

B. 3504

B*3505

B* 3508

B* 3512

B*3516

B*3517

B. 3530

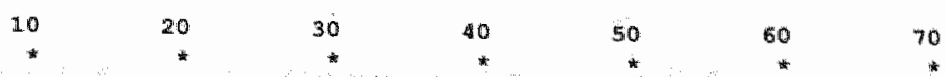

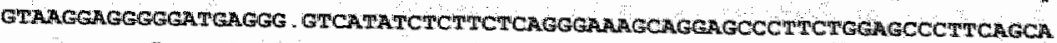

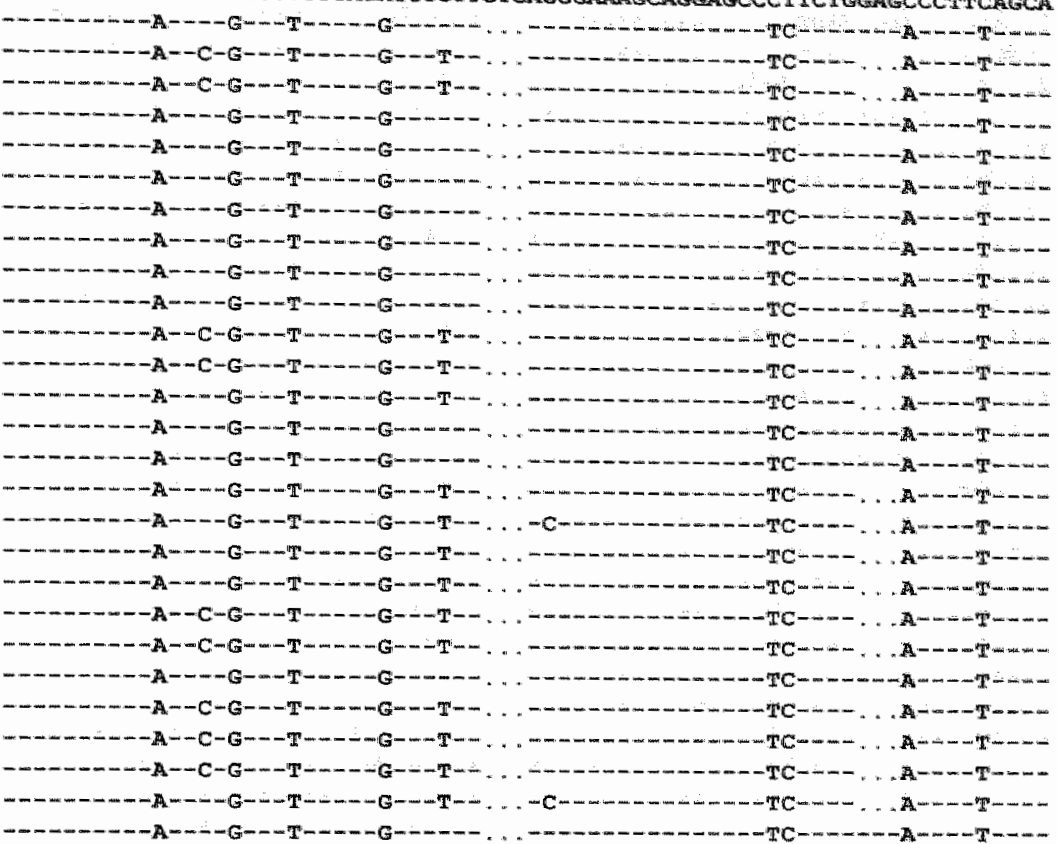

Figure 8.1 continued 


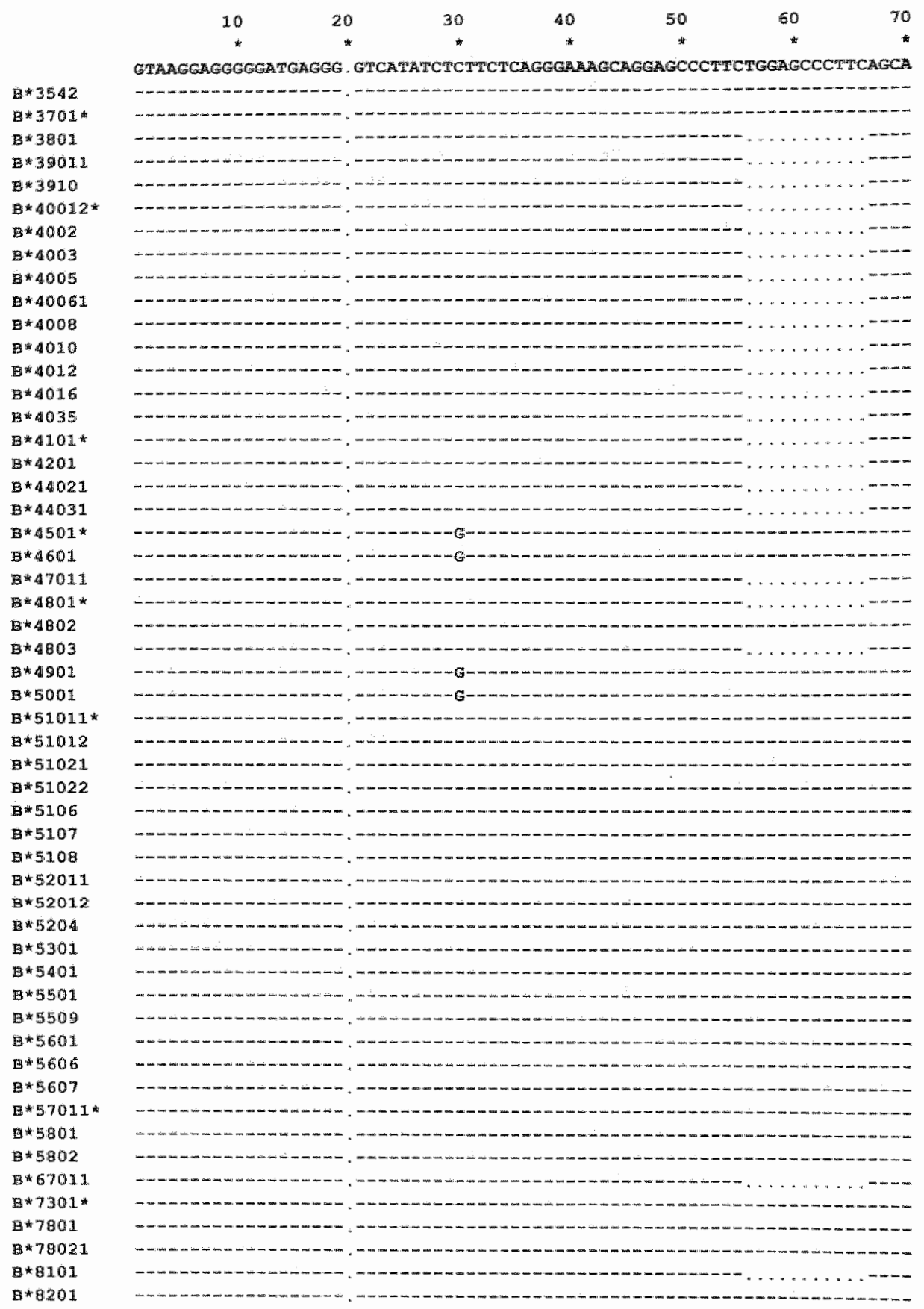

Figuire 8.1 continured 


$C * 0102$
$C w 0103$
$C * 02022$
$C * 02024$
$C w 03022$
$C w * 03031$
$C * 0308$
$C w * 4011$
$C w 0403$
$C w * 0501$
$C w * 0602$
$C w * 07011$
$C w * 07012$
$C w * 07021$
$C w * 07041$
$C w * 0706 *$
$C w * 08011$
$C w * 0802$
$C w * 12022$
$C w * 12031$
$C w * 14021 *$
$C w * 1403$
$C w * 15021 *$
$C w * 1506$
$C w * 1601$
$C w * 16041$
$C w * 1701$
$C * 1703$
$C w * 1801$
$C w * 1802$

$A * 01011$

A *02011

A. 0206

$A * 03011$

A.0305

A.1.1011

A 2301

A*24031

A *2407

A* 2419

$A * 2501$

1.2601

A. 29011

A*300*

A*3011

A*31012

A*3201*

A*301

A. 3303

A* 3402

D. 3404

. $* 3601$

1.0

\begin{abstract}
20
\end{abstract}
30

30

40

50

$\$ 10$

70

GTAAGGAGGGGGATAGGG GTCATATCTCTICTCNGGGAAAGCAGGAGCCCTMCITCAGCCCITCAGCA

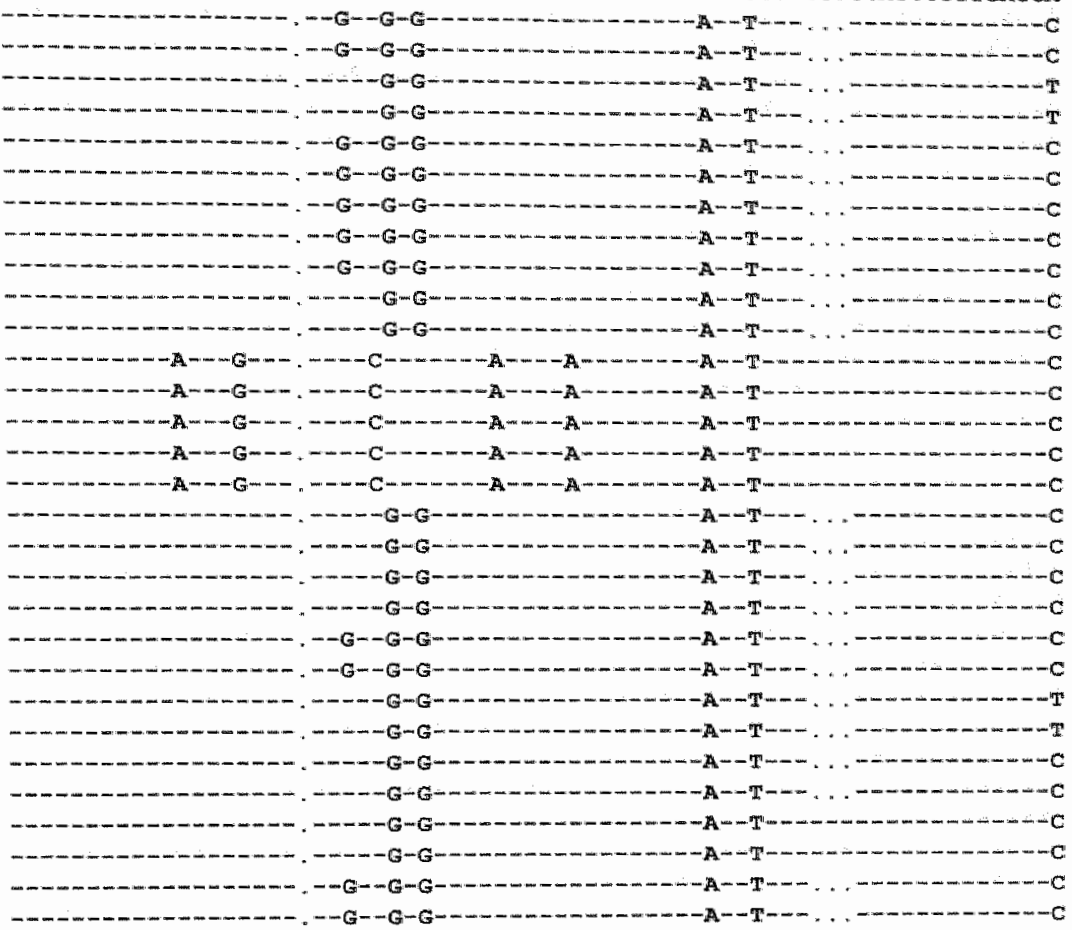

$\begin{array}{rrrrr}80 & 90 & 100 & 120 & 120 \\ * & * & * & * & *\end{array}$

\title{
GGGTCAGGGC . . . . . . . . . CCCTCATCTTCCCCTCCTTTCCCAG
}

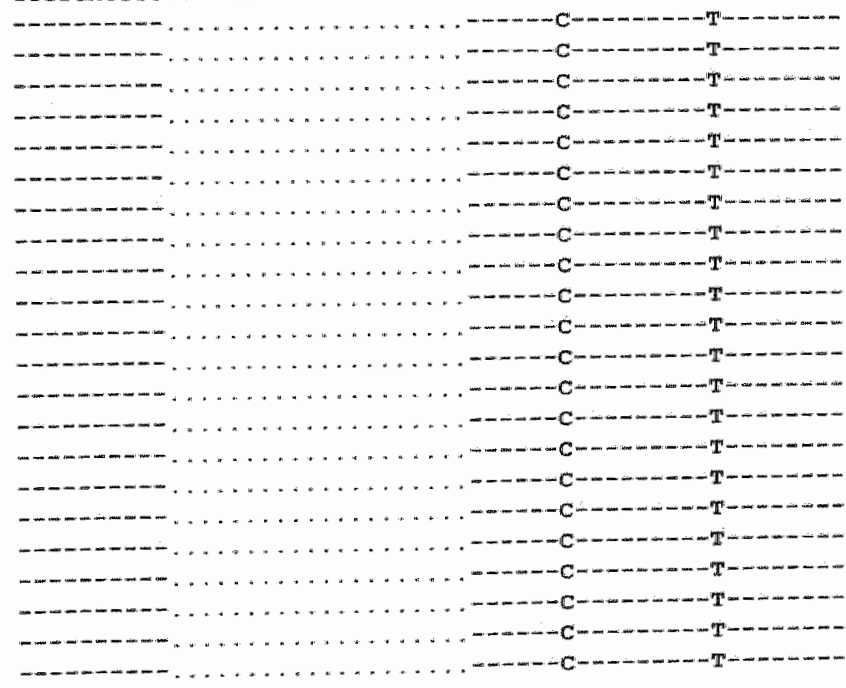

Figulne 8 . I continued 
. $* 51601$

A*6102

A*6901

A*7403*

A 8001

B.*07021

8* 0715

E. 0801

B. 1302

E*1402*

B* 15011

B. 1502

* 1503

因*12

B. 1516

且烟 15171

D** 1522

B. 18011

* * 1809

* 27052

B. 27054

B*2715

B*271.7

E* 35011

B*3502

D*3503*

B* 3504

B*35.05

B* 3500

B*3512

B*3516

[B*3517

13. 350

\$ $* 3542$

B*3701*

* *3801

B*39011

$\$ 310$

* 40012 *

3.4002

1. 4003

14005

B.40061.

12.4008

* 4010

- 4012

13016

B*4035

B* 4101 *

B.4201

[A 4021

*4031

B.401*

B 601

1.4011

90

100

110

120

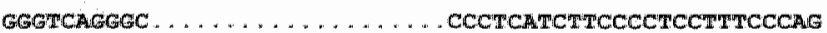
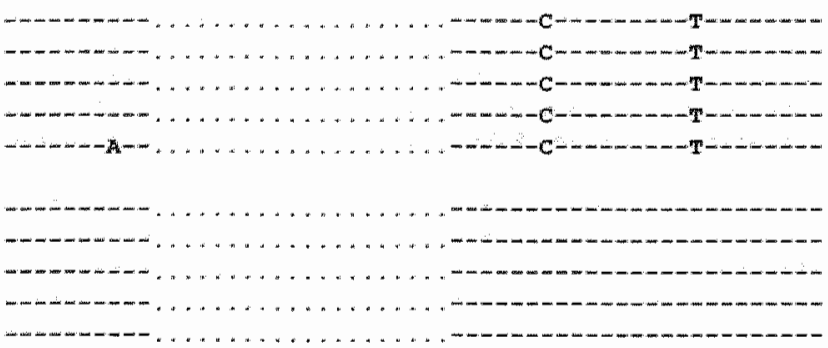

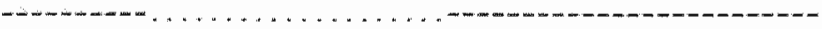
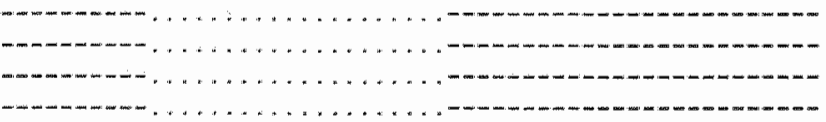

-
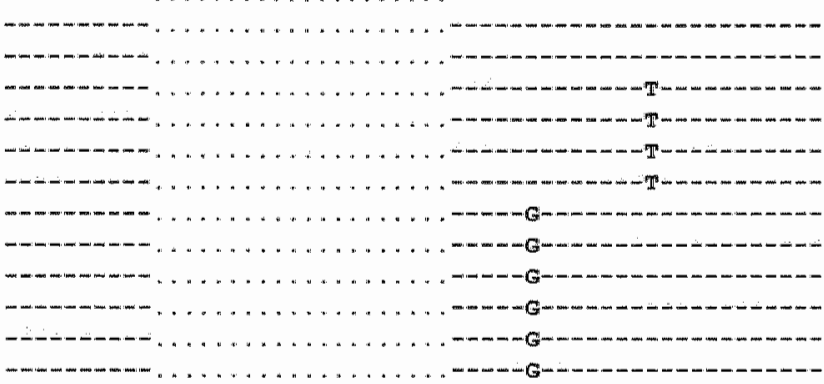

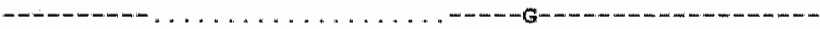
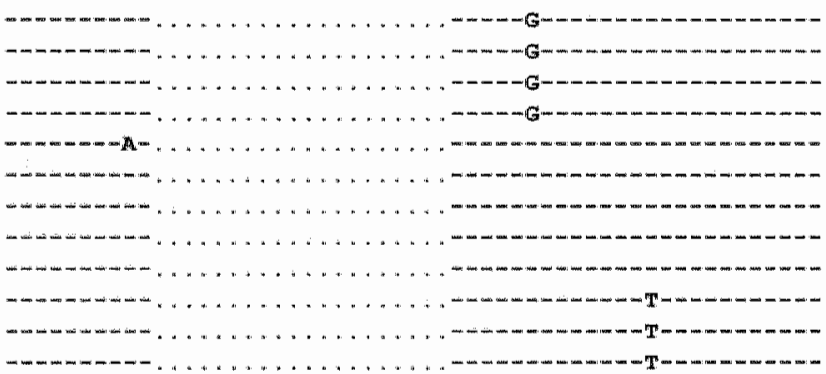

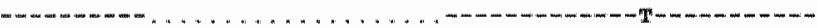
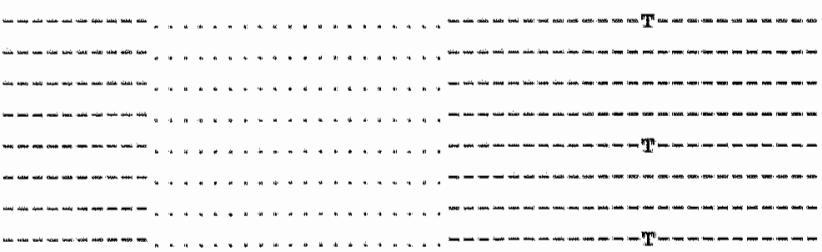

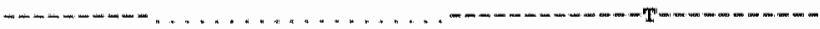
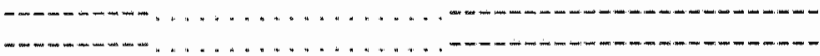

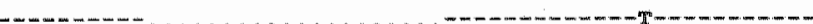

Figure 8.1 continuled 
1501*

B*4802

B.4803

B*4901

B*5001

B*5.1011*

B. 51012

$3 * 51021$

E.51022

B*5106

$B * 5107$

B* $510 \mathrm{~B}$

B*52011

B* 52012

B) 5204

B*5301

$E * 5401$

B. 501

* 5509

$B * 5601$

B*5606

B* 5607

B 57011 *

B*5801

B*5802

B*67011

B-7301*

…7801

B*78021

B*8101

$B * 8201$

C) 0102

Cw 0103

Cw $\$ 02022$

Cw*02024

corto 03022

EN 03031

CH * 308

C) 04011

C* $* 0403$

Cw 0501

C. 0602

Cw 107011

Cw 07012

CW*07021

C.*07041

CW 0706

C世0801 1

CN*0802

C*: 12022

Cw 12031

Cw*14021*

Cw* 1403

C础*1.5021

Crot 1506
$100 \quad 110 \quad 120$

GGGTCAGGGC . . . . . . . . . . CCCTCATCWMCCCTCCWMTCCCAG
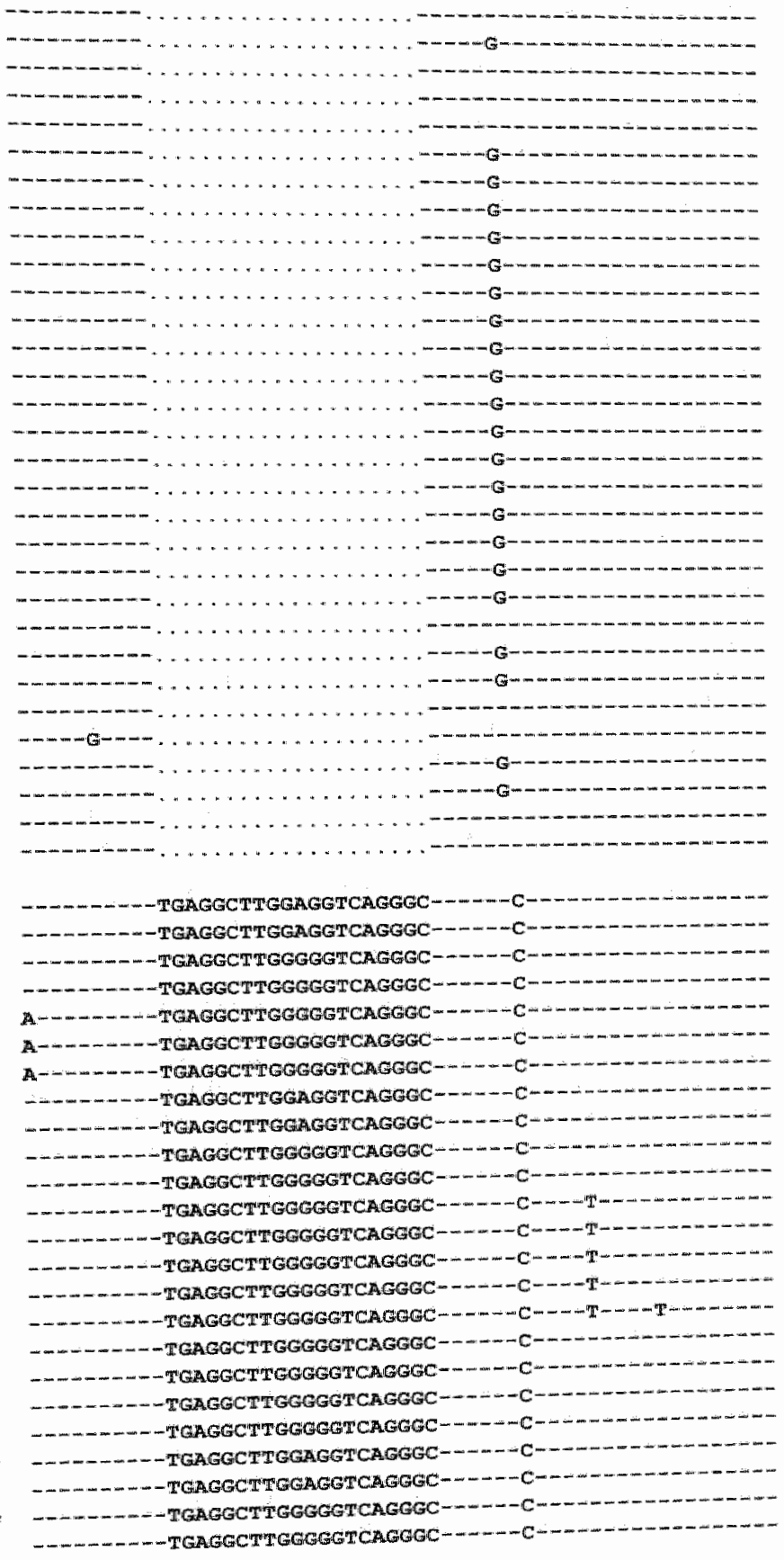

Figure e. 1 continued 


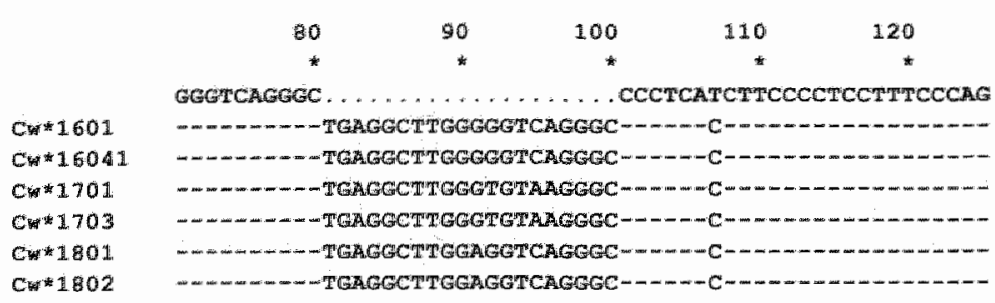

* The intron 4 sequence is confirmed in a second individual.

Figure 8.1 Alignment of the intran 4 nucleotide sequences of different HLA-A, $-B$ and $-C$ alleles to the consensus sequence. At polymorphic positions, the most frequently occurring nucleotide is represented in the consensus. Dots reflect deletions and nucleotide agreement with the consensus sequence is indicated by dashes

Comparison of intron 4 nucleotide sequences between HLA-A, $-B$ and $-\mathrm{C}$

Comparing the intron 4 sequences of HLA-A, $-B$ and $-C$, several differences were encountered. One remarkable difference was that HLA-A and $-B$ alleles had a deletion of 20 nucleotides at positions 81-100 compared with HLA-C, whereas the HLA-A alleles had an insertion of one nucleotide at position 20 and a deletion of three nucleotides at positions 33-35 compared with HLA-B and $-C$. Different kinds of polymorphic positions were present between HLA-A, $-B$ and $-C$. In HLA-A there were 10 positions that showed identical sequences within HLA-A, but different from the consensus. In HLA-C there were only three of those positions, of which one, position 107, was shared by HLA-A. The G at position 16 of all A-alleles was shared by $\mathrm{Cw}^{*} 07$, whereas all other $\mathrm{Cw}$-alleles shared the $\mathrm{G}$ at position 26 with all A-alleles. The T at position 117 of $\mathrm{Cw}^{*} 0706$, which was unique among HLA-C, was shared by HLA-A. At position 30 both HLA-A and $-B$ showed polymorphism between the different alleles. In total, 32 different polymorphic positions were detected between HLA-A, $-B$ and $-C$.

\section{Discussion}

In this study the intron 4 nucleotide sequence of at least one representative of each major allelic group of HLA-A, $-B$ and $-C$ was determined. In total, 27 different HLA-A, 81 HLA-B and 30 HLA-C alleles were sequenced. The length of intron 4 proved to be variable between 93 and 124 nucleotides. An extensive homology for HLA-A, $-B$ and $-C$ was detected, but also several locus- and group-specific sites were identified, similar to the introns 1 through 3 sequences $^{7-10,13}$ 
The nucleotide sequences of intron 4 were determined by allele-specific sequencing. For each locus different allele-specific primers were used dependent on the alleles present in the individual. All different primer combinations resulted in correct amplification and sequencing. As a result of the location of the sequencing primer, the sequencing product contained part of the exon 4 sequence next to intron 4 sequence data. Because of the short length of intron 4 , usually a part of exon 5 was also evaluated. These exon 4 and 5 sequences were used to check whether the correct allele was amplified in the allele-specific protocol. Of several individuals intron 4 was sequenced heterozygously for verification. For HLA-A, sequencing of the PCR product, obtained with the primer combination $A 02003$ and $A 02009$, resulted in strong stops using the sequencing primer A02006. Good sequencing results were obtained when the sequencing primer A02019 was used. For all other primer combinations correct and reliable sequences were observed using the sequencing primer $\mathrm{A} 02006$.

Thirty-three different allelic groups were represented by more than one allele. The intron 4 nucleotide sequences were relatively conserved within these groups. In three allelic groups, $B^{*} 40, B^{*} 48$ and $C w^{*} 07$, differences in the intron 4 sequence were noticed between alleles.

The $B^{*} 40$ group was represented by 10 different alleles. Four alleles, $B^{*} 40012$, * $4010, * 4012$ and * 4016 , showed a $C$ at nucleotide position 114 of intron 4 . The other alleles, B*4002, *4003, "4005, "40061, *4008 and *4035, had a $T$ at this position. A similar division of the alleles within the $B^{*} 40$ group can be made based on the coding sequence. According to the nucleotide differences in exon 1 (positions 15, 25, 41, 44, 48, 49 and 72), exon 2 (positions 103 and 106) and exon 3 (positions $603,605,610$ and 618 ), the $B^{*} 40$ alleles could be divided into two groups. The alleles $B^{*} 40012, * 4010,{ }^{*} 4012$ and ${ }^{*} 4016$ belonged to one group, whereas the alleles $B * 4002, * 4003, " 4005, " 40061, " 4008$ and *4035 belonged to another. As some discrepant PCR results were obtained with allele-specific primers, the intron 3 sequences of the $B^{*} 40$ alleles were determined. At position 613 a nucleotide difference was found between the two different $B^{*} 40$ groups. The alleles of the first group ( $B^{*} 40012,{ }^{*} 4010,{ }^{*} 4012$ and * 4016) showed an $A$ at this position, whereas in the alleles of the second group $\left(B * 4002,{ }^{*} 4003,{ }^{*} 4005,{ }^{*} 40061,{ }^{*} 4008\right.$ and $\left.{ }^{*} 4035\right)$ a $G$ was found. The intron 3 sequences of $B^{*} 4001$ and $B^{*} 4002$ were described previously $y^{7}$. In this study an $A$ was described at position 613 for $B^{*} 4002$, whereas in our study a $G$ was observed. As this $G$ was verified in a second individual typed $B^{*} 4002$ and in other $B^{*} 40$ alleles, all belonging to the second group, the $G$ seems to be the correct sequence. The discrepant PCR results could completely be ascribed to the $G$ at position 613 in intron 3 . The division observed within the $B^{*} 40$ group, 
based on both coding and non-coding sequences, is in concordance with the serological detection of $B 60$ (the first group) and $B 61$ (the second group) ${ }^{22}$.

Within the $B^{*} 48$ group, initron 4 sequence differences were noticed between the three different alleles determined in this study. The deletion of 11 nucleotides was present in $B^{*} 4801$ and * 4803 , but not in $B^{*} 4802$. Furthermore, $B^{*} 4801$ and "4803 had an $A$ at position 106 , whereas $B^{*} 4802$ had a $G$ at this position. A similar division was already known for the coding sequence, with $B^{*} 4802$ having several nucleotide differences with $B^{\star} 4801$ and $B^{\star} 4803$ in exons $3-8$. Actually, the exon sequences of $B^{*} 4802$ resemble the sequences of $B^{*} 35, B^{\star} 53$ and $B^{\star} 58$, which is also the case for the intron 4 sequence.

In this study, the intron 4 sequences of five different $\mathrm{Cw}^{*} 07$ alleles were determined: $\mathrm{Cw} w^{*} 07011,{ }^{*} 07012,{ }^{*} 07021,{ }^{*} 07041$ and ${ }^{*} 0706 . \mathrm{Cw}^{*} 0706$ showed a mismatch $(\mathrm{C} \rightarrow T)$ with all $\mathrm{CW}^{*} 07$ alleles at nucleotide position 117 . The $\mathrm{T}$ at this position was not present in other HLA-C or $-B$ alleles. In contrast, all HLA-A alleles showed a $T$ at this position. The $C w^{*} 0706$ allele also shows a unique nucleotide substitution $(T \rightarrow A)$ in exon 5 at position 992 compared with all other $\mathrm{CW}^{*} 07$ alleles, as well as with all other HLA-A, $-\mathrm{B}$ and $-\mathrm{C}$ alleles.

According to the phylogenetic tree of complete coding sequences, $\mathrm{Gu}$ and $\mathrm{Ne}^{23}$ classified polymorphic alleles from the HLA-A locus into five major allelic lineages. Group $A-1$ consisted of subtypes $A 23$ and A24; group A-II of $A 01$, $A 03, A 11, A 30, A 36$ and $A 80$; group $A-111$ included $A 29, A 31, A 32, A 33$ and A74; group A-IV was A25, A26, A34, A43 and A66; and group A-V consisted of $A 02, A 68$ and $A 69$. Blasczyk et al. ${ }^{24}$ have studied the intron 1 through 3 sequences of the majority of HLA-A allelic groups. The phylogenetic tree of the HLA-A introns 1-3 separated the sequences into six groups, the same five as indicated by $\mathrm{Gu}$ and Nei, but with a separate group for A80. According to the intron 4 nucleotide sequences of the different HLA-A alleles determined in this study, a division into five groups could be made using the polymorphic positions $14,30,37$ and 78 . The groups $A-1$ and $A-11$ showed no sequence differences in intron 4, nor did the groups A-IV and A-V. Within the A-III group a difference was noticed, dividing it into two subgroups: $A^{*} 29,{ }^{*} 31$ and ${ }^{*} 33$; and $A^{*} 32$ and ${ }^{*} 74$.

Within the HLA-B alleles, $B^{*} 7301$ was recognized with a very peculiar sequence and therefore this antigen has been defined as a second lineage of HLA-B alleles ${ }^{25}$. The exon 4 and 5 sequences of $B^{*} 7301$ resemble the sequences of HLA-C alleles. In exon 4 , several mismatches of $B^{*} 7301$ with other B-alleles show identity to $\mathrm{Cw}$-alleles. The insertion of three nucleotides in exon 5 of the $\mathrm{Cw}$-alleles in comparison to $\mathrm{A}$ - and B-alleles, is also present in $B^{*} 7301$. Strikingly, the $B^{*} 7301$ intron 4 sequence does not resemble the HLA-C sequence (figure 8.1). The deletion of 20 nucleotides, which distinguishes the $\mathrm{B}$-alleles from the Cw-alleles, is present in $\mathrm{B}^{*} 7301$. A gene conversion event of 
exon 4 and 5 of HLA-C for the origin of $B^{*} 7301$ is unlikely because of the differences in intron 4 . This is in agreement with the hypothesis of Parham et al $^{25}$, in that the $B^{\star} 7301$ allele has been separated from other HLA-B genes for an extended period of time in which many mutational and recombinational events have contributed to the sequence divergence. By contrast, $\mathrm{Gu}$ and $\mathrm{Nei}^{23}$ imply that $B^{\star} 7301$ was generated by interlocus recombination, which may have occurred shortly after the separation of human HLA-B and $-C$ when the sequence divergence between them was relatively small. Their theory rested on exon-based phylogenetic trees showing $B^{*} 7301$ as a hybrid allele with HLAB-like exons 2 and 3 and HLA-C-like exons 4-8.

In 1992, Zemmour and Parham ${ }^{26}$ divided the HLA-C alleles into two groups: the CW7 and the non-Cw7 group. A third lineage of HLA-C alleles, $C w^{*} 17$, was defined by Herrero et al. in $1997^{27}$. The intron 4 diversity of HLA-C determined in this study reflects the three ancestral lineages of HLA-C. The $\mathrm{Cw}^{*} 07$ and $\mathrm{Cw}^{*} 17$ alleles are clearly different from all other $\mathrm{Cw}$-alleles by the insertion of three nucleotides at positions 54-56. The $\mathrm{Cw}^{*} 07$ alleles are distinguished from $\mathrm{Cw}^{*} 17$ alleles by nucleotide differences at positions $12,16,25,26,28,33,38$, 92, 95 and 112. Based on the phylogenetic trees of complete coding sequences, Gu and Nei classified the other HLA-C alleles into three groups ${ }^{23}$. $\mathrm{CW}^{*} 03$ was one group, a second group consisted of $\mathrm{CW} \mathrm{W}^{*} 01,{ }^{*} 04,{ }^{*} 14$ and ${ }^{*} 18$ and the third group was composed of $C W^{*} 02,{ }^{*} 05,{ }^{*} 06,{ }^{*} 08,{ }^{*} 12,{ }^{*} 13,{ }^{*} 15$ and *16. In our study this latter group was further divided, $\mathrm{Cw}^{\star} 02$ and ${ }^{*} 15$ were separated from the others on the basis of a nucleotide difference at position 70 .

Recently, alignments of genomic sequences of HLA-A are available at the IMGT/HLA website (www.ebi.ac.uk/imgt/hla), including intron 4 nucleotide sequences. Furthermore, intron 4 sequences of several HLA-A, -B and $-C$ alleles were submitted to the EMBL database and can be retrieved by using accession numbers. Of the 27 different HLA-A alleles determined in this study, the intron 4 sequences of six alleles were already published on the internet (IMGT/HLA databank ${ }^{28}$, version April 2002). Twenty-three out of the 81 different HLA-B alleles and six out of the 30 different HLA-C alleles studied were previously submitted. The intron 4 sequences published on the internet were identical to the sequences determined in this study, except for three cases. The intron 4 sequence of $B^{*} 27052$ with accession numbers $M 12967$ and X03945 showed a deletion of a $G$ at position 73 compared with the $B^{* 27052}$ sequence determined in this study. The intron 4 sequences of $C w^{*} 0102$ and CW 02022 with accession numbers M16272 and M16273, respectively had a CG sequence at positions 68-69. In our study the sequence $\mathrm{GC}$ was found at these positions. Moreover, the intron 4 sequence of $\mathrm{Cw}^{*} 02022$ showed also mismatches with our sequence at positions 23 and 24 . The intron 4 sequence 
of $\mathrm{Cw}^{*} 02022$ submitted to EMBL showed $\mathrm{AC}_{\text {" }}$ whereas in our study the sequence $C A$ was determined at these positions.

The explanation for the differences between the intron 4 nucleotide sequences of $\mathrm{B}^{*} 27052, \mathrm{CW}^{*} 0102$ and $\mathrm{CW}^{*} 02022$ is unclear. As the data of the three alleles published on the internet were obtained at a time when molecular techniques were less advanced than today ${ }^{29,30}$, the discrepancies could be the result of errors in the sequence. The individuals used in the present study were different from the original sources analyzed to officially assign the alleles. Therefore intra-allele intron polymorphism could be another explanation for the observed discrepancies. 


\section{References}

1. Bjorkman PJ, Saper MA, Samraoui B, Bennett WS, Strominger JL, Wiley DC Structure of the human class I histocompatibility antigen, HLA-A2. Nature 1987;329:506-12.

2. Vlies van der SA, Voorter CEM. Berg van den-Loonen EM. There is more to HLA-C than exons 2 and 3 : sequencing of exons 1, 4 and 5. Tissue Antigens 1999;54:169-77

3. Voorter CE, Swelsen WT, Berg van den-Loonen EM. $B^{* 27}$ in molecular diagnostics: impact of new alleles and polymorphism outside exons 2 and 3. Tissue Antigens 2002:60:25-35.

4. Swelsen WTN, Voorter CEM, Berg wan den-Laonen EM. Sequence analysis of exions $1,2,3$, 4 and 5 of the HLA-B5/35 cross-reacting group. Tissue Antigens 2002;60:224-34.

5. Scheltinga SA, Johnston-Dow LA, White CB et al. A generic sequencing based typing approach for the identification of HLA-A diversity. Hum Immunol 1997;57:120-8.

6. Pera $C$, Delfino $L$, Morabito A et al. HLA-A typing: comparison between serology, the amplification refractory mutation system with polymerase chain reaction and sequencing. Tissue Antigens 1997;50:372-9.

7. Cereb $N$, Kong $Y$, Lee $S$, Maye $P$, Yang SY. Nucleotide sequences of MHHC class I introns 1,2, and 3 in humans and intron 2 in nonhumam primates. Tissue Antigens 1996:47:498-511.

8. Kotsch $K$, Wehling $J_{\text {"Kohler }} \mathrm{S}$, Blasczyk R. Sequencing of HLA class I genes based on the conserved diversity of the noncoding regions: sequencing-based typing of the HLA-A gene. Tissue Antigens 1997;50:178-91.

9. Gomez-Casado E, Vargas-Alarcon G, Martinez Laso J et al. Generation of the HLA-B35, -B5 $-B 16$, and $B 15$ groups of alleles studied by intron 1 and 2 sequence analysis Immunogenetics 1997:46:469-76.

10. Gomez-Casado E, Vargas-Alarcon $G$, Martinez Laso J et al. Evolutionary relationships between HLA-B alleles as indicated by an analysis of intron sequences. Tissue Antigens $1999 ; 53: 153-60$

11. Yao $Z$, Volgger $A, S c h o l z ~ S$, Albert ED. Sequence polymorphism in the HLA-B promoter region. Immunogenetics 1995:41:343-53.

12. Yao $Z$, Volgger $A$, Scholz $S$, Albert $E$. Polymorphism of the HLA-C promoter region. Immunogenetics 1997;45:428-31.

13. Summers CW, Hampson VJ, Taylor GM. HLA class I non-coding nucleotide sequences, 1992. Eur J Immunogenet 1993;20:201-40.

14. Voorter CE, Berg van den-Loonen EM. Identification of two new HLA-A alleles, $A^{*} 2419$ and $A^{*} 3011$, by sequence-based typing. Tissue Antigens 2002:59:136-8.

15. Voorter CEM. Vlies van der SA, Berg van den-Loonen EM. Sequence-based typing of HLA. $B$ : the $B 7$ cross-reacting group. Tissue Antigens 2000;56:356-B2.

16. Vies van der SA, Voorter CEM, Berg van den-Loonen EM. A rellable and efficient high resolution typing method for HLA-C ulsing sequence-based typing. Tissue Artigens 1998;52: $558-68$.

17. Miller SA, Dykes DD, Polesky HF. A simple salting out procedure for extracting DNA from human nucleated cells. Nucleic Acids Res 1988;16:1215

18. Bunce $M_{3}$ Barnardo MCNM, Welsh $\mathrm{KI}$. Improvements in HLA-C typing using sequencespecific primers (PCR-SSP) including definition of HLA-Cw 9 and $C w 10$ and a new allele HLA"Cw7/8v". Tissue Antigens 1994:44:200-3.

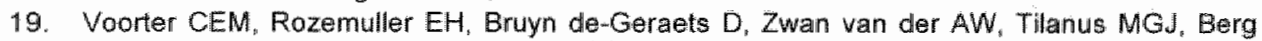
van den-Loonen EM. Comparison of DRB sequence-based typing using different strategies. Tissue Antigens 1997;49:471-6.

20. Voorter CEM: Bruyn de-Geraets D, Berg van den-Loonen EM. High-resolution HLA typing for the DRB3/4/5 genes by sequence-based typing. Tissue Antigens 1997:50:283-90.

21. Voorter CEM, Kik MC, Berg van den-Loonen EM. High-resolution HLA typing for the DQB1 gene by sequence-based typing. Tissue Antigens 1998;51:30-7.

22. Schreuder GMTh, Hurley CK, Marsh SGE et al, The HLA dictionary 1999: a surmmary of HLA$A, n B,-C,-D R B 1 / 3 / 4 / 5,-D Q B 1$ alleles and their association with serologically defined HLA,-A, $-B,-C,-D R$ and $-D Q$ antigens. Tissue Antigens 1999;54:409-37. 


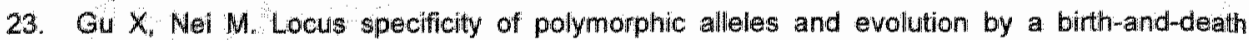
process in mammalian MHC genes. Mol Biol Evol 1999:16:147-56.

24. Blasczyk $R$, Wehling J, Kotsch $K$, Salama $A$. The diversity of the HLA class I introns reflects the serological relationship of the coding regions. Transfusionsmedizin 1996/1997,34:231-5.

25. Parham $P$, Arnett $K L$, Adams EJ et al. The HLA-B73 antigen has a most unusual structure that defines a second lineage of HLA-B alleles. Tissue Antigens 1994;43,302-13.

26. Zemmour 1, Parham $P$. Distinctive polymorphism at the HLA-C locus: inplications for the expression of HLA-C. J Exp Med 1992;176:937-50.

27. Herrero $M J$, Vilches $C$. Pablo de $R$. Puente $S$, Kreister $M$. The complete primary structure of Cw*1701 reveals a highly divergent HLA class I molecule. Tissue Antigens 1997;49:267-70.

28. Robinson J, Malik A, Parham P, Bodmer JG, Marsh SGE. IMGT/HLA database - a sequence database for the human major histocompatibility complex. Tissue Antigens 2000;55:280-7.

29. Weiss $E H_{1}$ Kuon $W$, Dorner $C$, Lang $M$, Rietmuller $G$. Organization, sequence and expression of the HLA-B27 gene: a molecular approach to anallyze HLA and disease associations. Immunobiol 1985;170:367-80.

30. GUssow D. Rein RS, Meijer I et al. Isolation, expression, and the primary structure of HLACW1 and HLA-CW2 genes: evolutionary aspects. Immunogenetics 1987:25:313-22. 


\section{Chapter}

\section{No HLA-A gene detectable on one of the haplotypes in a Caucasian family}

Wendy TN Swelsen", Christina EM Voorter", Marcel GJ Tilanus"2. Miriam AF Kamps ${ }^{3}$ and Ella M van den Berg-Loonen"

Human Immunology 2005;66:155-163

1. Tissue Typing Laboratory. University Hospital Maastricht, Maastricht, the Netherlands ${ }^{2}$ Department of Pathology, Uniwersity Medical Centre Utrecht, Utrecht, the Netherlands

${ }^{3}$ Department of Molecular Cell Biology, Research Institute Growth and Development (GROW), University of Maastricht, Maastricht, the Netherlands, 
detected in a family of a Caucasian transplant patient. Human leukocyte ne family demomstrated the absence of HLA-A on one of the haplotypes vers:

id A24, the other A2. Because they had one haplotype in common, the haplotype was supposed to be a null allele. Different molecular typing ne allele in both individuals. The results suggest a deletion of the I majof part of it: For confirmation "microsatellite analysis of the HLA-A six microsatellite markers. Both family members were heterozygous for of HLA-A could not be proven. Fluorescent in situ hybridisation (FISH) mid and PAC probes encompassing the HLA-A gene. Both probes il distribution pattern for diploid results. The absence of any serological zether with the results of the microsatellite and FISH analysis make a - encompassing the HLA-A gene, the most plausible explanation. 


\section{Introduction}

The major histocompatibility complex (MHC) plays a central role in the immune response to foreign antigens. Within the human $M \mathrm{HC}$, the highly polymorphic class I and II genes encode cell surface molecules that are immunological barriers to successful allogeneic transplantation. Human leukocyte antigen (HLA) matching between patient and donor is one of the critical factors affecting the success of transplantation. In the transition of HLA typing methods from serological to DNA typing, non-expressed HLA alleles, so-called null alleles, may become a potential problem. Although each HLA allele is identified by molecular typing, the corresponding antigen on the cell surface can not always be detected by serology.

For HLA-A, 24 of 309 alleles were found to be non-expressed ${ }^{1.7}$. The lack of expression can be different in origin; either point mutations giving rise to premature stop codons $s^{4,8-10}$, deletions or insertions leading to a frame shift and a premature termination ${ }^{4,5 \cdot 11-14}$, deletions causing a structural defect in the molecule $^{15}$, mutations affecting transcription ${ }^{2,7}$ and RNA splicing ${ }^{4,6,16}$ or hypermethylation leading to gene inactivation ${ }^{3}$.

In this study, we describe the complete absence of one of the HLA-A genes. Serological typing suggested the presence of a nuil allele, but molecular typing methods did not detect an HLA-A allele. The rare haplotype was demonstrated in the family of a Caucasian renal transplant patient. Patients waiting for a renal transplant are typed for their class I and II antigens. Family typings are performed to prove homozygosity, to establish farmily haplotypes or to identify potential family donors. Irregular segregation patterns can be the result of recombinational events, the existence of null alleles or exclusion of paternity. Irregular segregation patterns have also been described as a result of uniparental disomy of chromosome $6^{17,18}$ or cosegregation of two sets of DR and $D Q$ alleles on the same chromosome ${ }^{19}$. In this study, we report the segregation of a haplotype with no detectable HLA-A gene, a phenomenon not previously described. The haplotype was present in the patient and one of his siblings. Different methods were performed for HLA-A detection. Full length amplification, microsatellite analysis and fluorescent in situ hybridisation (FISH) technology were used to confirm the deletion of the HLA-A gene. 


\section{Materials and methods}

\section{Serological typing}

Ten family members in two generations of family CA were serologically typed for HLA-A, $-B,-D R$ and $-D Q$. Antisera routinely used for serological detection were obtained locally, commercially and by exchange with national and international colleagues. For routine typing $39 \mathrm{HLA}-\mathrm{A}, 73-\mathrm{B}, 40-\mathrm{DR}$ and 13 $-D Q$ sera were used. For the rare haplotype an extended HLA-A tray was used, increasing the total number of antisera for HLA-A to 76 . Serological typing was performed by the complement-dependent cytotoxicity test (CDC). For class I, $1 \mu \mathrm{l}$ antiserum and $1 \mu \mathrm{l}$ lymphocyte-suspension at a concentration of $4 \times 10^{6}$ cells $/ \mathrm{ml}$ were incubated for $30 \mathrm{~min}$ at $20^{\circ} \mathrm{C}$. After addition of $5 \mu \mathrm{l}$ rabbit complement (Bio-scope Foundation, Leiden, the Netherlands) incubation was prolonged for $60 \mathrm{~min}$ at $20^{\circ} \mathrm{C}$. For class $11,0.5 \mu \mathrm{l}$ antiserum and $1 \mu \mathrm{l}$ lymphocyte-suspension at a concentration of $10 \times 10^{6}$ cells $/ \mathrm{ml}$ were incubated at $20^{\circ} \mathrm{C}$. After $45 \min 2.5 \mu \mathrm{l}$ rabbit complement were added and followed by 105 min incubation at $20^{\circ} \mathrm{C}$. Cell lysis was assessed by automated fluorescence ratio measurements using CFDA and propidium iodide as labeling agents for intact and lysed celis, respectively.

\section{DNA isolation}

DNA was isolated from fresh heparinized blood or from lymphocytes stored in liquid nitrogen "either by the "salting out" extraction procedure as described by Miller et al. ${ }^{20}$ or by using QIA-AMP kits following the suppliers protocol (Qiagen, Westburg, Leusden, the Netherlands). Concentration and purity of DNA samples were measured at optical densities of 260 and $280 \mathrm{~nm}$.

\section{PCR-SSP}

PCR-SSP of HLA-A of the patient and his sibling was performed using five different commercial kits (Biotest, Soest, the Netherlands; Dynal, Hamburg, Germany; Heidelberg CTS, Heidelberg, Germany; One Lambda, Sambio, Uden, the Netherlands and Pel-Freez, Turnhout, Belgium) with which all known HLA-A alleles could be detected. Amplifications were carried out following the suppliers protocol with different cycling conditions for each kit. The reaction mixtures were analysed by agarose gel electrophoresis followed by staining with ethidium bromide to detect the presence of PCR products with the correct base length. An internal control was present in all mixtures. 


\section{Sequence-based typing of exons 1 through 7}

Patient and sibling were typed for HLA-A by sequence-based typing (SBT). The routine SBT strategy is based on heterozygous sequencing of exons 2 and 3 , both forward and reverse, extended with allele-specific sequencing and/or sequencing of other exons if necessary. In this case, additional primer combinations were used to sequence exons 1 through 7 of the patient. In table 9.1 the locations and sequences of the different amplification and sequencing primers are shown. Table 9.2 demonstrates the standard and additional primer combinations used for heterozygous sequencing of HLA-A. The Cy-5 labeled sequencing primers were designed and located internally of the PCR products to ensure specific sequencing. The PCR conditions used were previously described ${ }^{21}$. In brief, the PCR reaction was carried out in a final volume of $60 \mu l$, containing $600 \mathrm{ng}$ DNA, $2.0 \mathrm{U}$ Amplitaq DNA polymerase, $20 \mathrm{pmol}$ of biotinylated primer, $40 \mathrm{pmol}$ of unlabeled primer, $\mathrm{PCR}$ buffer according to Bunce $^{22}\left(67 \mathrm{mM}\right.$ Tris- $-\mathrm{HCl}_{1} \mathrm{pH} 8.8,16.6 \mathrm{mM}\left(\mathrm{NH}_{4}\right)_{2} \mathrm{SO}_{4}, 0.01 \%(\mathrm{v} / \mathrm{v})$ Tween 20), $1.5 \mathrm{mM} \mathrm{MgCl}_{2}, 6 \mu \mathrm{g}$ cresol red, $200 \mu \mathrm{M}$ each dNTP and $5 \%$ glycerol. The cycling conditions consisted of an initial denaturation at $96^{\circ} \mathrm{C}$ for $2 \mathrm{~min}$, 10 cycles of $10 \mathrm{~s}$ at $94^{\circ} \mathrm{C}, 60 \mathrm{~s}$ at $65^{\circ} \mathrm{C}$ and 30 cycles of $10 \mathrm{~s}$ at $94^{\circ} \mathrm{C}, 50 \mathrm{~s}$ at $61^{\circ} \mathrm{C}$ and $30 \mathrm{~s}$ at $72^{\circ} \mathrm{C}$, followed by a final extension at $72^{\circ} \mathrm{C}$ for $10 \mathrm{~min}$. The presence of PCR products with the correct base length was checked by agarose gel electrophoresis. A solid-phase sequencing approach was used as previously described ${ }^{23-26}$. The non-biotinylated DNA strand was removed by alkaline denaturation after attachment of $40 \mu \mathrm{l}$ of biotinylated product to streptavidin-coated beads (Dynal, ITK diagnostics, Uithoorn, the Netherlands). After annealing of the $C y-5$ labeled sequencing primer, the sequencing reaction was performed at $37^{\circ} \mathrm{C}$ for $5 \mathrm{~min}$ with T7 DNA polymerase. The samples were heated at $90^{\circ} \mathrm{C}$ for $2 \mathrm{~min}$, prior to loading on a $0.5 \mathrm{~mm}$-thick $6 \%$ polyacrylamide-7M urea gel. Electrophoresis was performed on an ALFexpress automated sequencer (Pharmacia Biotech, Uppsala, Sweden). Sequence data were processed automatically and evaluated manually. The HLA Sequityper software (Pharmacia Biotech) was used for allele assignments.

\section{Full length amplification}

The entire HLA-A locus of the patient was amplified using the Expand High Fidelity PCR system (Roche Diagnostics GmbH, Penzberg, Germany). The locus-specific amplification primers (5'A03047, ATACTCACGACGCGGACCC, -135-117 and 3'A03048, ACACAGACACATGCAGGTGCC, 2992-3012) "27 were located in the untranslated regions. Agarose gel electrophoresis was performed to analyse the PCR reaction as described above. 
Table 9.1 Sequence and location of amplification and sequencing primers used for heterozygous sequencing of exons 1 through 7 of HLA-A.

\begin{tabular}{|c|c|c|c|}
\hline Name & Sequence & Location & Position ${ }^{4}$ \\
\hline 5: $A 97063$ & KYGGGGTCSGGGCCAGGT & $12 / E 3$ & $699-716$ \\
\hline 5A97107 & CCAGACGCCGAGGATGGCC & SUT/E1 & $-13-6$ \\
\hline 5 A98008 & GTTTAGGCCAAAAATYCCCCC & 12 & 635 i 655 \\
\hline 5A98009 & GACAGCGACGCCGCGAGC & E2 & $311-328$ \\
\hline $5^{\prime A} \mathrm{AD} 3020$ & GCCATGTGCAGCATGAGGGT & E4 & $1798-1817$ \\
\hline $5^{\mathrm{A}} \mathrm{A} 03026$ & GAGGTTCCTCTAGGACCTTAA & 15 & $2439-2458$ \\
\hline 5.403047 & ATACTCACGACGCGGACCC & SUT & $-135-117$ \\
\hline 51403052 & TAAGGAGGGAGAYGGGGGT & 4 & $1847-1865$ \\
\hline $5, A 03054$ & CRTCCMCATCGTGGGCATCA & E5 & $1967-1986$ \\
\hline $3 A 96090$ & TGTTGGTCCCAATTGTCTCCCCTC & $\$ 3$ & $1055-1078$ \\
\hline 3'A97028 & GTGGCCCCTGGTACCCGT & $\mathrm{E} 3 / 13$ & $987-1004$ \\
\hline 3А97104 & GGCCTAAACTGAAAATGAAACC & 12 & $622-643$ \\
\hline 3'A02008 & GWGTARCTCCCTCCTTTTCT & E6 & $2509-2528$ \\
\hline $3 \mathrm{~A} 02009$ & CAGCGACCACAGCTCCAG & E5 & $2020-2037$ \\
\hline $3^{\prime} \mathrm{A0} 3024$ & AGAGCCCTGGGCACTGTCA & E7 & $2686-2704$ \\
\hline 3:A03027 & ACACAAGGCAGCTGTCTCACA & E8/3UT & $2899-2919$ \\
\hline $3: 403050$ & TTAAGGTCCTAGAGGAACCTC & 15 & 2439.2459 \\
\hline $5^{\prime} \mathrm{A} 96049 \mathrm{C}$ & TGGCTGCGACGTGG & E3 & $740-753$ \\
\hline $5: A 96050 \mathrm{C}$ & ${ }^{55}$ GCCAGGTIICTCACAC & I2/E3 & $710-724$ \\
\hline 5'A96094C & CY5 TCATTTTCAGTITAGGCCA & 12 & $626-644$ \\
\hline 5'A97080C & TCTCAGCCACTSCTCG & 11 & $183-198$ \\
\hline 5'A97097C & CCCCTCACCCTGAG & E4 & $1827-1840$ \\
\hline $5 \mathrm{Ag} 9010 \mathrm{C}$ & ${ }^{5}$ GGGACYGGGCTGACC & 12 & $684-698$ \\
\hline $5: A 98027 \mathrm{C}$ & ${ }^{c}$ GACGGCAAGGATTACA & E3 & $798-813$ \\
\hline $5^{\prime \prime A 01026 c}$ & ${ }^{15}$ GGGGAGAAGCAASGGGC & 11 & $108-124$ \\
\hline 5"AO2007c & "YICTGGGTTCTGTGCTC & 13 & $1445-1460$ \\
\hline $5 " A 02019 \mathrm{C}$ & GACCAGACCCAGGAC & E4 & $1689-1703$ \\
\hline $5 " A 02100 \mathrm{C}$ & CCGCACGCACCCACCO & 5'UT & $-29-44$ \\
\hline 5"A03022C & ACCTTTAGCAGGGTCA & 14 & $1903-1918$ \\
\hline $5 \mathrm{AD} 3028 \mathrm{C}$ & ATTCCTCCTCTAGCCA & 16 & $2620-2635$ \\
\hline 5:A030510 & TITCTGGTATCTCACAG & 15 & $2472-2488$ \\
\hline 3'A96093C & ATCTCGGACCCGGAGACT & 12 & $542-559$ \\
\hline 3'A97094C & TGTCGTCCACGTAGC & $\mathrm{E2}$ & $279 \times 293$ \\
\hline 3'A99045C & AGGCCAGCCCGGGAG & 13 & $1032-1046$ \\
\hline
\end{tabular}

The exon and intron nucleotide positions are numbered according to the genomic alignments of HLA-A avallable at the MGT/HLA website"

Microsatellite analysis

The microsatellite markers RF, D6S2707, D6S2706, D6S510, D6S265 and C3_2_11, were selected on the basis of a review of Foissac et al. ${ }^{28}$ in conjunction with the Genome Database (GDB) to narrow down the region around HLA-A. The marker C1_2_5 was used as a control because this marker is located between HLA-B and $-\mathrm{C}$, and both loci were shown to be present on the rare haplotype. 
Table 9.2 Primer combinations used for heterozygous sequencing of HLA-A.

\begin{tabular}{|c|c|c|c|}
\hline No. & Exan & Amplification primers & Sequencing primers \\
\hline \multicolumn{4}{|c|}{ Standard combinations } \\
\hline 1 & 2 & 5A97107+3'A97 104 & 5'A97080C $3^{\circ} 96093 \mathrm{C}$ \\
\hline 2 & 3 & 5'A980009+3'A96090 & $5,496094 c, 399045 c$ \\
\hline \multicolumn{4}{|c|}{ Additional combinations } \\
\hline 1 & 1 & $5^{\prime} \mathrm{A} 03047+3^{\prime} \mathrm{A} 97104$ & $5 \mathrm{~A} 02100 \mathrm{c}$ \\
\hline 2 & $1 / 2$ & $5 \mathrm{~A} 97107+3 \mathrm{~A} 97104$ & $3^{2} \mathrm{~A} 97094 \mathrm{C}, 5 \mathrm{A0} 1026 \mathrm{C}$ \\
\hline 3 & 3 & $5: A 98009+3496090$ & 5A98010C, 5A98027C \\
\hline 4 & $3 / 4$ & $5: A 98008+3$ AD2009 & $5^{\prime A} \mathrm{Ag} 050 \mathrm{C}, 5^{\circ} \mathrm{A02007 \textrm {C }}$ \\
\hline 5 & $3 / 4$ & 5:A98009+3'A02009 & $5 \mathrm{~A} 98027 \mathrm{C}, 5^{\circ} \mathrm{AO} 2019 \mathrm{C}$ \\
\hline 6 & $3 / 4$ & 5:A97063+3:A02009 & $5^{\prime} \mathrm{A} 98027 \mathrm{C}_{6} 5^{\prime} \mathrm{AO} 2019 \mathrm{C}$ \\
\hline 7 & 3 & 5'A98009+3'A97028 & $5^{3} \mathrm{~A} 96049 \mathrm{c}$ \\
\hline 8 & 5 & $5^{\prime} \mathrm{A}, 03020+3^{\prime} \mathrm{A} 03050$ & $5^{\prime} \mathrm{A} 97097 \mathrm{C}, 5^{\prime} \mathrm{A} 03022 \mathrm{C}$ \\
\hline 9 & 5 & $5 \mathrm{~A} 03020+3 \mathrm{A0} 02008$ & $5 \mathrm{AO} 3022 \mathrm{G}$ \\
\hline 10 & 5 & $5^{\prime} A 03052+3^{\prime} A 03050$ & $5^{\prime} A 030220$ \\
\hline 11 & $6 / 7$ & 5"A03026+3'A03027 & 5'A03051C, 5A03028c \\
\hline 12 & 6 & $5^{\prime \prime} \mathrm{A0} 3054+3^{\prime \prime} \mathrm{A} 03024$ & $5^{\prime} \mathrm{A} 03051 \mathrm{C}$ \\
\hline 13 & 7 & $5: 403054+3 \mathrm{~A} 03027$ & 5A03028C \\
\hline
\end{tabular}

Figure 9.1 shows the location of the seven microsatellite markers within the HLA class I region and table 9.3 indicates the characteristics of the different markers. Microsatellite analysis of family CA was performed according to Lie et al., with minor modifications ${ }^{29,30}$. The volume of the PCR reaction mix was $10 \mu \mathrm{l}$ and contained PCR buffer ( $50 \mathrm{mM} \mathrm{KCl}$ and $10 \mathrm{mM}$ Tris- $\mathrm{HCl}, \mathrm{pH} 8.0$ ), $2 \mathrm{mM}$ $\mathrm{MgCl}_{2}, 200 \mu \mathrm{M}$ each dNTP, $100 \mathrm{ng}$ DNA, $0.4 \mathrm{U}$ Amplitaq DNA polymerase and $2.5 \mathrm{pmol}$ of each primer with the $5^{\prime}$ primer $\mathrm{Cy}-5$ labeled. The cycling conditions consisted of 34 cycles of $15 \mathrm{~s}$ at $94^{\circ} \mathrm{C}, 30 \mathrm{~s}$ at $55^{\circ} \mathrm{C}$ and $30 \mathrm{~s}$ at $72^{\circ} \mathrm{C}$, followed by a final extension at $72^{\circ} \mathrm{C}$ for $10 \mathrm{~min}$. The $\mathrm{Cy}-5$ labeled PCR fragments were separated according to size by electrophoresis on an ALFexpress automated sequencer. Electrophoresis was run under denaturating conditions on a $4.25 \%$ polyacrylamide-7M urea gel at 25 Watt using $1 X$ TBE as running buffer. Before loading on the gel the samples were heated at $90^{\circ} \mathrm{C}$ for $3 \mathrm{~min}$. The ALFexpress Sizer 50-500 was used as external standard with well-defined peaks at increments of 50 bases ranging in size from 50 to 500 base pairs. As internal standards, Sizers 100 and 300 were used for all microsatellite markers, except RF and D6S2706. For these microsatellite markers, only Sizer 100 was used because the 300 base Sizer was located within the fragment size range, interfering with correct identification of the alleles (table 9.3). For analysis the Fragment Analyser software (Pharmacia Biotech) was used. 


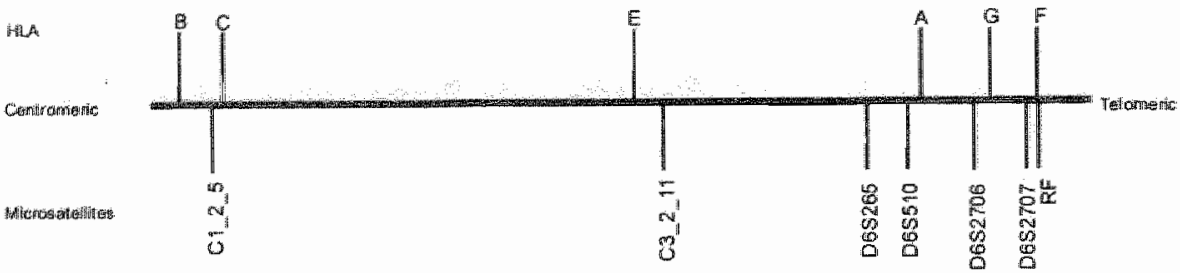

Figure 9.1 Position of microsatellite markers. Schematic outline of the HLA class I region indicating the positions of the microsatellite markers used in the present study.

Table 9.3 Characteristics of used microsatellite markers in the HLA class I region".

\begin{tabular}{|c|c|c|c|c|c|c|}
\hline Microsatelilibe & Approximate lacation & Repeat & $\begin{array}{l}\text { Size } \\
\text { (bp) }\end{array}$ & Allele:s & Heterozygosilly & $\begin{array}{l}\text { Prinner forward } \\
\text { Primer reverse }\end{array}$ \\
\hline \multirow[t]{2}{*}{$\mathrm{RF}$} & Tel (218Kb)HHLA-A & GAAn & $168-340$ & 19 & 0,95 & CTGTCCTATTTCATATGCTCAGG \\
\hline & & & & & & ATGAACTTGTCOTGAGAATGAAO \\
\hline \multirow[t]{2}{*}{0652707} & TEl (I9AKB)MLLA.A & CA & $137-171$ & $x^{a}$ & 0,87 & CAGTTTCOCAACCTGTTTGCC \\
\hline & & & & & & CATCAGGAGTCATTAGGGAAATGC \\
\hline \multirow[t]{2}{*}{0652706} & Tol $(99 \mathrm{~Kb}) / \mathrm{H} / \mathrm{L}-\mathrm{A}-\mathrm{A}$ & ATOT & $265 \times 317$ & - & 0,84 & CAGCCTCCATAATTGTGTGAGCC \\
\hline & & & & & & GCCACCAATCTTCTAACCCAAGC \\
\hline \multirow[t]{2}{*}{065510} & Centr $(28 \mathrm{~Kb}) / \mathrm{HLA}-\mathrm{A}$ & CAGA & $179-196$ & 8 & $0,740,84$ & AATGGGCTACTACTTCACACO \\
\hline & & & & & & CAACACACTGATTTCCATAGC \\
\hline \multirow[t]{2}{*}{ D65265 } & Cenis $(106 \mathrm{~KB})$ HLA LA & $\mathrm{CA}$ & $\| 18-140$ & 8 & 0,79 & ACGTTCGTACCCATTAACCT \\
\hline & & & & & & ATCGAGGTAAACAGCAGAAA \\
\hline \multirow[t]{2}{*}{$C 32_{-11}$} & Centr $(495 \mathrm{~K}$ b) $)\left(\mathrm{H}-\mathrm{A}_{-}-\mathrm{A}_{\mathrm{B}}\right.$ & GA & 梛 $7^{\prime}-229$ & 17 & 0,85 & AGATGGCATTTGGAGAGTGCAG \\
\hline & & & & & & TCCTTACAGCAGAGATATGTGG \\
\hline \multirow[t]{2}{*}{ Ci 25} & Centro $(1345 k, b) / H L A-A$ & $C A$ & $178-220$ & 20 & 0.89 & CAGTAGTAAGCCAGAAGCTATTAC \\
\hline & & & & & & AAGTCAAGCATATCTGCCATTTGO \\
\hline
\end{tabular}

1 Characteristics include the marker name, approximate telomeric (tel) or centromeric (centr) location with respect to HLA.A (http//genome.ucsc edu), type of nucleotide repeat, size range in base pairs, number of alleles, heterozygosity walues and the sequences of the primers used for amplification of the microsatellite markers (Genome Database, ${ }^{28,30}$ ) Number of alleiles unknown

\section{Interphase FISH}

Interphase FISH on lymphocytes of the patient and a control individual was performed using two different probes, either two overlapping cosmids C109 $\mathrm{K} 2118$ and $\mathrm{C} 109 \mathrm{~B} 0233^{31}$ or the clone PAC544A6 ${ }^{32}$. The approximate length and location of the different probes with respect to HLA-A ${ }^{32.33}$ are shown in figure 9.2. Interphase FISH was performed as previously described ${ }^{34,35}$. The cosmid and PAC probes were labeled by standard nick translation using biotin11-dUTP or digoxigenin (DIG)-11-dUTP. A probe detecting the centromeric region of chromosome 6 was used as control (Vysis, Abbott, Downers Grove, 
USA and ATCC, Manassas, USA). Cytospin preparations or cell spots from lymphocytes of patient and control were fixed in methanol and/or $70 \%$ ethanol, followed by pepsin treatment and post-fixation in 1.0 or $1.5 \%$ formaldehyde. The probes were applied under a coverslip at a concentration of $6 \mathrm{ng} / \mathrm{\mu l}$ for cosmid probes and $5 \mathrm{ng} / \mu \mathrm{l}$ for the PAC probe in a hybridisation mixture containing $50 \%$ deionized formamide, 2X SSC $1300 \mathrm{mM} \mathrm{NaCl}, 30 \mathrm{mM} \mathrm{Na}-$ citrate, pH 7.0), 10\% dextran sulphate and 50X COT-1 DNA (Invitrogen, Life Technologies, Breda, the Netherlands). Cosmid probes and target DNA were denatured simultaneously for $5 \mathrm{~min}$ at $75^{\circ} \mathrm{C}$, PAC probe was denatured separately for $15 \mathrm{~min}$ at $60^{\circ} \mathrm{C}$ and $7 \mathrm{~min}$ at $80^{\circ} \mathrm{C}$ and the target DNA at $80^{\circ} \mathrm{C}$ for $10 \mathrm{~min}$ in $70 \%$ formamide/2X SSC. Hybridisation of probes was performed overnight at $37^{\circ} \mathrm{C}$ in a moist chamber and followed by washing with $2 \mathrm{X}$ SSC/Tween $(3 \times 5 \mathrm{~min})$ and $4 \mathrm{XSSC} / \mathrm{Tw}$ ween $(5 \mathrm{~min})$. For the PAC probe an initial washing with $50 \%$ formamide/2X SSC/ Tween was applied. FITC-conjugated avidin (Vector, Burlingame, USA) was used for detection of the hybridised biotinylated probe and the signal was immunologically amplified using biotinlabeled goat anti-avidin (Vector), followed by a second layer of FITCconjugated avidin. The detection step of the DIG labeled probe included incubation with FITC labeled sheepa-DIG. Nucleil were counterstained with 4",6-diamidino-2-phenylindole (Sigma-Aldrich, Zwijndrecht, the Netherlands) or propidium iodide in the mounting medium Vectrashield (Vector). Two independent evaluations of each slide were performed, counting the fluorescent signals in 100 nuclei.

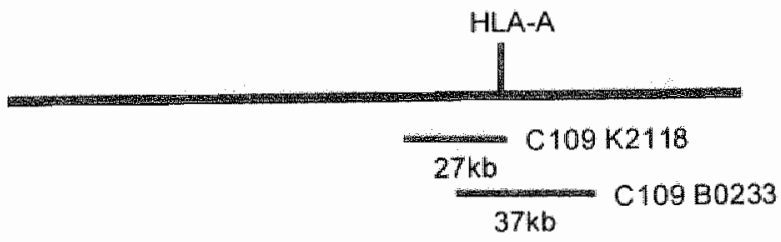

$163 \mathrm{~kb}$

Figure 9.2 Position of FISH probes. Approximate length and location of the cosmids $\mathrm{C} 109 \mathrm{~K} 2418$ and $\mathrm{C} 109 \mathrm{BO233}$ and clone PAC544A6 with respect to HLA-A. 


\section{Results}

\section{Serological typing}

The serological HLA typing results of ten family members in two generations enabled identification of the haplotypes. The pedigree of the family CA is shown in figure 9.3. On repeated typings no HLA-A antigen could be demonstrated on haplotype c present in the patient (II-2) and his sibling (II-3). The patient was typed A24 on haplotype a and his sibling A2 on haplotype b. Because they had haplotype $c$ in common, the HLA-A allele of this haplotype was supposed to be a null allele.

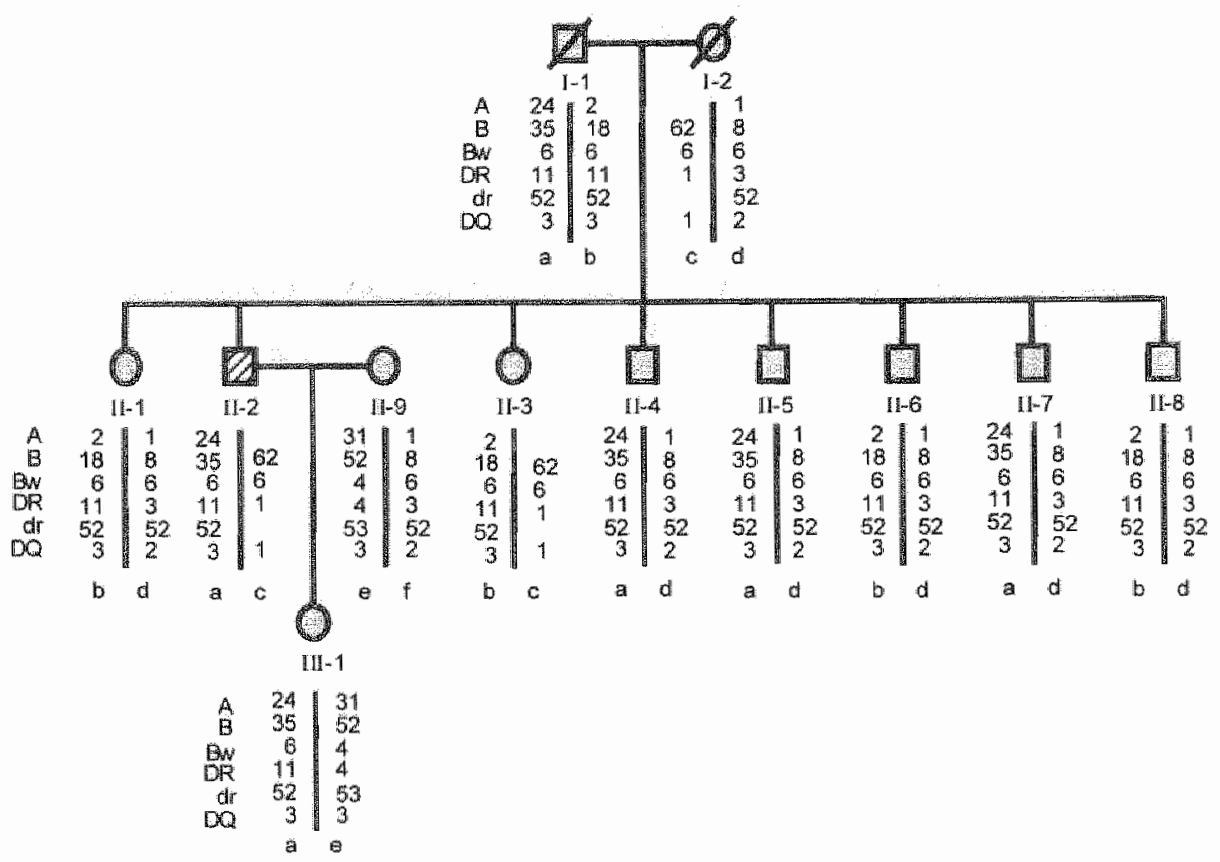

Figure 9.3 Serologicel typing of HLA antigens in family $\mathrm{CA}$. The patient (II-2) is indicated by shading. HLA elass I and II antigens are given by their official WHO nomenclature. An oblique line indicates that an individual was not tested. HLA haplotypes are given in lower cases. The haplotypes are (a) A24,B35, Bw6,DR11, DR52,DQ3, (b) A2, B18, Bw6. DR11,DR52,DQ3, (c) B62,Bw6,DR1,DQ1 and (d) A1,B8,Bw6,DR3,DR52,DQ2. The HLA typing of the parents (I-1 and I-2) was deduced from the typings of the children. The rare haplotype $\mathrm{c}$ was detected in the patient and one of his siblings (II-3).

\section{Molecular typing}

To identify the presence of an HLA-A null allele PCR-SSP and SBT of both individuals were performed. PCR-SSP was performed with five different 
commercial kits, all showing the presence of $A^{*} 24$ in the patient and $A^{*} 02$ in the sibling. Standard HLA-A SBT was performed for the patient and his sibling. Again in both individuals only one allele was identified, the patient was typed $A^{*} 240201$ and his sibling $A^{*} 020101$. No allelic drop-out has ever been noticed with the primers routinely used for heterozygous sequencing HLA-A. in addition primer combinations were used to sequence exons 1 through 7 of the patient to detect a second HLA-A allele, but all primer combinations showed only one Aallele. Although several of these primers showed mismatches with some rare A-alleles, no allelic drop-out or preferential amplification was ever shown. Mismatches of HLA-A alleles with primers located in the introns are difficult to determine because of limited information on the non-coding sequences. To circumvent allelic drop-out by intron primers, two primer combinations were used located entirely in the exons. But also these combinations failed to show an HLA-A allele on haplotype $\mathrm{c}$. The molecular typing results suggest a deletion of the complete HLA-A gene or a major part of it.

\section{Full length amplification}

To enable identification of a possible partial gene deletion, the entire HLA-A gene of the patient was amplified using primers located in the untranslated regions. Agarose gel electrophoresis revealed the presence of only one PCR product, 3.1 kilobases in length, encompassing the entire HLA-A gene. No additional smaller fragments were detected, and therefore a partial deletion of HLA-A could not be confirmed.

\section{Microsatellite analysis}

Microsatellite analysis was performed to determine whether a deletion was detectable beyond the HLA-A gene on haplotype $\mathrm{c}$. Six microsatellite markers were selected to narrow down the region around HLA-A. The markers D6S2706 and D6S510 were located closest to HLA-A, $99 \mathrm{~kb}$ telomeric and $28 \mathrm{~kb}$ centromeric of HLA-A, respectively (figure 9.1 and table 9.3 ) $^{28}$. The microsatellite analysis of marker D6S2706 for the different family members of family CA is shown in figure 9.4. The $X$-axis shows the fragment size in base pairs and the $Y$-axis the relative peak height in fluorescence. The different lanes represent the microsatellite fragments of the different family members, except the first lane, which shows the external standard sizers 250 and 300 . The microsatellite fragments of the family members were located within the range of 265 to 317 base pairs as reported for marker D6S2706 (table 9.3) ${ }^{28}$. Lower cases indicate the haplotypes of the different family members according to the pedigree (figure 9.3). The segregation of the marker on the different haplotypes was in accordance with the serological results. From the patterns it can be concluded that haplotypes a and c have identical fragment sizes. The 
microsatellite analysis of the patient (II-2) with haplotypes a and $c$ is therefore not conclusive. The sibling (II-3) with haplotypes $b$ and $c$ showed the presence of two different fragments demonstrating that a deletion for this marker on haplotype c was not present. All other microsatellite markers tested showed comparable results (data not shown). It was not possible to identify a microsatellite marker in the region of HLA-A showing a deletion on haplotype $c$.

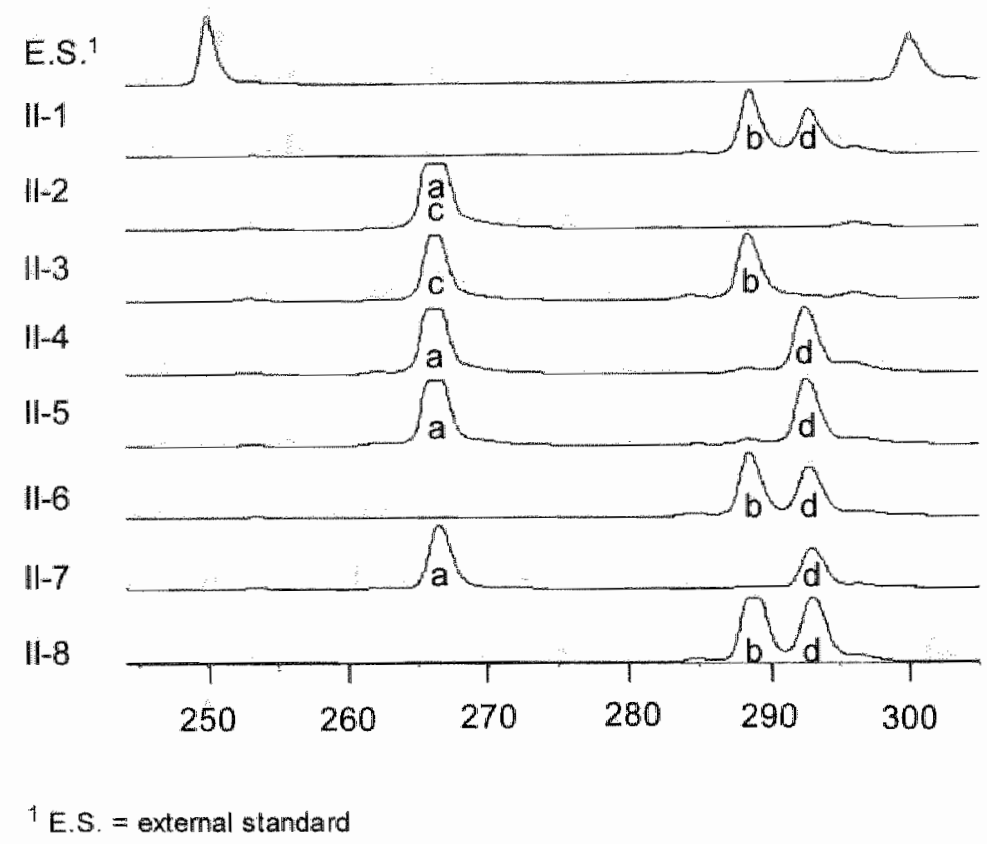

Figure 9.4 Microsatellite typing of marker D6S2706 for the different family members of family CA. The fragment size (in base pairs) is displayed on the $X$-axis and the peak height (in fluorescence) on the $Y$-axis. The first lane represents peaks of the externall standard. The other lanes represent microsatellite fragments of the different family members. The haplotypes of the family members are given in lower cases according to the pedigree (figure 9.3 ).

\section{Interphase FISH}

FISH analysis was performed to investigate a deletion of the HLA-A region on haplotype $c$ using two overlapping cosmids and a PAC probe encompassing the HLA-A gene (figure 9.2). Counting the fluorescent spots in the nuclei revealed no differences between the patient and a control individual; both showed an identical normal distribution pattern for diploid results. Therefore, a deletion of the cosmid or PAC region could not be confirmed. 


\section{Discussion}

HLA analysis of the family of a Caucasian renal transplant patient revealed an unusual phenomenon, namely the segregation of a haplotype without a detectable HLA-A allele by serological or molecular typing methods. Two family members, the patient and one of his siblings, possessed the haplotype. Although it cannot be excluded that all primer pairs used with both SSP and SBT were unable to anneal with an HLA-A allele on haplotype $c_{*}$ the use of many different primers located on different positions all over the HLA-A gene makes this possibility very unlikely. Therefore, the results of the different techniques used all point into the direction of a deletion of the HLA-A gene. Full length amplification of the entire HLA-A gene made partial deletion of the gene unlikely. The length of a possible deletion is restricted to less than $127 \mathrm{~kb}$ by the results of the microsatellite analysis. FISH analysis further limited the length of a deletion because two cosmid probes with a total length of $52 \mathrm{~kb}$ still showed hybridisation on both chromosomes 6 .

Although absence of HLA-A on haplotype $c$ in this study is most probably the result of a deletion, other causes are possible. In theory exclusion of paternity could explain the unusual inheritance pattern in this family. In that case two haplotypes, A24, B62, Bw6, DR1, DQ1 and A2, B62, Bw6, DR1, DQ1 had to be brought into the family by one or two fathers (figure 9.3). Patemity investigations in this family were not possible because both parents were deceased. However in eight children in this family only four different haplotypes were detected by HLA typing and microsatellite analysis, which makes exclusion of paternity of the legal father unlikely.

Recombination as reason for the absence of HLA-A in our study is possible if unequal recombination is involved causing removal of HLA-A on haplotype $c$. Previously, recombination has been described as the cause of absence of the HLA-DRB5 gene ${ }^{36,37}$. In normal DR2-positive individuals, the products of two HLA-DRB genes, DRB1 and DRB5, are expressed. A DR2 variant, DR2LUM, was described lacking the DRB5 gene ${ }^{38}$. Results of molecular characterisation implicated a recombinational event as origin for the deletion of DRB5 ${ }^{36}$. Both molecular analysis and the existence of haplotypes possessing DRB5 in conjunction with DRB $1^{\star} 01^{39-41}$ make recombination between a DR2 and a DR1 haplotype most probable. The HLA-A gene is present on all haplotypes, therefore lacking of the gene can only be explained by unequal recombination, which is an uncommon event.

Although uniparental disomy has been described for chromosome $6^{17.18}$ and also partial uniparental disomy can occur ${ }^{42,43}$ the event is so rare that it is unlikely to occur twice in one family. We therefore regard partial uniparental disomy as reason for the lack of the HLA-A gene improbable. 
Deletions of small parts of the HLA genes have been observed, both for class I and II, with or without affecting the expression of the molecule. Up to now four different HLA-A alleles, with small nucleotide deletions, have been identified and in all of them expression was impaired. The null allele $A^{*} 0303 \mathrm{~N}$ was characterised by a six nucleotide deletion in exon 3 , causing a structural defect ${ }^{15}$. In $\mathrm{A}^{*} 2436 \mathrm{~N}$ a two nucleotide deletion in exon 2 resulted in an immediate premature stop codon ${ }^{11}$. In both $A^{*} 2440 N$, with a deletion of two nucleotides in exon 4 , and $A^{*} 6811 \mathrm{~N}$, with a deletion of one nucleotide in exon 1 , the deletion resulted in a reading frame shift, causing a premature stop $\operatorname{codon}^{1,12}$.

In the other HLA genes a total of 11 alleles were detected with deletions causing non-expression of the molecule. Four alleles with one nucleotide deletion $\left(B^{*} 0808 N, B^{*} 3540 N, B^{*} 4419 N, C W^{*} 0409 N\right)^{44-47}$ and three with a two nucleotide deletion $\left(B^{\star} 3925 N, C w^{*} 0507 N, D R B 5^{\star} 0110 N\right)^{1,48}$ have been demonstrated. Furthermore, one allele was detected with a ten nucleotide deletion $\left(B^{*} 15010102 N\right)^{49}$, one with a deletion of 11 nucleotides $\left(\mathrm{DRB} 44^{*} 0201 \mathrm{~N}\right)^{50}$, one with a 15 nucleotide deletion $\left(\mathrm{B}^{*} 1307 N\right)^{1}$ and finally one with deletion of 19 nucleotides (DRB5*0108N) ${ }^{54}$. For the DQA1 gene more than half of the alleles have a deletion of three nucleotides, which has not been shown to be of influence on the expression of the molecule'. The same holds for DRB1*1513 and DQB1 ${ }^{*} 0309$ ".

The present study describes a unique condition for one of the haplotypes in the family of a Caucasian renal transplant patient. The absence of any serological and molecular reaction together with the results of the microsatellite and FISH analysis make a deletion of a very narrow region encompassing the HLA-A gene the most plausible explanation. Whether the deletion is actually present and to what extent has not yet been proven.

\section{Acknowedgements}

Wo gratefully thank Benedicte Lie (Oslo, Norway) for her suggestions in microsatellite analysis. We are indebled to Katja Jordanova (Leiden, the Netherlands) for Kindly providing the cosmids, C109 K2118 and C109 B0233 and to Hidetoshi Inoko (Kanagawa, Japan) for the clone PAC544A6. The FISH analysis was technically supported by Ywomne Arts, Dianne De Santis, Dick wan Wichen (Utrecht, the Netherlands) and Anton Hopman (Maastricht, the Netherlands). 


\section{References}

1. Robinson J, Waller MJ, Parham $P_{0}$ Groot de $N_{0}$ Bontrop $R_{s}$ Kennedy LJ, Stoehr $P_{s}$ Marsh SGE: IMGT/HLA and IMGT/MHC: sequence databases for the study of the major histocompatibility complex. Nucleic Acids Res 2003;31(1):311.

2. Lardy NM, Otting $N$, Horst van der AR, Bontrop RE, Waal de LP: $5^{\prime}$ Regulatory nucleotide sequence of an HLA-A*0101null allele. Immunogenetics 1997:46(2):152.

3. Lee $K W$, Shin J-Y, Lee J-Y: Expression defect of an HLA-A'24 allele associated with DNA methylation in a normal individual. Tissue Antigens 2003;61(4);325.

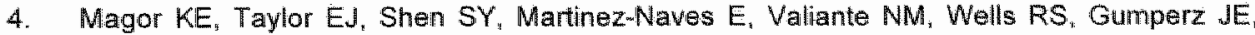
Adams EJ, Little A-M, Williams F, Middleton D, Gao X McCluskey d, Parham P. LienertWeidenbach $K$ : Natural inactivation of a common HLA allele (A*2402) has occurred on at least three separate accasions. J Immunol 1997;158:5242.

5. Zanone-Ramseier R, Gratwohl A, Gmür J, Roosnek E, Tiercy JM: Sequencing of two HLA-A blank alleles: implications in unrelated bone marrow donor matching. Transplantation 1999;67:1336.

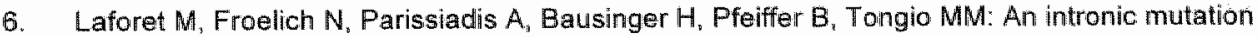
responsible for a low level of expression of an $H L A-A^{\star} 24$ allele. Tissue Antigens $1997 ; 50(4) ; 340$.

7. Balas A, Garcia-Sánchez F, Gómez-Reino F, Vicario JL: HLA class I allele (HLA-A2) expression defect associated with a mutation in its enhancer $B$ inverted cat box in two families. Hum Immunol 1994:41(1):69.

8. Bunce M, Procter J, Dunn PPJ, Day S, Ross J, Welsh Kl: Identification of the null HLA-A2 allelle, $A^{*} 0232 \mathrm{~N}$. Tissue Antigens $2000 ; 55: 31$.

9. Wu G-G, Cheng $L-H$, Deng $Z-H$, Wang $L-X$, Wei $T-L$, Yang $C-S$, Zhao T-M: Cloning and complete sequence of a novel HLA-A null allele, $A^{*} 0253 \mathrm{~N}$, with a termination codon generated by a $C$ to $G$ mutation in exon 2. Tissue Antigens 2002;59:328.

10. Ishikawa $Y$, Tokunaga $K_{0}$ Tanaka $H_{*}$ Nishimura Mu Muraoka M, Fujii $Y$, Akaza T, Tadokoro $K_{\text {, }}$ Juiji T: HLA-A null allele with a stop codon, HLA-A*0215N, identified in a homozygous state in a healthy adult. Immunogenetics 1995;43:1.

11. Li J, Hollander den $N$, Oasterwijk wan $A, N g$ C-M. Singai DP: Identification of a new HLA-A null allele, $A^{*} 2436 \mathrm{~N}$. Tissue Antigens 2002;60:184.

12. Laforet $M$, Froelich $\mathbb{N}$, Parissiadis $A$, Schell $A$, Pfeiffer $B$, Cazenave JP, Tongio MM: $A$, null HLA-A*68 allele in a bone marrow donor. Tissue Antigens 1999:53:573.

13. Laforet $M$. Froelich $N$, Parissiadis $A$, Pfeiffer $B$, Schell $A$, Faller $B$, Woehl-Jaegle M-L, Cazenave J.P. Tongio MM: A nucleotide insertion in exon 4 is responsible for the absence of expression of an HLA-A*01 allele. Tissue Antigens 1997;50(4);3:47.

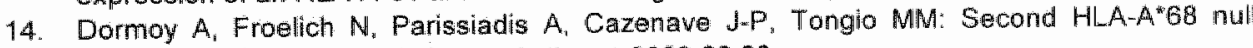
allele. $A^{*} 6818 \mathrm{~N}$, identified. Tissue Antigens 2002;60:88.

15. Lienert K, Russ $G$. Lester $S$, Bennett G, Gao X, McCluskey J: Stable inheritance of an HLA. "blank" phenotype associated with a structural muttation in the HLA-A"0301 gene. Tissue Antigens 1996:48:1187.

16. Elsner H-A, Bernard $G$, Eiz-Vesper $B$, Matteis de $M$, Bernard A, Blasczyk R: Non-expression of HLA-A*2901102N is caused by a nucleotide exchange in the mRNA splicing site at the beginning of intron 4. Tissue Antigens 2002;59(2):139.

17. Berg van den-Loonen $P M_{*}$ Savelkoul $P$, Hooff van $H$, Eede van $P$, Riesewijk $A$, Geraedts $d$ : Uniparental maternal disomy 6 in a renal transplant patient. Hum Immunol 1996:45:46.

18. Eggermann $T$, Marg $W$, Mergenthaler $S$, Eggerman $K$, Schemmel V, Stoffers U, Zerres $K$ Spranger S: Origin of uniparental disomy 6 : presentation of a new case and review on the literature. Annales de Génétique 2001:44:41.

19. Crowley J Hagan R. Clancy D. Rooney G, Dunne C, Lawlor E. Hayden P. Little AlM. Soleriou B. Marsh SGE, Madrigal JA: Two sets of HLA class II DRB and DQB1 alleles co-segregate among family members in a single maternal haplotype. Tissue Antigens 2003:61:487. 
20. Miller SA, Dykes DD, Polesky HF: A simple salting out procedure for extracting DNA from human nucleated cells. Nucl Acids Res 1988;16(3):1215

21. Voorter CEM, Vies van der SA, Berg van den-Loonen EM: Sequence-based typing of HLA-B: the $\mathrm{E7}$ cross-reacting group. Tissue Antigens $2000,56(4), 356$.

22. Bunce $M$, Banardo MCNM, Welsh $\mathrm{Kl}$ : Improvements in HLA-C typing using sequencespecific primers (PCR-SSP) including definition of HLA-CW9 and CW10 and a new allele HLA"CW7/8\%", Tissue Antigens 1994;44(3):200.

23. Vies van der SA, Voorter CEM, Berg van den-Loonen EM: A reliable and efficient high resolution typing method for HLA-C using sequence-based typing. Tissue Antigens 1998.52 .558 .

24. Voorter CEM, Rozemuller EH, Bruyn de-Geraets D, Zwan van der A.W. Tilanus MGJ, Berg wan den-Loonen $E M$ : Comparison of $D R B$ sequence-based typing using different strategies. Tissue Antigens 1997; $49(5): 471$.

25. Voorter CEM, Bruyn de-Geraets $D$, Berg van den-Loonen EM: High-resolution HLA typing for the DRB3/4/5 genes by sequence-based typing. Tissue Antigens 1997:50(3):283.

26. Voorter CEM, Kik MC, Berg van den-Loonen EM: High-resolution HLA typing for the DQB1 gene by sequence-based typing. Tissue Antigens 1998;51(1):80.

27. Wu G-G, Cheng L-H, LIZ, Deng Z-H, Zou H-Y, Wei T-L, Zhou D, LI D-C, Gao S-Q, Zhao TM: Identification of a new HLA allele, $A^{*} 11144$, in a Chinese family. Tissue Antigens $2003 ; 61(3): 253$.

28. Foissac $A$, Salhi M. Cambon-Thomsen A: Microsatellites in the HLA region: 1999 update. Tissue Antigens 2000;55:477.

28. Lie BA, Todd JA, Pociot F, Nerup J, Akelsen HE, Janer G, Dahl-Jørgensen, Rønningen KS, Thorsby $E$, Undlien DE: The predisposition to type 1 diabetes linked to the human leukocyte antigen complex includes at least one non-class II gene. Am J Hum Genet 1999;64:793.

30. Lie $B A$, Undien $D E$. Thorsby $E$ : The gemetics of disease susceptibility: strategies for analyzing polygenic HLA associations uising microsatellite markers. In Tilanus MGJ (ed): IHWG technical manual: genomic analysis of the human MHC, DNA-based typing for HLA alleles and linked polymorphism, 2000: p TM17.

31. Riemersma $S A_{\text {, Jordanova }} S_{v}$ Schop RFJ, Phillippo $K$, Looijenga $L H J$, Schuuring $E$, Kluin PM: Extensive genetic alterations of the HLA region, including homozygous deletions of HLA class 11 genes in B-cell lymphomas arising in immune-privileged sites. Blood 2000;96(10):3569.

32. Shiina $T$, Tamiya $G$, Oka $A$, Takishima $N$, Inoko $H$ : Genome sequencing analysis of the 1.8 Mb entire human MHC class I region. Immunol Rev 1999;167:193.

33. Pichon L, Carn $G$, Bouric $P$, Giffon $T$, Chauvel $B$, Lepourcelet M, Mosser J, Legall J-Y, David $V$ : Structural analysis of the HLA.A/HLA.F subregion: precise localization of two new multigene families closely associated with the HLA class I sequences. Genomics $1996 ; 32: 236$.

34. Voorter CEM, Ummelen MIJ, Ramaekers FSC, Hopman AHN: Loss of chromosame 11 and $11 \mathrm{p} / \mathrm{q}$ imbalances in bladder cancer detected by fluorescence in situ hybridization. Int $\mathrm{J}$ Cancer $1996 ; 65: 301$.

35. Hopman AHN, Voorter CEM, Speel EJM, Ramaekers FCS, Vooijs PG: Detection of genetic changes in cancer by interphase cytogenetics and comparative genomic hybridization. In Polak JM, McGee JOD (eds): In situ hybridization, vol Second edition. Londan and Oxford, Oxford University Press, 1998:93.

36. Young NT, Darke C: Molecular characterization of the HLA-DR2LUM haplotype. Tissue Antigens 1994;43(1):28

37. Corell $A$, Varela P. Morales P. Paz Artal $E$, Martinez-Laso J, Martin-Villa JM, Toilt du $E$, Arnaiz-Villena A: A study of DR2-LUM haplotype generation and the DRB6*0202 linkage to DRB1*160\%. Immunogenetics 1993;38(6):460.

38. Wade JA, Hurley $C K$, Hastings $A$, Ehrenberg $P$, Johnson AH, Martell RW, Toit du ED: Combinatorial diversity in DR2 haplotypes. Tissue Antigens 1993:41(3):113.

39. Tautz $C$. Marsh DG, Baur X: A novel HLA-haplatype containing a DRB5 gene not associated with DRB1"15 or DRB1"16 alleles. Tissue Antigens 1992;39(2):91. 
40. Perrier P. Leotard $B$, Henry MA: A novel HLA haplotype containing a DRB5 gene associated with the DRB1*0103 allele. Tissue Antigens 1993;42(5):518.

41. Berg van den-Loonen EM. Bignon JD, Toit du E, Pitchappan RM, Loon J, Singal DP. Olerup $O$, Perrier $P$. Constantinidou $N$. Papasteriades $C$, Schireuder $G$. Amaiz-Villena A, BredaCoimbra H. Poli F. Hashemi S, Petit le JC, Scorza $R$, Palma Carlos A, Bartova A Moraes ${ }^{\prime} R_{*}$ Thlanus $M$, Rani $\mathbb{R}$, Manzo $C$, Kamoun $M$. Cheung $K W K$, Nose $Y$, Lenhard $V$, Gandini $E$, Tongio MM, Sachs J Hansen JA, Emonds MP, Stewart D: AHSH11: HLAA-DR2 (DR15, DR16), DR54. In Charron D (ed): Twelfth International Histocompatibility Workshop and Conference, voll Saint Malo-Parijs, EDK, 1997:91.

42. Das $S$, Lese CM, Song M, Jensen $J L$, Wells LA, Barnoski BL, Raseberry JA, Canacho JM, Ledbetter DH, Schnur RE: Partial paternal uniparental disomy of chromosome 6 in an infant with neonatal diabetes, macroglossia, and craniofacial abnormalities. Am J Hum Genet 2000;67:1586.

43. López-Gutiérrez AU, Riba L, Ordonez-Sánchez ML, Ramirez-Jiménez $S$, Cerillo-Hinojosa M, Tusié-Luna MT: Uniparental disomy for chromosome 6 results in steroid 21-hydroxylase deficiency: evidence of different genetic mechanisms involved in the production of the disease. J Med Genet 1998;35:1014.

44. Carter V. Dunn PPJ, Cavanagh $G$, Day S, Ross J, Chapman C: An HLA-B null allele $\left(B^{*} 0808 N\right)$ caused by a nucleotide deletion in exon 3 , found in the family of a bone marrow transplant recipient. Tissue Antigens 2000;55(1):61.

45. Dunne C. Little AM, Cox ST, Masson D, Crowley J, Barnes T, Marsh SGE, Rooney G, Hagan $R_{1}$ Lawlor $E$, Madrigal JA: identification and nucleotide sequence of a new null allele, HLA $B^{*} 3540 N$. Tissue Antigens 2002; 59(6):522.

46. Bettens $F$. Tiercy JM: Sequence of a new class I null allele within the HLA-B44-specificity. Tissue Antigens 2000;56(5):441.

47. Balas A, Santos S, Aviles MJ, Garcia-Sánchez F, Lillo R, Alvarez A, Villar-Guimerans LM, Vicario JL: Elongation of the cytoplasmic domain, due to a point deletion at exon 7, results in an HLA-C null allele, Cw0409N. Tissue Antigens 2002;59(2):95.

48. Balas $A, O c o n ~ P$, Vicario JL, Alonso A: HLA-DR51 expression failure caused by a two-base deletion at exon 2 of a DRB5 null allele (DRB5 $0110 \mathrm{~N}$ ) in a Spanish gypsy falmily. Tissue Antigens 2000;55(5):467.

49. Curran MD, Williams F, Little AM, Rima BK, Madrigal $J A$, Middleton D: Aberrant splicing of intron 1 creates a novel null HLA-B*1501 allele. Tissue Antigens 1999;53(3):244.

50. Robbins F, Hurley CK, Tang $T$, Yao H, Lin $Y$, Wade J, Goeken N, Hartzman RJ: Diversity associated with the second expressed HLA.DRB locus in the human population. Immunogenetics 1997:46:104.

51. Voorter CEM, Roeffaers HET, Toit du ED, Berg van den-Loonen EM: The absence of DR51 in a DRB5-positive individual DR2ES is caused by a null allele (DRB5*0108N). Tissue Antigens 1987:50(4):326. 


\section{Chapter 10}

General discussion 
172 chapter 10 


\section{General discussion}

The most extensive allelic polymorphism of all human genes is presented by the major histocompatibility complex (MHC). HLA class I and II molecules are encoded by genes located on the short arm of chromosome 6 . They have a fundamental role in the functioning of the immune system. HLA typing is of great importance in many clinical settings, such as solid organ transplantation, bone marrow and stem cell transplantation and disease susceptibility. The introduction of the polymerase chain reaction (PCR) technology has resulted in the development of several molecular HLA typing methods. Molecular methods are based on amplification of locus-, group-, or allele-specific DNA fragments from the target genes. The HLA typing methods PCR-SSP (sequence specific primers), PCR-SSOP (sequence specific oligonucleotide probes) and PCRSBT (sequence-based typing) have become routine approaches. DNA sequencing is the only method with which the full extent and complexity of polymorphism within the HLA region can be obtained. The great difference with PCR-SSP and -SSOP is that the complete nucleotide information is obtained for the gene of interest and therefore the direct identification of novel polymorphisms ${ }^{1}$. Most polymorphism of HLA class I genes is located in exons 2 and 3 which code for the peptide binding region. Diversity in the $\alpha 1$ and $\alpha_{2}$ domains of the molecule may have originated from a high selective pressure to cope more efficiently with different pathogens by the peptide binding groove. This thesis shows that much polymorphism is present in exons 2 and 3 , but it is not restricted to the peptide binding groove. Extensive polymorphism is also present outside exons 2 and 3 both in coding and non-coding regions.

\section{Polymorphism of the coding regions}

To determine the degree of polymorphism we designed sequence-based typing methods for HLA-A and $-B$. The strategies were based on heterozygous sequencing of exons 2 and 3 . Several sequencing protocols for HLA class 1 have already been described ${ }^{2-16}$, but the sequencing strategy we designed differs from previous ones in that separate amplification and sequencing of exons 2 and 3 is performed. Most primers of the heterozygous sequencing protocols were located in the non-coding introns. The conserved intron regions of the different loci were used for the location of locus-specific amplification primers. Also the sequencing primers were located in the introns to enable sequencing of the complete exon. Primer design was a challenge because only limited information is available on the intron sequences. Although the sequences of the non-coding regions are known for at least one member of all major HLA-A and -B allelic groups, for more than 850 alleles they are still not elucidated ${ }^{5,14,17-23}$. Currently, the exon 2 and 3 sequences of 349 different 
HLA-A and 626 HLA-B alleles have been identified ${ }^{23}$. In the A10/A19 study a total of 54 different HLA-A alletes were sequenced. The HLA-B sequencing studies, the B5/35 cross-reacting group (CREG) study and the previously described B7 CREG study ${ }^{24}$, resulted in the identification of a total of 133 different HLA-B alleles. Many alleles were not included in the studies, probably due to their low frequency in the population. Since the primers were located in the non-coding regions and these sequences were unavailable for many alleles, it is not a priori certain whether the primers will amplify all alleles. However, the location of amplification and sequencing primers in rather conserved regions supports the idea that alleles not encountered, will be correctly amplified and sequenced. Furthermore, each exon is sequenced separately in the HLA-A and $-B$ strategies and the sequence data of the different exons are combined in the assignment program. The chance to miss an allele in both exons amplified and sequenced separately is very small and therefore our SBT strategy was considered to be very robust. Our SBT approach, consisting of genomic DNA as starting material, a solid-phase sequencing method, the use of an internally located sequencing primer and a one-step sequencing reaction using $T 7$ polymerase, resulted in high-quality sequence data necessary for reliable identification of heterozygous positions. It can be argued that heterozygous sequencing cannot identify the cis/trans location of nucleotides and can therefore overlook the presence of new alleles if their combination of sequences is identical to the heterozygous sequence of an already known combination of alleles ${ }^{25}$. However, allele-specific sequencing by several groups has not yet revealed identification of many new alleles. Genomic DNA as starting material has the disadvantage that pseudogenes can be coamplified. Pseudogenes show sequence homology to classical HLA genes. Since less information is available on pseudogene sequences, problems can be encountered in designing locus-specific amplification primers. In the HLA-A10/19 study we confirmed coamplification of a pseudogene HLACOQ or HLA-DEL linked to $A^{*} 3401$, as was also noticed by other groups ${ }^{26,27}$.

The extreme polymorphism of HLA class I loci is illustrated by the huge number of alleles known for each gene. HLA molecules are expressed co-dominantly, each individual carries two different HLA alleles for each locus. The enormous number of different alleles gives rise to an extreme number of possible different combinations of two alleles. In heterozygous sequencing several combinations are ambiguous if more than one allele pair has identical heterozygous sequences. Table 10.1 shows the ambiguity analysis for HLA class I. For each locus, the total number of alleles and the number of alleles with different exon 2 and 3 sequences are indicated. The number of genotypes represents all theoretically possible combinations of two alleles, including homozygous combinations. The number of ambiguous combinations corresponds to all 
combinations of two alleles, which do not resuit in a unique heterozygous sequence. Table 10.1 shows that for class I the percentage of all theoretical possible ambiguous combinations of all genotypes is less than $1 \%$. The actual number of ambiguous combinations encountered during typing is highly influenced by the allele frequencies: ambiguities with a combination of common alleles will occur frequently, even if the alternative allele combination is rare. In our HLA-A study, 45 out of 252 individuals $(18 \%)$ showed this type of ambiguity. In the HLA-B5/35 study ambiguous combinations were identified in 59 out of 225 individuals $(26 \%)$ and in the previously described B7 study in 45 out of 355 individuals $(13 \%)$. The number of ambiguous combinations is clearly biased by the use of selected individuals positive for $A 10 / 19, B 5 / 35$ or B7 alleles. All these ambiguities were resolved by allele-specific amplification and sequencing.

Table 10.1 Ambiguity analysis for HLA class I.

\begin{tabular}{lccccc}
\hline Locus & $\begin{array}{c}\text { Total number of } \\
\text { alleles }\end{array}$ & $\begin{array}{c}\text { Number of alleles with } \\
\text { different exon } 2 \text { and } 3 \\
\text { sequences }\end{array}$ & $\begin{array}{c}\text { Number of } \\
\text { genotypes }\end{array}$ & $\begin{array}{c}\text { Number of } \\
\text { ambiguous } \\
\text { combinations" }\end{array}$ & $\begin{array}{c}\text { Percentage of } \\
\text { ambiguous combinalions } \\
\text { of all genotypes }\end{array}$ \\
\hline HLA-A & 349 & 323 & 52326 & 257 & 0.49 \\
HLA-B & 626 & 600 & 180300 & 1421 & 0.79 \\
HLA-C & 182 & 163 & 13366 & 106 & 0.79 \\
\hline
\end{tabular}

\footnotetext{
Numbers are taken from IMGT/HLA Databank, Release 2.8.0, January $2005^{23}$

2 Calculated: \#genotypes = \#alleles with different exan 2 and 3 sequences * (\#alleles with different exon 2 and 3 sequences $+1 / 1 / 2^{72}$
}

Another type of ambiguity was noticed when alleles had identical exon 2 and 3 sequences and differences were located outside these exons. For HLA-A, at the four digit level this involved ten identical pairs of alleles. For HLA-B thirteen and for HLA-C seven identical allele combinations were found ${ }^{23}$. These ambiguities can be resolved by sequencing other regions or by serology for the difference between expressed versus null alleles. To resolve HLA.B ambiguities we have designed an SBT strategy for heterozygous sequencing of exons 1,4 and 5. The heterozygous sequence protocol enabled the use of generic primer combinations for all B-alleles without the necessity of prior typing results. Because exons 2 and 3 were also sequenced heterozygously, the allele assignment was directly available by comparing the sequences of all exons with the database.

Whether ambiguities will be identified depends on the ethnicity of the population studied, the SBT protocol and the sequence database used. With the recognition of new alleles the ambiguity list increases. Therefore it might be more efficient to replace the HLA class I heterozygous SBT strategy by allele- 
specific sequencing in the future. Furthermore the sequencing of other exons besides exons 2 and 3 will become a routine procedure for correct assignment of alleles at the four digit level. For example for HLA-A the exon 4 sequence is usually needed to resolve the $A^{*} 0201 /{ }^{*} 0209 /{ }^{*} 0243 / N^{*} 0266 /{ }^{*} 0275$ ambiguity due to high frequency of $A^{*} 0201$ in Caucasians.

The polymorphic exon 2 and 3 sequences of all class $\|$ alleles are known because these are the current minimum sequence requirements for the assignment of an official allele name by the WHO Nomenclature Committtee for factors of the HLA system ${ }^{28}$. The sequences of other exons of a number of infrequent class I alleles are unknown. To assess the degree of polymorphism for HLA-B outside the peptide binding region, the exon 1, 4 and 5 sequences were elucidated for $46 \mathrm{~B}$-alleles of which these sequences were unknown. The elucidation of these sequences has led to the conclusion that there is more polymorphism present outside exons 2 and 3 than previously thought. Nucleotide differences in these regions are mainly found between different allele groups, but less between different alleles within the same group. The polymorphism in thes $\theta$ exons merely reflects the lineage-specificity, with sequence heterogeneity between but not within a lineage, in contrast to exons 2 and 3 in which there is more polymorphism within a lineage. However in some cases deviating sequences within allele groups were found, which were either confirming the evolutionary origin of these alleles or were identified as new polymorphisms.

The functional role of the polymorphism observed outside the peptide binding groove is not well understood. Exon 1 encodes the leader peptide, which is cleaved from the mature HLA protein after transport across the endoplasmic reticulum. Part of the leader peptide of class I binds to HLA-E, which then migrates to the cell surface where it interacts with receptors on NK or T cells $^{29-31}$. Exon 4 encodes the $\alpha 3$ domain, which plays an important role in the association with the CD8 binding, the peptide loading complex and the interaction with $\beta 2$ microglobulin ${ }^{32-34}$ : CD8 binding affects cytotoxic $T$ cell recognition, whereas interaction with $\beta 2$ microglobulin is required for correct folding of the HLA protein ${ }^{35,36}$. Mutations in the $\alpha 3$ domain have shown to result in CD8 binding affinity variation, reduced cell surface expression and variation in peptide binding loading efficiency ${ }^{34,37-41}$. The transmembrane domain encoded by exon 5 was shown to be important for cell surface stability, which was modulated by transmembrane domain length variation ${ }^{42}$.

The number of polymorphic nucleotide positions for each exon of the three different HLA class 1 genes is indicated in table 10.2. The ratio indicates the number of polymorphic positions related to the length of the exon. Table 10.2 
shows that in general most polymorphism is located in exons 2 and 3 encoding the peptide binding groove. However in some other exons fairly high numbers of polymorphic positions are demonstrated. The fact that the exon 1,4 and 5 sequences of approximately $65 \%$ of the HLA class I alleles are still unknown, most probably as a result of their low frequency in the population, might not have much influence on the ratio. This is because the exon 1,4 and 5 sequences of at least one member of all major allelic groups is identified and most polymorphisms in these exons are group specific. The high numbers of polymorphic positions of exon 5 of HLA-B and $-C$ are predominantly caused by $B^{*} 7301$ and the alleles of $C W^{*} 07$ and $C w^{*} 17$, respectively. The sequences of these alleles revealed highly divergent class I molecules defining lineages distinct from HLA-B and $-\mathrm{C}^{43-45}$.

Table 10.2 Nucleotide polymorphism of HLA class 1.

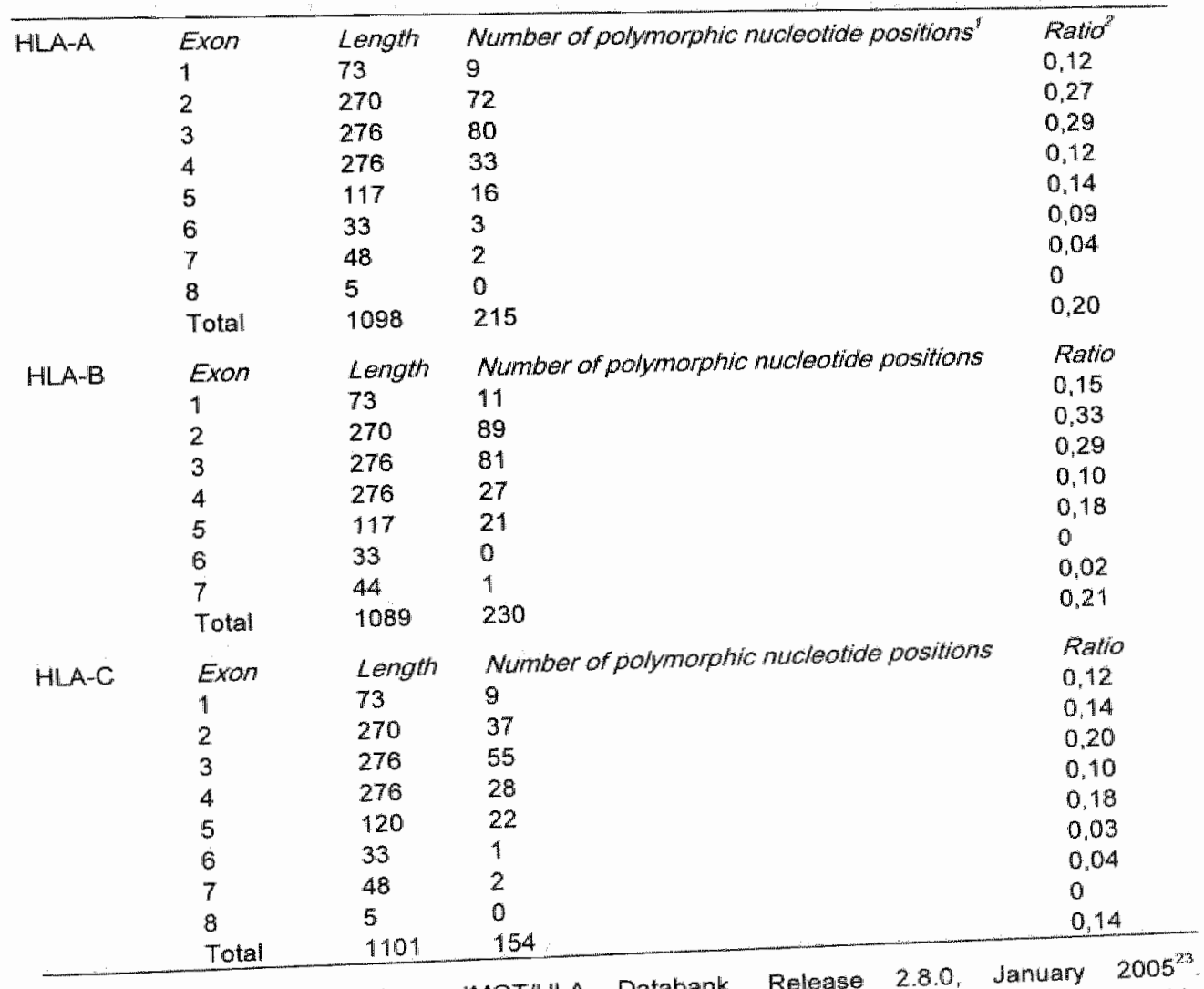

Numbers are taken from IMGT/HLA Databank, Release 2.8 .0 , January $2005^{23}$. Insertions/deletions are not counted as polymorphic positions. The polymorphic nucleotide positions represent bath synonymous and non-synonymous positions number of alleles with unknown exon sequences is not laken into account 


\section{Polymorphism of the non-coding regions}

To assess the degree of polymorphism outside the coding regions we have determined the intron 4 nucleotide sequence of at least one representative of each major allelic group of HLA-A, $-B$ and $-C$. The length of intron 4 proved to be variable between 93 and 124 nucleotides due to insertions and deletions between and within the different HLA loci. Although an extensive homology for $H L A-A,-B$ and $-C$ was detected, several locus- and group-specific sites were identified, comparable to the intron 1 through 3 sequences ${ }^{5,14,17,19-21,23}$. Thirtythree different allelic groups were represented by more than one allele. The intron 4 nucleotide sequences were relatively conserved within these groups, although in three allelic groups, $B^{*} 40, B^{*} 48$ and $C w^{*} 07$, differences in the intron 4 sequence were noticed between different alleles.

$B^{\star} 7301$ was identified with a very peculiar coding sequence and defined by Parham et al. as a second lineage of HLA-B alleles ${ }^{43}$. The exon 4 and 5 sequences of $B^{*} 7301$ resemble the sequences of HLA-C alleles. In exon 4 , several mismatches of $B^{\star} 7301$ with other $B$-alleles show identity to $C$-alleles. The insertion of three nucleotides in exon 5 of the $\mathrm{C}$-alleles in comparison to $\mathrm{A}$ and $B$-alleles, is also present in $B^{*} 7301$. In this thesis we have determined the intron $1,2,3$ and 4 sequences of $B^{*} 7301$. The overall intron 1 through 3 sequences resemble the sequence of other HLA-B alleles. This supports the idea that $B^{*} 7301$ is a hybrid molecule with HLA-B-like exons 2 and 3 and HLA$C$-like exons 4 and 5 . However, the elucidated intron 4 sequence of $B^{*} 7301$ does not resemble the HLA-C sequence. The deletion of 20 nucleotides, which distinguishes the $\mathrm{B}$-alleles from the $\mathrm{C}$-alleles, is also present in $\mathrm{B}^{\star} 7301$. A gene conversion event of exons 4 and 5 of HLA-C as the origin for $B^{*} 7301$ is unlikely, because of the differences found in intron 4 . This is a further argument for the hypothesis of Parham et al. ${ }^{43}$, that the $B^{\star} 7301$ allele has been separated from the other HLA-B alleles for an extended period of time in which many mutational and recombinational events have contributed to the sequence divergence.

\section{Polymorphic expression variants}

For HLA class I, 42 out of 1157 alleles were found to be non-expressed ${ }^{23}$. The lack of expression can be different in origin. The cause may be either point mutations giving rise to premature stop codons ${ }^{46-54}$, deletions or insertions leading to a frame shift and a premature or delayed termination ${ }^{48,55-64}$, deletions causing a structural defect in the molecule ${ }^{65}$, mutations affecting transcription ${ }^{66,67}$ and RNA splicing ${ }^{48,58,68-70}$ or hypermethylation leading to gene inactivation ${ }^{7 /}$. We have described a unique condition for one of the haplotypes in the family of a Caucasian renal transplant patient. The absence of any 
serological and molecular reaction together with the results of the microsatellite and FISH analysis make a deletion of a very narrow region encompassing the HLA-A gene the most plausible explanation. Whether the deletion is actually present and to what extent has not yet been proven. Deletions of small parts of the HLA genes have been observed, both for HLA class I and 11 , with or without affecting the expression of the molecule ${ }^{23}$. The deletion of a complete HLA class I gene is a phenomenon not previously described. On an individual level a deletion of one of the HLA-A genes might not have any deleterious effect. The possible deletion found in this study was present in the patient but also in a healthy sibling and moreover a lot of individuals are homozygous for a particular HLA allele. For population survival deletion of an HLA gene could have a negative impact.

\section{Concluding remarks and future}

Investigating HLA class I polymorphism has resulted in identification of more polymorphism outside exons 2 and 3 than previously thought. Polymorphism is present in coding regions outside the peptide binding groove as well as in the non-coding regions. Now that SBT has become a more routine technique for HLA typing, the number of HLA class I alleles will further increase. The actual extent and functional role of the genetic polymorphism of HLA class | outside the peptide binding groove still has to be investigated. To assess the degree of polymorphism the exon $1,4,5,6,7$ and 8 and the intron sequences of many HLA class I alleles have to be elucidated. Intron sequences are important for primer design in order to sequence complete exons, but also to gather information on the origin of several expression variants. It is unquestionable that the HLA class I genes display an extremely high polymorphism and that the number of polymorphic positions will increase continually in the future. 


\section{References}

1. Voonter CEM, Berg van den-Loonen EM. HLA and HPA typing-advances in the application of molecular biology. In: Smith Sibinga CTh, Klein $\mathrm{HG}^{*}$, ed. Molecular Biology in Blood Transfusion. Dordrecht, Boston, London: Kluwer Academic Publishers, 2000;61-71.

2. Pera $C$. Delfino $L$. Morabito $A$ et al. HLA-A typing comparison between serology, the amplification refractory mutation system with polymerase chain reaction and sequencing. Tissue Antigens 1997;50.372-9.

3. Norgaard L, Fugger L, Jakobsen BK, Svejgaard A. Sequencing-based typing of HLA-A locus using $M R N A$ and a single locus-specific PCR followed by cycle-sequencing with AmpliTaq DNA polymerase, FS. Tissue Antigens 1997, 49:455-65.

4. Scheitinga $S A$, Johnston $-D o w, L$, White $C B$ et al. $A$ generic sequencing based typing approach for the identification of HLA-A diversity. Hum Immunol 1997;57:120-8.

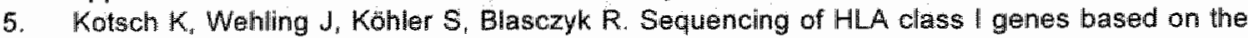
conserwed diversity of the noncading regions: sequencing-based typing of the HLA-A gene. Tissue Antigens 1997;50:178-91.

6. Santamaria $P$, Lindstrom AL, Boyce-Jacino MT et al. HLA class I sequence-based typing. Hum Immunol 1993;37:39-50.

7. Dormoy" A, Froelich $N$, Leisenbach $R$, Weschler $B$, Cazenave J-P, Tonglo M-M. Mono-allelic amplification of exons 2-4 using allele group-specific primers for sequence-based typing (SBT) of the HLA-A, $-B$ and $-C$ genes: preparation and validation of ready-to-Lise pre-SBT mini-kits. Tissue Antigens 2003;62:201-16.

8. Adams SD, Barracchini KC, Simonis TB, Stroncek D, Marincola FM. High throughput HLA sequence-based typing (SBT) utilizing the ABI Prism ${ }^{R} 3700$ DNA Analyzer. Tumori 2001;87: $540-543$.

9. Pozzi S, Longo A, Ferrara GB. HLA-B locus sequence-based typing. Tissue Antigens 1999; $53: 275-81$.

10. Eberle $M$, Knapp LA, Iwanaga KK, Domanico MJ, Aiyer K, Watkins DI. HLA-B typing by allele seperation followed by direct sequencing. Tissue Antigens 1997:49:365-75.

11. Petersdorf EW, Hansen JA. A comprehensive approach for typing the alleles of the HLA-B locus by automated sequencing. Tissue Antigens $1995 ; 46: 73-85$.

12. Delfino L, Morabito A, Longo A, Ferrara GB. HLA-C high resolution typing: analysis of exons 2 and 3 by sequence based typing and detection of polymorphisms in exons $1-5$ by sequence specific primers. Tissule Antigens 1998; $52: 251-9$

13. Turner $S$, Ellexson ME. Hickman HD et al. Sequence based typing provides a new look at H.A.C diversity. J Immunol 1998;161:1406-13.

14. Cox ST, MCWhinnie AJ, Robinson $d$ et al. Cloning and sequencing full-length HLA-B and $-C$ genes. Tissue Antigens 2003;61:20-48.

15. Dunn PP. Cox ST, Little AM. Sequencing protocols for detection of HLA class I polymorphism. Methods Mol Biol 2003:210:191-222.

16. Sintasath DM, Bei M, Steiner $N$ et al. Analysis of HLA.A and -B serologic typing of bone marrow registry donors using polymerase chain reaction with sequence-specific oligonucleotide probes and DNA sequencing. Tissue Antigens 1997;50:366-71.

17. Cereb $N$, Kong $Y$, Lee S, Maye P, Yang SY. Nucleotide sequences of MHC class I introns 1. 2 , and 3 in humans and intron 2 in nonhuman primates. Tissue Antigens 1996:47:498-511.

18. Yao Z, Volgger A. Scholz $S$, Albert ED. Sequence polymorphism in the HLA-B promoter region. Immunogenetics 1995;41:343-53.

19. Summers CW. Hampson VJ, Taylor GM. HLA class I non-coding nucleotide sequences, 1992. Eur J Immunogenet 1993;20:201-40.

20. Gomez-Casado E, Vargas-Alarcon G. Martinez Laso J et al. Evolutionary relationships between HLA-B alleles as indicated by an analysis of intron sequences. Tissue Antigens 1999;53:153-60. 


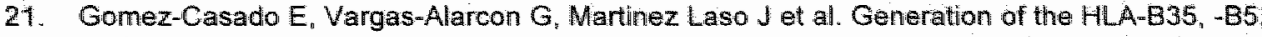
$-B 16$, and B15 groups of alleles studied by intron 1 and 2 sequence analysis. Immunogenetics 1997;46:469-76.

22. Yao Z, Volgger A, Scholz $S$, Albert E. Polymonphism of the HLA-C promoter region. Immunogenetics 1997;45:428-31.

23. Robinson J, Waller MJ. Parham P et al. IMGT/HLA and IMGT/MHC: sequence databases for the study of the major histocompatibility complex. Nucleic Acids Res 2003,31:311-4.

24. Voorter CEM, Vlies van der SA, Berg van den-Loonen EM. Sequence-based typing of HLA-B: the B7 cross-reacting group. Tissue Antigens 2000;56:356-62

25. Blasczyk R. HLA diagnostic sequencing - conception, application and automation. J Lab Med $2003: 27: 359-68$.

26. Coquillard $G_{1}$ Lau $M$, Kletzel $M$, Rodriguez-Marino $S G$. Identification of two pseudogenes with sequence homology to human and gorilla MHC class IA genes: ancestral haplatype in the Fillipino population. Hum Immunol 2004;65:665-73.

27. Lau M, Park MS, Cecka JM, Reed EF. Report of the International Cell Excharnge \#300. UCLA, Los Angeles, 2004:9-13.

28. Marsh SGE, Albert ED, Bodmer WF et al. Nomenclature for factors of the HLA system, 2002 Tissue Antigens 2002;60:407-64.

29. Garcia $P$, Llano $M$, Heredia de $A B$ et al. Human $T$ cell receptor-mediated recognition of HLAmE. Eur J Immuniol 2002;32:936 44 .

30. O'Callaghan CA. Molecular basis of human natural killer cell recognition of HLA-E (human leucocyte antigen-E) and its relevance to clearance of pathogen-infected and tumour cells. Clin Science 2000;99:9-17.

31. Braud VM, Allan DSJ, McMichael AJ. Functions of nonclassical MHC and non-MHC-encoded class I molecules. Curr Opin Immunol 1999;11:100-8.

32. Fayen $\downarrow$. Huang $\mathrm{J}-\mathrm{H}$, Meyerson $\mathrm{H}$ et al. Class I MHC alpha 3 domain can function as an independent structural unit to bind CD8 alpha. Moll Immunoll $1995 ; 32: 267-75$.

33. Bjorkman $P J$, Saper MA, Samraoui $B$, Bennett WS, Strominger $J L$, Wiley DC. Structure of the human class I histocompatibility antigen, HLA-A2. Nature 1987;329:506-12.

34. Williams $A$, Au Peh C, Elliott T. The cell biology of MHC class I antigen presentation. Tissue Antigens 2002;59:3-17.

35. Salter RD, Benjamin RJ, Wesley PK et al. A binding site for the T-cell co-receptor CD8 on the alpha 3 domain of HLA-A2. Nature 1990;345:41-6.

36. Hill DM, Kasliwall T. Schwarz E et al. A dominant negative mutant B2-micraglobulin blocks the extracellular folding of a major histocompatibility complex class I heavy chain. J Bioll Chem $2003 ; 278: 5630-8$.

37. Gao GF Willcox BE, Wyer JR et al. Classical and nonclassical class I major histocompatibility complex molecules exhibit subtle conformational differences that affect binding to CD\&alpha. alpha. J Biol Chem 2000;275:15232-8.

38. Salter RD, Norment $A M$, Chen BP et al. Polymorphism in the alpha 3 domain of HLA-A molecules affects binding to CD8. Nature 1989;338:345-7.

39. Connolly $\mathrm{JM}$, Hansen $T H$, Ingold $A L_{\text {. Potter }} T A$. Recognition by CD8 on cytotoxic $T$ lymphocytes is ablated by several substitutions in the class I alpha 3 domain: CDE and the T. cell receptor recognize the same class I molecule. Proc Natl Acad Sci USA 1990;87:2137-4\%.

40. Wesley PK, Clayberger $C$, Lyu $S$, Krensky AM. The CD8 coreceptor interaction with the alpha 3 domain of HLA class I is critical to the differentiation of human cytotoxic T-lymphocytes specific for HLA-A2 and HLA-Cw4. Hum Immunol 1993;36:149-55.

41. Salter RD. Mutant HLA-A201 heavy chains with lowered affinity for beta2m are transported after growth at reduced temperatures. Hum Immunol 1992;35:40=9.

42. Osborn $C K$, Grigoriev $V_{*}$ Crew MD. Modulation of class I major histocompatibility complex antigen cell-surface stability by transmembrane domain length variation. Mol Immunol 1997 34:771-80.

43. Parham $P$, Arnett $K L$, Adams EJ et all. The HLA-BT3 antigen has a most unusual structure that defines a second lineage of HLA-B alleles. Tissue Antigens 1994:43:302-13. 
44. Herrero $M J$, Vilches $C$, Pablo de $R$, Puente $S$, Kreisler $M$. The complete primary structure of Cw* 17011 reveals a highly divergent HLA class I molecule. Tissue Antigens 1997;49:267-70.

45. Zemmour $d$ Parham P. Distinctive polymorohism at the HLA-C locus: implications for the expression of HLA-C.J Jexp Med 1992,176:937-50.

46. Bunce M, Procter J, Dunn PPJ. Day S, Ross J, Welsh K1. Identification of the null HLA-A2 allefe, $A^{*} 0232 \mathrm{~N}$. Tissue Antigens $2000 ; 5531-6$.

47. Wu G-G, Cheng $L-H$. Deng $Z-H$ et al. Cloning and complete sequence of a novel HLA-A null allele, $A * 0253 N$, with a termination codon generated by a $C$ to $G$ mutation in exon 2 . Tissue Antigens 2002;59:328-30.

48. Magor KE, Taylor EJ, Shen $S Y$ et al. Natural inactivation of a common HLA allele (A*2402) has occurred on at least three separate occasions. J Immunol 1997; 158:5242-50.

49. Ishikawa $Y$, Tokunaga $K$, Tanaka $H$ et al. HLA-A null allele with a stop codon, HLA-A*0215N, identified in a homozygous state in a healthy adult. Immunogenetics $1995 ; 43: 1-5$.

50. Mine H, lishikawa $Y$, Hojo M et al. An HLA-B null allele $\left(B^{*} 1526 N\right)$ with a stop codon in exon 3 generated by a point mutation. Tissue Antigens 1997,50:351-4.

51. Hollander den $N, L I J$, Oosterwijk van $A, N g C-M$, Singall DP. Identification of a new HLA.B null allele, $B^{*} 1817 \mathrm{~N}$, in a family. Tissue Antigens $2002 ; 59: 341-3$.

52. Hammond L. Street J. Downing J, Thompson J, Darke $C$. Immunogenetics of a new HLA-B null alleie, HLA-B" $4423 \mathrm{~N}$. Eur J Immunogenet 2003;30:385-6.

53. Tamouza $R_{n}$ Sadki $K$, Schaeffer $V$ et al. A novel HLA-B null allele $\left(B^{*} 4022 N\right)$ generated by a nonsense codon in the alpha-1 domain. Tissue Antigens 2000;55:378-80.

54. Hou JY, Luning Prak E, Kearns $J$ et al. A nonsense mutation in exon 3 results in the HLA.B null allele $B^{*} 5127 \mathbb{N}$. Tissue Antigens 2002;60:262-5.

55. Li J. Hollander den $N$, Oosterwijk van $A, N g C-M$, Singall DP. Identification of a new HLA-A null allele, $A^{*} 2436 \mathrm{~N}$. Tissue Antigens 2002;60:184-5.

56. Laforet $M$, Froelich $\mathbb{N}_{1}$ Parissiadis $A$ et al. A null HLA-A"68 allele in a bone marrow donor. Tissue Antigens 1999;53:573-5.

57. Laforet $M$, Froelich $N$, Parissiadis $A$ ef al. A nucleotide insertion in exon 4 is responsible for the absence of expression of an HLA-A*01 allele. Tissue Antigens 1997;50:347-50.

58. Zanone-Ramseier $R$ "Gratwohl $A, G$ mür J, Roosnek E, Tiercy JM. Sequencing of two HLA-A blank alleles: implications in unrelated bone marrow donor matching. Transplantation 1999:67:1336-41.

59. Dormoy $A$, Froelich $M$, Parissiadis $A$, Cazenave J-P, Tongio MM. Second HLA-A*68 null allele, $A^{*} 6818 \mathrm{~N}$, identified. Tissue Antigens 2002;60:88-90.

60. Carter $V$, Dunn PPJ, Cavanagh $G$, Day $S$, Ross J, Chapman C. An HLA-B null allele (B*0808N) caused by a nucleotide deletion in exon 3 , found in the family of a bone marrow transplant recipient. Tissue Antigens 2000*55:61-4.

61. Dunne C. Little AM, Cox ST et all. Identification and nucleotide sequence of a new null allele. HLA B*3540N. Tissue Antigens 2002;59:522-4.

62. Bettens $F$, Tiercy JM. Sequence of a new class I null allele within the HLA-B444 specificity. Tissue Antigens 2000;56:441:5.

63. Balas A, Santos $S$, Aviles MJ et al. Elongation of the cytoplesmic domain, due to a point deletion at exon 7, results in an HLA-C null allele, $C w^{*} 0409 \mathrm{~N}$. Tissue Antigens 2002;59:95100.

64. Elsner H-A, Drábek J, Rebmanin V, Ambruzova Z, Grosse-Wilde H, Blasczyk R. Nonexpression of HLA-B*5111N is caused by an insertion into the cytosine island at exon 4 creating a frameshift stop cadon. Tissue Antigens 2001:57:369-72.

65. Lienert $K$, Russ $G$, Lester $S$, Bennett $G_{n}$ Gao $X$. McCluskey J. Stable inheritance of an HLLA"blank" phenotype associated with a structural mulation in the HLA-A*0301 gene. Tissue Antigens 1996;48: 187-91.

66. Lardy NM, Otting N, Horst van der AR, Bontrop RE, Waal de LP. 5' Regulatory nucleotide sequence of an HLA-A*0101null allele. Immunogenetics 1997:46:152-5.

67. Balas A, Garcia-Sianchez F, Gómez-Reino F, Vicario JL. HLA class 1 allele (HLA-A2) expression defect associated with a mutation in its enhancer $B$ inverted cat box in two families. Hum Immunol 1994;41:69-73 
68. Elsner H-A, Bernard G, Elz-Vesper B, Matteis de M, Bermard A, Blasczyk R. Non-expression of HLA-A $2901102 \mathrm{~N}$ is caused by a nucleotide exchange in the MRNA splicing site at the beginning of intron 4 . Tissue Antigens 2002:59:139-41.

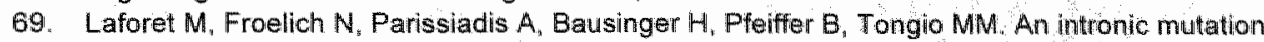
responsible for a low level of expression of an HLA-A'24 alleie. Tissue Antigens 1997:50: $340-6$.

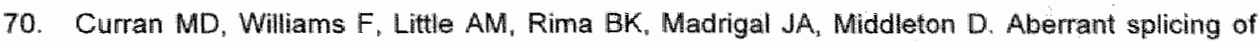
intron 1 creates a nowel null HLA-B*1501 allele. Tissue Antigens 1999;53:244-52.

71. Lee $K W$, Shin J-Y, Lee J-Y. Expression defect of an HLA-A*24 allele associated with DNA methylation in a normal individual. Tissue Antigens 2003;61:325-9.

72. Rozemuller EH. SBT resolution and ambiguities. Chapter 6. In: Tilanus MG Hansen $J A$, Hurley CK, ed. IHWG technical manual: genomic analysis of the human MHC DNA-based typing for HLA alleles \& linked polymorphisms. Seattle USA: Fred Hutchinson Cancer Research Center, 2001:TM6-2-TM6-33. 
Summary 
186 


\section{Summary}

The human leukocyte antigen (HLA) genes, encoded within the major histocompatibility complex (MHC), present the most extensive allelic polymorphism of the human genome. They are located on the short arm of chromosome 6 and divided into three regions, class I $\|$ and III. The major classical HLA class I molecules, HLA-A, $-B$ and $-C$, are expressed on all nucleated cells and platelets, whereas the class $\|$ molecules, HLA-DR, -DQ and -DP, have a more restricted expression. The essential role of the HLA molecules is the presentation of self and foreign antigens to the immune system. HLA typing is of clinical importance for solid organ transplantation, bone marrow and stem cell transplantation and disease susceptibility.

The polymorphism of HLA class $\mid$ genes is mainly located in exons 2 and 3 encoding the peptide binding groove of the HLA molecules. However, more and more polymorphism is detected in the coding regions outside exons 2 and 3 and in the non-coding regions. Historically HLA polymorphism was detected by serological methods. The discovery of DNA amplification techniques introduced various molecular HLA typing methods. Sequencing of a gene is the most detailed method to type for all alleles. In addition, novel polymorphisms will be identified directly. In this thesis the polymorphism of HLA class I genes is determined for the coding regions including exons 1 through 5 as well as for the non-coding regions, the introns.

In Chapter 1 an overview is given of the genomic organization of the MHC region and the structural features and the molecular genetics of the HLA class I molecules. Also antigen processing and presentation, extent of polymorphism. nomenclature system, clinical implications of HLA typing and different HLA typing methods, with special emphasis on sequence-based typing are discussed. The aim and scope of the thesis are explained.

Chapter 2 describes a reliable and efficient high-resolution sequence-based typing strategy for HLA-A. Exons 2 and 3 were amplified separately and sequenced heterozygously in both forward and reverse direction. Validation of the method was obtained by sequencing 11 individuals carrying alleles from all major HLA-A allele groups. Furthermore, a total of 252 unrelated individuals with at least one allele belonging to the A10 or A19 group were typed for HLA-A by this strategy. All alleles were identified correctly except $A^{*} 3401$. Unexpected polymorphic positions were shown in exon 3 , even in individuals homozygous for $A^{*} 3401$. The heterozygous results in $A^{*} 3401$ positive individuals proved to be due to coamplification of a pseudogene, HLA-COQ or HLA-DEL, linked to $A^{*} 3401$. The problem was resolved by using different amplification primers for exon 3 with mismatches for the two pseudogenes. 
In Chapter 3 the sequence-based typing strategy developed for HLA-B was used to type 225 unrelated individuals with at least one allele belonging to the $\mathrm{B} 5 / 35$ cross-reacting group. The heterozygous sequencing strategy included separate amplification of exons 2 and 3 using amplification primers located in introns 1,2 and 3 . The SBT strategy proved to be reliable and efficient for high resolution typing of $\mathrm{B} 5 / 35 \mathrm{CREG}$ alleles. Furthermore the exon 1,4 and 5 sequences of 26 different $B 5 / 35$ alleles were determined by allele-specific sequencing to assess the level of polymorphism. Three new alleles were detected, one by SBT of exons 2 and $3\left(B^{*} 5204\right)$ and two by sequencing exons 1,4 and $5\left(B^{*} 3542\right.$ and $\left.B^{*} 510105\right)$. The study suggested that more polymorphism might be present outside exons 2 and 3 than previously thought.

Sequence-based typing methods for HLA-B are based on elucidation of exon 2 and 3 sequences. The elucidation of the exons 1,4 and 5 sequences has led to an increase of ambiguities with alleles having identical exon 2 and 3 sequences but differences in other exons. The ambiguities can be resolved by sequencing the exon in which the difference is located. In Chapter 4 , an SBT strategy for heterozygous sequencing of exons 1,4 and 5 of HLA-B has been described. The strategy was validated against a panel of 25 individuals, carrying HLA-B alleles from 33 different allele groups and was used to resolve ambiguities in 50 individuals. It proved to be a valuable tool for resolving ambiguities of HLA-B alleles with differences in these exons, as well as for studying the polymorphism of HLA-B outside exons 2 and 3 .

At present more than 600 HLA-B alleles are identified by sequence analysis. The polymorphic exon 2 and 3 sequences of all HLA-B alleles have been described. However, the exon 1,4 and 5 sequences of a number of infrequent HLA-B alleles are unknown. In Chapter 5 the exon 1,4 and/or 5 sequences of 39 of such B-alleles were elucidated by allele-specific sequencing. In general, these exon sequences showed identity with the majority of the known sequences from the corresponding allele groups. The polymorphism observed in these exons merely reflects the lineage specificity of HLA-B. Several alleles showed exon 1, 4 and/or 5 sequences not resembling the sequences of the corresponding allele group namely: $B^{*} 4010, B^{*} 4415, B^{*} 4416$ and $B^{*} 5606$. The deviating sequences found were either confirming the evolutionary origin of the alleles or showed new polymorphisms.

The number of HLA-B alleles is increasing continually and therefore molecular methods have to be updated regularly. In Chapter 6 an extended sequencebased typing method for subtyping of $\mathrm{B}^{\star} 27$ and an updated polymerase chain reaction sequence-specific primer (PCR-SSP) method to detect the presence or absence of $B^{*} 27$ are described. The presence of $B^{*} 27$ is used as a 
diagnostic marker for ankylosing spondylitis. The sequences of exons 1 through 4 of 78 individuals were determined to unequivocally assign the $B^{*} 27$ alleles. Eleven different subtypes were detected including three new alleies: $B^{*} 270504, B^{\star} 2715$ and $B^{\star} 2717$.

The sequence database of HLA class genes focuses on the coding sequences, the exons. Limited information is available on the non-coding sequences of the different HLA class 1 alleles. The unknown intron 1,2 and 3 sequences of $B^{*} 7301$ were elucidated in Chapter 7 . Overall the $B^{*} 73$ sequence resembles the sequence of other HLA-B alleles, although 35 differences were found with a consensus intron sequence. The insertions and deletions shown in intron 2 of $B^{*} 73$ were strikingly similar to the sequences of the HLA-C alleles, as was the $5^{\prime}$ end of intron 3 . Furthermore a unique deletion was observed in the middle of intron 3 , not present in HLA-B or $-C$ alleles. In Chapter 7 the reason that $B^{*} 73$ was not amplified with our HLA-B SBT strategy was unraveled by analysis of the intron sequences of $B^{*} 7301$. The heterozygous amplification primers of the HLA-B SBT protocol showed mismatches with $B * 73$ intron sequences, causing the allelic drop-out. Correct amplification of exons 2 and 3 of $B^{\star} 7301$ was enabled by the design of new primers in introns 2 and 3 .

To assess the degree of polymorphism the intron 4 nucleotide sequences of at least one representative of each major allelic group of HLA-A, $-B$ and $-C$ have been determined by allele-specific sequencing in Chapter 8 . The sequences revealed that the length of intron 4 varies as a result of insertions and deletions with a minimum of 93 and a maximum of 124 nucleotides. There were remarkable similarities and differences within HLA-A, $-B$ and $-C$ alleles, as well as between them. Both HLA-A and $-B$ alleles can be divided into two major groups, one with a deletion and one without a deletion in intron 4. Remarkable was the deletion of 20 nucleotides in all HLA-A and -B alleles compared with HLA-C. Thirty-three different allelic groups were represented by more than one allele. The intron 4 nucleotide sequences were relatively conserved within these groups. In three allelic groups $B^{*} 40, B^{*} 48$ and $C w^{*} 07$, differences in the intron 4 sequence were noticed between alleles. The intron 4 sequence of $B^{*} 7301$ resembles the sequences of other B-alleles, the deletion of 20 nucleotides is present in $B^{\star} 7301$. Although the exon 4 and 5 sequences of $B^{*} 7301$ resemble the HLA-C sequences, the elucidated intron 4 sequence makes a gene conversion event of exons 4 and 5 of HLA-C for the origin of $B^{*} 7301$ unlikely.

Chapter 9 describes an unusual haplotype detected in a family of a Caucasian renal transplant patient. HLA analysis of ten family members in two generations demonstrated the absence of HLA-A on one of the haplotypes present in the 
patient and a sibling. The absence of any serological or molecular reaction together with the results of microsatellite and fluorescent in situ hybridisation (FISH) analysis suggested a deletion of a very narrow region, encompassing the HLA-A gene. The actual presence and extent of the deletion could not be proven, however it is unlikely that the findings can be explained by another phenomenon.

Chapter 10 contains the general discussion and places the different topics studied in the previous chapters, in perspective. Polymorphism is present in exons 2 and 3 , but also outside these regions both in the coding and noncoding regions. The polymorphism observed in these regions merely reflects the lineage specificity of the different HLA class I genes. The actual extent and functional rolle of polymorphism outside the peptide binding groove is still an issue to be investigated. However, it is unquestionable that the HLA class I genes display an extensive polymorphism and that the number of polymorphic positions will increase further in the future. 
Samenvatting 


\section{Samenvatting}

De HLA (human eukocyte antigen) genen zijn de meest polymorfe genen die bij de mens bekend zijn. De genen zijn gelokaliseerd op de korte arm van chromosoom 6 en liggen in een gebied dat het Major Histocompatibilty Complex (MHC) genoemd wordt. De functie van HLA moleculen is de controlle van zelfherkenning en dus verdediging tegen vreemde antigenen. De HLA moleculen presenteren antigenen aan het immuunsysteem. De presentatie van eigen peptiden zal, normaal gesproken, genegeend worden door het immuunsysteem als gevolg van zelftolerantie. Echter, de presentatie van vreemde peptiden zal leiden tot de activatie van immuuncellen. HLA typering is van klinisch belang voor orgaantransplantaties, beenmerg/stamcel transplantaties en bij ziekte associaties.

Binnen het MHC kunnen drie regio's worden onderscheiden; klasse I, klasse II en klasse III. De klasse I regio bevat genen die coderen voor de zware keten van de drie klassieke HLA moleculen, HLA-A, -B en -C. De klasse Il genen Heveren de genprodukten voor de HLA-DR, -DQ en -DP moleculen. De klasse I en II regio's behoren tot het HLA complex. De klasse III regio bevat gienen die coderen voor moleculen met verschillende functies, zoals componenten van het complement systeem en cytokines. Het onderzoek in dit proefschrift richt zich op HLA klasse a genen.

De HLA klasse I moleculen zijn glycoproteinen die aanwezig zijn op het oppervlak van alle kemhoudende cellen en bloedplaatjes. Ze bestaan uit twee polypeptide ketens, een polymorfe MHC-gecodeerde zware keten met een

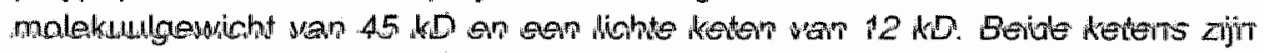
non-covalent gebonden. De zware keten bestaat uit drie extracellulaire domeinen, $\alpha 1, \alpha 2$ en $\alpha 3$, een hydrofoob transmembraan gebied en een hydrofiele cytoplasmatische staart. De zeer polymorfe $\alpha 1$ en $\alpha 2$ domeinen vormen samen de groeve waarin peptiden worden gebonden. De lichte keten is het $\beta 2$-microglobuline dat gecodeerd wordt door een gen op chromosoom 15 .

De genen die coderen voor de zware keten van de HLA klasse I moleculen hebben een karakteristieke structuur waarbi] de genetische informatie voor de verschillende domeinen van het eiwit gelokaliseerd is in verschillende exonen. De HLA-A en -C genen bevatten 8 exonen en het HLA-B gen zeven. Exon 1 codeert voor het leiderpeptide en de exonen 2, 3 en 4 voor de extracellulaire $\alpha 1, \alpha 2$ en $\alpha 3$ domeinen. De genetische informatie voor het transmembraan gebied is gelokaliseerd in exon 5 en voor de cytoplasmatische staart in exonen 6. $7 \mathrm{en} / \mathrm{of} 8$. 
Het extreme polymorfisme van HLA genen wordt geillustreerd door het grote aantal allelen dat bekend is voor de verschillende loci. Het aantal allelen is de afgelopen jaren enorm gegroeid en dit zal in de toekomst waarschijnilijk blijven gebeuren. HLA-B is het meest polymorfe locus met 626 verschillende alleien. Voor HLA-A zijn 349 en voor HLA-C 182 allelen bekend. Het polymorfisme van HLA moleculen verschaft individuen de diversiteit in antigen presentatie, noodzakelijk voor populatieoverleving. Nieuwe allelen ontstaan door verandering in de base volgorde van het gen. Genetische mechanismen hierbij kunnen zijn: puntmutaties, deleties, duplicaties, recombinaties en conversies. Sommige polymorfe varianten hebben invloed op de HLA expressie. HLA allelen die niet op het oppervlak van een cel tot expressie komen worden nulallelen genoemd.

Er bestaan verschillende technieken om HLA polymorfisme te detecteren. In het verleden werden vooral serologische methoden gebruikt. De introductie van DNA amplificatie technieken heeft geleid tot HLA typering op genetisch niveau. De drie moleculaire technieken die het meest gebruikt worden zijn. PCR-SSP (sequentie specifieke primers), PCR-SSOP (sequentie specifieke oligonucleotide probes) en PCR-SBT (sequentie gebaseerd typeren). Het typeren van HLA allelen door middel van sequentie-analyse is de meest volledige methode, waarbij bovendien nieuwe polymorfismen direct kunnen worden geïdentificeerd.

Het polymorfisme van HLA klasse I genen is voornamelijk gelokaliseerd in de exonen 2 en 3 , welke coderen voor de peptide bindingsgroeve van de HLA moleculen. Steeds meer polymorfismen worden echter gedetecteerd in de coderende regio's buiten exon 2 en 3 alsook in de niet-coderende regio's. In dit proefschrift is het polymorfisme bestudeerd van HLA klasse I genen voor de coderende regio's, de exonen 1 tot en met 5 en de niet-coderende regio's, de intronen.

In hoofdstuk 1 wordt een overzicht gegeven van de genomische organisatie van het MHC gebied, de structurele kenmerken en de moleculaire genetica van de HLA klasse I moleculen. Ook worden antigen-produktie, peptidepresentatie, het uitgebreide polymorfisme, nomenclatuur, klinische implicaties van HLA typering en de verschillende HLA typeermethoden, met speciale nadruk op SBT, bediscussieerd. Vervolgens wordt het doel van dit proefschrift uiteengezet.

Hoofdstuk 2 beschrijft een betrouwbare en efficiënte hoge resolutie SBTstrategie voor HLA-A. De exonen 2 en 3 werden afzonderlijk geamplificeerd en de sequentie werd heterozygoot bepaald van zowel de coderende als de 
complementaire DNA streng. De methode werd gevalideerd door sequentieanalyse van 11 individuen, positief voor allelen uit de meest voorkomende HLA-A allel groepen. Daarnaast werden 252 niet-verwante individuen, positief voor ten minste 1 allel behorend tot de A10 of A19 groep, met deze strategie getypeerd voor $H \perp A-A$. Alle allelen werden correct geïdentificeerd behalve het allel $A^{*} 3401$. Hierbij werden onverwachte polymorfe posities gevonden in exon 3 , zelfs in individuen die homozygoot waren voor $A^{*} 3401$. De heterozygote resultaten in $A^{*} 3401$ positieve individuen waren het gevolg van co-amplificatie van een pseudogen, HLA-COQ of HLA-DEL, gekoppeld aan $A^{*} 3401$. Het probleem werd opgelost door het gebruik van andere amplificatie primers voor exon 3 die gemismatcht waren met de twee pseudogenen.

In hoofdstuk 3 wordt de SBT-strategie, ontwikkeld voor HLA-B, gebruikt om 225 niet-verwante individuen met ten minste 1 allel behorend tot de $B 5 / 35$ kruisreagerende groep te typeren. De heterozygote sequentie-strategie bestond uit afzonderlijke amplificatie van de exonen 2 en 3 , waarbij amplificatie primers gebruikt werden die gelokaliseerd waren in de intronen 1, 2 en 3. De SBT-strategie bleek betrouwbaar en efficiënt te zijn voor hoge resolutie typering van B5/35 allelen. Daarnaast werden de exon 1,4 en 5 sequenties van 26 verschillende $B 5 / 35$ allelen bestudeerd door middel van allel-specifieke sequentie-bepaling, om de mate van polymorfisme te onderzoeken. Drie nieuwe allelen werden geïdentificeerd, een met SBT van de exonen 2 en 3 $\left(B^{\star} 5204\right)$ en twee met sequentie-analyse van de exonen 1,4 en $5\left(B^{\star} 3542\right.$ en $\left.B^{\star} 510105\right)$. De studieresultaten suggereerden dat meer polymorfisme aanwezig is buiten de exonen 2 en 3 dan eerder werd aangenomen.

SBT-strategieën voor HLA-B zijn gebaseerd op exon 2 en 3 sequenties. De opheldering van exon 1,4 en 5 sequenties heeft geleid tot een toename van ambiguiteiten waarbij allelen identieke exon 2 en 3 sequenties hebben, maar verschillen in andere exonen. De ambiguitteiten kunnen worden opgelost door de exon-sequentie te bepalen op de plaats waar het verschil gelokaliseerd is. In hoofdstuk 4, wordt een SBT-strategie voor de heterozygote sequentiebepaling van exonen 1, 4 en 5 van HLA-B beschreven. De strategie werd gevalideerd met behulp van een panel van 25 individuen met HLA-B allelen uit 33 verschillende allel groepen en gebruikt om ambiguiteiten op te lossen van 50 individuen. De strategie bleek een waardevol instrument te zijn, om ambiguiteiten van HLA-B allelen met verschillen in exonen 1,4 en 5 op te lossen alsmede voor het bestuderen van HLA-B polymorisme buiten de exonen 2 en 3.

Op dit moment zijn met sequentie-analyse meer dan 600 HLA-B allelen geïdentificeerd. De polymorfe exon 2 en 3 sequenties van alle HLA-B allelen 
Zijn beschreven, maar de exon 1,4 en 5 sequenties van een aantal niet frequent voorkomende HLA-B allelen Zijn onbekend. In hoofdstuk 5 werden de exon 1, 4 en/of 5 sequenties van 39 HLA-B allelen opgehelderd door allelspecifieke sequentie-bepaling. In het algemeen kwamen deze exon-sequenties overeen met de reeds bekende sequenties van de corresponderende allel groepen. Het polymorfisme, gezien in deze exonen, weerspiegelde de afkomst van het allel. Een aantal allelen vertoonden exon 1, 4 en/of 5 sequenties die niet overeenkwamen mel de sequenties van de corresponderende allel groepen namelijk; $B^{*} 4010, B^{*} 4415, B^{*} 4416$ en $B^{*} 5606$. De gevonden afwijkende sequenties bevestigden de evolutionaire afkomst van de allelen of bleken nieuwe polymorfismen te zijn.

Aangezien het aantal HLA-B allelen voortdurend toeneemt moeten moleculaire methoden regelmatig worden bijgewerkt. Hoofdstuk 6 beschrijft een uitgebreide SBT methode voor subtypering van $B^{*} 27$ en een bijgewerkte PCR-SSP methode om de aan-en afwezigheid van $B^{*} 27$ te detecteren. De aanwezigheid van $B^{*} 27$ wordt gebruikt als een diagnostische marker voor ankylosis spondylitis. Om ondubbelzinnig $B^{\star} 27$ allelen te detecteren werden de exon 1 tot en met 4 sequenties bepaald van 78 individuen. Elf verschillende subtypes werden geïdentificeerd waaronder drie nieuwe allelen: $B^{*} 270504, B^{*} 2715$ en $B^{*} 2717$.

De sequentie databank van HLA klasse I genen is gericht op de coderende sequenties, de exonen. Beperkte informatie is beschikbaar voor de nietcoderende sequenties van de verschillende HLA klasse I allelen. De onbekende intron 1,2 en 3 sequenties van $B^{*} 7301$ werden opgehelderd in hoofdstuk 7 . Over het algemeen vertoonde de intron $1-3$ sequentie van $B^{*} 73$ overeenkomst met de sequentie van andere HLA-B allelen, hoewel er 35 verschillen gevonden werden met de consensus intron-sequentie. De inserties en deleties van $B^{*} 73$ in intron 2 waren opvallend gellik aan de sequenties van HLA-C allelen, wat ook het geval was voor de $5^{\circ}$ uiteinde van intron 3 . Daarnaast werd er een unieke deletie gevonden in het midden van intron 3 , die niet aanwezig was in andere HLA-B noch in HLA-C allelen. Door de analyse van de intron-sequenties van $B^{*} 7301$ is de reden ontrafeld waarom $B^{*} 73$ niet geamplificeerd werd met onze HLA-B SBT-strategie. De heterozygote amplificatie primers bleken gemismatcht te zijn met de $B^{*} 73$ intron-sequenties, waardoor een allel drop-out werd veroorzaakt. Correcte amplificatie van de exonen 2 en 3 van $B^{*} 7301$ werd mogelijk gemaakt door nieuwe primers te ontwerpen in de intronen 2 en 3.

Om het polymorfisme in intron 4 te bestuderen "werden in hoofdstuk 8 de desbetreffende sequenties van bijna alle voorkomende allel groepen van HLA- 
$A_{i}-B$ en -C opgehelderd. Dit werd gedaan door allel-specifieke sequentiebepaling. De sequenties lieten zien dat de lengte van intron 4 varieert als gevolg van inserties en deleties, met een minimum van 93 en een maximum van 124 nucleotiden. Er werden opmerkelijke overeenkomsten en verschillen gevonden binnen de genen HLA-A, -B en -C alsook tussen de verschillende genen. Zowel HLA-A als -B allelen kunnen worden onderverdeeld in twee grote groepen, een met deletie en een zonder deletie in intron 4. Opvallend was de deletie van 20 nucleotiden in alle HLA-A en -B allelen vergeleken met HLA-C. Drieëndertig verschillende allel groepen waren vertegenwoordigd met meer dan één allel. De intron 4 nucleotide sequenties waren betrekkelijk geconserveerd binnen deze groepen, behalve voor $B^{*} 40, B^{*} 48$ en $\mathrm{Cw}^{*} 07$. De intron 4 sequentie van $B^{*} 7301$ vertoonde overeenkomst met de sequenties van andere B-allelen want de deletie van 20 nucleotiden was hier aanwezig. Hoewel de exon 4 en 5 sequenties van $B^{\star} 7301$ overeenkomsten vertonen met $\mathrm{C}$-allelen, maakte de opgehelderde intron 4 sequentie een gen conversie van exonen 4 en 5 van HLA-C als herkomst voor $B^{*} 7301$ onwaarschijnlijk.

Hoofdstuk 9 beschrijft een ongewoon haplotype gedetecteerd in de familie van een Kaukasische niertransplantatie patiënt. HLA analyse van 10 familieleden in twee generaties demonstreerde de afwezigheid van HLA-A op een van de haplotypen aanwezig in de patiënt en zijn zuster. De afwezigheid van enige serologische of moleculaire reactie samen met de resultaten van microsatelliet en fluorescentie in situ hybridisatie (FISH) analyses suggereerden een deletie van een klein gebied, waarbinnen het HLA-A gen gelegen is. De feitelijke aanwezigheid en grootte van de deletie konden niet definitief worden bewezen, het is echter onwaarschijnlijk dat de bevindingen verklaard kunnen worden door een ander fenomeen.

Hoofdstuk 10 bevat de algemene discussie en plaatst de verschillende onderwerpen, bestudeerd in eerdere hoofdstukken, in perspectief. Polymorfisme is aanwezig in exonen 2 en 3, maar ook buiten deze regio's zowel in coderende als niet-coderende gebieden. Het polymorfisme dat gezien wordt in deze regio's is vaak een weerspiegeling van de groep-specifieke afkomst van de verschillende HLA klasse I allelen. De werkelijke aard en functionele rol van polymorfisme buiten de peptide bindingsgroeve zullen nog verder onderzocht moeten worden. Echter, het is duidelijk dat de HLA klasse I genen een uitgebreid polymorfisme vertonen en dat aan de groei van het aantal polymorfe posities voorlopig geen eind lijkt te komen. 
Dankwoord 
19t 


\section{Dankwoord}

Promoveren doe je niet alleen. Veel mensen zijn direct dan wel indirect betrokken geweest bij de totstandkoming van mijn proefschrift. Op deze plaats wil ik hen hier hartelijk voor bedanken, een aantal mensen in het bijzonder.

Allereerst wil ik mijn copromotor, Dr. C.E.M. Voorter en mijn promotor, Prof dr. P.M. van den Berg-Loonen, danken voor hun fantastische begeleiding.

Beste Christien, veel bewondering heb ik voor jouw toewijding aan en enthousiasme voor de wetenschap. De tijd die je immer hebt vrijgemaakt voor onze nuttige overleggen heb ik erg gewaardeerd. Deze overleggen motiveerden mij altijd om verder te gaan met mijn onderzoek. I heb veel van jouw kritische houding ten aanzien van het verrichten wan onderzoek geleerd.

Beste Ella, veel dank voor het kritisch beoordelen van de manuscripten, het geven van waardevolle adviezen en het bieden van mogelijkheden om mij via verschillende cursussen en congressen verder te ontwikkelen in de immunogenetica. Ik heb de efficiënte manier van werken van jou als zeer prettig ervaren.

Vervolgens gaat mijn dank uit naar de leden van de beoordelingscommissie, Prof.dr. M.H. Hofker (voorzitter), Prof.dr. F.H.J. Claas, Prof.dr. J.P.M. Geraedts, Prof.dr. J.P. van Hooff en Dr. S.G.E. Marsh, voor hum bereidwilligheid mijn manuscript te beoordelen. Dr. S.G.E. Marsh, it is a great honour that you were willing to participate in the assessment committee and to review my thesis. Thank you very much.

Het secretariaat, Diana en Mieke, hartelijk dank voor al jullie hulp en belangstelling.

Collega promovendus en kamergenote, Joke, fijn dat ik bij jou altijd mijn hart kon luchten. Ik wens je veel succes met jouw eigen promotieonderzoek!

Van het laboratorium wil ik in de eerste plaats de 'sequencers', Christel, Dennis, Eva, Fausto, Lisette en Melanie bedanken voor alle sequentieanalyses die jullie voor mijn onderzoek hebben verricht.

June, het was prettig om een stagiaire die zo gemotiveerd was als jij te begeleiden.

Natuurlijk gaat mijn dank ook uit naar alle andere (oud-)collega's van Weefseltypering: Coline, Désiré, Els, Evy, Hilde, IIse, Ines, Judith, Marjan, Meriam, Sandra en Sarah. Ik heb graag met jullie samengewerkt. Het was voor mij een gezellige tijd. 
Voor de FISH-analyses dank ik Miriam Kamps en Dr. Anton Hopman van de afdeling Moleculaire Celbiologie van de Universiteit Maastricht en Yvonne Arts, Dianne De Santis, Dick van Wichen en Dr. Marcel Tilanus van de afdeling Pathologie van het Universitair Medisch Centrum Utrecht.

Frank Mulders, bedankt voor het ontwerpen van de omslag. Jouw creatieve blik op een piekenpatroon heeft mij verrast.

Tiny Wouters, dank voor het verzorgen van de lay-out. Ik heb jouw toewijding om er een mooi boekje van te maken zeer gewaardeerd.

Mijn paranimfen, mijn broer Roel en mijn vriendin Bianca, fijn dat jullie met zoveel enthousiasme zijn ingegaan op mijn verzoek. Bedankt voor alle moeite! Bianca, ik wens je veel succes met jouw eigen promotieonderzoek.

Mijn zus Marloes, familie en vrienden, bedankt voor jullie belangstelling gedurende de afgelopen jaren.

Tot slot wil ik een bijzonder woord van dank richten aan mijn ouders en Erik. Lieve pap en mam, jullie warmte, onvoorwaardelijke steun en interesse tijdens mijn promotieonderzoek zijn voor mij heel belangrijk geweest.

Lieve Erik, halverwege mijn promotieonderzoek heb ik jou ontmoet. Jij hebt mijn leven veranderd en laten zien dat er meer is dan promoveren. Jouw liefde, steun en gezelligheid hebben ontzettend veel voor mij betekend. Ik verheug me om samen met jou in Utrecht een hele mooie toekomst op te gaan bouwen!

Wendy

Maastricht, mei 2005 
Curriculum vitae 


\section{Curriculum vitae}

Wendy Tonnie Nicole Swelsen was born on May 9, 1978 in Heerlen. After she finished secondary school (Eijkhagencollege, Landgraaf) in 1996, she studied Biomedical Health Sciences at the Faculty of Medicine of the University of Nijmegen and graduated in 2000. Her first training position was with the Department of Clinical Pharmacy, University Medical Center Nijmegen (March till June 1999) where she assisted with research in the pharmacokinetics of the HIV protease inhibitor indinavir. She finished her study with a second training period from February till July 2000 at the Laboratory of Toxicology, Pathology and Genetics of the National Institute for Public Health and the Environment (RIVM), Bilthoven. During this period, she studied genetic associations between severe respiratory syncytial virus bronchiolitis in infants and polymorphism in cytokine genes. In October 2000 she started her PhD project at the Tissue Typing Laboratory of the University Hospital Maastricht under supervision of Prof.dr. P.M. van den Berg-Loonen and Dr. C.E.M Vooter. The study was focussed on genetic polymorphism of HLA class I and the results are described in this thesis. 
204 
List of publications 
${ }_{200} \mid$ 


\section{List of publications}

Voorter CEM, Swelsen WTN, Berg van den-Loonen EM. Intron sequences of HLA-B*73. Tissue Antigens 2001;57:463-8

Bont L, Versteegh J, Swelsen WTN, Heijnen CJ, Kavelaars A, Brus $F$. Draaisma JMTh, Pekelharing-Berghuis $M$, van Diemen-Steenvoorde RAAM, Kimpen JLL. Natural reinfection with respiratory syncytial virus does not boost virus-specific T-cell immunity. Pediatr Res 2002:52:363-7

Voorter CEM, Swelsen WTN, Berg van den-Loonen EM. B*27 in molecular diagnostics: Impact of new alleles and polymorphism outside exons 2 and 3 . Tissue Antigens 2002;60:25-35

Swelsen WTN, Voorter CEM, Berg van den-Loonen EM. Sequence analysis of exons $1,2,3,4$ and 5 of the HLA-B5/35 cross-reacting group. Tissue Antigens $2002 ; 60: 224-34$

Swelsen WTN, Voorter CEM, Berg van den-Loonen EM. Polymorphism of intron 4 in HLA-A, $B$ and $-C$ genes. Tissue Antigens 2003;61:475-83

Swelsen WTN, Voorter CEM, Berg van den-Loonen EM. Ambiguities of human leukocyte antigen-B resolved by sequence-based typing of exons 1, 4, and 5 . Tissue Antigens 2004;63:248-54

Swelsen WTN, Voorter CEM, Tilanus MGJ, Kamps MAF, Berg van den-Loonen EM. No HLA-A gene detectable on one of the haplotypes in a Caucasian family. Human Immunology 2005;66:155-63

Swelsen WTN, Voorter CEM, Berg van den-Loonen EM. Sequence-based typing of the HLA-A10/A19 group and confirmation of a pseudogene coamplified with $A^{*} 3401$. Human Immunology 2005;66:535-42

Swelsen WTN, Voorter CEM, Chak KY, Berg van den-Loonen EM. Elucidation of exon 1, 4, and 5 sequences of 39 infrequent HLA-B alleles. Human Immunology 2005;66:543-53 